University of Warwick institutional repository: http://go.warwick.ac.uk/wrap

A Thesis Submitted for the Degree of PhD at the University of Warwick

http://go.warwick.ac.uk/wrap/36143

This thesis is made available online and is protected by original copyright.

Please scroll down to view the document itself.

Please refer to the repository record for this item for information to help you to cite it. Our policy information is available from the repository home page. 


\title{
Economic Aspects of Audit Regulation and Auditor Liability
}

\author{
by \\ Marleen Willekens \\ Catholic University of Leuven, Belgium \\ Department of Applied Economics
}

University of Warwick

Warwick Business School

A dissertation submitted for the degree of Doctor of Philosophy

March 1995 
In her soft wind I will whisper

In her warm sun I will glisten

Till we see her one again

In a world without end

(Neil Finn, 1991, she goes on) 


\section{Table of contents}

Table of contents $\quad$ i

List of tables $\quad v$

List of figures $\quad v$

List of graphs $\quad$ vi

Acknowledgements vii

Declaration viii

Summary $\quad$ ix

List of symbols $\quad$. $\quad x$

Chapter 1: Introduction

1. Introduction to the problem 2

2. Major research objectives 3

3. Research methodology 4

4. Major contributions of thesis 4

5. Limitations of the thesis $\quad \cdot \quad 5$

6. Thesis structure $\quad 6$

\section{Part I}

Chapter 2: Audit production as a process to control audit-related risks:

Audit risk modelling versus audit decision modelling

1. Introduction

2. The risk analysis approach: a review of risk modelling in auditing 11

2.1 A close look at the audit risk concept 11

2.2 The early days of risk modelling: the joint audit risk model (ARM) 13

$\begin{array}{ll}2.3 \text { Shortcomings of the ARM } & 17\end{array}$

2.4 Bayesian approach to risk modelling 21

2.4.1 Application of Bayes theorem to assess achieved (ex post) audit risk

2.4.2 Literature on Bayesian audit risk models 23

$\begin{array}{ll}2.5 \text { Concluding comments } & 30\end{array}$

3. Normative decision models of auditing: the 'audit modelling approach' 31

3.1 Decision theory approaches to audit production 34

3.1.1 Single-person decision models $\quad 35$

3.1.2 Auditing in a multi-person decision environment: strategic nature of auditing 38

3.2 A critical assessment of the decision theory approach 43

4. Conclusions 

streams

1. Introduction

2. Economic rationales for audit demand and the changed role of auditing in a regulated environment

3 Audit pricing and audit production: theory and evidence 55

3.1. Simunic's (1980) landmark study

3.1.1 An audit pricing model based on loss sharing between auditee and auditor

3.1.2 Framework for a test of competition in the audit market 61

3.2 Empirical evidence of audit pricing and production

3.2.1 A review of the major conclusions about audit pricing 64

$\begin{array}{ll}\text { 3.2.2. Determinants of audit quantity } & 70\end{array}$

3.2.3 A critical look at audit fee research $\quad 75$

4 Major conclusions

\section{Chapter 4: Auditing, Regulation and Liability}

1. Introduction

2. Accounting regulation and public interest theory

2.1 Economic arguments for and against accounting regulation

2.1.1 Market failure arguments for accounting regulation

2.1.2 Economic arguments against accounting regulation

2.2 Public interest versus private interest theory of accounting regulation $\quad 87$

3. Auditing regulations and liability as means to correct for accounting market failure $\quad 88$

3.1 Information asymmetry: a popular rationale for auditing regulation $\quad 89$

3.2 Accounting information, auditing and externalities 90

3.3 Ex ante regulation versus ex post liability 91

3.4 The relative social desirability of audit standards versus auditor liability in the audit production context

3.5 Regulation of audit production: self-regulation or state regulation 98

4. Policies affecting the audit environment

4.1 Policies affecting external audit demand

$\begin{array}{ll}4.2 \text { Policies affecting audit supply and production } & 105\end{array}$

4.2.1 Ex ante regulations 105

4.2.2 Ex Post policies: Auditor liability 106

4.2.3. The audit industry's response to the litigation crisis 110

5. Conclusion

\section{Part II}

\section{Chapter 5: Audit Demand, Liability and the statutory audit requirement}

1. Introduction

2. Definitions and assumptions

2.1 Modelling the directors

2.2 Modelling the external auditor

2.3 Costs, losses and objective functions

3. Compliance when the quality norms $Q_{c}$ and $q_{2}$ are certain 
3.1 The external auditor's problem under certainty 126

3.2 The directors' problem under certainty

3.3 The impact of a statutory audit requirement on overall financial statement quality when quality norms are certain

4. Compliance when the quality norms $Q_{c}$ and $q_{2}$ are uncertain 133

4.1 The auditor's reaction function under uncertainty

4.1.1 Impact of uncertainty, $\delta$, on external audit quality quality production

4.1.2 The impact of internal and external audit demand levels on the auditor's decision

4.2 The directors' demand decision under uncertainty

4.2.1 The impact of auditor compliance on the directors' decision

4.2.2 The effect of uncertainty, $\varepsilon$, on the directors' decision for alternative levels of auditor compliance (g)

5. Statutory audit requirements and uncertainty about liability

5.1 The effectiveness of statutory audit requirements $\quad 154$

5.1.1 Analysis when $\mathrm{f}^{*}=\mathrm{f}^{\prime} \quad 158$

5.1.2 Analysis when $\mathrm{f}^{*}>\mathrm{f}^{\prime} \quad 160$

5.2 Need and effectiveness of statutory audit requirements 163

6. Conclusions

Chapter 6: Auditor liability, professional standards and audit quality production

1. Introduction

2. The auditor's decision environment: assumptions and definitions $\quad 170$

2.1. Assumptions

170

2.2. Business Risk and auditor reputation

173

3. Audit quality production when legal standards of care are certain 175

4. Audit quality production when there is uncertainty over the finding of negligence $\quad 182$

4.1 The auditor's decision problem when legal standards are uncertain $\quad 183$

4.2. General impact of uncertainty on audit quality production 187

4.3 Impact of uncertainty on audit quality production when beliefs are normally distributed

4.4 Audit quality production: certainty versus uncertainty about the finding of negligence

$\begin{array}{ll}\text { 5. The impact of an ex ante quality standard on audit quality production } & 196 \\ 6 \text {. The impact of liability restriction on audit quality production } & 200\end{array}$

7. Conclusion 202

\section{Chapter 7: Auditor liability, professional standards and social efficiency}

1. Introduction 204

2. Socially efficient audit production 205

3. Social efficiency of negligence standards 208

3.1. Efficiency of certain legal standards of care when there is no restriction 209

3.2 Efficiency of certain legal standards of care when there is restriction of liability 213

$\begin{array}{ll}3.3 \text { Conclusion } & 218\end{array}$

4. Social efficiency of uncertain legal standards of care when there is no restriction $\quad 219$

$\begin{array}{ll}\text { 4.1 Efficiency of negligence standards for an individual audit engagement } & 219\end{array}$

4.2 Efficiency of negligence standards in a particular jurisdiction 221 
4.3 Conclusion

5. Social efficiency of the imposition of an ex ante quality standard when negligence standards are uncertain and where there is no restriction of liability

5.1. Social efficiency for an individual audit engagement

5.2 Efficiency of a general ex ante standard in a particular legal environment

5.3 Conclusion

6. Uncertain negligence standards and restriction of liability to classes of claimants

6.1 Social efficiency for an individual audit engagement

6.2 Efficiency of restriction of liability in a particular legal environment

6.3 Uncertain legal standards of care, restriction and an ex ante quality standard

6.4 Conclusion

7. Summary and conclusions

\section{Chapter 8: Conclusions}

1. Auditing as a professional, economic and regulated activity: conclusions from the literature review

2. Audit demand, liability and statutory audit requirements: major conclusions from the analysis in chapter 5

3. Audit quality production, liability and regulation: major conclusions from the analysis in chapters 6 and 7

4. Limitations of the thesis and directions for future research

Bibliography

Appendices

Appendix I: Review of empirical audit fee research

Appendix II: The directors' problem when $0<\mathrm{g}<1$

Appendix III: Overview of propositions and corollaries 


\section{List of Tables}

Table 1.1: $\quad$ Thesis structure 8

Table 2.1: Major stages in audit risk model development: the early days 15

Table 2.2: $\quad$ Major stages in Bayesian audit risk model development 29

Table 2.3: $\quad$ Comparison of risk analysis approach and audit modelling approach 35

Table 3.1: Test for competition: interpretation of possible differences in average residual total system costs of auditees using big eight versus non-big eight auditors across market segments

Table 3.2: Overview of hypothesised audit fee determinants in the regression analyses of audit fee research studies and allocation to categories and subcategories

Table 4.1: Shavell's determinants of policy choice applied to the auditing context

Table 4.2: Parties affected by ex ante regulation and ex post liability in the audit context

Table 5.1: Loss distribution in case of joint liability and negligence rules for external auditors and directors

Table 5.2: Overview of the auditor's reaction function for different $\delta$ values

$\begin{array}{lll}\text { Table 5.3: } & \text { Critical values on } \varepsilon & 148\end{array}$

Table 5.4: Directors' choice for alternative levels of $\varepsilon$ and $g \quad 150$

Table 5.5: Conditions for increased overall level of financial statement quality produced when $q_{r}>Q^{*}$, and hence $f^{\prime}>f^{*}$

Table 5.6: The need for statutory audit requirements

Table 6.1: Certainty versus uncertainty about legal standards: comparison of auditor compliance for alternative levels of $\mathrm{q}_{\mathrm{c}}$

Table 7.1: Compliance with legal standards of care and distribution of costs and losses among auditors and users

Table 7.2: $\quad$ Example of the introduction of an ex ante quality standard in a stylised legal environment, with $b=2 / 3$ and a constant $q_{s}=1.57$

Table 7.3: Example of restriction of liability in a stylised legal environment, with $b=0.5$

\section{List of figures}

Figure 2.1: Simplified audit outcome space 23

Figure 2.2: $\quad$ Simple ladder tree diagram of CICA risk model 26

Figure 2.3: Simplified model of routes to an opinion on an account 37 


\section{List of Graphs}

Graph 5.1: Auditor compliance when the due care level is certain

Page

Graph 5.2: The auditor's reaction function when the due care level is uncertain, and the corresponding optima for the directors

128

138

Graph 5.3: Panel A : Effect of an increase in internal audit quality demand on the critical $\delta$ values

Graph 5.3: Panel B: Effect of an increase in external audit quality demand on the critical $\delta$ values

Graph 5.3: Panel C: Effect of an increase in external audit quality demand on the critical $\delta$ values, when $f$ remains constant

Graph 5.4: The directors' choice, $Q^{*}$, as a function of $\varepsilon$ and $g$

Graph 5.5: The auditor's reaction to increased demand from imposing a statutory audit requirement, where $\mathrm{q}_{2}{ }^{*}<\mathrm{qr}_{\mathrm{r}}<\mathrm{Q}^{*}$ and hence $\mathrm{f}^{\prime}=\mathrm{f}^{*}$.

Graph 5.6: The auditor's reaction to increased demand from imposing a statutory audit requirement, where $q_{r}>Q^{*}$ and hence $f^{\prime}>f^{*}$.

Graph 6.1: Audit quality production for alternative levels of $q_{c}$ when legal standards of care are certain

Panel A: when $q_{c}<q_{m} \quad 178$

Panel B: when $\mathrm{q}_{\mathrm{c}}=\mathrm{q}_{\mathrm{m}} \quad 178$

Panel C: when $q_{m}<q_{c}<q_{c, u}$

Panel D: when $q_{c}=q_{c, u} \quad 179$

Panel E: when $\mathrm{q}_{\mathrm{c}}>\mathrm{q}_{\mathrm{c}, \mathrm{u}} \quad 180$

Graph 6.2: The probability of being found liable for a given quality level ,q 186

Graph 6.3: Audit quality production for alternative levels of uncertainty, when $C^{\prime}\left(q_{c}\right)+0.5 D^{\prime}\left(q_{c}\right)>0$

Graph 6.4: Ex ante quality standards: effective versus non-effective standards $\quad 199$

Graph 7.1: The socially efficient level of audit quality production 207

Graph 7.2: Social cost as a function of $\mathrm{q}_{\mathrm{c}}$, when $\mathrm{q}_{\mathrm{c}}$ is certain. 212

Graph 7.3: Restriction on liability and social efficiency: illustration of the auditor's decision when $\alpha=\alpha_{l}$ 


\section{Acknowledgements}

I acknowledge with thanks the assistance of the following:

Professor Anthony Steele, my supervisor, and Professor David Miltz, my co-supervisor at the Catholic University of Leuven (Belgium). Their generous allocation of time, helpful comments, enthusiastic reception of my research ideas and exceptional dedication played a significant role in the molding together of this thesis. Special thanks to professor Steele, for his hospitality during my visits to the University of Warwick, and for organising an enjoyable and stimulating work environment. Special thanks to Professor Miltz for being my mentor over the past five years in Leuven and for the opportunities created.

Professor Ray Ball (University of Rochester), Professor Dan Simunic (University of British Columbia), Professor David Gwilliam (University of Wales at Aberystwyth), Professor Luc Lauwers (Catholic University Leuven), and many other academics who have given generously of their time and commented on earlier drafts of my research.

The Department of Accounting and Finance at the University of Warwick, for providing me the opportunity to do my Ph.D. studies at this university, and for travelling funds for a seminar (Audit Standards and Auditor Liability, June 1994). Various members of this department for their comments and for their hospitality during my visits.

The Department of Applied Economics at the Catholic University of Leuven, and especially Professor David Miltz, for the time and means provided to work on my thesis research. My collegues and friends at the Catholic University of Leuven for their comments and support.

The faculty and participants of the EAA Doctoral Colloquium in Accounting (Turku, Finland, April 1993), particularly Professor Ray Ball, Professor Dieter Ordelheide and Professor Stephen Zeff, for comments on 'External Audit Demand and Resource Allocation in Competitive but Regulated Audit Markets'.

The participants of The Ernst \& Young Auditing Symposium (University of Wales in Aberystwyth, September 1993), The EIASM Workshop in Financial Accounting (EIASM, Brussels, September 1993), and the Maastricht Audit Research Symposium III, (University of Limburg in Maastricht, The Netherlands, October 1993) for comments on 'Audit Standards and Auditor Liability: A Theoretical Model'.

The Participants of the Auditing Parallel session at the 17th Annual Congress of the EAA (Venice, Italy, April 1994), for comments on the paper 'Directors' and Auditors' Compliance with Uncertain Legal Standards of Care'.

My friends, for their support that has helped make this research so enjoyable, and for keeping auditing out of my world - at least for a while.

My parents, Jan and Brigitte, and my sister, Katlijne, for their love, support and encouragement. 


\section{$\underline{\text { Declaration }}$}

I hereby declare that this dissertation is entirely my own and includes nothing which is the outcome of work done in collaboration with others. I also declare that it has not been submitted in part or in full for any degree, diploma or other qualifications of any other university.

The chapters in this thesis are (partially) based on the following papers I wrote over the last three years:

1) "Directors' and Auditors' Compliance with Uncertain Legal Standards of Care", presented at the 17th Annual Congress of the European Accounting Association, Venice (Italy), April 1994

2) "Audit Standards and Auditor Liability: A Theoretical Model", presented at

* Ernst \& Young Auditing Symposium, held at the University of Wales at Aberystwyth, September 1993

* Workshop in financial Accounting, EIASM, Brussel, September 1993

* Maastricht Audit Research Symposium, Rijksuniversiteit Limburg, Maastricht (The Netherlands)

3) "External audit Demand and Resource Allocation in Competitive but Regulated Audit Markets where the Auditor acts as an Insurer", presented at the EAA Doctoral Colloquium in Accounting, Turku (Finland), April 1993

4) "A Review of the literature on Audit Risk Modelling, Risk-based Audit Decision Modelling and Audit Market Research", staff paper, Catholic University of Leuven (Belgium), November 1992. 


\section{Summary}

This thesis provides one of the first (to the author's knowledge, the first) micro-economic analyses of audit regulation and auditor liability. The analysis draws on insights from the economics and law literature that liability and regulation affect behaviour of individuals and organisations. The major research questions addressed in the thesis are the following: 1) How is demand for external audit services affected by joint and several liability of directors and external auditors? 2) How do auditor liability and professional audit standards affect audit quality? 3) Is it in the public interest to use auditor liability and professional audit standards jointly to monitor audit quality? The analysis is general, in the sense that a number of alternative regulatory scenarios are considered, and therefore hopes to be of relevance to various legal environments. Propositions about audit demand and production behaviour are drawn, as well as corollaries about the welfare implications of audit regulation and liability.

Some major conclusions from the economic analysis are the following. 1) Consistency in judicial reasoning should be promoted. Certainty about what constitutes 'due care' leads to compliance by directors and auditors. 2) Uncertainty about due care crucially affects behaviour, both of auditors and directors. 3) Liability insurance arguments are irrelevant for audit demand when the due care level for directors is fairly certain. 4) Statutory audit requirements should only be imposed under limited circumstances. 5) More prescriptive professional audit standards have a positive effect on audit quality, but one standard for all client situations can never lead to social efficiency. 6) Liability restriction has a negative effect on audit quality. It may however promote socially efficient behaviour when there is overproduction of audit quality. 7) The joint use of liability restriction and more prescriptive professional audit standards may lead to a status quo in terms of audit quality produced, and therefore not welfare improving. 


\section{List of symbols}

\section{Chapter 5:}

C(q) direct external audit cost incurred by external auditors; is a function of external audit quality produced

$\mathrm{C}_{1}\left(\mathrm{q}_{1}\right) \quad$ Cost of demanding (and producing) internal audit quality, incurred by directors

$\mathrm{C}_{2}\left(\mathrm{q}_{2}\right) \quad$ Cost of demanding external audit quality, incurred by directors; equals the audit fee

$\delta \quad$ parameter indicating the level of uncertainty about the due care level of external audit quality production

$\delta_{\mathrm{e}} \quad$ critical value on $\delta$; value of $\delta$ at which the external auditor produces exactly the level that is demanded and $g=0.5$

$\delta_{l} \quad$ critical value on $\delta$; value of $\delta$ at which the external auditor's production is such that he would be held liable with certainty, and $g=0$

$\delta_{u} \quad$ critical value on $\delta$; value of $\delta$ at which the external auditor complies with certainty with the due care level of external audit quality and $g=1$

$\varepsilon \quad$ parameter indicating the level of uncertainty about the due care level of overall financial statement quality demand

$\varepsilon_{\mathrm{e}} \quad$ critical value on $\varepsilon$; value of $\varepsilon$ at which the directors' demand equals the expected due care level, and $\mathrm{f}=0.5$

$\varepsilon_{l} \quad$ critical value on $\varepsilon$; value of $\varepsilon$ at which the directors demand level is such that they would be held liable with certainty, and $\mathrm{f}=0$

$\varepsilon_{\mathrm{u}} \quad$ critical value on $\varepsilon$; value of $\varepsilon$ at which the directors comply with certainty with the overall financial statement quality norm and $f=1$

f probability that directors comply with the overall financial statement quality norm ex post set by the courts. Also $f\left(q_{1}, q_{2} ; Q_{c}\right)$

$\mathrm{f}^{*} \quad$ privately optimal probability for directors of complying with the overall financial statement quality norm ex post set by the courts.

$f^{\prime} \quad$ privately optimal probability for directors of complying with the overall financial statement quality norm ex post set by the courts, when there are statutory audit requirements.

g probability that external auditors comply with the external audit quality norm ex post set by the courts. Also $\mathrm{g}\left(\mathrm{q} ; \mathrm{q}_{2}\right)$

$\mathrm{g}^{*} \quad$ value that $\mathrm{g}$ would take when $\mathrm{q}_{1}{ }^{*}$ and $\mathrm{q}_{2}{ }^{*}$ are known.

L expected losses to financial statement users from defects in those statements 
$\theta \quad$ relative importance weight, as seen by the courts, of internal audit quality in achieving overall financial statement quality

q external audit production variable

$\mathrm{q}^{*} \quad$ private optimum for external audit quality production

$q^{\prime} \quad$ private optimum for external audit quality production when there are statutory audit requirements

$\mathrm{q}_{1} \quad$ internal audit quality demand (and production) variable

$\mathrm{q}_{1}^{*} \quad$ private optimum for internal audit quality demand

$\mathrm{q}_{1}^{\prime} \quad$ private optimum for internal audit quality demand when there are statutory audit requirements

$\mathrm{q}_{2}$ external audit quality demand variable

$\mathrm{q}_{2}{ }^{*} \quad$ private optimum for external audit quality demand

$\mathrm{q}_{2}{ }^{\prime} \quad$ private optimum for external audit quality demand when there are statutory audit requirements

$\mathrm{q}_{\mathrm{r}} \quad$ external audit quality level implied by statutory audit requirements

$\mathrm{Q} \quad \equiv \theta \mathrm{q}_{1}+\mathrm{q}_{2}$; overall financial statement quality demand variable

$Q_{c} \quad$ due care level for directors, set by the courts ex post; also called: overall financial statement quality norm

$Q^{*} \quad$ private optimum for overall financial statement quality demand

Q* Privately optimal level of demanded overall financial statement quality if the directors' optimisation problem were unconstrained.

$\mathrm{Q}^{*} \quad$ private optimum for overall financial statement quality demand when there are statutory audit requirements

$\mathrm{Q}_{\mathrm{p}}{ }^{*} \quad \equiv \theta \mathrm{q}_{1}{ }^{*}+\mathrm{q}^{*}$; produced level of overall financial statement quality

$\mathrm{Q}_{\mathrm{p}}{ }^{\prime} \quad \equiv \theta \mathrm{q}_{1}{ }^{\prime}+\mathrm{q}^{\prime}$; produced level of overall financial statement quality when there are statutory audit requirements

$s_{1} \quad$ fraction of losses to be borne by directors if found negligent

$s_{2} \quad$ fraction of losses to be borne by external auditors if found negligent 


\section{Chapters 6 and 7}

Note that 'audit quality' relates to external audit quality production.

$\alpha \quad$ liability restriction parameter, representing the ratio of losses to classes of claimants and losses to all users of financial statements

$\alpha_{e} \quad$ critical value on $\alpha$; value of $\alpha$ at which $\mathrm{q}^{*}=\mathrm{q}^{* *}$ (uncertainty case).

$\alpha_{l} \quad$ critical value on $\alpha$; value of $\alpha$ at which $\mathrm{q}^{* *}=\mathrm{q}_{\mathrm{c}, \mathrm{u}}$ (certainty case)

$\mathrm{b}$ a constant defined as the relative uncertainty resulting from jurisdiction in a particular legal environment

$b_{e} \quad$ critical value on $b$ at which audit quality production would be socially efficient

$C(q)$ direct audit cost, as a function of audit quality

$\delta \quad$ random variable, related to the auditor's uncertainty about the court's standard of due care

$\mathrm{D}(\mathrm{q})$ damage payments, as a function of audit quality

$E[D(q)] \equiv D(q) . N(q)$; Risk premium or expected damage payments

$\mathrm{E}[\mathrm{TC}(\mathrm{q})]$ total expected cost function for an individual audit engagement

f subjective belief function of the auditor about the legal standard of care (uncertainty case)

L(q) negative externalities or losses suffered by users of financial statements, defined as a function of audit quality

$\mathrm{N}(\mathrm{q}) \quad$ probability that the auditor will be held liable (certainty case)

q audit quality variable

$\mathrm{q}^{*} \quad$ privately optimal level of audit quality

$\mathrm{q}^{* *} \quad$ engagement specific socially efficient level of audit quality

$\mathrm{q}_{\mathrm{c}}$ the courts' standard of due care; in the case of uncertainty: the expectation of the courts' standard of due care

$\mathrm{q}_{\mathrm{c}, \mathrm{u}} \quad$ critical value on $\mathrm{q}_{\mathrm{c}}$ defined by $\mathrm{C}\left(\mathrm{q}_{\mathrm{c}}\right)=\mathrm{C}\left(\mathrm{q}_{\mathrm{m}}\right)+\mathrm{D}\left(\mathrm{q}_{\mathrm{m}}\right)$

$\mathrm{q}_{\mathrm{c}, l} \quad$ critical value on $\mathrm{q}_{\mathrm{c}}$ defined as the value of $\mathrm{q}_{\mathrm{c}}$ at which $\mathrm{C}^{\prime}\left(\mathrm{q}_{\mathrm{c}}\right)+\mathrm{D}^{\prime}\left(\mathrm{q}_{\mathrm{c}}\right)=0$

$\mathrm{q}_{\mathrm{m}} \quad \equiv \operatorname{Arg} \min \mathrm{C}(\mathrm{q})+\mathrm{D}(\mathrm{q})$

q

$\mathrm{q}_{\mathrm{s}} \quad$ audit quality level implied by ex ante professional audit standards

$\mathrm{R}(\mathrm{q})$ probability that the auditor will be held liable as a function of audit quality

$\sigma \quad$ standard deviation of the due care level in the uncertainty case

S(q) probability that the auditor will be held liable in case of complementary use of (effective) ex ante professional standards

SC(q) total social cost of an individual audit engagement defined as a function of 
audit quality

$\sigma_{\mathbf{e}} \quad$ critical value of $\sigma$ at which the auditor's private quality decision coincides with the expectation about the level of due care set by the courts, when there is no restriction on liability

$\sigma_{\mathbf{r}} \quad$ critical value on $\sigma$ at which the privately optimal level of audit quality equals the socially efficient level when there is restriction on liability 


\section{Chapter 1: Introduction}

\section{Introduction to the problem}

Auditor liability is a hot topic. Over the past years the outstanding claims against public accounting firms have risen exponentially, especially in the United States and Australia, but also in the United Kingdom. This has resulted in the audit profession considering itself as an insurer. Lobbies to change the legal framework in which the auditor operates and to restrict auditor liability have emerged. At the same time, however, the quality of auditing has been under much public scrutiny, with allegations at the address of the profession of producing audit services of too low quality. A popular suggestion is to increase the audit quality standards.

Liability and regulation are alternative policy instruments available to governements to monitor behaviour of individuals and organisations. In the auditing context, both instruments are used, and both demand and production of audit services are affected. To the author's knowledge, however, no formal economic analyses have been performed of the impact of the of liability rules and regulations which apply to the auditing context. Without an understanding of the effects, it is difficult to address the auditing crisis, and to assess whether legal changes are indeed necessary and if so, what they should look like.

Throughout this thesis, the view taken by the author is that auditing is a professional, economic and regulated activity, and that these three aspects are interrelated. This approach implies that, for auditors who behave in a rational economic way, the audit production process is a process of risk management. Risk is not minimised, but total audit cost is. For each individual client situation there exists a cost minimising level of 
audit quality, which is specific to that situation. The auditor's quality decision is however influenced by liability rules and professional audit standards, which form constraints on the auditor's behaviour.

The implication of the approach on audit demand is that, apart from statutory audit requirements and liability rules for directors, auditor liability may have an impact on the audit demand decision. This provides a framework to investigate whether and under which circumstances the insurance rationale for audit demand is valid.

\section{Major research objectives}

This thesis will attempt to address the above mentioned caveat, and provides an economic analysis of the impact of audit liability and audit regulation on audit demand and audit production. The objective is to address the following research questions:

1) How does liability and regulation affect audit demand. In particular:

a) how does joint liability of directors and external auditors for losses to users from defective audited statements affect demand for external audit services; and b) are statutory audit requirements an effective policy instrument in monitoring the level of quality of financial statements provided to users.

2) How do auditor liability and professional audit standards affect the production of audit services. In particular:

a) how do liability rules, professional audit standards and liability restriction affect the quality of the external audit service; and

b) is the joint use of auditor liability and professional audit standards to monitor the auditor's production behaviour socially efficient. 


\section{Research methodology}

For the literature reviews and description of the problem setting the main research technique utilised was a familiarisation with relevant literature, both in the auditing and economics area. In the auditing area this included the large body of literature on riskbased auditing and audit decision modelling, the economics of auditing, the economics of accounting and auditing regulation, and audit liability.

The methodologies employed in the development of the theoretical components of the study include familiarisation with the broadly defined areas of law and economics, applied welfare economics and public policy. The analyses of behaviour of directors (chapter 5) and external auditors (chapters 5,6 and 7) are of a micro-economic nature, and involved the analytical technique of optimisation. The economic framework adopted allows for the impact of liability rules and regulation which form constraints on behaviour. Consultations with other researchers concerned with similar issues, and the incorporation of feedback obtained from the presentation of staff and conference papers contributed further to the development of the thesis.

\section{Major contributions of thesis}

The thesis hopes to make contributions in the following areas:

\section{The economics of auditing.}

To the author's knowledge, the first formal analysis of the insurance hypothesis for audit demand is provided. From the analysis, propositions about the directors' demand for auditing are derived, given the liability rules applying to them and to the auditors. 
Propositions about the effectiveness of statutory audit requirements in attaining a specified level of financial statement quality are also derived.

\section{The economics of auditor liability and audit regulation.}

To the author's knowledge no prior study exists that examines the joint impact of liability and professional audit standards on audit quality production. A number of propositions about audit quality production for alternative regulatory scenarios are derived. From these propositions a set of corollaries about the social efficiency of alternative regulatory scenarios are drawn.

3. The author hopes that the analysis may serve as a guide to public policy makers, courts and the audit profession when changes in liability rules, professional audit standards and statutory audit requirements are considered.

\section{Limitations of the thesis}

Economic analysis is a technology of simplification, powerful in revealing structure, but subversive in privileging certain assumptions and conjectures, neglecting others. The major limitations of the thesis are related to some of the assumptions adopted in part 2 of the thesis, and are the following:

1. Audit quality and negligence are treated as having a single component.

2. Auditors and directors are assumed to be risk neutral.

3. In chapter 5 it is assumed that uncertainty about the legal standard of care is uniformly distributed. In chapters 6 and 7 a normal distribution of beliefs about the legal standard is assumed. Both assumptions are compatible, since both types of belief 
functions belong to the category of symmetrical distributions. Alternative types of belief functions may however have a different impact on behaviour.

4. In chapters 6 and 7, a Bayesian revision of beliefs is assumed in modelling the impact of professional audit standards on the subjective belief function about the legal standard of care. Alternative assumptions may have a different impact on behaviour.

5. Not all feasible public policy alternatives are investigated in chapters 6 and 7. The analysis has focused on alternatives in use, but can be easily extended to other scenarios for liability, such as, for example, proportionate liability.

6. Equity and distributional concerns are omitted from consideration in the analysis of social efficiency of liability and professional audit standards in chapter 7. Social efficiency in a Pareto sense is assumed.

7. For the analysis of uncertainty about negligence standards on social efficiency, in chapter 7 , it is assumed that the expected legal standard of care equals the socially efficient level.

8. The conclusions in chapter 7 about social efficiency of alternative regulatory scenarios for all engagements in a legal environment are based on the assumption that beliefs in a legal environment are homogeneous.

9. The study focuses on auditor liability to third parties, and ignores liability in contract.

\section{Thesis structure}

Part I of the thesis includes reviews of the literature in areas that are relevant to the subject, and consists of chapters 2,3 and 4. Part II incorporates theoretical chapters 5, 6 and 7, which are associated with the formal economic analysis of the impact of liability and regulation on audit demand and production, and are the contribution of the author. 
The logic underlying the literature review in part $I$, is the view that external auditing is a professional, economic and regulated activity. In chapter 2 , the external audit is approached as a professional and risky activity. The literature review focuses on normative models of audit production which have a risk component. In chapter 3 , external auditing is considered as an economic activity, and the external audit service as a commodity traded in the audit market. A review is provided of competing audit demand rationales, and of empirical evidence on audit pricing determinants based on a model of audit demand. In chapter 4 , auditing is seen as a regulated activity. A review of economic arguments for and against accounting and auditing regulation is provided. Alternative policy instruments available to governments to modify behaviour are discussed, and identified in the audit context.

Part II consists of the economic analysis from which propositions are derived about auditor and directors behaviour given liability and regulation. Chapter 5 provides a - micro-economic analysis of the impact of directors' and auditors' liability on the audit demand decision. The effectiveness of statutory audit requirements in achieving a target level of financial statement quality is also examined. Chapters 6 and 7 propose a microeconomic analysis of audit quality production. The focus of chapter 6 is the impact of auditor liability, professional audit standards and liability restrictions on quality produced, whereas chapter 7 analyses whether and when auditor liability and regulation are socially efficient. Overall conclusions to the thesis are drawn in chapter 8.

Table 1.1 provides an a concise overview of the thesis' contents, based on a classification of the chapters into 'audit production' and 'audit demand'. 
Table 1.1: Thesis structure

\section{AUdIT PRODUCTION}

Chapter 2

Normative model of audit production

Chapter 3

Empirical assessment of attributes of the audit product that are priced

\section{Chapter 4}

* Regulations and liability rules which affect audit production

Chapter 6

* Economic analysis of the impact of liability and regulation on audit quality production:

Chapter 7

* Social efficiency of regulation and auditor liability

Chapter 8

*Conclusions

\section{AUdiT DEMAND}

Chapter 3:

* Audit demand hypotheses

* Audit pricing studies based on a model of audit demand

\section{Chapter 4}

* Regulations and liability rules which affect audit demand

Chapter 5

* Economic analysis of the impact of liability and regulation on audit demand
Chapter 8

*Conclusions 
Part I 


\section{Chapter 2:}

\section{Audit production as a process to control audit-related risks:}

\section{Audit risk modelling versus audit decision modelling}

\section{Introduction}

In this chapter the focus is on auditing as a professional activity. The audit process is seen as a production process leading to an opinion on the financial statements by which the auditor controls and manages the various audit-related risks and risk components. The objective of this chapter is to provide an overview of major developments in prior normative auditing research that focused on formal models to describe the audit production process and which were developed as an aid for practising auditors in conducting a systematic and consistent risk-based audit. A review of the normative audit production literature in this area is relevant at least for the following two reasons. First, it gives an indication and discussion of perceived determinants of audit-related risks. Second, it covers a normative economic approach to formal audit production modelling.

Auditing is a risky activity. In general two different but related types of audit-related risks are distinguished: audit risk and business risk. Audit risk can generally be defined as the risk or probability of incorrectly reporting on the financial statements ${ }^{1}$, and is a function of a number of auditor and auditee related risk components (for details see subsection 2.2). Business risk relates to the many potential adverse consequences to the

\footnotetext{
${ }^{1}$ This is not a unique definition; but rather the most general one. SAS 47 , for example, defines audit risk as the probability that the auditor fails to detect an error, given that one exists, and issues an unqualified opinion. This is clearly less general than the definition given here. See also section 2.1. for more details.
} 
audit firm arising from any litigation or criticism concerning the auditor's work or the client's audited financial statements. The principal elements of business risk [see, for example, Brumfield, Elliott and Jacobson (1983)] are litigation, sanctions imposed by public or private regulatory bodies, and impaired professional reputation which can occur as a result of adverse publicity. Unlike audit risk, business risk is not expressed in terms of probability but is rather a monetary concept, and is, amongst other things, a function of client specific factors and auditor liability rules.

Two distinct normative modelling approaches ${ }^{2}$ evolved : the risk analysis approach (also called audit risk modelling) and the audit modelling approach (also called decision modelling approach). Major developments in audit risk modelling are reviewed in section 2 , major types of decision models of auditing are reviewed in section 3, and conclusions are given in section 4 . An important distinction between both approaches relates to their alternative focus on auditing-related risks. The risk analysis approach only focuses on audit risk, thereby ignoring business risk, whereas audit decision models often take a broader view and formally relate audit risk and business risk considerations. Also important is that the former approach is non-economic in nature, whereas the latter approach is economic in nature. The risk analysis approach relates to audit risk models developed to help the auditor to obtain a given degree of confidence that the financial statements do not contain a material error. Since economic considerations are ignored, the focus is rather on effective audit risk control. The decision modelling approach refers to audit decision models which are more comprehensive in nature as a broader set of parameters are taken into consideration, such as, for example, economic considerations. This type of models may serve as an aid for auditors to identify an efficient and cost effective way by which a suitable level (i.e.

\footnotetext{
${ }^{2}$ A distinction between these two aprroaches was made by Cushing and Loebbecke (1983). Gwilliam (1987a, chapter 12) also makes a similar distinction and reviews major developments in both areas untill 1985.
} 
cost minimising) of confidence can be achieved. Unlike the general attention from the profession to audit risk modelling, decision modelling and business risk issues have been rather the focus of academic auditing research.

\section{The Risk analysis approach: a review of risk modelling in auditing}

The audit risk concept and audit risk modelling received considerable attention in the authoritative, professional oriented and academic audit literature over the past twenty five years. This has been the result of a movement towards the idea of basing audit scope and timing decisions on a more explicit analysis of audit risk. This evolution is not surprising as the whole process of gathering audit evidence is nothing but a means to attain an acceptable level of assurance about the truth and fairness of the financial statements under consideration. The higher the level of assurance (reliance) the auditor achieves, the lower is the risk that he may make an incorrect judgement about the financial statements. Audit risk is the complement of the level of assurance the auditor gets by performing audit procedures and reflects the very nature of the audit proces. In this section the major developments in audit risk modelling are summarised.

\subsection{A close look at the audit risk concept}

The most general definition of audit risk is the risk or probability of incorrectly reporting on the financial statements. This embodies both the risk of incorrect rejection or $\alpha$-risk (also type I error risk) and the risk of incorrect acceptance or $\beta$-risk (also type II error risk). The distinction between $\alpha$ and $\beta$ risk is used both in the context of a single reported book value and at the aggregated level of the financial statements as a whole. The difference between $\alpha$ and $\beta$ risk is clarified in a landmark paper by Elliott 
and Rogers (1972). It stems from the application of the statistical hypothesis testing approach to the audit setting, which permits the auditor to measure and control both types of risk. Two very convenient alternate hypotheses exist in auditing, namely:

$\mathrm{H}_{0}$ : The financial statement amount is correct, and $\mathrm{H}_{1}$ : The financial statement amount is materially in error.

$\alpha$ is the risk of rejecting $\mathrm{H}_{0}$ if $\mathrm{H}_{0}$ is true and $\beta$ is the risk of accepting $\mathrm{H}_{0}$ if $\mathrm{H}_{1}$ is true 3 . In most of the audit risk literature, audit risk is perceived and defined as $\beta$-risk alone (see, for example, SAS 1, 39 and 47; Roberts 1978), that is as the risk that financial statements that are materially in error will be accepted.

Along another dimension which directly relates to the use of statistical sampling methods in audit testing, audit risk can also be seen to entail two other types of risk: sampling and non-sampling risk. Roberts (1978) defined sampling risk as "the portion of audit risk of not detecting a material error that exists because the auditor examined a sample of the account balances or transactions instead of every one". Nonsampling risk then is "the portion of audit risk of not detecting a material error that exists because of inherent limitations of the procedures used, the timing of the procedures, the system being examined, and the skill and care of the auditor". Although both types of risk are defined here in the light of $\beta$-risk, a distinction between sampling and nonsampling risk

\footnotetext{
${ }^{3}$ This hypothesis test is easily converted into an equivalent test stated in terms of confidence and precision where the decision rule is that the book value will be accepted if it is included in the confidence interval but rejected otherwise. The conversion is expressed as follows:

$$
\begin{aligned}
& C L=1-\alpha \\
& P=M /\left(1+Z_{\beta} / Z_{\alpha / 2}\right)
\end{aligned}
$$

where $\mathrm{CL}=$ confidence level, $\mathrm{P}=$ precision, $\mathrm{M}=$ the amount considered material, $\mathrm{Z} X$ is the normal table value which includes an area of $0.5-\mathrm{X}$.
} 
equally applies to $\alpha$-risk or to total audit risk ( $\alpha$-risk $+\beta$-risk). Roberts further defines $\delta$-risk, as the sampling risk of unwarranted reliance in statistical compliance tests.

Apart from these two alternative dimensions along which the audit risk concept can be viewed, it is important to emphasise that there exist three distinct forms of (total) audit risk to the auditor (see, for example, Arens \& Loebbecke (1984); Sennetti (1990) ). First, there is the planned level of acceptable audit risk (or, desired audit risk), specified before the substantive audit procedures are performed; second, there is the true ex post level of audit risk (a synonym for ex post audit risk is achieved audit risk) that is unknown to the auditor; and third there is the estimate of ex post audit risk as made by the auditor. The recognition of these three forms of audit risk has a profound effect on modelling risk (see also section 2.4).

\subsection{The early days of risk modelling: the joint audit risk model (ARM)}

The use of an audit risk model for audits of financial statements has been established in several auditing standards. General statements about risk consideration have evolved into detailed guidance on quantitative risk assessment by means of a risk model. An understanding of the importance of risk evaluation was already shown in Professional Standards in the US as early as 1963 (see AU Section 150.05 of AICPA professional Standards):

\footnotetext{
" The degree of risk involved also has an important bearing on the nature of the examination......The effect of internal control on the scope of the examination is an outstanding example of the influence on auditing procedures of a greater or lesser degree of risk of error; i.e., the stronger the internal control, the less the degree of risk".
} 
The first explicit incorporation of a formula in the standards only occurred in 1972, when the AICPA published Statement of Auditing Procedure 54 (which was later incorporated as Section 320 of the Codification of Statements of Auditing Standards (SAS 1)). Table 2.1 summarises the major stages in the quantification of joint audit risk measures ${ }^{4}$. In those days the problem was modelled as one of setting the 'reliability' level of substantive test of details (S) so that its combination with the subjective reliance on internal accounting control and other relevant factors (C) would provide a combined reliability level (R) sufficient to meet the auditor's overall objectives for the audit. The relationship with risk is described as follows:

"...The combined reliability is the complement of the combined risk that none of the procedures would accomplish the particular audit purpose, and the combined risk is the product of such risks for the respective individual procedures..." (SAS 1 section 320B.31)

Subsequent suggestions made in the second half of the seventies to extend the SAS 1formula ( see e.g. Stringer (1975), Anderson (1977) and Leslie, Teitlebaum \& Anderson (1979) and Warren (1979)) are all based on concepts which were already discussed in SAS 1, but which were not explicitly incorporated into the formula.

\footnotetext{
${ }^{4}$ Table 2.1 displays the evolution in the development (both authoritative and non-authoritative) of quantitative audit risk formulas. As such only SAS 1 (or SAP 54) SAS 39 and SAS 47 are included in the table as they firmly established the appropriateness of a risk-driven audit approach for the external auditor by incorporation of a quantitative assessment formula. However, the understanding of the importance of risk evaluation continued to be upheld in other (later) pronouncements of the Accounting Standards Board.
} 
Table 2.1: Major stages in audit risk model development: the early days.

\section{YEAR AUTHOR DEVELOPMENT}

1972

AICPA

SAP 54, Appendix B; later incorporated in SAS1, section 320

$$
S=1-\frac{(1-R)}{(1-C)}
$$

Stringer

1975

1979

1981

AICPA

1983

AICPA

SAS 47
SAS 39

Anderson

Warren auditor

$\mathrm{UR}=\mathrm{IC} * \mathrm{AR} * \mathrm{TD}$

Where : given that it occured,

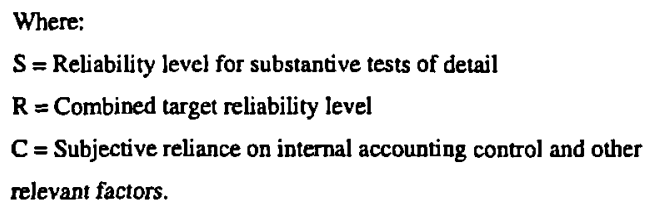

Where:

$\mathrm{D}=$ Reliance assigned to tests of details

$A=$ Reliance assigned to analytical review procedures
Suggests to incorporate inherent risk into the model

Proposes the following extension to the AICPA formula of audit risk:

$$
(1-R)=(1-S)(1-C) M E
$$

Where ME represents the likelihood of material error as subjectively assessed by the

Supersedes sections $320 \mathrm{~A}$ and $320 \mathrm{~B}$ of SAS1; introduces risk factors instead of reliance factors and incorporates a factor for analytical review risk; inherent risk is conservatively set at 1

$\mathrm{UR}=$ ultimate risk that financial statements are materially misstated after completion of the audit; IC = the risk that the system of internal accounting control will fail to detect a material misstatement

$\mathrm{AR}=$ The risk that analytical review procedures will fail to detect a material misstatement given that it occured, and has not yet been detected by the system of internal accounting control;

TD = the risk that substantive tests of detail will fail to detect a material misstatement given that it occured, and has not yet been detected by the system of internal accounting control.

Explicit incorporation of inherent risk and integration of AR and TD

$\mathrm{AR}=\mathrm{IR} * \mathrm{CR} * \mathrm{DR}$

where:

$A R=$ the audit risk (which replaces UR of SAS 39)

IR = inherent risk of material misstatement occuring in the process of preparing financial statements without consideration of control procedures;

$\mathrm{CR}=$ the same as IC above;

$D R=$ :the risk that the auditor's procedures will fail to detect a material error not detected by the system of internal control (combines AR and TD of SAS 39) 
Anderson (1977, p.86), for example, suggests to examine the concept of an appropriate degree of assurance from the audit opinion "..in terms of the complement of such assurance: the risk of undetected misstatement remaining in the audited financial statements", and further states that:

"This risk is in turn a product of three factors:

1. inherent risk (the risk of an error in the first place),

2. control risk (the risk of the control system failing to prevent or detect such error, which is the complement of the relative strength of internal control) and,

3. audit risk ${ }^{5}$ (the risk of the audit procedures failing to detect such errors)."

In 1981 with the issuance of SAS No. 39, the AICPA incorporated into its formula some of the modifications proposed in prior literature. First, the notation used in the formula was altered to reflect risk factors instead of reliance factors. Second, a factor for analytical review procedures and other relevant substantive tests was incorporated. SAS No. 39 also raises the issue of inherent risk, but asserts that this risk is potentially costly to quantify and that for this reason it is implicitly and conservatively set at one. SAS No. 39 further suggests that the proposed model might be used in planning a statistical sample by selecting an acceptable ultimate risk, subjectively assessing control risk (IC) and audit risk (AR) and then solving for tests of detail risk (TD) as follows: $\mathrm{TD}=\mathrm{UR} /(\mathrm{IC} * \mathrm{AR}$ ) (for a definition of each component, see Table 2.1). The derived formula for test of details risk can be seen as the complement of the formula proposed by Stringer (1975) (see table 2.1). SAS 39 does not contemplate the use of the formula to conditionally revise an audit plan or to evaluate audit results.

SAS 47, however, emphasises the need of audit risk and materiality .."to be considered together in determining the nature, timing, and extent of auditing procedures and in

\footnotetext{
${ }^{5}$ Note that the term 'audit risk' is used here to indicate one risk component in the ARM and coincides with detection risk in SAS 47. It clearly differs from the general definition adopted in this chapter.
} 
evaluating the results of these procedures [par.1]" (italics added). SAS 47 updated the concepts and terminology of SAS 39 to provide further guidance in considering audit risk both at the financial statement level and at the level of individual account balances or classes of transactions. The basic approach remains the same though certain terms have been redefined. SAS 47 explicitly incorporates a factor for inherent risk and combines analytical review risk (AR) and test of details risk (TD) in one risk factor, namely detection risk (DR). The extension to use the ARM for risk evaluation has been heavily criticised in subsequent audit risk research, as the model is clearly not fit to correctly measure achieved (ex post) audit risk (see also subsection 2.4.2).

In subsequent literature the audit risk model (ARM) often takes the form of a combination of the models in SAS 39 and SAS 47 and is defined as the product of the following factors (see table 2.1 for a definition of each factor):

Ultimate Risk or Audit risk $=\mathrm{IR} * \mathrm{CR} * \mathrm{AR} * \mathrm{TD}$

\subsection{Shortcomings of the ARM}

A very interesting discussion of the assumptions and limitations of the ARM has been provided by Cushing \& Loebbecke (1983). The major points of their criticism are the following. First, it is assumed that the individual risk components of the ARM are independent of each other, whilst there exist interdependencies between these factors. Inherent risk, analytical review risk and substantive test of detail risk all depend on control risk. Failure to consider these interdependencies when internal control is less than good tends to understate the risk factor being assessed. As a result the use of the model might expose the auditor to a higher level of ultimate risk than he would consider acceptable. Second, the model does not provide any guidance for aggregating 
the risk assessments made at the disaggregated level of accounts or transactions to the risk for the financial statements as a whole. Third, the model only considers sampling risk (and $\beta$-risk) and assumes that the nonsampling risk component is neglible. Fourth, the ARM is ill-equiped to explicitly consider economic factors such as the audit cost or the effect of potential misstatement. Therefore, a more comprehensive model is advocated which considers risk as one of several relevant parameters ( see also section 3) and which identifies the appropriate relationships among those parameters. Fifth, the ARM should only be used as a planning tool, namely to determine the appropriate level of sampling risk for substantive tests of details, and not as a risk evaluation model.

The point that the ARM should only be used as a planning tool has been the focus of a paper by Kinney (1983), who states that the use of the model to conditionally revise an audit plan or to evaluate audit results may subject the auditor to more risk than might be indicated by the ARM formula, although the opposite may also be possible. In a later paper Kinney (1989) elaborates the issue of sequential decision making in auditing and of possible understatement of achieved audit risk, and defines a complete audit outcome space in a Bayesian context (see section 2.4.2).

Although the audit risk model as defined by SAS $39 / 47$ has been accepted by several auditing firms as a planning aid for their audits 6 , there appear to be wide differences in the way in which audit firms implement the audit risk model. This is not surprising in itself, since little guidance is provided in audit standards about the underlying determinants of the risk components in the model (in particular w.r.t. inherent risk and control risk), which might result in differences in their conceptual interpretations. A

\footnotetext{
${ }^{6}$ For example, Holstrum \& Kirtland (1982) discussed the application of the ARM in Deloittes, Haskins \& Sells; and Grobstein \& Craig (1984) in Ernst \& Whinney. Elliott (1983) discussed the planning activities in Peat Marwick International, which are among other things, clearly based on assessments of inherent risk and control risk..
} 
number of empirical studies (see, for example, Jiambalvo and Waller (1984), Daniel (1988), and Strawser $(1990,1991))$ have investigated some behavioral aspects related to the use of the ARM in practice. In each of these studies a sample ${ }^{7}$ of practising auditors has been subject to a risk-assessment exercise from hypothetical or real case information. A major concern was that the multiplicative nature of the ARM might not be descriptive of the cognitive framework adopted by auditors when they combine component risks and process underlying risk information. Jiambalvo and Waller (1984) and Daniel (1988) indeed report results that point in this direction. Strawser (1990, 1991) aims to extend these prior research efforts, and gives a possible explanation for this feature. He argues that auditors may not perceive that each risk component has an equal effect on overall audit risk and may combine the component risks using different subjective weightings, and therefore utilises the human information processing methodology for determining the effect of each risk component on overall audit risk. Strawser also investigates whether the subjective weightings attached to each risk component differ across auditors affiliated with different-sized accounting firms. From the evidence he concludes that auditors' risk judgements may depart from the basic premise of the SAS 39/47 risk model in some situations. Big eight auditors associated a high level of overall audit risk with situations characterised by ineffective analytical procedures, while regional and local auditors associated a high level of overall audit risk with situations characterised by ineffective tests of details procedures.

Waller (1993) takes a different approach and investigates the alleged dependence of audit risk model components. His study reports empirical evidence on auditors' inherent and control risk assessments by analysing archival data drawn from the working papers

\footnotetext{
${ }^{7}$ Note that the number and the nature of test subjects differs across studies: Jiambalvo and Waller (1984) included 13 auditors from one big 8 firm; Daniel (1988) included 33 auditors from 9 different large accounting firms, and Strawser $(1990,1991)$ included 40 auditors from two big 8 firms and 38 auditors from various regional and local firms.
} 
of one big six accounting firm (i.e. KPMG Peat Marwick). Insignificant association between inherent risk and control risk assessments was found. This finding runs counter the idea that dependence exists between the audit risk model components.

Although generalisation from limited empirical material provided might be inappropriate, it certainly indicates a need to further investigate both the role of underlying risk-information cues (i.e. underlying determinants of the risk components) for the assessment of audit risk, and the cognitive framework adopted by the auditor when processing risk-information. 


\subsection{Bayesian approach to risk modelling}

An alternative approach for the combination of risk components into an overall ex post audit risk measure is derived from the application of Bayesian theory of conditional dependence 8 to the audit judgement process. The approach is fundamentally different from the SAS $39 / 47$ model which is a joint (multiplicative) ad hoc risk model. From a theoretical perspective the Bayesian approach to risk modelling is superior as it is based on the laws of subjective probability theory.

\subsubsection{Application of Bayes theorem to assess achieved (ex post) audit risk}

At the aggregate level of opinion-forming on the financial statements as a whole, 'Bayesian audit $\beta$-risk', or the risk of incorrectly accepting the financial statements as being error free, can be defined as the posterior or conditional probability of financial statement error after the performance of audit tests and the resulting issuance of an unqualified opinion ( denoted as $\mathrm{P}(\mathrm{E} \mid \mathrm{A})$ ). Using Bayes' rule, $\beta$-risk is then defined as follows:

${ }^{8}$ In its simplest form Bayes theorem states:

$P(A \mid Z)=\frac{P(A) P(Z \mid A)}{P(Z)}$

where $P(A \mid Z)$ is the probability of $A$ conditional on $Z$, or the posterior judgement weight given to state $A$ after having observed evidence $Z ; P(A)$ is the prior judgement weight given to state $A$, that is before evidence $Z$ is collected; and $P(Z \mid A)$ is the likelihood of the evidence $Z$ given state $A . P(Z)$ can be seen as merely a rescaling constant. Interesting is that Bayes theorem can be restated as: POSTERIOR is proportional to PRIOR x LIKELIHOOD. 
$\begin{aligned} P(E \mid A)=\frac{P(A \mid E) * P(E)}{P(A)} & =\frac{P(A \mid E) * P(E)}{[P(A \mid E) * P(E)]+[P(A \mid 0) * P(0)]} \\ & =\frac{\text { prob. incorrect acceptance }[P(I A)]}{\text { prob. incorrect acceptance }[P(I A)]+\text { prob. correct acceptance }[P(C A)]}\end{aligned}$

Where $\quad \mathrm{P}(\mathrm{E} \mid \mathrm{A})=$ posterior (conditional) risk as defined above;

$=$ probability of error given acceptance of statements as being error free

$\mathrm{P}(\mathrm{AIE})=$ probability that audit procedures fail to detect the error, given that the error exists

$\mathrm{P}(\mathrm{E}) \quad=$ prior probability of error

$\mathrm{P}(\mathrm{A}) \quad=$ total probability that the financial statements are accepted

$=$ probability of incorrect acceptance $[\mathrm{P}(\mathrm{IA})]+$ probability of correct acceptance [P(CA)]

$\mathrm{P}(\mathrm{A} \mid 0)=$ probability that error free financial statements are accepted

$\mathrm{P}(0) \quad=$ prior probability of no error $=1-\mathrm{P}(\mathrm{E})$

The above equation reveals that the probability of error in the accepted financial statements equals the probability of incorrectly accepting the financial statements divided by the total probability of accepting the financial statements (both correctly and incorrectly). In the same way $\alpha$-risk, or the risk of incorrectly rejecting the financial statements as being in error where they are actually error-free can be defined as:

$\begin{aligned} \mathrm{P}(0 \mid \mathrm{R})=\frac{\mathrm{P}(\mathrm{R} \mid 0) * \mathrm{P}(0)}{\mathrm{P}(\mathrm{R})} & =\frac{\mathrm{P}(\mathrm{R} \mid 0) * \mathrm{P}(0)}{[\mathrm{P}(\mathrm{R} \mid 0) * \mathrm{P}(0)]+[\mathrm{P}(\mathrm{R} \mid \mathrm{E}) * \mathrm{P}(\mathrm{E})]} \\ & =\quad \text { prob. incorrect rejection [P(IR)]}\end{aligned}$

prob. incorrect rejection $[\mathrm{P}(\mathrm{IR})]+$ prob. correct rejection $[\mathrm{P}(\mathrm{CR})]$

Where $\quad P(0 \mid R)=$ posterior (conditional) $\alpha$-risk as defined above; $=$ probability of no error given rejection of statements

$\mathrm{P}(\mathrm{R} \mid 0)=$ probability that audit procedures incorrectly detect an error, given that no error exists

$\mathrm{P}(\mathrm{R})=$ total probability that the financial statements are rejected $=$ probability of incorrect rejection $[\mathrm{P}(\mathrm{IR})]+$ probability of correct rejection [ P(CR)]

$P(R \mid E)=$ probability that erronous financial statements are rejected 
Figure 2.1 illustrates the above definitions by way of a simplified audit outcome space. It is clear that the joint audit risk formula understates the achieved (ex post) $\beta$ risk.

Figure 2.1: Simplified audit outcome space

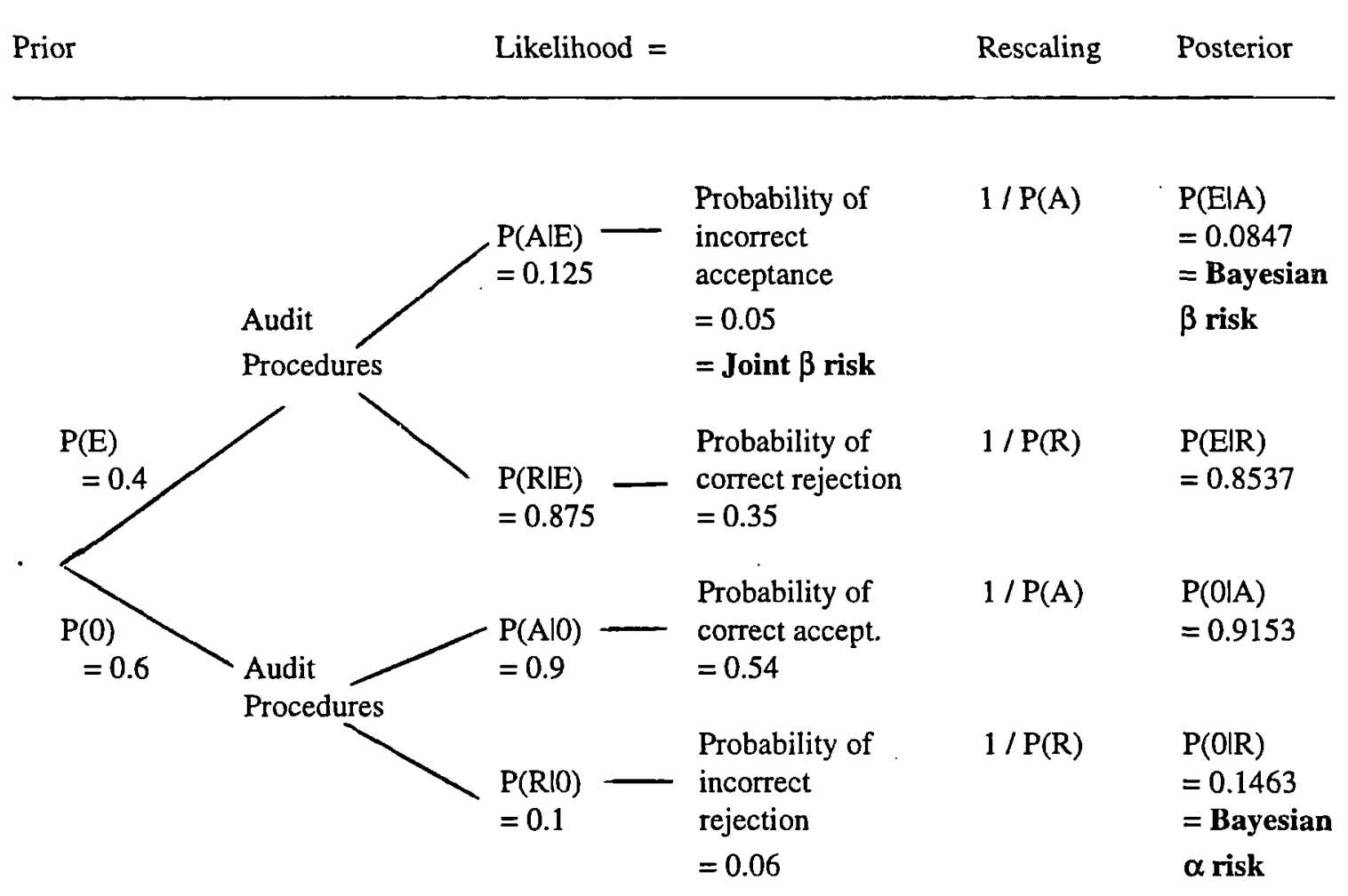

\subsubsection{Literature on Bayesian audit risk models}

Several versions of Bayesian audit risk models exist, based on alternative assumptions about the conditional nature of various steps in the audit process. Table 2.2 provides an overview of major developments in Bayesian audit risk modelling. Two categories of models can be distinguished. A first category consists of models ( see, for example, the CICA model (1980) and Leslie (1984)) which do not recognise the sequential and conditional nature of various audit procedures. Such models assume that internal 
control risk, analytical review risk and test of detail risk are independent of results observed at previous stages in the audit. In a second category of models (see, for example, Kinney (1989) and Sennetti (1990)) the conditional and sequential nature of various audit procedures is explicitly recognised. Examples of both approaches are discussed in the following paragraphs.

An early version of a Bayesian risk model was introduced in 1980 by the Canadian Institute of Chartered Accountants (CICA, 1980). The CICA model was developed at the time (1980) that the concept of inherent risk was only very generally dealt with in the US authoritative risk modelling literature (i.e. it was assumed to be equal to 1). The component risk factors in the CICA model (see table 2.2) are similar to those in the SAS 39/47 model. The CICA-approach is however fundamentally different as inherent risk is viewed as the prior probability of error ( referring to section 2.4.1, $\Pi H=P(E)$ ). Ultimate risk (UR) is the posterior probability of financial statement error, after accumulation of audit evidence and the resulting issuance of an unqualified opinion. An important consequence is that ultimate risk will always be conditional on the initial assessment of inherent risk. On the contrary, it is assumed that control risk (CR), analytical review risk (AR) and test of details risk (TD) are set a priori and are independent of results observed at previous stages in the audit. Hence, the probability that audit procedures fail to detect an error, given that an error exists ( referring to section 2.4.1, this is $\mathrm{P}(\mathrm{A} \mid \mathrm{E})$ ) is set equal to the product of $\mathrm{IC}, \mathrm{AR}$ and TD 9 . From comparison of the CICA-formula in table 2.2 with the general Bayesian risk formula given in section 2.4.1, it also follows that the CICA model makes two further

9 Given the assumptions underlying the CICA model, the general Bayesian risk formula can be rewritten as follows:

$$
\mathrm{P}(\mathrm{E} \mid \mathrm{A}) \text { or } \mathrm{UR}=\frac{\mathrm{P}(\mathrm{AIE}) * \mathrm{P}(\mathrm{E})}{[\mathrm{P}(\mathrm{AIE}) * \mathrm{P}(\mathrm{E})]+[\mathrm{P}(\mathrm{A} \mid 0) * \mathrm{P}(0)]}=\frac{(\mathrm{IC} * \mathrm{AR} * \mathrm{TD}) *(\mathrm{IH})}{[(\mathrm{IC} * \mathrm{AR} * \mathrm{TD}) *(\mathrm{IH})]+[1 *(1-\mathrm{IH})]}
$$


simplifying assumptions: first, that there exists no chance of incorrect rejection ( that is $P(R \mid 0)=0$ and $P(A \mid 0)=1)$; and second, that a detected error (even at the control evaluation stage) will always lead to rejection.

The difference between joint risk (SAS 39/47 model) and posterior risk in the CICA model is illustrated in figure 2.2 by means of a simple ladder tree diagram which is based on Leslie (1984). In the Bayesian case, a change in inherent risk has a large leverage effect on the posterior risk, where in the joint risk case the effect is simply multiplicative. Note that if inherent risk were assumed to be 1.00 , as is in SAS 39 , the ultimate risk in the CICA model would always be $1.00^{10}$. Important is also that joint risk (that is UR as defined in the AICPA model) is equal to the numerator in the CICA formula; or stated alternatively, the denominator of the SAS 39/47 model is set at 1.00. In other words, the SAS $39 / 47$ model only considers one branch of the decision tree, namely the top branch.

10 If inherent risk were equal to 1 , ultimate risk according to the CICA model would be:

$\mathrm{UR}=\frac{(1 * \mathrm{IC} * \mathrm{AR} * \mathrm{TD}}{[1 * \mathrm{IC} * \mathrm{AR} * \mathrm{TD}]+[1-1]}=1$ 
Figure 2.2: Simple Ladder Tree Diagram of CICA risk model

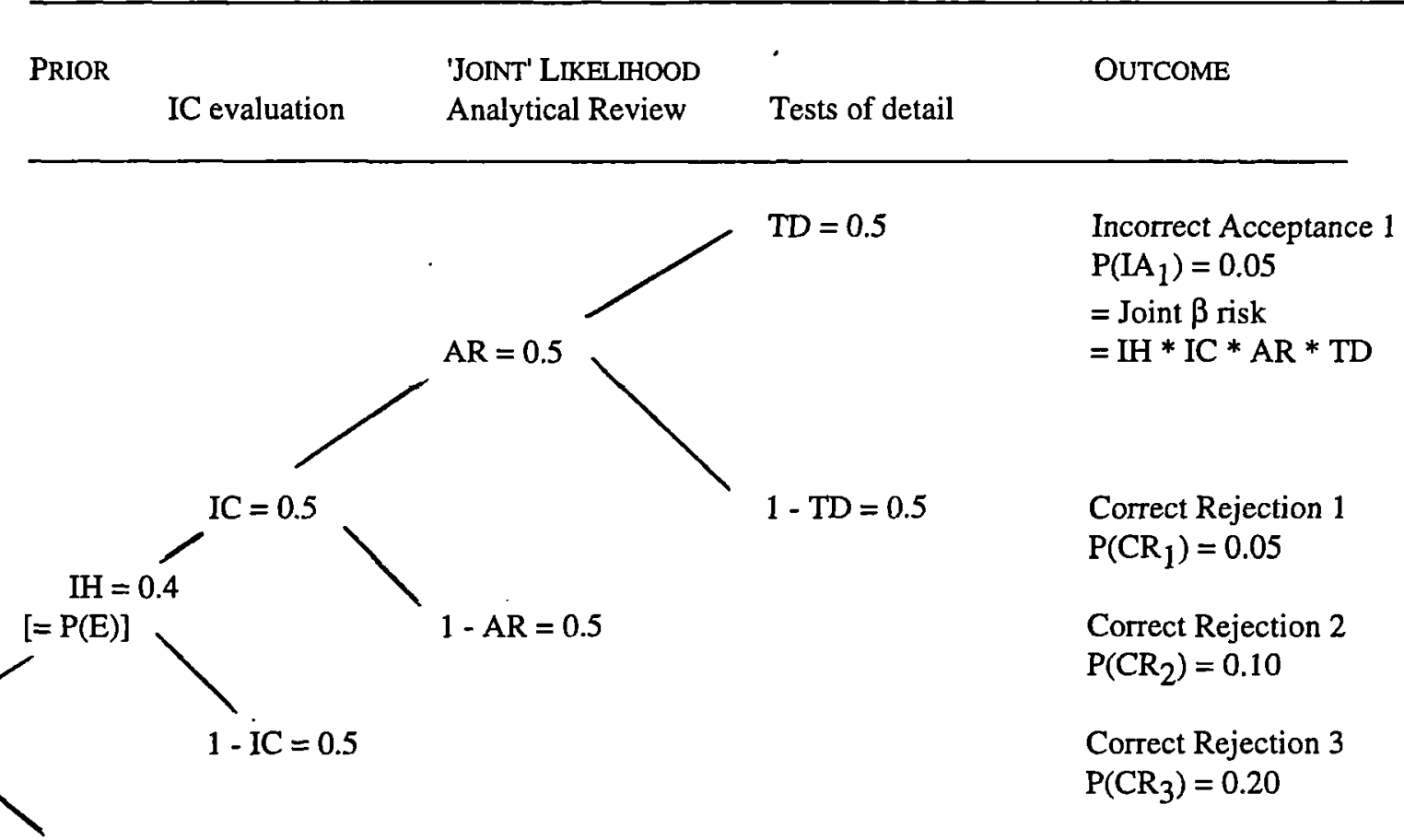
$1-\mathrm{IH}=0.6$ $[=P(0)]$

$$
\mathrm{P}(\mathrm{A} 10)=1
$$

$$
\mathrm{CICA} \beta \text { risk }=\frac{\mathrm{IH} * \mathrm{IC} * \mathrm{AR} * \mathrm{TD}}{[\mathrm{IH} * \mathrm{IC} * \mathrm{AR} * \mathrm{TD}]+[1-\mathrm{IH}]}=0.0769
$$

CICA $\alpha$ risk $=0$

Kinney (1989) provides an interesting extension to Bayesian audit risk modelling by formally recognising a sequential, conditional dependence of the extent of audit work at the stage of analytical review procedures and tests of detail, on the results of the previous stages in the audit process. Two sequential audit process trees are provided in his paper, one with one substantive test (tests of detail only) and another with two substantive tests ( first analytical review procedures and then, conditional on the results, tests of detail). Inherent and control risk are implicitly incorporated in the prior, or 
referring to the general Bayesian model in section 2.4.1, $\mathrm{P}(\mathrm{E})$ equals the product of $\mathrm{IH}$ and CR. In Kinney's approach the 2 CICA-assumptions mentioned above are relaxed (i.e. that there exists no chance of incorrect rejection and that a detected error will always lead to rejection). In a Bayesian context of posterior risk, a sampling theory approach is employed, as the probabilities of various feasible outcomes in the tree are related to frequencies of occurrence in a population (or portfolio) of audit engagements. Kinney also developed a risk formula for planning purposes to manage achieved audit risk level at a pre-determined level.

An interesting discussion and comparison between the CICA/Leslie ladder tree and Kinney's approach can be found in Aldersley (1989), who discussed their crucial differences as follows. The key feature of Leslie's ladder tree diagram models is the fixed (unconditional) nature of audit strategies, that is detection risk at each stage of the ladder is set a priori and is independent of the results observed at previous stages. Kinney's model, on the contrary, formally recognises a sequential, conditional dependence of the extent of audit work at each stage on the results of the previous stages in the process.

An interesting extension to Kinney's work is provided by Senetti (1990). Sennetti attempts to establish conceptual clarity about the modelling concepts of audit risk planning and of audit risk evaluation. He emphasises the inconsistency of the SAS $39 / 47$ model with the definition of audit risk in SAS 47, which is the risk that the auditor may unknowingly fail to appropriately modify his opinion on financial statements that are materially misstated. Sennetti states that the audit risk definition given in SAS 47 necessitates a Bayesian, sequential approach both for planning and evaluation of achieved audit risk, and develops a sequential model which is very similar to the one developed by Kinney (1989) for 2 substantive tests. The major difference with the Kinney model, is that Sennetti explicitly incorporates "reliance risk on the 
assessment of control risk" in his sequential decision tree and as such in his ex post risk formula, whereas Kinney considers the product of inherent and control risk as prior risks. Hence, Sennetti's model is slightly more complete and can be seen as a complete sequential Bayesian decision model. 
Table 2.2: Major stages in Bayesian audit risk model development

YEAR AUTHOR

1980

\section{CICA}

1984

1989

1989

1990
Kinney

Leslie

Aldersley

Sennetti

\section{DEVELOPMENT}

Bayesian approach to audit risk modelling: Inherent risk is viewed as a prior probability of error in the financial statements; ultimate risk, after the performance of audit testing is calculated as follows:

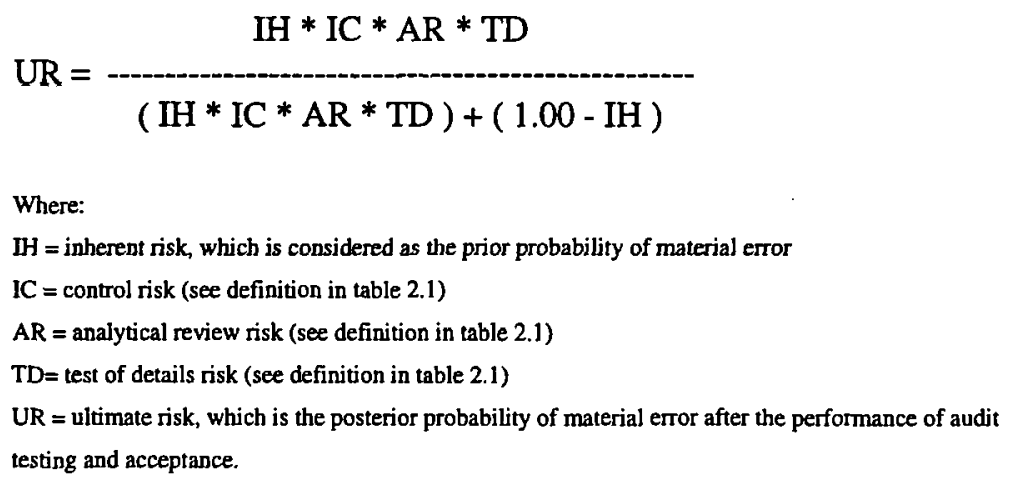

Further elaborates concepts of CICA model (Bayesian) by way of Ladder tree diagram models; the risk of detection at each stage in the ladder is set a priori and is independent of the results observed at previous stages.

Elaborates a tree model approach (Bayesian) by identifying a complete sequential audit outcome space; emphasises the likelihood of understatement of achieved audit risk because of incomplete definition of the audit outcome space in previous models. Constructs a formula to control for achieved audit risk during audit planning.

proposes a tree-approach which is a combination of Leslie's (a priori, unconditional) tree and Kinney's (sequential, conditional) tree

Constructs a full sequential tree and related risk model which is similar to Kinney's, but control evaluation is explicitly incorporated in the sequential decision model. 


\subsection{Concluding comments}

The focus of the risk modelling literature of the past decades has been twofold. First, at an early stage, to develop a practical audit risk model (i.e. the joint risk model) which was mainly intended to serve as a tool for auditing firms in determining the scope of the audit procedures. Second, and based on the many flaws in the proposed practical model, to develop an alternative risk approach (i.e. Bayesian risk model) which is based on a formal model (based on the laws of subjective probability theory) of audit judgement, and which is appropriate both for planning and evaluation purposes.

The joint risk model has not only been subject to criticism from a theoretical perspective (see e.g. Cushing \& Loebbecke (1983), Kinney $(1983,1989)$, Sennetti (1990)), its practical use has also been questioned. A few studies, which have

empirically investigated this issue, conclude that the risk model as defined in SAS39/47 might not be descriptive of risk judgement in practice. One of these studies (Daniel (1988)) reports similar findings about the descriptive validity of the CICA model. This raises the more general question of how auditors actually process information to make risk judgements in practice and which information cues they use.

Another drawback of using audit risk models is that they do not pay explicit attention to business risk considerations. Brumfield, Elliott and Jacobson (1983) discuss the relationships between audit risk and business risk and suggest the following approach to control for business risk within the risk analysis approach. First, business risk increases in a situation of increased audit risk and when there has not been compliance with professional standards. Second, most of the factors that determine the level of business risk are also determinants of the level of inherent risk, which is a component of audit 
risk. Third, if in an audit engagement there exist factors ${ }^{11}$ which are normally associated with increased business risk, the auditor may control for this by correspondingly increasing the audit work beyond the level normally necessary to satisfy generally accepted auditing standards (GAAS). So the auditor controls for business risk by lowering the maximum acceptable level of audit risk. Brumfield et al. (1983) emphasise that an assessment of low business risk, however, should under no circumstances lead to a decrease of the audit effort below that required by GAAS, or in other words should not lead to an increase in the maximum acceptable level of audit risk. Models that formally relate audit risk and business risk are discussed in the following section.

\section{Normative decision models of auditing: the 'audit modelling approach'}

The risk analysis approach does not only ignore business risk (or the expected ex post losses from performing an audit job), but also the cost of auditing procedures. As a result it does not focus on the most efficient or cost effective way to attain 'a' level of ex post audit risk and hence does not provide guidance about what the optimal level of achieved audit risk should be. Further, it also ignores the relationship between audit risk and materiality, and does not address the practical problem of how to assess the prior likelihood of material error.

Cushing and Loebbecke (1983) made the case for what they called 'the audit modelling approach'. This approach incorporates a more comprehensive view of the auditing process and treats audit risk as merely one element within this more comprehensive modelling framework. Characteristic of the research effort undertaken in this area is that

11 For a list of such business risk factors see Brumfield, Elliott \& Jacobson (1983, p. 65) 
the auditor's choice problem is recasted in terms of the optimisation of an auditor objective function which is, as in the theory of consumer choice, based on maximisation of subjective expected utility. Audit risk is then rather viewed an output of the model, there where it is considered an input in the risk analysis approach. In table 2.3 the features of a 'prototype' audit modelling approach as suggested by Cushing and Loebbecke are compared to the risk analysis approach. An audit model which incorporates all of the features of the 'prototype' audit modelling approach does not yet exist. However, models of a more comprehensive nature have been proposed which incorporate one or some of the features as described in table 2.3. The focus of the next two subsections (3.1 and 3.2) is on research studies which adopted a decision theory framework to formally model one or several aspects of the auditor's choice problem in a decision theoretic framework (feature 5) ${ }^{12}$ and/or which included a broader and more complete set of parameters (feature 1). Important here is that the auditor's objective is stated as to minimise total expected costs of an audit engagement, which are the sum of direct audit costs and expected losses from auditing (or business risk).

Steele $(1984,1992)$ provides an informal but comprehensive model of audit opinionforming. It exhibits several characteristics of the audit modelling approach, and is related to audit judgement approaches advocated by various audit researchers for over twenty years. Characteristic for Steele's model is that the financial statement audit is disaggregated into the examination of a number of fundamental elemental propositions from which they are assembled. Subjective probability theory is advocated as a sound approach for quantifying the auditor's judgement about the degree of confidence in each elemental proposition. The auditor's prior judgement of the variety of values that a

\footnotetext{
12 Among the authors which have addressed features 2, 3 and 4 are Heimann and Chesley (1977) and Cushing, Searfoss and Randall (1979), who addressed explicitly the aggregation issue (feature 2); Scott (1975) and $\mathrm{Ng}$ (1978) who address the relationship between the auditor's role in society and the objectives of an auditing model; and Felix and Grimlund (1977) who deal with the auditor's aggregation of subjective and objective information.
} 
particular proposition can take is treated as a prior subjective probability density function. Prior subjective density functions are revised and become posterior or conditional subjective density functions as the auditor learns more about the audited entity by performing analytical review procedures, compliance tests and substantive tests. By collecting evidence, the auditor is changing his degrees of belief for the variety of values that each proposition can take. Acceptance or rejection of a propostion is the result of comparing the degrees of belief with the reported book value taking explicitly the materiality interval into consideration. Opinion-forming at the aggregated level of financial statements is the financial step in the decision process, and is the result of evaluating accept/reject decisions across propositions.

Steele's informal model clearly exhibits characteristics of the audit modelling approach. First, more parameters are included into the decision model, such as materiality intervals and prior beliefs. Second, the issue of aggregating evidence across elemental propositions is considered, albeit informally. Third, several decision points in the audit process are distinguished. In his 1992 monograph Steele focuses on the critical aspects of the applicability of the model to a realistic audit setting and provides a formal interface between theory and practice. The key ideas for implementing the above model of audit opinion-forming can be very roughly summarised as: (1) the use of Bayes theorem for combining prior judgements and the likelihood of audit evidence, which derives from the postulate of coherence; (2) the use of conjugate distributions as a practical standard way to quantify judgements and the representation of non-sampling and prior judgement as being equivalent to a hypothetical audit sample; note that Steele's detailed focus in this issue is an important contribution to the audit modelling approach; and (3) collecting evidence in such way that the cost of evidence are balanced against the expected cost of risk. 


\subsection{Decision theory approaches to audit production}

Decision theory approaches to auditing can be classified in two types of models. Singleperson decision models developed first (see, for example, Scott (1973), Kinney (1975a, 1975b), Kinney and Warren (1979), Boockholdt and Finley (1980), Finley (1983), Menzefricke (1983), Kissinger (1983), Finley and Boockholdt (1987)). Multi-person decision models developed afterwards (see, for example, Demski and Swieringa (1974), Fellingham and Newman (1985), Newman and Noel (1989), Shibano (1990), Patterson (1993)). Single-person decision theory models focus on decisions to be made by the auditor and don't take possible actions of the auditee into account; hence, they essentially represent games against nature. Multi-person or game theoretic audit decision settings consider the audit as a game between two players: the auditor and the auditee. 
Table 2.3: Comparison of risk analysis approach and audit modelling approach

\section{RISK ANALYSIS APPROACH}

1. Focuses explicitly on audit risk and tolerable error for audit planning and risk evaluation purposes; does not consider economic factors related to audit risk.

2. Does not address the issue of aggregating audit risk and evidence concerning individual systems and accounts in assessing overall audit risk and formulating an overall opinion on the financial statements (see also 3.2.2).

3. Is not based on any explicit assumptions about the role of auditing in society and the objectives of the auditor.

4. Does not distinguish between objectively verifiable and subjectively assessed variables.

5. Considers only one audit decision point, i.e. the point of planning substantive tests.

\section{'PROTOTYPE' AUDIT MODELLING APPROACH}

1. Identifies and explicitly incorporates all relevant audit parameters in the model, i.e. audit costs, economic impacts of financial statement error, materiality, the auditor's prior beliefs about the clients reported amounts, the effectiveness of various auditing procedures, sampling risks.

2. Addresses the issue of aggregating audit evidence concerning individual systems and accounts in formulating an overall opinion on the financial statements.

3. Proceeds from an explicit assumption concerning the role of auditing in society to the development of an "auditor's objective function" which provides guidance to the auditor throughout the auditing process.

4. Distinguishes subjective assessments from objectively verifiable parameters, and assigns weights to each.

5. Explicitly identifies all important decision points in the audit, including: the point of acceptance or rejection of the client, the internal control evaluation stage, the substantive test planning stage, the substantive test evaluation stage, and the opinion formulation stage. Also coordinates the decision processes at each of these points.

Based on Cushing and Loebbecke (1983)

\subsubsection{Single-person decision models}

A model that is widely considered to be representative of its kind is the decision theory model developed by Kinney (1975a). The objective of the auditor is stated as to select the optimal sample size in order to minimise the total costs of sampling and of making 
type I and type II errors. Kinney's (1975a) paper only involves one aspect of the audit decision process, as it modelled the auditor's choice problem at the point in time after the study and evaluation of internal control but before a decision concerning any additional tests of detail. His approach differs from the traditional confidence-interval and hypothesis-testing approaches by explicitly considering the above costs and the probability of occurence of possible states ( which is the same as incorporating prior beliefs).

The essentials of Kinney's decision model can be summarised as follows. A reported book value can be in two possible states: it can either be true or not. For each state a (prior) probability of occurence is assessed. The auditor then has the following action choices: 1) he can immediately accept the reported book value, 2) he can immediately reject the reported book value, or 3) he can postpone the decision and perform tests of detail, and then decide to accept or reject the reported book value. The auditor's accept/reject decision can either be correct or incorrect. The cost functions in the model relate to: 1) sampling costs, when the auditor decides to perform tests, and 2) costs of incorrect decisions, namely, when a book value that is not true is accepted (Type $\Pi$ error) and when a book value that is true is rejected (type I error). The auditor's objective is to minimise the total expected cost.

Kinney assessed the sensitivity of the model results to misspecification of the parameters in the model. His conclusion is that the results appear to be most sensitive to misspecification of parameters which are best known to auditors, such as the variable cost of sampling, and relatively insensitive to errors in the lesser known and more difficult to estimate parameters, such as the expected costs of potential lawsuits and loss of professional reputation. Nevertheless, the results remain sensitive to misspecification of prior probabilities attached to each state, which embodies the assessment of the prior beliefs of the auditor. This parameter is difficult to estimate. 
In a subsequent paper, Kinney (1975b) attempts to integrate all relevant audit decision points into an overall modelling framework. The model is derived from a simplified network of the routes to an opinion on an account as depicted in figure 2.3.

Figure 2.3: Simplified model of the routes to an opinion on an account

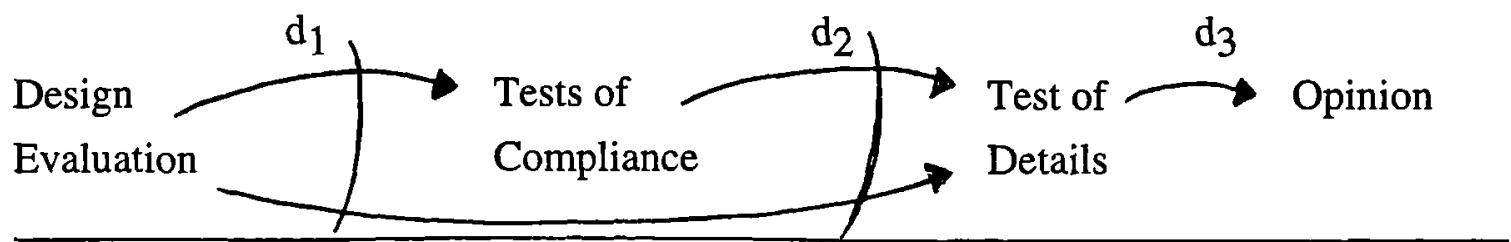

Source: Kinney (1975b), p. 19.

At the first decision point $\left(\mathrm{d}_{1}\right)$ the auditor must decide whether to continue with the internal control study by conducting compliance tests (CT route) or to proceed directly to tests of details (TD route). If it has been decided to undertake compliance tests, the result of this procedure will enable him to make the second decision $\left(\mathrm{d}_{2}\right)$ which involves the decision with respect to the extent and kind of substantive tests to undertake. The third decision $\left(\mathrm{d}_{3}\right)$ involves the accept/reject decision for the reported account balance based on the results of the compliance tests and/or substantive tests procedures that have been performed. The optimal solution set of decisions is obtained by beginning with the posttest of details accept/reject decision for the reported account balance $\left(d_{3}\right)$ and then working back through decision $d_{2}$ which "embeds" $d_{3}$ and, finally $d_{1}$ which embeds $d_{2}$ and $d_{3}$. As in his earlier model, the objective is to select the action which will minimise the total cost of sampling (compliance and substantive testing) and type I and II errors. 
Kinney and Warren (1979) extended Kinney's (1975a) decision theory approach to include nonsampling error, which had not been incorporated into the earlier model. Other models that adopt a similar approach as Kinney (1975a) are provided by Finley (1973) and Kissinger (1983). Another (related) category of models adopted a constrained optimisation approach (see, for example, Boockhold and Finley (1980), Menzefricke (1983) and Finley and Boockhold (1987)). In this type of models type II error risk is treated as a constraint, and the optimal sample size and type I error risk are selected in such a way that the total costs of sampling and making type I errors are minimised.

\subsubsection{Auditing in a Multi-Person Decision Environment: Strategic Nature of}

\section{Auditing}

Game-theoretic approaches to audit decision making are a 'relative' novelty, as compared to single-person models. Optimal audit decisions and the evaluation of audit risk might be considerably different when auditee actions are integrated in the audit decision model. Behavioral influences of audits, such as anticipatory effects of an audit, have long been recognised in the audit literature (see, for example, Carmichael (1970)). Dresher and Moglewer (1980), for example, make the point that classical hypothesis testing might no longer be applicable in a competitive environment ( where the sample or the population or both may have been tampered with to accomplish some objective) because such testing assumes only stochastic situations, which means that all uncertainties are due to chance and there is no deliberate tampering. Note that any model of the audit problem which uses an agency framework of principal-agentinteractions (see e.g. Antle (1982), Baiman, Evans and Noel (1987) and Yoon (1990)) relies on a multi-person decision setting. 
An early audit model which applies a multi-person decision setting is provided by Demski and Swieringa (1974). Their paper is however not of a game-theoretic nature, as the audit process is modelled as a co-operative effort between the auditor and the auditee to minimise joint costs of the accounting system employed. A Bayesian view of the audit problem is presented, but with utility and probability functions quite different from those in a single-person decision framework; in particular group-level surrogate utility and probability functions are derived from the Pareto optimal behaviour of auditor and auditee. The use of surrogate functions allows to model the behaviour of the auditee and the auditor as though they were a single rational individual. Fundamental here is that the auditor is not an independent agent and with both the auditor and the auditee sharing the consequences, the optimal audit program is clearly affected by the beliefs and opinions of both parties.

A step forward in understanding the implications of strategic auditing aspects on the current views on some important auditing concepts (e. g. audit risk) is provided by game-theoretic audit modelling. Both Fellingham and Newman (1985) and Newman and Noel (1989) present simplified stylised audit games with fixed payoff structures, not to propose a specific model as a guide to auditors, but rather to illustrate the inherent strategic nature of the audit problem and the inadequacy of single-person statistical audit decision models. Their approach is fundamentally different from that in Demski and Swieringa (1974), as both parties are here considered as opposing players which seek to maximise their own utility separately.

The Fellingham and Newman (1985) model allows a prospective audit to influence the behaviour of the auditee by means of greater effort and care to reduce the likelihood of material error occurring in the financial statements. As in single-person decision-theory approaches, the problem is formulated as one of minimising expected costs. For given 
cost structures the authors illustrate Nash equilibrium solutions ${ }^{13}$. They suggest that these solutions highlight that both the auditor and the auditee may frequently use a randomised strategy, which raises a serious question regarding the legitimacy of singleperson decision theory modelling in auditing, because random strategies are never strictly preferred to pure strategies in a game against nature (the single-person decision theory approach). The solutions further illustrate that the auditor's strategy depends on the interaction between the accounting control system and the auditee's decisions. Fellingham and Newman also discuss the changed meaning of the audit risk concept in a game-theoretic audit environment, and demonstrate that the use of single-person decision-theory may cause errors in estimating audit risk because it fails to consider audit influences on the auditee. It is shown how the equilibrium auditee strategies may be used to determine the analogue of the prior probability distribution used in singleperson decision theoretic analyses of audit risk.

Newman and Noel (1989) aim to examine the effect of changes in the exogenous payoff parameters on error rates and detection rates in the population of auditors and auditees. Therefore, the proposed audit game is kept deliberately simple, with a restricted number of strategies for both the auditor and the auditee. Both the auditee and the auditor have only two strategies, i.e. for the auditee to have material errors in the account or not, and for the auditor to accept the reported balance or to reject it. A two-person, two-action game is built, the payoffs of which are exogenously specified. As in the above model, the objective of each player is to maximize expected payoff and Nash equilibrium solutions are derived together with comparative statics on the equilibrium strategies with respect to auditor and auditee payoffs. Although the results of the analysis are specific to the parametric setting of the model, some interesting conclusions are drawn

\footnotetext{
${ }^{13}$ A Nash equilibrium solution is one where no player, assuming the other is committed to his strategy, can increase his payoff by unilaterally changing strategies.
} 
which emphasise the need to include strategic interaction between auditor and auditee in audit modelling and the incomplete nature of single-person decision theory models. In particular, there where changes in auditors' payoffs seem to have unambiguous implications for the probability of undetected errors and the probability of incorrect rejection, changes in auditees' payoffs, in contrast, may either increase or decrease undetected errors or incorrect rejections due to a dual impact on error rates and detection rates. The absence of the auditee's payoffs in a single-person decision theory formulation of the problem, and consequently its impact on error rates and detection rates, results in an alternative optimal solution.

A contribution to the understanding of the concept of audit risk, defined as the probability of failing to detect a material misstatement, when the auditor and auditee interact strategically is provided by Shibano (1990). Based on the observation that prior game-theoretic analyses (ad described above) do not formally include the possibility of intentional misstatements, Shibano presents a strategic testing theory, which uses gametheoretic analyses, that includes the possibility of either unintentional (called errors) and intentional misstatements (called irregularities). This theory then forms a formal basis for an expanded version of the Audit Risk Model (ARM) which applies to both errors and irregularities. Shibano explicitly distinguishes between nonstrategic audit risk (NSAR) which arises from errors (unintentional misstatements) and strategic audit risk (SAR) which arises from irregularities (intentional misstatements). A suggested expanded version of the Audit Risk Model is:

$N S A R=\mathbb{R}^{e} \times C R^{e} \times D R^{e}$, which refers to audit risk for error-prone accounts (superscript $\mathrm{e}_{\text {indicates that the risk }}$ component is related to errors); and 
$S A R=I^{i} \times C R^{i} \times D R^{i}$

which refers to audit risk for irregularity-prone accounts ( superscript ${ }^{i}$ indicates that the risk component is related to irregularities).

Shibano distinguishes between three viable audit settings in which an auditor performs audit tests: 1) single-person decision theoretic testing (which is comparable to the Kinney (1975a) approach), 2) strategic testing for a hidden action (which is refers to moral hazard and is comparable to the Fellingham and Newman (1985) and Newman and Noel (1989) approaches) and 3) strategic testing of a report of hidden information (which refers to adverse selection and is a major contribution of Shibano's approach). The single-person decision-theoretic setting is considered appropriate for substantive testing of error-prone accounts; hence $\operatorname{IR}^{\mathrm{e}}$ and $\mathrm{DR}^{\mathrm{e}}$ are derived accordingly. When irregularity-prone accounts are the object of substantive testing, strategic testing of a report of hidden information is considered the appropriate setting, and will be used to derive $\operatorname{IR}^{\mathrm{i}}$ and $\mathrm{DR}^{\mathrm{i}}$. The hidden action framework is used to derive both $\mathrm{CR}^{\mathrm{e}}$ and $\mathrm{CR}^{\mathrm{i}}$. The author provides formal derivations of each of the risk components according to the decision setting considered appropriate. The conclusions from the analysis are however not revolutionary. First, in auditing for errors, increases in inherent risk do not necessarily increase NSAR as might be expected. This stems from the ability of the auditor to counteract the increase in inherent risk by decreasing detection risk. Second, in auditing for irregularities, decreased incentives of the auditee to misreport do not necessarily decrease SAR, because the auditor can respond by rejecting the auditee less frequently thereby increasing detection risk.

In the game theoretic models discussed so far sample size was held constant. Patterson (1993) presents an interactive auditing model that considers sample size choice.

Compared to the fixed sample size models there is increased interaction between the 
players because a change in either player's payoffs results in a change in both players equilibrium strategies. An interesting result is that the auditor may choose an optimal sample plan that produces a greater audit risk from defalcation despite an increase in the cost of undetected defalcation or a decrease in the cost of obtaining sampling evidence.

\subsection{A critical assessment of the decision theory approach}

The single-person audit modelling approach is often viewed as a superior method of conceptualising the audit problem in the audit literature but, as Gwilliam (1987a) points, its present formulations suffer from rather severe implementation problems. The need to specify model inputs, especially prior probabilities as to the likelihood of material error and realistic loss functions, are a serious barrier. With regard to audit cost input data, however, it is more than likely that audit firms should have sufficient data available to provide reasonable accurate estimates. The need to devise comprehensible and convenient means of solution to the optimisation problem is a further barrier. Although the multi-person or strategic decision models suffer from similar implementation problems, their purpose is rather to better understand the strategic nature of the audit process and its consequences on the present view on auditing concepts, such as for example audit risk. For this purpose, they are usually kept extremely simple and abstract. The danger however, is that, as Antle (1989) points, their specification may be too vague on particulars and thereby leave important elements unspecified.

Very few research effort has been undertaken to specify realistic loss functions and hence very little is known about their magnitude and shape. Scott $(1973,1975)$ provides some basic theoretical work with respect to loss functions and addresses the issue of 
what the loss function should look like. He suggests that the auditor's loss function derives from the various financial statement users, which suffer an opportunity loss of expected utility if they rely on the audited financial statements as inputs to decisions when those statements contain auditor's errors. In particular, Scott derives a formal loss function is from a consumer-investment model. Empirical work to determine the appropriate form of the loss function is as good as non-existing.

In most decision models, the problem is avoided by considering a state space of only two or three points, by taking the loss function as given (either implicitly or explicitly) or by suggesting that loss functions may be nearly flat over certain ranges. In some cases a sensitivity analysis of the model output to misspecification of the magnitude and the shape of the loss function is performed (see e.g. Scott (1973), Kinney (1975a) and Finley and Boockholdt (1987)). There seems to be consensus that type II error losses are of a substantially larger magnitude than type I error losses (given that they occurred). With respect to the shape of the loss function the evidence of studies of legal cases involving the auditor's liability (see e.g. St Pierre and Anderson (1984)) points in the direction of asymmetrical loss functions. In particular, a loss due to understatement is expected to be smaller than a loss due to overstatement. Most models, however, do not take this into account.

Another important input parameter in single-person Bayesian decision models is the prior probability distribution which involves the assessment of the auditor's prior beliefs (Note that in a game-theoretic setting the prior distribution is determined by the action strategy of the auditee and is determined in equilibrium by the model). In all studies the prior distribution function is assumed to be given; in some cases the sensitivity of the model output to misspecification is provided. The accuracy of this input parameter depends on the capability of auditor to provide realistic estimates of prior distributions in a consistent and meaningful way. Gwilliam (1987a) concludes in his review study 
that there is little evidence that auditing firms actually use Bayesian methodology to audit situations and that the reason for this apparently is the difficulty to estimate prior distributions together with a lack of confidence in the prior probability distributions. Steele (1992) recognises this problem and proposes techniques to use conjugate distributions as a practical way to quantify judgements and the representation of prior judgement as being equivalent to a hypothetical audit sample.

An implicit assumption of all decision (single-or-multi-person) models discussed in this section which apply a cost minimisation approach is that audit fees are exogenously determined and hence independent of the decision. This assumption seems rather unrealistic. In the case of single-person decision models where the objective is to find the optimal sample size (except for Patterson (1993)), it is likely that the level of audit fee will be affected by the extent of audit work carried out ${ }^{14}$. Also in the multi-person or strategic models, it might be interesting to incorporate the audit fee in the payoff structure of the model, as both the auditor's and auditee's strategic actions may be influenced by expectations about present and future fees ${ }^{15}$. Another deficiency, which is formulated by Watts (1990) and which relates especially to the game-theoretic studies, is that they do not address the auditor's decisions over locations, timing of tests, and sample size, even though such decisions may represent action choices which could influence auditee behaviour.

A final aspect of the decision theory approach relates to the willingness of audit partners to analyse the audit process in terms of maximising utility (Gwilliam (1987a)).

\footnotetext{
${ }^{14}$ Note that this has been an assumption of empirical research on the determinants of audit fees. A review of this research is provided in chapter 3.

15 The only model that explicitly incorporates the audit fee is the co-operative model by Demski and Swieringa (1974), but is assumed to be independent of the action, system and audit decisions actually made.
} 
Ashton (1982) empirically tested whether auditors violate utility theory and hence whether normative decision theory is valid in auditing contexts ${ }^{16}$. The results showed less utility violations than in non-auditing situations and far more consistent utility judgements than those displayed by subjects in previous tests. Consequently, it seems realistic to take the view that audit firms are influenced by economic factors, and don't only operate on the basis of professional standards.

\section{Conclusions}

The objective of this chapter was to provide an overview of the major developments in normative research in risk-based audit production modelling. Two different approaches exist: the risk analysis approach and the audit modelling (or decision modelling) approach. Important distinctions between the two are that audit risk models are of a non-economic nature and only address audit risk, whereas the audit decision models are of an economic nature and formally relate audit risk and business risk. Audit risk models can be seen as a tool for practising auditors to monitor ex post audit risk at a pre-specified level. They may be relatively easy to implement, and when adopted correctly, may result in effective audit procedures. However, audit risk models do not necessarily result in a cost minimising audit production process. To achieve such a process, expected losses from incorrectly reporting need to be incorporated in the auditor's decision framework. Decision theory models can be seen as a major step in the development of efficient audit programmes. Although they are difficult to implement, they are conceptually more complete taking more parameters into consideration. Following the decision modelling approach, audit production can be seen as a process of risk management or control. Audit risk is the output of the audit production process

\footnotetext{
16 This was tested by recasting the Allais problem in two auditing settings, in one of which the probabilities of costs in terms of loss of fee income and/or litigation costs were made explicit in relation to a decision whether or not to qualify.
} 
and the objective is not to minimise audit risk, but to produce a level of audit risk, or alternative a level of confidence in the client's financial statements (or a level of audit quality ${ }^{17}$ ), which corresponds with a minimum level of total audit costs (i.e. direct audit costs plus expected losses).

Normative decision models of audit production have a relatively long history and originated when the auditor's litigation risk was far less pronounced than today. Prior decision models, although they explicitly included expected losses into cost, have ignored the process by which these losses eventuate, that is, have ignored the regulatory framework in which the auditor operates. One reason is that expected losses were only broadly defined and did not only relate to legal losses. Given today's litigious audit environment, litigation risk has become a paramount element of business risk. It is the author's opinion that a cost minimising auditor necessarily has to include a regulatory parameter when assessing the total expected cost of an audit engagement. A model of audit production that includes the process by which litigation losses eventuate is developed in chapter 6 of part 2. Although introduced there as a 'positive' model of audit quality production, and adopted in the context of analysing the effect of alternative regulatory scenarios on the level of produced audit quality, a similar modelling framework could also be developed for normative audit decision modelling. A decision theory model that explicitly incorporates a regulatory parameter is a worthwile topic for future normative research in auditing process modelling.

\footnotetext{
${ }^{17}$ Audit quality is sometimes defined as the levels of assurance that financial statements are error free. Alternative approaches to audit quality do however exist. See, for example, Moizer (1993) and Sutton (1993).
} 


\section{Chapter 3}

\section{Auditing as an Economic Activity:}

\section{An overview of major research streams}

\section{Introduction}

Apart from the professional (see chapter 2) and regulatory (see chapter 4) aspects, auditing is clearly also an economic activity. The objective of this chapter is to provide an overview and discussion of major developments in economic research in auditing that is of a positive nature. The angle focused on in this review is that the external audit service is a commodity that is demanded, supplied and produced in a market. Auditing has without doubt some public good characteristics, however, the audit service is not provided by governement but is sold in the market place by audit partnerships and is purchased by the auditee. The relationships between the parties involved is however more complex than in a traditional market setting. The consumers (e.g. third parties) of the service are not necessarily the ones who (directly) pay for it, and furthermore is demand and supply affected by laws and regulations. Although auditing firms in the past have been mainly interested in research which directly adds to improvements in the audit process, audit judgements and audit techniques, an important body of academic research has dealt with the economic role of auditing and audit market analysis.

An agreed economic framework within which the present activities of auditing firms and their role in the market economy can be fully explained does not exist. Application of existing economic theory has resulted in a number of alternative (and overlapping) hypotheses which explain the demand for auditing. These hypotheses are briefly reviewed in section 2 of this chapter. Note that research in this area is mainly theoretical in nature. 
An alternative and very vibrant research stream in the economics of auditing consists of audit supply, demand and market type studies which are based on the application of neoclassical economics to the audit setting. Translation of the basic conceptual constructs underlying textbook neoclassical economics into the complex audit setting is however not straightforward. As the audit service is not a very tangible product, a number of issues are yet unsolved and offer tremendous potential for future research. These include questions such as: (1) how is the audit product defined, what is a unit of auditing and what is audit quality; (2) what is audit price; (3) what are the components of the audit fee, and (4) what does the audit production function look like. Past audit market research is mainly empirical in nature, and mainly focused on points 2 and 3. A number of audit pricing and production hypotheses have been directly tested in crosssectional studies. Conclusions are drawn about price competitiveness in audit markets, product differentiation in the audit industry, economies of scale for large audit firms, knowledge spillovers between the audit product and complementary products offered by accounting firms, and the presence of learning curve effects in audit production. The results of these studies are reviewed in detail in section 3 of this chapter, together with a critical discussion of the evidence.

Another category of empirical studies has focused on the structure of audit markets and analyses auditor (seller) concentration in different countries and markets. A common interpretation of seller concentration in a market is that it determines the degree of competitive pricing (see Carlton and Perloff (1990)). This interpretation has been a major motivation for the measurement of seller concentration in audit markets. A general finding ${ }^{18}$ is that there is a significant level of auditor concentration that is fairly

${ }^{18}$ Amongst others, the following studies have addressed auditor concentration issues: Zeff and Fossum (1967), Dopuch and Simunic (1980), Eichenseher and Danos (1981), Danos and Eichenseher (1986), Moizer and Turley (1989), Tomczyck and Read (1989), Zind and Zéghal (1989), Buyinck and Maijoor (1993). 
stable over time (see, for example, Buyinck and Maijoor, 1993)). Concentration studies, thus, only indirectly test the hypothesis of non-competitive pricing, since no data are gathered and analysed for individual client situations. As a result, they do not focus on characteristics of the audit production function. A detailed review of these studies is beyond the scope of this thesis.

\section{Economic rationales for audit demand and the changed role of}

\section{auditing in a requlated environment}

Today the majority of external audit services are purchased and supplied in a regulated market. This has not always been the case however ${ }^{19}$. As Watts \& Zimmerman (1986) point, auditing and accounting have been companions in the history of the corporate firm for over 600 years. In 1494, for example, in a treatise on double-entry bookkeepping Pacioli ${ }^{20}$ advises the appraisal of accounts by an independent person. The persistence of audits through time in unregulated environments ${ }^{21}$ and unregulated segments of the economy today which are voluntarily audited, provide evidence of the valuation of auditing services in excess of their perceived costs by consumers. Several researchers have attempted to establish an economic rationale for auditing within a

\footnotetext{
${ }^{19}$ Note however, that the auditor's professional liability, which is a form of ex post regulation by common law (see further in chapter 4) has a longer history than ex ante regulations.

${ }^{20}$ Pacioli devoted a chapter on double-entry bookkeeping, entitled: 'De Particularis de Computis et Scripturis' (about accounts and onther writings) in his 'Summa de Arithmetica, Geometria et Proportionalita'. This book, published in 1494 contains the first printed important description of doubleentry bookkeeping rules and is considered as a reflection of accounting practice in those days. See also, for example, Lauwers and Willekens (1994).

${ }^{21}$ Chow (1982), for example, examined the incentives of firms to voluntarily hire external auditors within an agency theory framework. His conclusion, which is drawn from a sample of both NYSE and OTC firms in the year 1926 when there were no externally imposed audit requirements, is that agency cost considerations (i.e. leverage and accounting -based debt covenants) play an important role in the decision to hire an external auditor.
} 
coherent theoretical framework by clarifying the incentives of auditees to purchase an external audit service 22 . This has resulted in a number of competing and overlapping demand hypotheses. According to the agency theory/stewardship hypothesi ${ }^{23}$, the audit serves to monitor the performance of management on behalf of the shareholders or as a demonstration by management to existing or potential shareholders of their effort and performance. Related to agency theory is the contracting theory explanation of auditing. In this context auditing is defined as "a specialist adjudication function for completing contracts whose payoffs have been defined in terms of accounting numbers" (Ball, 1989). According to the information hypothesis of audit demand, auditing is a service to investors and other users who demand audited financial information to make rational investment decisions. Related to this approach is the application of signalling theory ${ }^{24}$ to audit related information. In this context audited information, auditor choice, or auditor change, for example, are used as signals to credibly convey 'good news' to potential shareholders and creditors. The insurance/deep pocket hypothesis ${ }^{25}$ offers a third and recently popular explanation for audit demand and derives from management's liability exposure for losses attributable to defective financial statements. The auditor's professional liability exposure creates incentives for managers and professional participants in financial activities to insure themselves via auditors' participation.

\footnotetext{
22 For an overview and comparison of competing audit demand hypotheses see e.g. Wallace (1980), Gwilliam (1987a), and Steele (1992).

23 Examples of agency models of auditing are Antle (1982, 1984), Datar (1985), Baiman, Evans and Noel (1987), Nagarajan (1988), Yoon (1990).

${ }^{24}$ Examples of signalling models of auditing are Bar-Yosef and Livnat (1984), Titman and Trueman (1986), Melumad and Thoman (1990), Datar, Feltham and Hughes (1991). A test of the model by Datar, Feltham and Hughes is provided by Clarkson and Simunic (1992).

25 Very few models exist that view the role of the auditor as that of an insurer. Antle's (1982) model, although it is an agency model, can be seen as an insurance model, as the audit fee is purely regarded as a compensation for risk sharing with the principal. Melumad and Thoman (1990) examined the effects of litigation against auditors on the equilibrium solutions of their signalling model.
} 
An unregulated audit environment can be thought of as an environment where corporations are free to contract or not for external auditing services with those who supply them (i.e. external auditors), and where both parties are free to determine the conditions of the contract, such as for example the content and the attributes of the audit service. Agency and contracting theory offer thus genuine arguments for audit demand in unregulated environments. In fulfilling his contract monitoring role, the auditor determines if contracts have been breached. The audit service will however only be valuable if third parties to the firm believe that the auditor will be capable to discover a given breach (competence) and that he will report the discovered breach (independence). Consequently the auditor, although he was originally free to determine how to perform the audit service, had to convince the market that he is capable and independent from his clients. As a result, institutions and contractual arrangements evolved that provided the auditor with incentives to be independent. These include the auditor's reputation, professional societies, the audit firms' organizational form and large-scale audit firms (Watts and Zimmerman (1986)).

According to Watts and Zimmerman (1986), audit regulation has typically expanded the scope of the audit beyond contract monitoring and changed its emphasis. While regulation has broadened the nature of the audit and increased audit demand to meet legal requirements, it decreased the contract demand for audit services. The reason is the imposition of accounting standards has reduced the effectiveness of accountingbased contracts in reducing agency costs, and hence reduce firms' demand for auditing as a contract monitoring device. Regulation has however provided the opportunity to the auditor to expand his service range with complementary services, such as lobbying and information services, which in turn may have given him the ability to transfer wealth from corporations to himself. 
Kaplan and Ruland (1991) have criticised existing agency theory as a positive theory for explaining audit demand on the grounds that it does not provide a theory of accounting regulatory development. They state that if the world behaved only in terms of agency theory, regulation by mandating audits would not exist. The fact that mandated audits and related disclosure requirements do exist may represent evidence that a market failure has occurred. Their conclusion is that a confluence of theories is most likely to provide the richest description of "what is".

There were the agency theory hypothesis of audit demand emphasises market forces to result in an appropriate and economically most efficient level of external financial reporting and external auditing, information theory arguments tend to support the need for compulsory requirements for disclosure and external audit of financial statements. Although both theories of audit demand are overlapping, information theory pays greater attention to the needs of investors and prospective investors. As information is a special kind of economic good, collective provision might be cost-effective, especially because prospective investors are unlikely to have a contractual relationship with an individual firm's management. In case the market fails to provide the right amount of auditing (for example due to public good characteristics of audited information) there is a case for enforcing the external audit by statute. However, the validity of the arguments for compulsory external audit is further dependent on both the extent to which investors rely upon reported financial information in making their decisions, and on the extent an audit report affects the importance they attach to such information ${ }^{26}$.

\footnotetext{
26 It is important to note that the early disclosure regulation rationales are closely related to information theory arguments. Researchers in the positive accounting tradition ( such as e.g. Beaver $(1973,1976)$, Beaver and Demski (1974), Benston (1969a, 1969b, 1973) and Leftwich (1980) and Watts and Zimmerman (1986) for a summary) have however criticized early disclosure regulation rationales, as these rationales seemed no longer valid in capital markets that are described by market efficiency. As auditing regulation can be seen as the monitoring component of disclosure regulation these criticisms could be formulated in this context as well. For a more detailed discussion, see chapter 4 .
} 
The third hypothesis of audit demand based on insurance / deep pocket theory follows directly from the professional liability exposure of auditors, which is affected by legislation and judicial reasoning (common law). The effect of liability exposure on audit demand does not only depend on the legislative framework, but also on the extent to which the auditor is able to price his liability exposure in the market. In an increasingly litigious business environment, the insurance theory arguments may become a more important motivation for demanding the audit service. Increased regulation by statutory audit requirements combined with today's increased liability exposure of auditors ${ }^{27}$ seems to shift the burden of 'financial statement risk' 28 in the direction of the auditor. In this context, some authors have questioned the incentives of governmental bodies and politicians for audit and disclosure regulation ${ }^{29}$. Wallace (1980), for example, states that audit regulation can be seen as a governmental means to socialise business risk (which is broader than financial information risk). By providing society with deep pockets relative to bankrupt companies that cannot pay, auditors are in the position to offer protection from an otherwise uninsurable business risk. This risk is however socialised only in the case where the auditor can shift this cost to his clients through higher fees and this then can be shifted to society through higher prices and lower returns on investment. Irrespective of the fact that the auditor's portion of financial statement risk is priced, government regulators can shift responsibility to auditors by requiring that companies be audited by auditing firms, who bear the liability

\footnotetext{
${ }^{27}$ More details of the regulatory audit environment and the evolution of the auditor's liability exposure over time are provided in chapter 4.

${ }^{28}$ Financial statement risk is here defined as the expected value of losses to external parties (or externalities) deriving from defective financial statements.

${ }^{29}$ The point that politicians and regulators are no different than anyone else, that is they act in their selfinterest was generally raised in the economics literature, see e.g. Downs (1957a, 1957b), Niskanen (1971), Stigler (1971) and Peltzman (1976). Positive accounting researchers have borrowed upon this literature to explain disclosure regulation rationales in the absence of accounting market failures.
} 
burden. A similar conclusion can also be found in Gaa (1991), who observes a status quo of state regulation in the US in the 1980s, as opposed to an increase of selfregulation by the profession. This tendency is explained by capture of state regulators, in the sense that they prefer self-regulation by the profession to decrease the probability that the state regulators will be held directly responsible for audit failures.

\section{Audit pricinq: theory and evidence}

Since the late 1970 's considerable research effort has been devoted, predominantly in the U.S., to the economics of auditing. Much of this effort has been empirical in nature, and has tested various hypotheses of audit pricing. The empirical work can be seen as a response to, for example, allegations of monopolistic behaviour by large accounting firms, of low balling when bidding on engagements thereby impairing audit quality, and of reduction of auditor independence by the joint performance of auditing and management consulting services by accounting firms (O'Keefe et al. (1992)).

\subsection{Simunic's (1980) landmark study}

\subsubsection{An audit pricing model based on loss sharing between auditee and} auditor

The purpose of Simunic's (1980) landmark research in this area was to investigate whether price competition prevailed throughout the US market for audits of publicly held companies. He therefore first developed a positive model of the process by which audit fees are determined. Since the audit fee is a product of unit price, denoted by $p$, and the quantity of services demanded, denoted by q, cross sectional differences in 
audit fees may stem from either price differences or quantity differences. The model was developed to help identifying likely determinants of audit demand or audit quantity, such that unit prices could be examined. Based on the co-operative model of Demski and Swieringa $(1974)^{30}$ he considers the external audit as a subsystem of an auditee's overall financial reporting system. Auditee and auditor are assumed to be jointly and severally liable to financial statement users for losses attributable to defects in the audited financial statements. The audit service is viewed as an economic good to the auditee, which has substitutes and complements in consumption. Consequently the demanded quantity of auditing will result from equalisation of marginal private benefits and costs. Simunic hypothesises that the audit benefits are in the nature of liability avoidance of auditee and auditor to financial statement users.

Simunic models audit pricing both in a competitive and noncompetitive market setting, and also analyses the effects of auditor production economies. Simunic's model for a competitive market setting can be summarised as follows. The auditee's problem is expressed as an unconstrained minimisation problem of expected total costs of its financial reporting system. In particular, demand for internal control and external audit services is modelled as the auditee's choice of the system design variables $(a, q)$, such that the following function is minimised:

$$
E(T C)=v \cdot a+p \cdot q+E(d \mid a, q) \cdot(1-E(\theta)
$$

${ }^{30}$ Demski and Swieringa (1974) model the audit process as a cooperative effort between the auditor and the auditee to minimise joint costs of the financial accounting system employed (see also chapter 2). 
where:

$\mathbf{a}=$ the quantity of resources utilised directly by the auditee in operating the internal accounting system;

$q=$ the quantity of resources utilised by the auditor in performing the audit examination;

$v=$ the per-unit factor cost of internal accounting system resources to the auditee, which is a market parameter;

$\mathrm{p}=$ per-unit price of audit resources which will depend on the state of competition in the market for audit services;

$E(d \mid a, q)=$ expected present value of possible future losses which may arise from this period audited financial statements and which is conditional on a and $q^{31}$; $E(\theta)=$ expected value of ex-post fraction of losses borne by the auditor.

Simunic does not explicitly model an internal control and external audit production function, but assumes that resources are utilised efficiently so that a and $q$ denote both inputs and corresponding unique quantities of output constructs.

The auditor's minimum supply price, $\mathrm{p}$, per unit of $\mathrm{q}$ is the marginal cost. Thus, the minimum audit fee which is the product (p.q), for different levels of audit quantity will be equal to the expected incremental total cost, denoted $E(C)$, or:

$$
E(C)=c \cdot q+E(d \mid a, q) \cdot E(\theta)=p \cdot q
$$

The auditor's expected costs are thus a function of the auditee's financial reporting system. Hence, the auditee's problem can be rewritten as follows:

\footnotetext{
${ }^{31}$ Diminishing marginal benefits from internal control and external audit demand are assumed. In particular: $\partial \mathrm{E}(\mathrm{d}) / \partial \mathrm{a}<0, \partial^{2} \mathrm{E}(\mathrm{d}) / \partial \mathrm{a}^{2}>0, \partial \mathrm{E}(\mathrm{d}) / \partial \mathrm{q}<0, \partial^{2} \mathrm{E}(\mathrm{d}) / \partial \mathrm{q}^{2}>0, \partial^{2} \mathrm{E}(\mathrm{d}) / \partial \mathrm{q} \partial \mathrm{a}>0$ are assumed to hold.

A further assumption is that there is diminishing substitutability between a and $\mathrm{q}$, or that: $\mathrm{da} / \mathrm{dq}<0$ and $\mathrm{d}^{2} \mathrm{a} / \mathrm{dq}{ }^{2}>0$ holds.
} 
and the first order conditions for optimality become:

$$
\begin{array}{ll}
\frac{-\partial E(d)}{\partial a} & =v \\
\frac{-\partial E(d)}{\partial q} & =c+m
\end{array}
$$

The effects of monopolistic auditor behaviour are that the quantity of audit services demanded decreases relative to the competitive case, and that the quantity of desired internal control increases ${ }^{32}$. Further, the overall quality ${ }^{33}$ of the auditee's financial reporting system will decrease, because of diminishing substitutability between internal control and external audit resources in controlling liability losses. As a result, the level of expected residual liability losses will be larger under monopoly pricing, and so will be the total system cost. The impact on the level of the audit fee is however indeterminate ( $p$ increases, and $q$ decreases) and depends on the price elasticity of demand for external audit services. Inelastic demand would result in an increase in audit fees, whereas elastic demand in a decrease in audit fees.

Simunic also theoretically addresses the effects of production economies on audit quantity demanded, unit prices and system costs. Assuming that there is competition among auditors who achieve such economies, the first order condition for minimisation of expected costs with economies is:

\footnotetext{
${ }^{32}$ This is so because reduction of $q$ makes the value of $\partial E(d) / \partial a$ more negative at any a, since $\partial^{2} E(d) / \partial a \partial$ $\mathrm{q}>0$ holds.

${ }^{33}$ Note that quality is here implicitly defined in terms of the degree of reduction in loss exposure of a financial reporting system.
} 


$$
\begin{aligned}
& \lambda \cdot \frac{-\partial \mathrm{E}(\mathrm{d})}{\partial \mathrm{q}}=\mathrm{c} \\
& \frac{-\partial \mathrm{E}(\mathrm{d})}{\partial \mathrm{q}}=\frac{\mathrm{c}}{\lambda} \quad \text { where } \lambda \geq 1
\end{aligned}
$$

where $\lambda$ denotes an auditor's relative efficiency in reducing expected losses. The characteristics of this solution are the reverse of the results under monopoly pricing. That is: 1) the quantity of external audit services demanded increases and the quantity of desired internal control decreases; 2) the unit price decreases; 3 ) total system costs decrease (v.a. + p.q); and 4) the effect on audit fee is indeterminate and depends on the price elasticity of demand.

It is interesting that the 'legal' environment in which auditees and auditors behave is taken into account in Simunic's pricing model. In particular, the legal exposure of the auditee's financial statements is assumed to drive the choice of the level of internal control and external audit work. However, the legal setting in Simunic's model has been strongly simplified. First, the impact of ex ante regulation by professional audit standards on audit production is ignored. Simunic's model is basicly an audit demand model, and the analysis only generally addresses auditor production issues in relationship with their impact on audit demand and pricing. Second, the model does not take into consideration the process by which losses are to be distributed over both parties, as the loss sharing ratio, $\theta$, is assumed to be a random variable. This derives from the assumption that auditee and auditor act in concert. This simplified setting results in an optimal solution for $(a, q)$ which is invariant to the incidence of third party liability of one party or the other. The reason is that the auditee expects to incur all system costs, and thus the full amount of ex post liability losses, anyway. The interpretation of this feature is that the auditor's ex post liability exposure is assumed to 
be priced through to his clients. The model, thus, does not derive from a deep pocket hypothesis of external audit demand. Modifying the model in the above sense, would require a non-cooperative approach, whereby a 'minimum legal norm' of due care for auditees and auditors needs to be defined which would then be determining for each party's actions and corresponding legal responsibility. Such a model is proposed in chapter 5 in part 2 of this thesis.

\subsubsection{Framework for a test of competition in the audit market}

For the empirical test of competitive pricing, Simunic further assumes that price competition prevails in the submarket for the audits of "small" companies and tests for the effects of increased big eight concentration on prices paid by "large" auditees. Simunic warns for the complexity of the pricing of audit services and states that any price difference between big eight firms and other auditors must be interpreted with care. In this light, he takes into consideration that alternative audit pricing for large and small auditees might be a result of scale economies which can be exploited by large accounting firms, or of product differentiation ${ }^{34}$. He points that the market for audits is a hedonic market in which differentiated products are not observed directly but are rather revealed by differences in prices which are associated with differences in observed product characteristics. The principal differentiating characteristic of the audit service is likely to be the identity of the supplier, and again it is the big eight auditor which enjoys visibility and brand-name recognition among buyers ${ }^{35}$.

\footnotetext{
${ }^{34}$ Product differentiation refers to audits of different quality. For a discussion of the relationship between auditor size and audit quality see e.g. DeAngelo (1981b).

${ }^{35}$ Note, however, that a general definition of audit quality has not yet evolved. For a discussion of this issue, see; for example, Moizer (1993), and Sutton (1993).
} 
Relevant data were gathered for a sample of auditees stratified by auditee size. To test the hypothesis of price competition it was necessary to control for differences in audit quantity, q. For this purpose, a number of control variables were chosen in correspondence of the pricing model ${ }^{36}$. Simunic computed cost residuals for both the segment of small (defined as sales $<\$ 125$ million) and large (defined as sales $>\$ 125$ million ) auditees. Cost residual was defined as the audit cost not explained by the control variables. Differences in the average cost residuals between auditees using big eight and those using non-big eight firms were interpreted using table 3.1. Simunic found no significant differences in cost residuals, and hence audit prices, between big eight and non-big eight accounting firms in the US market both for a sample of small companies and a sample of large companies. This result is consistent with a competitive market structure and no scale economies to the big eight (scenario 5).

\footnotetext{
${ }^{36}$ Simunic made a distinction between control variables for differences in loss exposure, E(d), and control variables for differences in assessed loss sharing ratio, $E(\theta)$. For a list of the control variables used in Simunic's study, see appendix I.
} 
Table 3.1 : Test for competition: Interpretation of possible differences in average residual total systems costs of auditees using big eight versus non-big eight auditors across market segments

Results for the "small" auditee segment

\begin{tabular}{|c|c|c|c|}
\hline $\begin{array}{l}\text { Results for the "large" } \\
\text { auditee segment }\end{array}$ & $($ CREI8) $>$ CREIN8) & $(\mathrm{CRE} \mid 8)=\mathrm{CRE} \mid \mathrm{N} 8)$ & $($ CREI8) < CREIN8) \\
\hline$\left(\right.$ CREI8) $>$ CREIN8) ${ }^{*}$ & $\begin{array}{l}\text { (1) Competition with } \\
\text { differentiated } \\
\text { product to the big } \\
\text { eight }\end{array}$ & $\begin{array}{l}\text { (2) Monopoly pricing } \\
\text { by the big eight }\end{array}$ & $\begin{array}{l}\text { (3) Monopoly } \\
\text { pricing by the big } \\
\text { eight together with } \\
\text { scale economies to } \\
\text { the big eight }\end{array}$ \\
\hline$(\mathrm{CRE} \mid 8)=\mathrm{CRE} \mid \mathrm{N} 8)$ & $\begin{array}{l}\text { (4) Competition with } \\
\text { differentiated } \\
\text { product to the big } \\
\text { eight together with } \\
\text { diseconomies to the } \\
\text { non-big eight with } \\
\text { "large" auditees }\end{array}$ & $\begin{array}{l}\text { (5) Competition } \\
\text { without any scale } \\
\text { economies to the big } \\
\text { eight }\end{array}$ & $\begin{array}{l}\text { (6) Monopoly } \\
\text { pricing by the big } \\
\text { eight together with } \\
\text { scale economies to } \\
\text { the big eight }\end{array}$ \\
\hline$(\mathrm{CRE} \mid 8)<\mathrm{CRE} / \mathrm{N} 8)$ & $\begin{array}{l}\text { (7) Competition with } \\
\text { differentiated } \\
\text { product to the big } \\
\text { eight together with } \\
\text { diseconomies to non- } \\
\text { big eight with } \\
\text { "large" auditees }\end{array}$ & $\begin{array}{l}\text { (8) Competition with } \\
\text { diseconomies to non- } \\
\text { big eight with "large" } \\
\text { auditees }\end{array}$ & $\begin{array}{l}\text { (9) Competition } \\
\text { with scale } \\
\text { economies to the } \\
\text { big eight }\end{array}$ \\
\hline
\end{tabular}

Source: Simunic (1980)

\subsection{Empirical evidence of audit pricing}

Simunic's landmark audit pricing research has been followed by a number of empirical studies which have tested hypotheses concerning unit prices (using audit fees) in a number of alternative audit markets. As in Simunic's study, multiple regression models are constructed where the audit fee is the dependent variable and a number of auditee 
and auditor characteristics are the hypothesised independent variables. Auditor-related variables, such as auditor size, have been considered as important test variables, whereas auditee-related variables have often been merely considered as control variables for audit effort or audit quantity. Appendix I gives an overview of the hypothesised independent variables for most studies under review, indicates which variables were found to be significant and gives the sign of their coefficients. Table 3.2 below provides an overview of popular independent variables across studies, whereby each of these is allocated to a particular category and/or subcategory. Note that the latter exercise represents the view of the author of this thesis.

In this subsection, a summary of market evidence found in these studies is provided. The major conclusions are summarised in subsection 3.2.1., determinants of audit quantity are discussed in subsection 3.2.2. and a critical discussion of audit fee research is provided in subsection 3.2.3..

\subsubsection{A review of the major conclusions about audit pricing}

Audit pricing research derives mainly from the US [ see, for example, Simunic (1980, 1984), Wallace (1984), Simon (1985), Palmrose (1986a, 1986b, 1989), Francis \&

Simon (1987), Simon \& Francis (1988), Turpen (1990), Ettredge \& Greenberg (1990), Gist (1992), Rankine \& Felix (1993)], but also from Australia [ see, for example, Francis (1984), Francis \& Stokes (1986)], the UK [ see, for example, Taylor \& Baker (1981), Chan, Ezzamel \& Gwilliam (1991), Pong \& Whittington (1993), Ezzamel, Gwilliam \& Holland (1994)], New Zealand [ see, for example, Firth (1985)], and Singapore [ see, for example, Low, Tan \& Koh (1990)]. One study [ Haskins \& Williams (1988)] has made a comparision between audit fee determinants across countries (i.e. US, UK, Ireland, New Zealand and Australia) and across big 8 firms. In all studies independent variables relating to auditee size and complexity were 
significantly positively correlated to the level of audit fee (except for Firth (1985) who reports a non-significant complexity variable). The focus of most studies was however not to identify an exhaustive list of significant audit fee determinants as such, but rather either: (1) to investigate whether there exists an auditor firm size effect, i.e. whether big-8 (or big-6) accounting firms charge higher audit fees than non-big- 8 firms both in segments of large and small auditees, and hence to draw conclusions with respect to competition, product differentiation and scale economies in the market for audit services; and/or (2) to examine whether there is evidence of price cutting on initial audit engagements; and/or (3), to examine the effect of management advisory services provided by the auditor on audit pricing.

There does not exist consensus as to the impact of auditor size on audit fees and as to whether the impact differs between the small auditee market and the large auditee market. Simunic (1980) provided supportive evidence of competition in the US market for audit services without any scale economies to the big eight firms (scenario 5 in table 4), as there was no significant effect of auditor size on the level of audit fee, i.e. there was no siginificant big 8 price premium, in both the segment of large and small auditees. Firth (1985) also reported a non-significant auditor size effect in the New Zealand market for audit services (without partitioning into large and small auditees). However, other studies which tested the effect of auditor size on audit fees found significant results for both auditee segments, or the small auditee segment alone. Francis (1984), who replicated Simunic's test for competition in the Australian audit market, reports a significant auditor size variable for both small and large auditees, which is supportive for a competitive audit market with product differentiation to big-8 accounting firms (scenario 1 in table 1). Significant big 6 price premiums were also reported by Chan et al.(1991) for a sample of UK auditees, and no price differential was observed between small and large auditees. Francis \& Stokes (1986) report only significant big 8 price premiums for the small auditee segment of the Australian audit 
market, as do Palmrose (1986a) and Francis \& Simon (1987) for the US audit market. These results are consistent with scenario 4 in table 4 , that is, competition with product differentiation to big- 8 accounting firms and diseconomies of scale to the non big- 8 in the audits of large companies.

Taken together, the evidence is supportive of a fairly competitive market for audit services, in the sense that it reveals that big 8 audit fees in the large auditee segment are never significantly and strictly larger ${ }^{37}$, ceteris paribus, than big 8 audit fees in the small auditee segment. This excludes scenarios 2,3 and 6 from being descriptive of practice, which are exactly the scenarios which would indicate monopoly pricing by big 8 firms. However, there exists no consensus about the existence of product differentiation and scale (dis)economies, although most results (i.e. those supporting scenarios 1 and 4) point in the direction of product differentiation. Note that this lack of consensus does not necessarily derive from country-specific elements. Inconsistent evidence with respect to big 8 premium prices occurs within countries. Simunic (1980) and Palmrose (1986a) both examined US samples and report such contradictory evidence; the same holds for Francis (1984) and Francis \& Stokes (1986) with respect to Australian samples. This may however be attributable - as Francis \& Stokes (1986) and Francis \& Simon (1987) pointed - to the differences between the studies w.r.t the average auditee size in the respective samples of small and large auditees. The average auditee size in Simunic's subsample of small auditees is substantially larger than in all other studies ${ }^{38}$, which might explain the non-significant effect of auditor size for the small subsample.

37 in particular referring to the test of competition in table 4, if (CRE|8) $>$ (CREIN8) holds for the large auditee segment, then $(\mathrm{CRE} \mid 8)=(\mathrm{CRE} / \mathrm{N} 8)$ and $(\mathrm{CRE} / 8)<(\mathrm{CREIN8})$ never holds for the small auditee segment; and if $($ CREI8) $=($ CREIN8) holds for the large auditee segment, then (CREI8) $<$ (CREIN8) never holds for the small auditee segment.

${ }^{38}$ Average auditee size, measured in terms of total assets, for the samples of small auditees was 8 million Australian dollar in Francis (1984) (at that time 1 Australian dollar was worth between 1.15 and 1.35 USD); 40 million USD in Palmrose (1986a); 1.8 million Australian dollar in Francis \& Stokes (1986) (at that time 1 Australian dollar was worth 0.88 USD); and 30 million USD in Francis and Simon (1987). Other studies did not made a partitioning in subsamples of large and small auditees (i.e. Firth (1985), 
An interesting study that investigates the competitive pricing hypothesis in a different way than the studies mentioned above was performed by Rankine \& Felix (1993). Given the evidence of seller concentration in the audit market (see section 1), the objective of Rankine and Felix' study is to assess whether such concentration is indicative of reduced competition that is manifested in higher audit fees, or on the contrary whether such concentration is a competitive process that leads to lower audit fees. A multiple regression analysis for a sample of Arthur Andersen clients in 11 different states of the US was performed. Unlike the other cross sectional pricing studies, no proxies were used for audit effort; but actual audit labour hours of four different types (i.e. partners, managers, seniors ans staff) were included as independent variables. Furthermore, test variables were included that were hypothesised to be representative for the degree of competition in the market ${ }^{39}$. No evidence was found that audit fees and concentration are positively correlated. On the contrary, some evidence was found that measures of degree of rivalry in the audit market have a negative effect on audit fees.

Another issue that has been the focus of empirical audit fee research is whether audit firms apply differential pricing for new clients. The motivation for this kind of empirical work derives from the AICPA's (Commission on Auditors' Responsibilities, 1978) statement that low balling (i.e. setting audit fees below total current costs on initial audit engagements) is a direct threat to auditor independence by creating a future

however the average asset size for the total sample here is 62 million New Zealand dollar, which is rather small and hence might support Simunic's conclusion) or did not measure auditee size in terms of total assets ( Chan et al. (1991)).

39 These variables were: market share of Arthur Andersen (in each of the 11 states, or, in the client's industry), a concentration ratio of the four largest auditing firms, the Herfindahl index (which is an indicator of seller concentration, calculated as the sum of the squared market shares for each client's industry), fee pressure, parnter time and industry growth. 
economic interest in clients. DeAngelo (1981a) however demonstrates by means of a model of intertemporal audit pricing, that low balling is a competitive response to the expectation of future quasi-rents (i.e. learning curve effects), and does not itself impair auditor independence. Critical here, is that initial fee reductions are considered to be sunk in future periods and therefore do not impair auditor independence. Magee and Tseng (1990) extend DeAngelo's model to identify conditions under which a client specific quasi-rent may lead an auditor to compromise independence. They show that, when contingent fees are not allowed and when auditors and clients cannot make multiperiod commitments that are binding, the auditor's value of incumbency only presents a threat to independence under limited circumstances. These are that : 1) auditors in the market must disagree among themselves as to the appropriateness of the reporting policy desired by the client; and 2) the reporting issue must affect the client more than one reporting period. However, even when both conditions hold, a positive value of incumbency will not compromise independence on reporting issues that are regarded as very important by either the auditor or the client.

The evidence with respect to the existence of price cutting on initial engagements in the US market for audit services is quite consistent. Francis \& Simon (1987), Simon \& Francis (1988), Turpen (1990), and Ettredge \& Greenberg (1990) all report significantly lower pricing in audits of new clients. Simon \& Francis (1988) report an average fee reduction of 24 percent during the engagement year, and of 15 percent during each of the next two years. By the fourth year fees seem to increase to their normal levels. Turpen (1990) reports that fee reductions on initial engagements are granted by all types of auditing firms (big 8 , national and local), and even in audits of relatively unprofitable companies. Ettredge and Greenberg's (1990) found that the level of fee cuts are significantly affected by variables such as change in auditor class, the number of auditors bidding on the engagement, and the difference in technological efficiency and situational expertise between the new and the old auditor. Pong and Whittington 
(1993) report envidence of low balling in the UK market, particularly when the new auditor was not a member of the big 8 . On the contrary, no evidence of price cutting behaviour was reported by Francis (1984) for the Australian audit market.

A final contribution of the empirical audit fee studies is the evidence provided of $a$ positive relationship between audit fees and non-audit or consulting fees. For the US market such evidence was, for examplè, reported by Simunic (1984), Simon (1985), Palmrose (1986b), and Turpen (1990). Palmrose (1986b) reports significant positive effects of fees for various categories nonaudit services (i.e. accounting related MAS, non-accounting related Mas and tax services). The results were strongest for accounting related MAS. In the UK Ezzamel, Gwilliam and Holland (1994) are currently investigating this phenomenon, and state in a preliminary report that the relationship is dependent upon specification of the regression model. In common with researchers in the US, a strong positive relationship between audit fee and the non-audit fees is reported when logarithmic transformations of the dependent variable (i.e. audit fee) and some of the independent variables are used. However, when the models are differently specified, the relationship seems much less apparent.

Some explanations have been put forward to explain the positive relationship between audit fees and non-audit fees. Simunic (1984) theoretically examined the client's (auditee) decision to purchase MAS and audit services when their production functions are interdependent, which results in knowledge externalities. Very crudely stated this analysis demonstrates that the production of MAS reduces the marginal cost of auditing, and hence a higher quantity of auditing might be demanded (i.e. if the demand for auditing is relatively price elastic) than otherwise would be the case, at the expense of the demand for audit substitutes (i.e. internal auditing) which would decrease. However, companies purchasing MAS from their auditors might do so because they 
face unusual problems. This in turn, would motivate an abnormally large amount of auditing.

\subsubsection{Determinants of audit quantity}

The analysis in this subsection can be interpreted as if audit effort proxies were the test variables and auditor-related variables were the control variables. The rationale for such an approach is that it might reveal to some extent what is priced in the audit market, or in other words, what determines audit quantity.

In general, auditee size and complexity together account for the most variance explained by the regression analyses. As a result they are often considered as proxies of the amount of audit work performed.The most significant explanatory variable in all studies is the auditee's size. This is not surprising since the client's size is an indicator of the amount of work to be performed by the auditor, and hence for the fee charged. Most studies have used an auditee size-variable based on total assets in their regression model. Since audit approaches are often balance sheet based this seems a fair proxy for the amount of audit work performed. Chan, Ezzamel and Gwilliam (1991) claim that turnover ${ }^{40}$ may be a better explanatory size-variable, if auditors employ a transactions based approach. Since the relationship between auditee size and audit fee is unlikely to be linear ( because of economies of scale in the auditor's production function, for example those derived from using sampling techniques, and the likelihood of more

\footnotetext{
${ }^{40} \mathrm{Chan}$, Ezzamel and Gwilliam (1991), use turnover as a proxy for auditee-size. Their motivation is that total asset measures may vary significantly between otherwise similar companies due to different accounting policies (e.g. relating to fixed asset revaluations, treatment of goodwill, etc..) or differences in age profiles. More important even, is their point that other variables in the regression model may be linked with total assets, such as some risk and complexity variables which incorporate total assets directly in their calculation. Interdependencies between the variables in the regression models cause mulitcollinearity problems, a problem which is encountered in almost all studies.
} 
developed internal control procedures in large companies) log or square root transformations of auditee size measures are typically used.

Auditee complexity also appeared to be generally significant in explaining audit fees. Again, the more complex the auditee's organisation, the more audit effort needed and hence the higher the audit fee. Measures of complexity variables included in the studies are the number of subsidiaries, locations, foreign operations, and diversification. 
Table 3.2: Overview of hypothesized audit fee determinants in the regression analyses of audit fee research studies and allocation to categories and subcategories

\section{Auditee}

A.Size:Total assets (TA); Turnover; Profit; Operating revenue

B. Complexity:No. of subsidiaries; No. subsid. / Tot. subsid; Diversification;

Foreign assets / TA; No. of locations

C. Risk: Liquidity:Receivables / TA; Inventory / TA; Current Assets / TA; Quick ratio

Profitability: Prior losses; ROI; ROE

Variability of return:systematic risk $(\beta)$; unsystematic risk

Nature of business: industry indicator; regulated/unregulated

Prior audit opinion

External Parties: leverage; Ownership: private / public

D. Internal Control: Internal audit expenses; Reduction in fee from internal audit

E. Other:Month of year end (Busy audit season); Audit delay; No. of special reports demanded;

\section{Auditor}

A. Size: Big-8 firm/ non big-8 firm

$B$. Experience: No. of years as auditor in firm; Industry specialist; Initial audit engagement

C. Non-audit services: MAS-fee; Fee for accounting services; Fee for nonaccounting services

D. Other: Auditor location

\section{Non-incumbent auditor}
A. Fee for (non-principal) Audit services
B. Fee for non-audit services

Auditee risk variables cover a broad category of quite distinct auditee-related variables. They have in common that they, to some extent, might affect the auditor's perception of 'inherent risk' of the client ( this is the likelihood of material error in the auditee's statements before any audit work has been done) and/or the perception of business risk 
associated with a client situation. High inherent risk might lead to increased audit effort and direct cost. High business risk relates to an increased likelihood or size of expected financial losses (accruing to the auditor). Unlike the above two categories (auditee size and complexity), the evidence as to the power of auditee-risk variables in explaining the level of audit fees is mixed. A comparison of the results across studies (see appendix I) reveals that, from the list of risk-related variables in table 3.2 , only profitability and prior audit opinion were found to be significant in explaining cross sectional variations of audit fees. However, no consensus exists for liquidity measures. The results for the other types of risk variables are very weak or mixed.

Two more categories of independent variables were included in some of the audit fee studies, which are classified here as internal control and other. Wallace (1984), Palmrose (1986a, 1986b) and Turpen (1990) included an internal control variable in their regression model, and in all cases it was found to be significant. From this limited evidence it can be concluded that internal control/auditing can be at least considered as a partial substitute of external auditing. This is not a surprising result, as the presence and quality of a system of internal control in the audited company may reduce the requisite amount of testing by the auditor. 'Other' is a final category of auditee-related variables which are neither size-related or likely risk determinants per se. Two variables relate to the timing of the audit. 'Month of accounting year end of the auditee' (or in some studies named 'busy audit season') has been included in four studies (Francis (1984), Firth (1985), Francis and Stokes (1986), and Chan et al. (1991)) to account for off-peak pricing. This variable was however not significant in all four studies. 'Audit delay' refers to the lag between the accounting year end of the auditee and the audit report date. Short lags might indicate tight reporting deadlines which may in turn lead to inefficient and higher cost auditing; long lags however might be the result of audit problems requiring additional audit work. Only Firth (1985), and Chan et al. (1991) investigate the significance of this variable and report contradictory findings. A final 
auditee-related variable is 'Number of special audit reports demanded' which refers to an extended scope of the audit beyond what is required by audit standards and which will lead to a higher audit fee. It has only been tested in two studies (Firth (1985) and Palmrose (1986b), both of which report significant results. 


\subsubsection{A critical look at audit fee research}

A major problem with past audit fee research is that the proxies for audit effort - or audit quantity - used as control variables in the regression models have rarely been subject of experimental interest. As a result, little is known about the way in which the control variables affect audit effort, as their real impact on audit cost and audit production is not known. Instead, ad hoc models were specified where the dependent variable is often transformed logarithmically. By doing this, universal multiplicative interaction between independent variables is assumed, but the joint impact of these is not tested. Pong and Whittington (1993) criticise the ad hoc nature of prior audit fee regression models. They argue - without reference to Simunic's pricing model - that previous studies on the determinants of audit fees have been implicitly estimating the supply curve (i.e. the willingness of audit firms to supply audit services at different audit fee levels), but that this has not been explicitly stated in these studies. In support of their argument, they state that demand for audit services is relatively inelastic to audit fee, because the audit is a statutory requirement, and hence mainly depends on the amount of audit work required. This interpretation is interesting since the control variables in Simunic's (1980) landmark study, and many subsequent studies have included similar variables, were chosen 'in correspondence' with a pricing model that is driven by auditee demand. Irrespective of what is measured (demand or supply), past audit fee studies do not allow to test what constitutes a 'unit' of audit service (q) and what is a determinant of audit price (p), the reason being that proxies of audit effort an ad hoc specified regression models are used. Also no conclusions can be drawn with respect to what constitutes audit quality, since it is assumed that audit quality (i.e. product differentiation) is determined by auditor size.

In the light of the discussion above, two competing hypotheses of what constitutes a unit of audit service (and of what is priced) could be the following. First, audit quantity 
could be defined as the effort by the audit firm in terms of resources dedicated to an engagement. Second, audit quantity could be perceived as a composite of audit effort plus some (partial) insurance against future losses to users of financial statements. According to the latter scenario, both elements will necessarily be priced in the market. It is worth noting that Simunic (see section 3.1.1), by assuming that $q$ is both an input and output construct of the audit process, does not provide clarity about the variable $q$. On the one hand, $\mathrm{q}$, is defined as an input construct in the audit process representing the amount of external audit resources spent in an engagement, which corresponds with the first hypothesis above. On the other hand, the audit fee, defined as p.q, is the sum of resource cost plus a mark up for ex post loss exposure. As such, the audit service, $q$, could be interpreted as a composite of control work done for the auditee (which could be considered as a substitute to internal control) plus an 'insurance' component that is priced (which could be considered as a complement to internal control). This corresponds with the second hypothesis above.

A major conclusion from the above discussion is that the use of proxies of audit effort in ad hoc specified regression models may lead to inferences about audit pricing that are distorted. Inferences about unit prices in a market are only possible if the product that is priced is fully understood. Future research along at least three dimensions may help clarify the issues raised above. A first category of research could examine the impact of re-specifying regression models on the results in prior studies. This would provide an insight into the robustness of the pricing evidence obtained so far. Some recent studies have already addressed this issue. Pong and Whittington (1993) have suggested an alternative regression model which does not a priori assume a multiplicative relationship between the independent variables. A quadratic regression model is adopted which allows the explicit examination of interactions between explanatory variables. The ongoing study by Ezzamel et al. (1994) adopts three alternatively 
specified regression models in order to test for the robustness of the findings. A preliminary conclusion was that the results differ across the models.

Another worthwile research area is to follow the research approach of Rankine \& Felix (1993) and to test audit pricing hypotheses using actual data on audit effort (hours) instead of proxies.

A third suggestion for future research is to investigate the audit production function, by studying the determinants of audit effort. Pioneering work in this area has been done by O'Keefe et al. (1993). In their study the effects on audit hours of client size, complexity and risk were examined for a major public accounting firm. Their conclusion was that cross-sectional variation in the quantity of labour inputs can be largely explained by the same category of independent variables which have been found important in prior research on audit fees. More studies, covering other accounting firms and clients are needed to establish faith in audit effort proxies.

\section{Major conclusions}

The economics of auditing is currently a very vibrant and fertile area of research, which offers a lot of potential both for empirical and theoretical work. In the context of the formal analyses in part 2 of this thesis, the following conclusions are relevant. Unlike the agency and information theory rationales for audit demand, little formal economic analysis has been devoted to the liability insurance/deep pocket rationale for audit demand. A reason is that auditor liability rules have not been included in prior models of audit demand. Although Simunic's model of audit demand assumes loss sharing between auditee and auditor based on their joint and several liability for losses to users of defective financial statements, the model was clearly not developed to investigate the 
impact of liability rules on audit quantity demanded and demanded internal monitoring . Simunic's model of demand is based on co-operation between auditees and auditors, whereas a model that analyses liability insurance demand requires an non-cooperative setting. Such a model is proposed in chapter 5 . The review also revealed that very few 'positive' models of audit production have been developed, and to the author's knowledge, no audit production model is published which includes a legal parameter. The impact of liability on audit production is modelled in chapter 6.

Of further relevance is that empirical tests of audit pricing have provided evidence that internal control may serve as a substitute to external audit services. This is an assumption of the demand model proposed in chapter 5. From reviewing the audit pricing studies, some empirical evidence was found in support of price competition and product differentiation. These are assumptions underlying the audit production model proposed in chapter 6. 


\section{Chapter 4}

\section{Auditing, Regulation and Liability}

\section{Introduction}

Auditing is a regulated activity. The objective of this chapter is, first, to discuss why some scholars think that auditing should be regulated, and second, to assess how auditing is regulated and which alternatives to audit regulation are available to public policymakers to intervene in the audit market. Regarding the first question, regulation is often seen as a means to achieve public interest maximisation or in other words, to establish maximum social welfare in an economy where parties can be expected to act in their own self-interest, and where the market mechanism fails to establish the supposed social optimum, or where a market is non-existing. A rich literature has developed on economic rationalisations for accounting regulation. Since auditing (regulation) forms a part of accounting (regulation), the arguments put forward in this literature also apply to audit regulation.

The accounting and auditing literature has focused far less on the second question of how auditing is (or should be) regulated, and has ignored the related question of which policy instruments other than regulation that governments can use to pursue welfare maximisation. Behaviour of individuals and organisations can be modified in an ex ante way by governments specifying what this behaviour should be. By setting regulations behaviour can be imposed. Behaviour can be modified in an ex post way by relying on a tort system and liability laws which are used as a threat to deter non-wanted behaviour instead of ex ante specification of wanted behaviour. Since both types of policy instruments are used to affect financial reporting and auditing behaviour, it is 
interesting to identify the characteristics of either instrument, their advantages and disadvantages, as well as the forms these policies take in the auditing context.

The chapter is organised as follows. In section 2 a summary overview is given of the literature on economic rationales for accounting (and hence auditing) regulation. Note that the arguments developed in this literature could also be used to support (or object to) the use of liability law as a policy option. In section 3 the focus is on (ex ante) auditing regulation and (ex post) liability as alternative policy options to pursue welfare improvement. Based on findings in applied welfare economics and the literature on law and economics, preliminary conclusions are drawn regarding the relative ability of each policy to achieve welfare optimisation in the audit context. The major types of current regulations and liability doctrines affecting audit demand, supply and production are discussed in section 4, together with recent developments in this area. Conclusions are presented in section 5 . 


\section{Accounting regulation and public interest theory}

In the accounting literature various rationalisations for accounting regulation have been put forward. In this section only economic rationalisations for accounting regulation are briefly summarised ${ }^{41}$. Two main categories of economic theories of regulation exist (Posner, 1974)) and are applied to accounting regulation, namely: public and private interest theories. The emphasis in this section is mainly on economic rationales in the public interest theory tradition ${ }^{42}$.

\subsection{Economic arguments for and against accounting regulation}

Accounting regulation consists of two distinct but related sets of regulations (Maijoor (1991)). First, there is regulation of disclosure of financial information. This type of regulation determines for example the items in financial reports that need to be disclosed, the rules or standards that are to be adopted in drawing up financial reports, and the frequency of financial reporting and disclosure. Second, there is regulation of the audit of financial information. Audit regulation prescribes for example which entities are required to be audited by an independent audit firm, who can perform the audit activity, and how this activity should be performed. Auditing regulation can be seen as the monitoring component of disclosure regulation. Arguments in favour of (or against) disclosure regulation may therefore apply to auditing regulation as well.

\footnotetext{
41 More detailed reviews of the literature on economic rationalisations for accounting regulation are provided by Maijoor (1991) and Watts and Zimmerman (1986).

42 Other (than economic) theories of regulation have also been applied to the accounting context, such as: 1) a political economy approach to accounting regulation (See, for example, Cooper and Sherer (1984)); 2) a socio-historical approach to accounting regulation (see, for example, Merino and Neimark (1982)); and 3) A radical approach to accounting regulation (see Tinker (1984)). These are, however, beyond the scope of this thesis.
} 


\subsubsection{Market failure arguments for accounting regulation}

An early rationale for corporate disclosure and related audit regulation was that investors cannot distinguish between efficient and less efficient firms ${ }^{43}$. This argument seemed however no longer valid in capital markets which are predominantly characterised in terms of market efficiency. In response to demands for alternative disclosure regulation rationales, accounting researchers in the positive economics tradition introduced more sophisticated rationales, taken from the economic literature on market failures. A market failure exists when the quantity or quality of a good supplied differs from the supposed social optimum. Market failures suggest that government regulation that moves the private output of a good closer to the social optimum can improve social welfare in a Pareto sense. Applied to the market for accounting information, market failure is alleged to exist because the output of information in accounting reports is nonoptimal in a Pareto sense in the absence of disclosure and audit regulation. Stated alternatively, an accounting market failure exists as a result of inequitable or "unfair" resource allocation resulting from the market for financial information (see, for example, Burton (1974)).

In the accounting literature four problems have been identified which may justify regulation of accounting information on the grounds of accounting market failure: the public good problem, the information asymmetry problem, the speculation problem and the redundant information problem. Each of these problems are briefly considered below.

\footnotetext{
${ }^{43}$ Due to a number of reasons, such as (see Leftwich (1980)): monopoly of information by management, naive investors, functional fixation, meaningless numbers, diversity of procedures and lack of objectivity. For a summary of the discussion of the appropriateness of each of these regulation arguments see Leftwich (1980), and Watts \& Zimmerman (1986). For the original analyses see e.g. Beaver (1973, 1976); Beaver \& Demski (1974); Benston (1969a, 1969b, 1973).
} 
A public good is a good for which consumption by one individual does not prevent consumption by another individual (Just et al. (1982), p. 284). Information in accounting reports could be considered as a public good. This may result in free-rider problems both on the demand and supply side of the accounting information market (see, for example, Gonedes and Dopuch (1974), Gonedes et al. (1976), Beaver (1977), Foster (1980), Easterbrook and Fischel (1984), Solomons (1986)), and in a joint-supply problem (see, for example, Bromwich (1985)). Underproduction of accounting information may result from free-riding and joint-supply in an unregulated market.

Information asymmetry exists when one party to a potential transaction has more information than another ${ }^{44}$. Some authors have suggested that this problem is applicable to accounting information (see , for example, Gonedes et al. (1976), Beaver (1977), Gonedes (1978), Foster (1980), and Cooper and Keim (1983)). Accounting regulation may be justified on the grounds that information asymmetry may lead to adverse selection, moral hazard and signalling behaviour. The adverse selection problem can be summarised as follows. Securities with varying expected returns and risk, and thus of various qualities, are traded on the stock market. If there is lack of information, buyers will consider all securities as average, since they cannot distinguish between securities. This may result in negative consequences on the supply side of the stock market, since there is an incentive to offer low-quality securities. Negative consequences on the demand side may also result, because uninformed investors will withdraw knowing that they are in a disadvantageous position.

The fact that managers have more information about the value of the firm than outside (potential) investors may result in moral hazard problems and signalling problems. In this context disclosure of accounting information may serve as a signal of management's beliefs about the future income streams of the firm. From a societal point

\footnotetext{
44 The problem was developed in the economics literature by Akerlof (1970), Arrow (1973), Spence (1973) and Stiglitz (1975).
} 
of view two negative consequences may eventuate. First, since signals may affect security prices, management may have an incentive to provide distorted signals (the moral hazard problem). Second, firms whose share prices are undervalued have an incentive to signal this event. However, since part of the information is related to past performance and may not relate to future performance, it may not yield any social benefits (signalling problem, also called screening problem). In this instance signalling can cause overproduction of accounting information.

The speculation problem (see, for example, Hirschleifer (1971), Fama and Laffer (1971) and Barzel (1977)) and the redundant information problem may also result in overproduction of accounting information in unregulated markets. It has been stated that private information production for speculative purposes does not improve the efficiency of the allocation of society's resources, but merely redistributes wealth between individuals ${ }^{45}$.

The essence of the redundant information problem can be summarised as follows (see, for example, Gonedes et al (1976) and Easterbrook and Fischel (1984)). Various (potential) investors will privately search for the same information about a firm in a non-regulated environment. This would mean that resources are wasted, since information is costly to obtain and individual investors spend resources on the production of the same piece of information. Consequently, mandating managers to disclose accounting information reduces the incentive for (potential) investors to privately search for the same information.

\footnotetext{
45 Famous examples of the speculation problem are the "potato crop example" by Hirschleifer (1971) and the "wheat crop example" by Barzel (1977).
} 


\subsubsection{Economic arguments against accounting regulation}

Some authors have however identified fallacies in the above mentioned market failure rationales, and these can be seen as arguments against accounting regulation. Maijoor (1991) identified three groups of arguments against accounting regulation: 1) arguments concerning the possibility of private consumption of accounting information, 2) arguments concerning the incentives for firms to voluntarily disclose accounting information, and 3) arguments concerning the costs of both unregulated and regulated accounting information markets.

The possibility of private consumption of accounting information can be seen as an objection to the public good justification of accounting information regulation. Accounting information may well have public good characteristics, however, to some extent, it is a private good. If accounting information is consumed privately, investors may earn, on average, a normal return on their investment in information search (see, for example, Cooper and Keim (1983), Watts and Zimmerman (1986), Benston (1976)). The use of information on undervalued securities will drive the price up and reduce the information's value for other investors. Further, accounting information has no intrinsic collective characteristics. As a result, an unregulated market for accounting information might develop systems to allow for the exclusion of non-purchasers and for private contracting for accounting information.

Mechanisms which would provide incentives to managers to voluntarily provide the right amount of accounting information are suggested by: 1) agency theory, 2) signalling theory, and 3) the Coase theorem (contracting theory, See Coase (1937)). Publication of accounting information reduces agency costs for managers (see, for example, Horwitz and Kolodny (1982)). These costs arise if ownership and control are 
arrangement for its attainment. Watts and Zimmerman (1986) point out that market failure arguments do not consider the contracting costs inherent in every institutional arrangement, and state that if private contracting costs are included in the analysis, it is no longer apparent that there needs to be a market failure. If private contract costs are greater than the private benefits, there is only market failure if government's contracting costs are lower than the private costs. When the costs of remedying the market failure are often assumed to be zero, the costs of regulating corporate financial disclosure may be substantial. Not only direct regulation costs should be considered, such as the cost of resources consumed by regulatory bodies in making and enforcing rules and by firms in meeting those rules and regulations. Also indirect costs may be substantial, such as the effect of rules on investment, financing and production decisions in a way that is not necessarily socially optimal in a Pareto sense. Watts and Zimmerman (1986) further state that lack of thorough investigation of the costs and benefits of disclosure regulation suggests that the descriptive ability of the social welfare maximization objective should be investigated.

\subsection{Public interest versus private interest theory of accounting regulation}

Inconsistencies between regulators' actions and the "public interest" hypothesis has led some economists and political scientists to assume that politicians and regulators are no different to anyone else, that is they act in their self-interest ${ }^{47}$. Stigler $(1971,1975)$, for example, models regulation as a purely self interested process whereby the state's power to coerce is actively sought and obtained by influential economic groups for their own benefit. Similar "private interest" arguments can be raised in the context of accounting

\footnotetext{
${ }^{47}$ See, for example, Downs (1957a, 1957b); Niskanen (1971), Stigler (1971, 1975); Peltzman (1976).
} 
and auditing regulation ${ }^{48}$. The private interest theory, sometimes called the interest group theory of government, tries to explain the gap between standard economic rationalisations for government intervention and observed regulatory behaviour (Tollison 1982, p. 588). An important theoretical difference between the public interest and private interest theory of regulation, is that in the public interest model the relationship between regulators and regulation is not specified, whereas it is in the private interest model. However, public and private interest theory need not be diametrically opposed (Haddock and Macey (1987)). The private interest view does not necessarily lead to the conclusion that regulation is not in the public interest. It might well be that political mechanisms encourage regulators to pursue the public interest.

\section{Auditing requlations and liability as means to correct for accounting market failure}

In prior accounting and auditing literature little attention has been addressed on how to optimally influence accounting market behaviour, and on alternative policy instruments than regulation to govern accounting market failure. The choice of the most efficient policy for correcting market failure is a major issue in applied welfare economics and the economics and law literature. In this section some basic principles of this literature are summarised and then applied to the context of auditing. In subsection 1, an early and popular market failure rationale for auditing regulation based on information asymmetry is given. Financial information production and auditing are then defined as externality generating activities in subsection 3.2. Next, in subsection 3.3 , the major differences between ex ante and ex post policy instruments for correcting externalities are discussed in general and as we apply them to the audit context. Then, in subsection

\footnotetext{
48 Some attempts to apply the private interest theory of regulation to accounting are Watts and Zimmerman (1978, 1979), Sutton (1984), Lindahl (1987).
} 
3.4 , some determinants of relative social desirability of each alternative are discussed in general, and are then applied to the audit context. Finally, in subsection 3.5, attention is paid to the advantages and disadvantages of self-regulation or state regulation, a matter that is very much relevant in the context of auditing.

\subsection{Information asymmetry: a popular rationale for auditing regulation}

An early rationale for audit regulation was that the primary purpose of regulating the external audit has been to protect the users of financial information (i.e. the investors), as they were presumed not to have perfect access to company information (see, for example, Watts \& Zimmerman (1986)). Note that a similar motivation for disclosure regulation has been put forward. In the U.S., for example, the 1933 and 1934 Securities Acts were disclosure acts which aimed to prevent the capital markets from overvaluing securities, thus protecting the interest of the shareholder. The 1933 Act also requires firms to be audited by independent or certified public accountants. As Wiesen (1978) points, the auditor's intended role is to monitor management's disclosure of information that is used by investors for decision making. Further, the statutory imposition of legal liability by the Acts increases the incentive of the external auditor to fulfil this role.

Motivations for regulation of audit demand (for example, statutory audit requirements) which tie in with the market failure argument can be derived easily from traditional auditing literature. An example is a list of four conditions that create a demand for auditing provided by The Committee on Basic Auditing Concepts (1973). These are:

1. Conflict of interest - conflict between information preparer and a user can result in biased information production;

2. Consequence - information can have substantial economic consequences to a decision maker; 
3. Complexity - expertise is often required for information preparation and verification;

4. Remoteness - users are frequently prevented from directly assessing the quality of information.

\subsection{Accounting information, auditing and externalities}

Disclosure of accounting information might create negative external effects or externalities $^{49}$ to users of this information. In general, an externality exists where an action of one economic agent affects the utility of another in a way that is not reflected in the market place ( Just, Hueth \& Schmitz (1982, p. 269)). Losses to financial statement users due to resource allocation decisions based on defects in audited financial statements which the auditor did not detect or report, could be seen as an "externality". The directors and the external auditors can thus be considered as jointly responsible for hazardous financial reporting. The externality is aggravated by informational asymmetry. Directors and external auditors have more information about the value of the firm than external parties. In addition, the delivered audit quality by auditors cannot be observed by clients and third party users of financial statements. The social objective of audit regulations and liability law could be seen as to correct for externality generating financial reporting behaviour (by directors) and audit behaviour (by external auditors) in such way that total social utility is improved. Policies adopted to correct for hazardous financial reporting behaviour - that is the behaviour of the directors - will necessarily have an impact on audit demand (since the directors are the ones which acquire audit services). Policies adopted to correct for externality generating

\footnotetext{
${ }^{49}$ Although "market failure" and "externality" are related concepts, and sometimes used interchangeably, they are not synonyms. Market failure can be caused by externalities, but can also be caused by other other factors, such as for example monopoly situations, public goods and informational asymmetry (See, for example, Cooter and Ulen (1993)).
} 
audit behaviour will necessarily affect audit production - or the behaviour of the auditor. Examples of current audit regulations that affect audit demand and production are given in section 4 .

\subsection{Ex ante regulation versus ex post liability}

Ex ante regulation and ex post liability are two very different approaches to control for activities (such as the production of audit services) that create risks of harm to third parties or externalities. From its beginnings the literature on optimal regulation has focused on alternative types of ex ante policies, such as for example safety standards, Pigouvian taxes and transferable permits. Ex ante policy instruments modify behaviour in an immediate way through requirements that are imposed before, or at least independent of the actual occurrence of harm, and are public in nature (Shavell, 1984a). Ex ante rules can be pronounced directly by the state through civil servant, or the state can delegate its authority to another body. In the context of audit regulation, an ex ante policy which applies to the auditee is the statutory audit requirement. For the auditor, professional audit standards could be seen as an ex ante policy. Auditing standards are however (as opposed to disclosure standards) very general in the sense of stressing objectives rather than a means of reaching those objectives. Their power as a legal defense of "due care" in litigation is uncertain as they are advisory and do not have the same authoritative and enforcing character as standards set by statute. Therefore they may be considered as a 'weak' form of an ex ante policy.

The second policy instrument, namely liability in tort, works through the deterrent effect of damage actions that may be brought after harm has occurred, and hence is private in nature (Shavell, 1984a)). The threat of suit causes the potential injurer to internalise the expected social harm and hence to take optimal precaution. In the audit 
case this would imply that audit liability is an incentive for the auditor to produce an optimal level of audit quality. It is only since the 1980s that researchers have also analysed the ability of exposure to ex post liability, to correct for externalities. Cooter (1991), for example, points that the elaboration of price theory by mathematical economists in this century took the legal framework for granted. Liability law is, however, an important mechanism for allocating resources. Nowadays, economic theories tend to understand liability law as a search for efficiency in incentives and riskbearing. The basic premise of law and economics is that legal rules create implicit prices on behaviour and that responses of individuals and organisations to those prices can be anaysed in exactly the same way that responses to explicit prices can be analysed (Ulen (1993)). The threat of litigation to audit firms can thus be expected to affect audit production behaviour, and potential liability from the part of corporate management (that is, the directors) to third parties might affect demand for auditing services. It is further important to realise that alternative liability laws, such as for example strict liability versus a negligence standard ${ }^{50}$, or joint and several liability versus proportionate liability 51 , may affect behaviour of auditors and auditees differently and may result in alternative resource allocations, some of which might not be socially efficient.

Note that the distinction between ex ante regulations and ex post liability as alternative policies to correct for accounting market failure can also be made in the context of

\footnotetext{
50 Strict liability can be defined as liability without fault (Black's Law Dictionary, 1990, p. 1422). Under strict liability an injurer is liable for all losses he causes to the victim (Shavell, 1987, p.8). Negligence can be defined as the failure to use such care as a reasonable prudent and careful person would use under similar circumstances (Black's Law Dictionary, 1990, p. 1032). Under a negligence rule an injurer will only be held liable for the losses that he causes if he was negligent. Negligence implies that the injurer's level of care was less than a level specified by the courts, called due care (Shavell, 1987, p.8). 51 Joint and several liability is used when there are multiple injurers and when both are responsibe together and individually. This means that the person that has been harmed can sue and recover from both wrongdoers or from either one of the wrongdoers (Black's Law Dictionary, 1990, p. 914). Proportionate liability means that a wrongdoer is only liable according to a certain rate, percentage or proportion (Black's Law Dictionary, 1990, p. 1220). See also section 4.2.3.
} 
disclosure regulation. Corporate disclosure is however mainly regulated in an ex ante way (see also exhibit 4.2 , in section 4 ).

Although current policies dealing with externality-generating activities frequently use ex ante regulation and ex post liability jointly (as in the audit case), economic analyses have very rarely recommended the complementary use of both policy types. Various authors in the economics and law literature have identified inefficiencies associated with one or the other policy52. Shavell (1984b, 1987), Posner (1986) and Kolstadt, Ulen and Johnson (1990) have suggested that ex ante regulation and ex post liability can complement each other in that their joint use can correct the inefficiencies of using either alone to correct for an externality. Shavell concludes that there may be inefficiencies in using liability liability alone, due to potential bankruptcy of injurers and the uncertainty of suit by victims. Kolstadt, Ulen and Johnson (1990) take a different approach, and prove that ex post liability alone may result in underprotection (below social optimal amount of precaution) if there is high uncertainty from the part of the injuring parties regarding the level of due care that will be adopted by the courts in case of a law suit. In that case the complementary use of ex ante regulation may correct this situation. Posner (1986) considers (ex ante) regulation as a supplement to common law (or ex post liability) where tort does not supply sufficient incentive for efficient behaviour of injurers and where potential damages for individual victims may be too small or too large to justify separate claims through the courts. In chapter 7 of this thesis it will be considered whether similar arguments hold in the audit context, in particular whether the joint use of ex ante audit regulations and ex post audit liability is justified on the grounds that they complement each other in achieving socially efficient audit production behaviour.

52 See , for example, Weitzman (1974), Baumol and Oates ( 1971), Rose-Ackerman (1973), Wittman ( 1977), Calfee and Craswell (1984), Shavell (1984a, 1984b, 1987), Posner (1986), Kolstadt, Ulen and Johnson (1990), Cooter and Ulen (1993), Ogus (1994)). 


\subsection{The relative social desirability of audit standards versus auditor liability in the audit production context}

In general, the choice between ex ante and ex post policies usually depends on the nature of the activity that is governed. Shavell (1984a) discusses a number of theoretical determinants of the relative social desirability of ex post liability versus ex ante regulation. These include: (1) the difference in knowledge about risky activities as between private parties (externality-generator or injurer), courts and a regulatory authority; (2) the likelihood of incapability of private parties to pay for the full magnitude of harm done; (3) the chance that parties would not face the threat of suit for harm done; and (4) the administrative costs incurred by private parties and the public in using the tort system or direct regulation. The first and the fourth determinant have an impact on the cost of using either system. The second and the third determinant have an impact on the private party's incentives to take care and to avoid externality-generating (or, risky) behaviour. In the remainder of this subsection all four determinants are evaluated in the audit production setting in order to provide a first qualitative analysis of the relative desirability of ex post liability versus ex ante audit standards.

Relating to the first determinant (i.e. the difference in knowledge about risky activities as between private parties, courts and a regulatory authority) considerations of economic efficiency suggest that regulation should be in the hands of the better informed, or who can become better informed at least cost, the ex post court or the ex ante regulator. In particular, if the private party and/or the court is better informed (or if it is cheaper for them to become better informed), ex post liability is favoured, whereas ex ante standards are preferred in case that the regulator is better informed. In the audit case, it appears that auditors have an informational advantage because of their expertise and their superior knowledge about client specific factors. In result, general ex ante auditing standards may be too stringent or too lax, or may be too expensive to set, and 
ex post liability is favoured. This argument could be partially overruled, in the selfregulating case where the regulatory authority is the audit profession, which has auditing expertise as well. Even where the regulator was well informed, pure ex ante standards require one level of care for all cases. This would mean that cases which caused little social harm would be over-regulated, and cases that involved large harm were under-regulated. Consequently, the information asymmetries tend to favour ex post liability.

With respect to the second determinant, Shavell states that if private parties might be incapable of paying for the full magnitude of harm done, ex ante regulation should be favoured over ex post liability. This is the case when it is highly probable that the size of the assets of the private party is smaller than the magnitude of harm (for example, in case the private party are the directors of a firm). In this instance the injurer's incentive to take care is mitigated. Shavell further states that the purchase of (mandatory or voluntary) liability insurance might mitigate or exacerbate this disincentive to take care, should it exist under ex post liability. If the insurer is able to link the premium or other terms of coverage to the injurer's precautions (risk-reducing behaviour) this moral hazard problem will be mitigated. In the audit case, arguments in favour of ex ante standards based on inability to pay for the full magnitude of harm do not generally apply, as most audit firms are partnerships ${ }^{53}$. Ex ante standards would become more important in environments where a cap on liability is allowed. In addition as audit firms cannot normally obtain full coverage for liability risk from insurance companies, and premiums are generally linked to the risk profile of the audit firm ${ }^{54}$ (for example, previous litigation) it can be expected that their incentives to take care will not be diluted under a scheme of ex post liability in the absence of ex ante standards.

\footnotetext{
${ }^{53}$ Although incorporation is allowed in the UK, most audit firms seem to prefer the partnership form of organisation.

54 Illustrative of this point is that professional indemnity insurance costs for auditors have risen sharply, due to the acceleration of litigation against auditors over the past years.
} 
Shavell's third determinant (i.e. the chance that parties would not face the threat of suit for harm done) also dilutes the incentives to take precaution and hence favours ex ante regulation, if the chance is high. Such a situation may exist when harm is widely dispersed, when it takes a long time before harm manifests itself, or when it is difficult to attribute harm to the injurer. Applied to auditing, a case for ex ante audit standards could be made, since financial statement users are a very vaguely and broadly defined category, and the causality of losses to users may be hard to trace. However, the trend over the past decades to broaden the category of third party users to whom the auditor owes a duty of care (see section 4.2.2 for a more detailed discussion) would be favourable for ex post liability. Reversal of this trend in the UK, where liability to third parties other than existing shareholders as a body was rejected in 1990 in the ruling in the Caparo case (see further), leads to the conclusion that ex ante audit standards might be preferable.

The fourth determinant discussed by Shavell, (i.e. the magnitude of administrative costs incurred by private parties and by the public in using the tort system or direct regulation), favours the least expensive system for a particular activity. In general, there is a cost advantage in favour of liability as its infrequent use limits its cost. The research and lobbying cost of setting national and international precise ex ante audit standards may be enormous. However, if the number of court cases in which auditors are involved continues to rise in the future at the same rate as it did in the past few years, and legal costs continue to rise sharply, it might be not so trivial which option is preferred from an economic perspective. 
Table 4.1: Shavell's determinants of policy choice applied to the auditing context

\section{DETERMTNANT}

Difference in knowledge about risky audit activities as between auditors, courts and regulatory authority

Inability of audit firm to pay for the full magnitude of harm

Chance that audit firms don't face the threat of suit

magnitude of administrative costs by auditors, users, auditees and the public

\section{EVALUUATION}

* informational advantage for audit firm because specialisation \& expertise * informational advantage to the profession because of expertise

* low because partnerships * insurance coverage incomplete and premium linked to risk profile of firm

* existent

* harm may be dispersed over many different users

* causality of losses to users not always clear

* Litigation wave may increase cost of using tort system;

* Research \& lobbying cost for standards will be high

\section{POLICY EAVOURED}

Ex post Liability to lesser extent: Ex ante audit standards

Ex post Liability

Ex ante Standards

Indeterminate

From the above "qualitative" discussion it seems that there are arguments in favour of both regulatory policies in the auditing context, and that the complementary use of both policies might be justified. A formal economic analysis of the joint use of ex ante and ex post policies affecting audit production will be provided in chapters 6 and 7 of this thesis. 


\subsection{Regulation of audit production: self-regulation or state regulation}

Apart from the question whether ex ante regulation or ex post liability or both should be used to correct for audit market failure, the question arises who is to set ex ante regulations in the audit production context, if it is to be adopted: the audit profession or the state. With a self-regulatory process, the risk of regulatory capture is generally perceived as much greater. Researchers in the critical accounting area have commented on the flaws in self-regulation by the profession and have criticised the profession's 'monopolistic' regulatory power. Without going into the details of this literature, a popular accusation at the address of the profession is that self-regulation is used for 'impression management' (see, amongst others, Neu (1991), Byington \& Sutton (1990)). In this context audit standards are perceived to be used to project an image of professional quality, but are not set at a level that is congruent with the expectations of third parties. The prevalence of settlements of negligence claims out of court, such that the quality standards issued by the profession cannot be fully tested, is used in support of this argument.

Of particular interest is a study in the critical accounting area by Fogarty et al. (1991), in which the litigation crisis is perceived to be institutional in nature, and therefore not remediable within current social arrangements. In this study succesful legal actions against auditors are seen as a result of the partially institutionalised environment in which the public accountancy profession functions. Public accounting is expected to serve the public interest, but at the same time it exists on an operational level which is ruled by short term profit maximising. Legal losses and suits can be understood as an immediate consequence of the contradictions implicit in acting on these two levels. Therefore, if public accountancy would act to reduce their malpractice exposure, it would only do so to the extent that the alterations necessary did not contradict the economic reality that defines the operational level. 
Fearnley and Page (1993) list some arguments in favour of self-regulation derived from interviews with UK advocates of self-regulation. The validity of these arguments is, of course, not proved. They include: 1) flexibility, 2) sensitivity, 3) practioner commitment, 4) legitimacy, and 5) economy. Self-regulation is alleged to be more flexible, since statutory codes require more time and delays in altering them may hamper state systems. Self-regulatory systems may also be more sensitive to outside interest groups. This argument lacks, however, rational support if self-regulation does not provide valuable advantages to the professional body or its members that they would not wish to lose by acting in a self-interested manner. Auditors may also be more committed to the success of a system that is devised by their representatives. Two more arguments were listed that coincide with two of Shavell's determinants. First, professionals are acknowledged experts in their subject, and second, self-regulation is 'supposed' to be cheaper.

A model providing a theoretical framework to explain the dynamics of the choice between self-regulation and state regulation is provided by Gaa (1991). The author reviews the 'expectations controversy' over the social role of auditors in the US and concludes therefrom that self-regulation by the profession increased over the years ${ }^{55}$, whereas state regulation appeared to remain at a status quo level. The expectations controversy is modelled as a two-person non-cooperative sequential game between representatives of the public accounting profession and representatives of society at large (i.e. regulators and legislators). Each player must make a rational choice from a number of strategies available to it, given the rational choice of the other player. The profession must decide on the level of regulation it will impose on its members; this can

\footnotetext{
55 Supportive of this conclusion is for example the issuance, in 1988, by the Auditing Practice Board of the AICPA of nine Auditing Standards in response of the Dingell Committee's investigation. The Dingell Committee was formed in 1985 to invest the quality of financial reporting in the US, in response to a number of prominent business failures.
} 
be to keep self-regulation status quo, to increase it or to decrease it. The representatives of society must choose a level of government regulation, and again three options are available (namely: status quo, increase and decrease). Preference orderings for the strategies of each players are assumed, based on an analysis of recent self-regulatory behaviour of the profession and government regulation. The nature of a sequential game also includes the possibility that the players have threat strategies available to them. The outcome of the game is an agreement concerning the social responsibilities of auditors. A major conclusion of Gaa's analysis is that the actual outcome of the controversy in the US coincides with a game where less self-regulation is not a feasible strategy for the profession (for example, because of public pressure by a congressional committee). It is shown that in such a situation both the profession and a captured ${ }^{56}$ regulator have a threat strategy available. Implementation of the regulator's threat, followed by a rational reaction by the profession results in an increase in professional self-regulation and retention of the status quo level of government regulation. The result is a modest increase in social welfare, with a relatively large decrease in the profession's welfare.

\section{Policies affecting the audit environment}

An analysis of current regulations and laws affecting the audit market reveals that public policymakers have chosen for the joint use of both ex ante and ex post policies to control for externalities deriving from financial statement defects. Both auditees (i.e. firm's management) and external auditors are subject to forms of ex ante regulations and ex post liability. This implies that policies have been adopted that affect both audit

\footnotetext{
$56 \mathrm{Gaa}$ supports the assumption that state regulators are captured and favour that the profession regulates itself. The rationale is that one of the effects of having a profession regulate itself is to decrease the probability that the state regulators will be held directly responsible for audit failures. A captured regulator would therefore more closely follow the preference of the profession for less government regulation.
} 
demand and production. Table 4.2 gives a simplified overview of ex ante regulations and liability doctrines that are typically applied in the audit context. Note that the overview is general in nature, and does not intend to be descriptive of the situation in one particular country. Note also that changes in liability rules are being proposed in several countries at the moment, in response to the audit litigation wave (see also subsection 4.2.3). 
Table 4.2: Parties affected by ex ante regulation and ex post liability in the audit context.

\begin{tabular}{ll} 
PARTY & EX ANTE REgUlation \\
\hline CORPORATE MANAGEMENT, & *Financial reporting and \\
I.E. AUDITE & $\begin{array}{l}\text { disclosure regulations } \\
\text { (policies affecting audit demand) }\end{array}$ \\
(beyond the scope of this thesis):
\end{tabular}

* For some categories of firms: Statutory audit requirement by an independent and as such qualified auditor to attest the accounting information provided by management.

\section{EX POST LIABULITY}

* Liability of directors to third parties, since auditee and auditor are "jointly and severally" liable to third parties for losses from defective audited financial statements

* In case of an action brought against auditors, the external auditor may call for apportionment of damage with the auditee.

* the auditee is not strictly liable, but has a duty of care in preparing financial statements.

EXTERNAL AUDITOR (policies affecting audit production and supply)

* Regulated profession: -licensing; registration

* Professional audit standards (state regulation or selfregulatory profession)
* Liability of the auditor to third parties, since the auditor and the auditee are jointly and severally liable for harm to third party users due to defective audited financial statements,

* contractual liability towards auditees (i.e. clients)

* liability to auditees and third parties is subject to a negligence rule: "due care"; with the defense of contributory negligence 


\subsection{Policies affecting external audit demand 57}

Financial reporting and disclosure regulations (for example, accounting and disclosure standards) and statutory audit requirements are forms of ex ante regulations which affect audit demand. As the producer of financial statements, the auditee is first of all subject to disclosure regulation, which tends to be fairly specific in nature. As auditors enforce disclosure regulations through the reporting of non-compliance, the complexity of the former will have an impact on audit demand and production (see, for example, Wallace, 1980). This is however beyond the scope of this thesis.

The enforcement of disclosure regulation is also regulated in an ex ante way in most countries, as the external audit of financial statements is a statutory requirement for certain classes of business organisations, although differences exist between countries as to the nature and size of those organisations. For example, in the UK such regulation applies to the majority of registered limited liability companies, whereas in the US it normally applies to only those companies registered with the SEC. These requirements will necessarily have an impact on audit demand.

An ex post policy that might affect audit demand is the liability of directors towards third party users of financial statements for losses to third parties resulting from defective audited financial statements. This results from the joint and several liability doctrine and from the fact that auditors and directors are - at least in theory - considered as joint tort-feasers. In the U.S. both the directors' and the external auditors' liability is in place by statute. Section 11(f) of the Securities Act of 1933 and Section 18(b) of the Securities Act of 1934 provide for joint and several liability of auditees and external auditors to financial statement users for losses attributable to defects in the audited

\footnotetext{
57 Or alternatively, policies for correcting externality generating financial reporting behaviour by directors (see also section 3.2)
} 
financial statements. In the UK Sections 227-230, 239 and 245 of the Companies Act 1985 make the directors individually and collectively responsible for the provision of accounts showing a true and fair view. Since third party actions in the UK lie in tort, it is open to the third party users to litigate against either the directors or the auditors for the full amount of the damage incurred. In both the US and the UK, the entire amount of damages suffered by a third party can be collected from any person liable, with that person retaining rights to recover a contribution from all other persons liable for the same damage. This is called apportionment of damages.

Note however that directors are not strictly liable for losses suffered by third parties, but have a 'duty of care' in preparing the accounts (for a definition see footnote 9). Gwilliam (1988), however, states that the UK courts have traditionally been reluctant to make the duties of the directors too rigorous, and that it is therefore not clear how Section 245 of the Companies Act 1985 would be interpreted. Although the directors of a company may be argued to act as guarantors of truth and faireness of the financial statements, it is equally arguable that courts may be reluctant to hold a directors who signed a set of accounts which had been prepared by qualified accountants of good reputation liable for failure of those accounts to show a true and fair view.

In today's litigation crisis, joint and several liability of directors and auditors is often considered as problematic by the audit industry, claiming that auditors are often taken to court because they are perceived to have 'deep pockets'. Some reactions by the profession in this context are discussed in section 4.2.3. 


\subsection{Policies affecting audit supply and production 58}

\subsubsection{Ex ante regulations}

Audit supply is regulated in an ex ante way, as the classes of persons who can offer the statutory audit service are restricted through occupational licensing. In the US only certified public accountants can offer the independent audit service, whereas in the UK only registered ${ }^{59}$ auditors can.

Another form of ex ante regulation which affects audit production is self-regulation of audit practice by the profession through the issuance of audit standards. Over the years, the profession has developed a number of auditing standards and guidelines which aim to provide an aid to auditors in fulfilling their professional responsibilities and include considerations of professional qualities (competence and independence), reporting requirements and evidence (Arens and Loebbecke (1984)). Auditing standards tend however - as opposed to accounting standards - to be very general in the sense of stressing objectives rather than a means of reaching those objectives (Wallace (1980)). As a result, their power as a legal defense of "due care" in litigation is uncertain.

Self-regulation by the profession is a process much favoured by the UK government, as the APB has no formal state recognition in the UK (Fearnley and Page (1993)). In the US, the SEC has some power to influence the profession's own regulations. It does not, however, explicitly have legal responsibility to promulgate auditing standards or standards of professional conduct. This is unlike the SEC's responsibility for the

\footnotetext{
58 Or alternatively: policies correcting for externality generating audit behaviour (see also section 3.2).

${ }^{59}$ Registration of auditors in the UK was only introduced in 1989 by the Companies Act 1989, as a result of the implementing the Eight Directive of the EC. A "Registered" Auditor is an auditor who is registered with one of the following five bodies: the three chartered accountancy institutes covering the UK, The Chartered Association of Certified Acountants, and the Association of Authorised Public Accountants.
} 
promulgation of accounting principles which is explicitly stated, but which it has delegated to the Financial Accounting Standards Board (Gaa, 1991)). Some authors, however (see , for example, Arens and Loebbecke (1984)), state that the SEC retains considerable influence in setting professional standards.

\subsubsection{Ex Post policies: Auditor liability}

As the legal liability risk of auditors is of crucial importance for much of the analysis in the second part of this thesis, this issue is discussed in some more detail. The acceleration of litigation against auditors over the past decades and especially the past few years, and uncertainty regarding the scope and nature of the auditor's legal liability has resulted in a substantial body of audit literature analysing the auditor's professional responsibilities ${ }^{60}$. Although auditors may be found to have been criminally liable under some circumstances, the major focus of research in this area has been on their civil liability, and the latter is the only concern in this analysis ${ }^{61}$. In principle, the auditor can only be found liable if he has been acting in a negligent manner. In this context two important questions require some further comment (Gwilliam, 1987a, p. 134): first, what is negligent auditing (under which circumstances will the auditor be held liable), and second, to whom does the auditor owe a duty of care not to act in a negligent manner.

\footnotetext{
${ }^{60}$ For recent discussions of the evolution of the auditor's professional liability over time through analysis of case-law and/or statutory law in the UK and Commonwealth see, for example: Pound \& Courtis (1980), Davison (1982) Gwilliam (1987a, 1987b, 1988a, 1988b, 1991, 1992, 1994), Godsell (1993), Chua (1993). For discussions of the evolution of liability over time through analysis of case-law and/or statutory law in the US see, for example: Davies (1979), Schultz \& Pany (1980), Largay \& Paul (1983), Minow (1984), Brecht (1988). For empirical research regarding factors associated with lawsuits in the US see, for example: St Pierre \& Anderson (1984), Palmrose (1987, 1988, 1991), Stice (1991).

61 The reason is that criminal actions against auditors are rare, and our primary concern is with his liability to reimburse financial statement users for monetary losses due to audit failure, which is governed by the auditor's civil liability.
} 
Related to the first question, the auditor is expected to carry out his audits with 'reasonable care and skill'. A general definition of what this exactly embodies is difficult to provide and the courts have the final jurisdiction over what is and what is not the exercise of reasonable care and skill. As every court case brought against auditors is different, uncertainty exists about the exact content of the negligence standard a court will use in its judgement. Moreover, there is little 'hard' case law covering wide aspects of audit activity, the reason being that a relatively small number of cases relating to audit matters are fully contested through the courts. This is especially true in European countries, but to a lesser extent in the U.S. and Australia where there is a significant body of recent case law. In addition, the applied court standards tend to change as expectations and responsibilites change over time.

After the examination of legal evidence, Gwilliam (1987a, p. 157) formulates the following important conclusion:

..although compliance with professional standards is an important factor in determining what constitutes reasonable care and skill (and is more likely to act as a complete defense to allegations of negligence in the UK than in US courts) in some areas (, for example, duties in regard to fraud and appraisal of internal control) courts generally expect more to be done by the auditor than is currently stated or implied by professional standards (emphasis added)."

Professional audit standards, thus, although they may be seen as a 'weak' form of an ex ante regulatory policy, appear to be used today as a complement to the existing ex post liability. From Gwilliam's analysis it can be derived that the level of audit quality implied by audit standards is set below the legally required level.

With respect to the second question, i.e. to whom does the auditor owe a duty of care, the auditor has, in first instance, a contractual relationship with his client (the auditee), 
and is liable for losses resulting from negligent auditing. Lack of privity of contract ${ }^{62}$ has been a defence for auditors against third party claims for many years. The scope of the auditor's liability has however broadened over the years to include third parties. Gwilliam (1987a, 1987b), for example, identified a long-term trend in judicial reasoning in the UK and the Commonwealth expanding the auditor's duty to (1) specific third parties known to be relying on the statements, to (2) limited classes of third parties known to be relying on the statements, to (3) third parties whose future reliance can be reasonably foreseen as a consequence of their dealing with the client. Brecht (1988), after analysing judicial reasoning in precedent-setting US cases deciding duty of care to third parties, concludes that there has been a comparable expansion of the auditor's duty of care to 'foreseen' third parties. The trend of expanding the scope of the auditor's liability in the UK was reversed in 1990 by the House of Lord's judgement in the Caparo $^{63}$ case. The ruling was that the auditors owed a duty of care only to directors and shareholders as a body, but not to individual shareholders or other users of accounts, such as for example prospective shareholders. In the US, however, a similar ruling that restricts the categories of claimants does not exist.

Some subsequent differences in the UK and US legal environments, are that in the UK, actions brought by third parties against auditors are torts, and hence the auditor's liability to third parties is essentially a matter of common law ${ }^{64}$. In the US the situation is more complex, as the auditor's liability for harm to third parties was established by

\footnotetext{
62 Privity of contract refers to a direct relationship between two or more parties to a contract. In the audit context, the client and any third party that is named in the engagement letter have privity of contract (Arens \& Loebbecke (1984, p. 106).

${ }^{63}$ Caparo Industries vs Dickman (1990) was a case in which the plaintiffs claimed to have relied on audited financial statements in their decision to acquire the company. The ruling in this case was that the auditor has no responsibility towards the plaintiffs in their roles of prospective investors in the company.

${ }^{64}$ Laws that have been developed through court decisions rather than through government statutes.
} 
statutory law ${ }^{65}$ in the 1934 Securities act, although the option for recourse to common law is also available ( a substantial number of court cases against auditors are a question of common law).

One way for the auditor to attempt to alleviate the burden of expanded liability scope is to seek for apportionment with either their clients or third parties by application of the tenets of contributory negligence ${ }^{66}$. The defense is, however, with the auditor who has to demonstrate that his client or a third party plaintiff has been acting negligently and that this negligence has been a direct cause of the loss he suffered.

A final consideration regarding the auditor's expanded liability scope relates to the extent to which courts balance public policies to protect the public interest by providing remedy with public policies protecting the audit profession's capacity to serve the public. Davies (1979) describes the evolution of common law from the privity of contract doctrine towards more liberal doctrines of third party liability as a process of implementing a 'deep pocket theory' of liability placement. He states that various courts' interpretations have often been influenced by individual fact findings and the degree of auditor's liability that would be socially and economically tolerable at that time. Reversal of the trend of expanding the role of the auditor in the UK by the ruling in Caparo, could be seen as legislation against the deep pocket theory of liability placement. Also, the lobbies by the audit industry to reform liability law in the US,

${ }^{65}$ Laws that has been passed by a country's legislative governmental body.

${ }^{66}$ Contributory negligence can be defined as the conduct by a plaintiff which is below the standard to which he is legally required to conform for his own protection and which is a contributing cause which cooperates with the negligence of the defendant in causing the plaintiff's harm (Black's Law Dictionary, 1990, p.1033). In the UK the statute applicable in this instance is the Law Reform (Contributory Negligence) Act of 1945; In the US statutes regarding contributory negligence are a matter of state law, but this tenet is accepted in almost all states. 
Australia and the UK in response to what is often called 'the litigation crisis', can be interpreted in this way.

\subsubsection{The audit industry's response to the litigation crisis}

The audit and accounting profession is currently dealing with a litigation crisis ${ }^{67}$. This crisis is most profound in the US. Today, the total amount of open claims against accounting and audit firms in the US is estimated at $\$ 30 \mathrm{bn}$, compared to $\$ 15 \mathrm{bn}$ in 1992. Outside the US, Australian accountants appear to be most heavily exposed to litigation, but accountancy firms in at least 50 countries have experienced one or more claims over the past few years. In Europe, the British accounting industry seems to be most prone to law suits. The biggest single suit to date - worldwide - is located in the UK, where Price Waterhouse and Ernst \& Whinney (now part of Ernst \& Young) face an $\$ 11$ bn writ in connection with their audit of the collapsed Bank of Credit and Commerce International. Claims against accounting firms have also spread across continental Europe, even in countries with no Anglo-Saxon law tradition, such as for example, France.

In the US, Australia and recently also in the UK, efforts to bring about law reforms emerged, with lobbies developed to appeal for changes in liability laws. As part of a wider tort reform, a Bill to replace 'joint and several' liability into 'proportional' liability has been proposed in America's House of Representatives. Under the existing system of 'joint and several' liability every defendent is liable for up to $100 \%$ of the value of a claim, no matter how limited its role. In such a situation, it might be that accountants are taken to court because they are perceived to have 'deep pockets', relative to failing

${ }^{67}$ The litigation crisis received considerable attention in the Financial and Economic press. A review of the press forms the basis of the conclusions in this subsection. 
companies. Under a 'proportionate' liability rule, claims against defendants would be in proportion to their degree of responsibility. To deter opportunistic litigation, the House Bill also introduced a provision for the recovery of legal costs by defendants from the plaintiffs if the former win the case. Note that a similar practice has always been followed in the UK.

In Australia, proposals to introduce a cap on auditor liability were submitted but foundered twice. However, a change in the law to proportionate liability is under consideration. In the UK, reactions have lagged behind. In early 1994 Britain's eight largest accounting firms launched a campaign to bring about some law reforms ${ }^{68}$. Two major suggestions are to allow contractual capping of auditor liability and to make insurance for directors compulsory. The first suggestion would require an amendment of Section 310 of the Companies Act 1985, which currently forbids auditors to limit their liability by contract. A minimum limit on liability in an audit contract of at least 10 times the audit fee and not below $£ 50,000$ for a sole practioner and $£ 100,000$ for other professionals is suggested. Compulsory insurance for directors and officers of companies is proposed to ensure that these have assets worth pursuing through litigation, rather than accountants being the sole target for redress because they have deep pockets.

Other options were considered, but dismissed. First, unlike in the US and Australia, a reform of joint and several liability to proportionate liability is not envisaged. The argument is that this would require a fundamental change on a principle which most parties consider equitable, and would hence prejudice other more likely proposals.Second, the introduction of a statutory cap on liability was considered but not further sustained. Such a cap already exists in Germany, but it is considered to be too

\footnotetext{
68 See, Gough, B., Whithe R., and I. Brindle (eds.), News Release: Reforms of Auditors' Liability, London, February 1994.
} 
difficult to convince governments that capping is necessary and equitable. Reference was made to the Australian case, where such a proposal was foundered twice.

\section{Conclusion}

Since the 1970s, economic rationalisations in the public interest tradition for regulation of disclosure of financial information have been on the research agenda of the economic oriented accounting literature. A whole literature emerged discussing arguments for and against 'accounting' regulation. Striking is that the focus of this research has been mainly on discussing rationales for 'ex ante' policies of government control, and that little attention has been directed towards the question of how audit demand and production are optimally governed. Applied welfare economics and externality theory offer a viable framework for analysing economic impacts of audit regulations and liability. An economic rationale for policies that affect both audit demand and production is that the production of audited financial information is an externality generating activity. As such, both directors and external auditors are considered to be jointly responsible for hazards. Two alternative policies for controlling hazards are discussed in the economic literature on optimal policy choice: ex ante regulation and ex post liability. In this chapter, policy instruments of either type that affect audit demand and production were identified and discussed. On the audit demand side, statutory audit requirements can be seen as an ex ante policy to control hazardous behaviour of directors, and liability provisions applying to directors as an ex post policy. On the production side, professional audit standards were identified as an ex ante policy to monitor externality generating behaviour of auditors and liability provisions applying to auditors as an ex post policy. 
It is clear that ex post policies cannot be ignored as a public policy instrument in the audit context, and that liability law clearly affects the behaviour of the parties involved. Supportive of this argument is, for example, that the provision of 'joint and several liability' of auditors and directors has been recently under much scrutiny in accounting circles. Audit lobbies have identified this provision as a major reason why the audit profession faces a litigation crisis. Some parties claim that current liability provisions may well be an explicator of 'deep pocket' demand for external audit services. It is also likely that the auditor's production behaviour is influenced by serious threat of litigation. In the remaining chapters of this thesis, three major questions will be formally addressed in a partial equilibrium setting. First, in chapter 5 , it will be analysed under which circumstances, and given the liability framework in which audit demand and production take place, the deep pocket hypothesis of audit demand can be sustained. Second, in chapter 6, the impact of alternative policies (combining ex ante regulation and ex post liability) on audit production will be analysed. And third, it will be investigated whether the joint use of ex ante audit standards and ex post liability affecting audit production is socially efficient, and whether restriction of auditor liability (for example, proportionate liability) is socially efficient. 
Part II 


\section{Chapter 5}

\section{Audit Demand, Liability and the Statutory audit requirement}

\section{Introduction}

A rationale to purchase external auditing is that it may provide firms and its management with (some) insurance against future liability to third party users of audited financial statements. The insurance hypothesis of external auditing has often been put forward as a rationale for external audit demand (see also chapter 3), but has not been subject to formal analysis. This chapter provides a micro-economic analysis of insurance demand for external audit services. The legal environment in which firms make their external audit quality decision is taken into account (see also chapter 4, section 4.1 for a discussion). The approach taken is that firms and their management want to control their legal exposure to third party users of financial statements by acquiring an optimal mix of internal control and external audit services. It is assumed that auditees and external auditors are jointly liable for defects in the financial statements, and that their respective liability is subject to a standard of negligence, which holds for the situation in the UK and the US. The problem is modelled in a leader-follower framework, where the auditees are the central actor or the leader who conjecture the certified auditor's (who is the follower) production behaviour, before making a decision on demand. Directors thus, not only take the liability rules into account which apply to them, but also the liability rules which apply to the external auditors.

This chapter first introduces a free-contracting model of demand, where the auditee is free to contract for external audit services with an external auditor. A free-contracting world is assumed in sections 2,3 and 4 . The impact of ex ante regulation, i.e. of a 
statutory audit requirement, on demand for external audit services and on the financial statement quality is then examined in section 5.

The free contracting model (sections 2, 3 and 4) can be seen as an extension to Ball's (1989) approach, based on Coase (1937) that the firm's economic function is to minimize contracting costs. Ball (1989), however, ignores the coercive role of the political process (i.e. legislation, regulation,...) in his contracting theory approach towards accounting and auditing. Throughout this chapter the focus is on the impact of liability on audit demand; and in section 5 the impact of ex ante regulation (a statutory audit requirement) is analysed.

According to Coase (1937), the firm is a specialist contracting intermediary, intermediating between consumers and suppliers of factors of production, exploiting economies of scale in repetitive contracting by centralizing contracting in one institution. Ball (1989) states that accounting and auditing can be seen as components of firms' efficient contracting technologies. Accounting is viewed as a specialist function for providing information that assists firms in establishing their quasi-prices, or even providing the quasi-prices themselves (see also chapter 3 , section 2 ). Since payoffs are not specified ex ante, functional completion of accounting based contracts is necessary to establish ex post quasi prices, and this involves a form of adjudication. In Ball's (1989) model auditing is viewed as a specialist adjudication function for completing contracts whose payoffs have been defined in terms of accounting numbers. In this sense, internal and external auditing both have similar roles, although they have different institutional roles. Internal accounting techniques might not all be 'efficiently' specified ex ante, which might create a demand for an independent adjudicator.

Functional completion of contracts both in firms and in markets is a normal method of completing the contractual mapping from states to payoffs. Auditing is not the only 
mechanism available to firms for functional completion. Functional completion can be done by enumeration - ex ante - and/or by (some) function. However, the cost of completing contracts is assumed to be large and the prevalence of a variety of institutional mechanisms for this purpose suggests that completion by enumeration is deficient. Ball (1989) lists a variety of institutional mechanisms by which market contracts provide for "functional completion". These include: 1) negotiation between the contracting parties (implicit and explicit rules accepted by both contracting parties); 2) the law of contract (in its common law sense, that is ignoring the political process) which is presumably more efficient than identifying all possible states and specifying all payoffs at the time of entering the contract; 3) common law (and legal precedent) which is seen as an efficient method of determining payoffs in a subset of states for which payoffs have not been unambiguously defined ex ante.

The model proposed in sections 2, 3 and 4 of this chapter, assumes that the firm has the choice between internal and external auditing, or a mixture, for functional completion of its accounting based contracts, and that it will choose the most cost-efficient combination. It differs partially from Ball's approach in the sense that (at least some) functional completion by way of common law is assumed to be inherent to the setting in which the firm makes its decision. By this it is meant that - no matter what combination of internal and external auditing the firm chooses - there will always be some functional completion by common law. The reason is that the laws predicts that firms (management) are liable for errors in the financial statements. The model, thus, incorporates the constraint that the legal environment poses on the firm's decision, whereas Ball ignores the coercive role of the political process in his analysis.

The major objectives of this chapter are: 1) to analyse how liability of directors and external auditors affects demand for overall financial statement quality, internal audit quality and external audit quality; 2) to examine the impact of uncertainty about the 
respective due care levels of directors and external auditors on the directors' demand decision; and 3) to address the question whether statutory audit requirements are an effective complementory policy to monitor the produced level of overall financial statement quality (both when due care levels are certain and uncertain).

The structure of the chapter is as follows. In section 2 the definitions and assumptions underlying the analysis are discussed. In the subsequent two sections compliance with legal standards of care by directors and auditors is examined, as well as the impact of liability on the level of quality demanded. The simple case where the legal quality standards are ex ante certain is first examined in section 3 . In section 4 the effects of uncertainty about the legal standards are analysed. In section 5 it is investigated whether statutory audit requirements are an effective policy instrument to increase the level of overall financial statement quality produced. Conclusions are given in section 6.

\section{Definitions and assumptions}

The approach taken in this chapter is that top management (i.e. the directors) of firms wants to control its legal exposure (litigation risk) to third party users of financial statements ${ }^{69}$. The threat of suit, thus, causes the directors of firms to internalise expected third party losses and hence to take optimal precaution against the occurrence of damage payments to financial statement users. Precaution in this context means that directors want to exhibit 'reasonable care and skill' in the design of their external financial reporting system, such that they are not found negligent if users litigate against

\footnotetext{
${ }^{69}$ A similar approach can also be found in Simunic's $(1980,1984)$ audit fee determination model, where it is hypothesised that the potential legal liability of auditees and auditors drives the design of external financial reporting systems. Simunic's model however does not explicitly takes into account the liability rules applying to auditees (or firm's management) and auditors.
} 
them. To take adequate precaution, it is assumed that directors have the choice between two distinct types of control procedures. First, they can acquire internal control or audit services of a certain quantity and quality which are performed by the internal audit department of the company. Second, they can acquire external audit services of a certain quantity and quality from independent certified public accountants. Both types of auditing services contribute to precaution, but at different cost. By contracting for external audit services of a specified quality, directors can shift a part of the liability burden to certified public accountants. In this setting, internal and external auditing services can be seen both as complements and as substitutes. They are substitutes to some extent, because they both contribute to improving the quality of the financial reporting system, and hence precaution (at different cost); they are also complements because the external audit service may provide (some) liability insurance against litigation losses. Note that not only the directors want to monitor their legal exposure; since certified auditors may also be held liable if they are found to be negligent, they also want to take sufficient precaution. As the focus in this chapter is predominantly on the directors' behaviour, the precautionary behaviour of the certified auditor will be looked at from their perspective. However, the analyses of external audit production behaviour could stand on their own ${ }^{70}$.

It is assumed that directors and external auditors are risk neutral and expected utility maximisers. The directors' utility is defined in terms of total expected costs and the external auditors' utility is defined in terms of auditor profit. Joint and several liability of directors and external auditors for losses to third party users is assumed, which corresponds with the situation in the US and the UK. It is also assumed that directors think that the financial statement users will always litigate against directors and/or external auditors if they suffer losses. They further think that, when third parties litigate

\footnotetext{
${ }^{70}$ The external auditor's audit quality production decision is analysed in detail in chapters 6 and 7 .
} 
against only one party and this party is found liable by the courts, it will seek for apportionment of damage payments with the other party. Furthermore, the users are either fully compensated or not compensated at all for losses that they have incurred, or in other words, it is assumed that users will not be contributory negligent. The court's standard of reasonable care and skill for the directors is here defined in terms of overall financial statement quality; whereas the court's standard of reasonable care and skill for the auditor is defined in terms of external audit quality. The problem is modelled as a leader-follower problem ${ }^{71}$, where the directors are the central actor or the leader who conjecture the certified auditor's (who is the follower) audit quality production behaviour and the uncertainty about the due external audit quality standard.

A further assumption is that internal and external auditing is a contract monitoring device to control for accidental error in the financial statements. This implies that there is no agency problem between managers and shareholders, or that the directors' actions are congruent with the shareholders' desires. If this were not the case, contract monitoring between shareholders and managers would have to allow for detection of deliberate error (for example, fraud). Since the focus is on harmful actions of directors/firms (and hence liability) towards third parties, contract monitoring between the firm and its third parties is envisaged, and accidental errors are assumed.

\footnotetext{
71 This is an application of using backward induction to solve an optimisation problem. In microeconomic theory, the Stackelberg model is an application of backward induction. In the Stackelberg model ( von Stackelberg (1934), and discussed in various micro-economic textbooks, see, for example Varian (1984)) a sequential approach is adopted to analyse the quantity decisions by firms operating in an oligopoly and where there is quantity leadership. The assumption is that one firm chooses its quantity first, or is the quantity leader, and another firm is a quantity follower. The quantity leader conjectures the quantity decision of the follower, given alternative levels of quantity supplied by the leader.
} 


\subsection{Modelling the directors}

It is hypothesised that the quality of a firm's financial reporting system, and hence the quality of the financial statements, is described by the ordered pair $\left(q_{1}, q_{2}\right)$, where $q_{1}$ is internal control or audit quality and $q_{2}$ is external audit quality. It is assumed that demand of internal and external audit quality by directors is not regulated in an ex ante way. This implies that the mix of $q_{1}$ and $q_{2}$ is voluntary and entirely to the director's discretion. A further assumption is that the level of internal audit quality that is demanded by the directors equals the level that will actually be produced by the internal audit department of the firm.

In most countries however, external audit demand is regulated in an ex ante way by statutory audit requirements. This situation could be included in the model by imposing a constraint on the directors optimisation problem, i.e. $q_{2} \geq q_{r}$, where $q_{r}$ is the level of external audit quality implied by a statutory audit requirement. The effect of such a lower bound on the choice of $\mathrm{q}_{2}$ is examined in in subsection 3.3 when due care levels are certain. In section 5 the effect of a statutory audit requirement is examined when due care levels are uncertain.

In the event of litigation against directors the courts will reveal the legally required level of 'reasonable care and skill' that applies to the directors, which is defined here as the minimum due level of overall financial statement quality ${ }^{72}$, denoted by $Q_{c}$. The directors will be held liable - ex post - if the financial statement quality level that is actually demanded is below $Q_{c}$. Note that $Q_{c}$ is unknown at the time that they have to make the decision as to the mix of $q_{1}$ and $q_{2}$. Since $Q_{c}$ is ex ante uncertain, it is defined as a random variable about which the directors have some subjective beliefs. Let $f\left(q_{1}\right.$,

\footnotetext{
72 In jurisdictions where directors are strictly liable for losses to users, and where no negligence standard exists, the minimum due level of financial statement quality, $Q_{c}$, would take the value $+\infty$.
} 
$q_{2} ; Q_{c}$ ) be the subjective probability distribution of the directors that the court will judge that $\left(q_{1}, q_{2}\right)$ is sufficient to guarantee the minimum quality norm $Q_{c}$.

The total expected cost of the liability control system for the directors is the sum of the financial efforts allocated to internal auditing and external auditing plus the firm's expected liability payments (see section 2.3 and table 5.1 for details). Expected liability payments are defined by the expected losses, denoted by $L$, to financial statement users from defects in those statements times the probability that the directors will be held liable. The directors will choose $q_{1}$ and $q_{2}$ such that the total expected liability control cost is minimised. A cost minimising system is described by the ordered pair $\left(q_{1}{ }^{*}, q_{2}{ }^{*}\right)$. The corresponding level of overall financial statement quality demanded by $Q^{*}$.

\subsection{Modelling the external auditor}

In order to complete their optimisation problem, the directors need to capture the external auditor's quality production behaviour and therefore to specify the external auditor's reaction function. Given the level of $q_{2}$ demanded by the directors, the external auditor has to decide upon the level of external audit quality that he will actually produce, which is denoted by $q$. In the event of litigation external auditors are only held liable if they did not perform the audit job with reasonable care and skill, or in other words, the external auditor's liability is subject to a negligence standard. The legally required level of due auditor diligence is here defined in terms of external audit quality, and equals the external audit quality level $q_{2}$ demanded by the directors. The external auditor will only be held liable if the court's assessment of the audit quality level as produced by the auditor is below its assessment of the level demanded by the directors. Although the external auditor knows the level $q_{2}$ that is demanded, he is ex ante uncertain about the court's evaluation of legal evidence he will provide in support of sufficient quality provision. Since the directors are treated as the central actor in this 
chapter, they have to capture this uncertainty in the decision process of the external auditor. Let $g\left(q ; q_{2}\right)$ be the subjective probability distribution that the courts will judge that $q$ is sufficient to guarantee the demanded audit quality norm $q_{2}$, as conjectured by the directors.

The total expected cost of producing a level of audit quality $q$ for the external auditor is equal to the sum of the financial effort allocated to the audit job and the external auditor's expected liability payments to financial statement users (see section 2.3 and table 1 for details). The latter are the product of expected losses $L$ to users from defects in audited financial statements and the probability that the external auditor will be held liable in the event of litigation. The external auditor will choose $q$ such that his profit is maximised. The external auditor's profit equals the audit fee minus the total expected cost of producing a level of audit quality $q$. It is assumed that the audit fee is exogenous to the auditor's decision problem. The corresponding optimal audit quality level produced by the external auditor is denoted by $q^{*}$.

\subsection{Costs, losses and objective functions}

Table 5.1 gives an overview of how losses to third party users will be distributed over directors and external auditors (in the form of liability payments), and to users (in the form of losses that are not compensated) in legal systems, such as in the US and the $\mathrm{UK}$, where the liability of directors and external auditors is subject to a standard of negligence and where auditors and directors are jointly liable for losses to third parties for defects in financial statements and where each party can call for apportionment of damage payments with the other liable party. The objective function of the directors, given that they are uncertain about the financial reporting quality norm, $\mathrm{Q}_{c}$, is: 


$$
C_{1}\left(q_{1}\right)+C_{2}\left(q_{2}\right)+L \cdot\left[1-f\left(q_{1}, q_{2} ; Q_{c}\right)\right] .\left[s_{1}+s_{2} \cdot g\left(q^{*} ; q_{2}\right)\right]
$$

The first two terms are direct audit quality costs, where $C_{i}\left(q_{i}\right)$ stands for the cost to the directors to acquire an audit quality $q_{i}$. The index $i=1$ [resp. $i=2$ ] refers to internal audit [resp. external audit]. By assumption, $C_{i}\left(q_{i}\right)$ is convex and increasing in $q_{i}$. The third term expresses the expected damage payments for the directors (see table 1 for details). Note that the losses, $L$, are assumed to be constant. Further, $s_{I}$ is the liability payment sharing ratio when both directors and external auditors are judged to have been negligent and liable; it represents the fraction of the expected damage payments $L$ to be paid by the directors; $s_{2}=1-s_{1}$ represents the fraction to be paid by the external auditor. Finally, the variable $q^{*}$ denotes the audit quality produced by the external auditor. The value $q^{*}$ is obtained from minimising the external auditor's objective function which is

$$
C(q)-C_{2}\left(q_{2}\right)+L \cdot\left[1-g\left(q ; q_{2}\right)\right] \cdot\left[s_{2}+s_{1} \cdot f\left(q_{1}, q_{2} ; Q_{c}\right)\right]
$$

$C(q)$ stands for the cost to external auditor to produce an external audit quality level q. By assumption, $C(q)$ is convex and increasing in $q$. The third term expresses the expected liability payments for the external auditor (see table 1 for details). Note that it is assumed that the produced level of external audit quality $q$ is the only variable that the external auditor is able manipulate, since his fee $\left[C_{2}\left(q_{2}\right)\right]$ is negotiated before he performs the actual job. The external auditor's objective can hence be reduced to minimising

$$
C(q)+L \cdot\left[1-g\left(q ; q_{2}\right)\right] \cdot\left[s_{2}+s_{I} \cdot f\left(q_{1}, q_{2} ; Q_{c}\right)\right]
$$




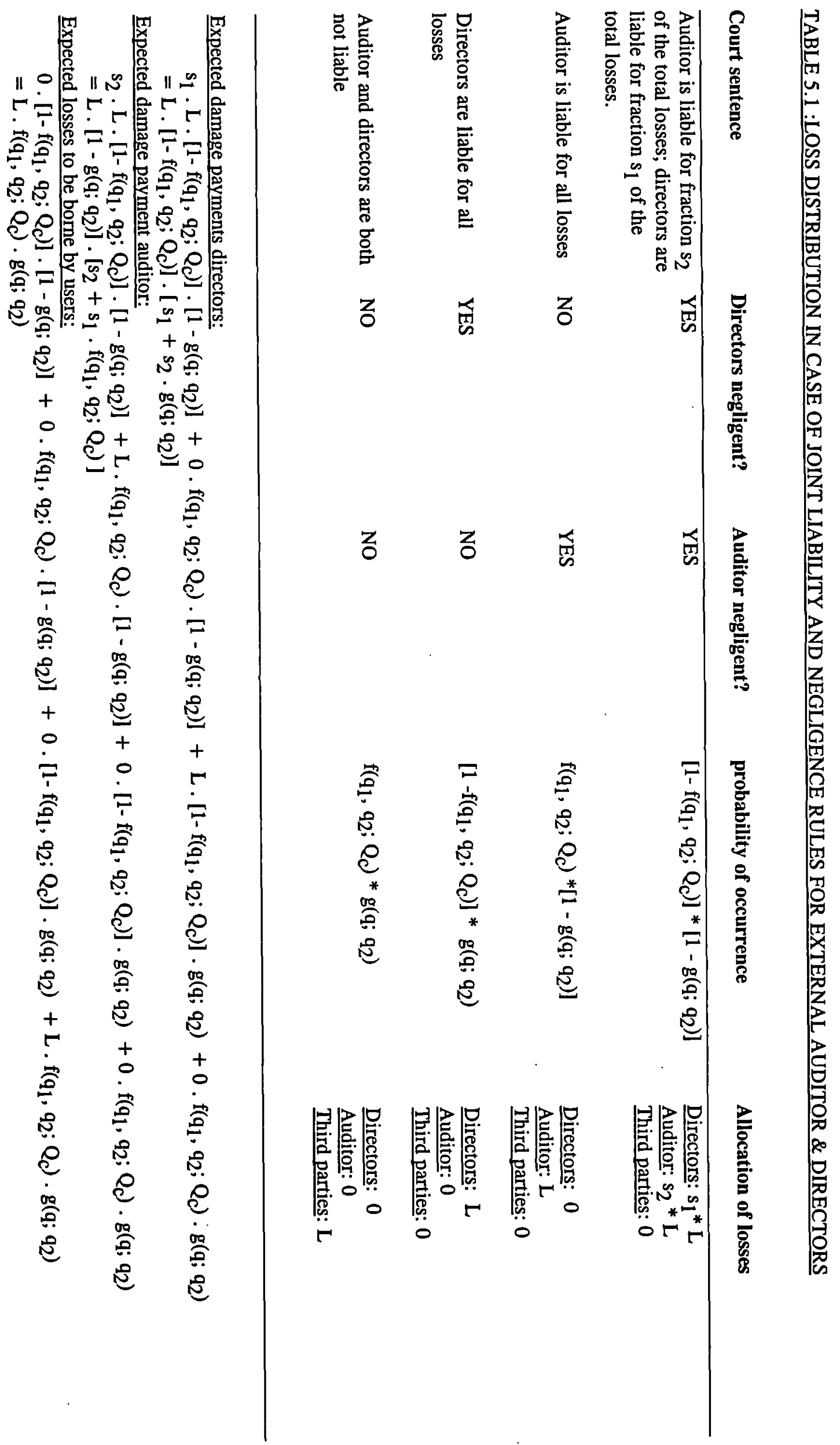




\section{$\underline{3 .}$ Compliance when the quality norms $Q_{\underline{c}}$ and $\mathbf{q}_{2}$ are certain}

The directors' choice as to the optimal mix $\left(q_{1}{ }^{*}, q_{2}{ }^{*}\right)$ and the external auditor's optimal production behaviour $q^{*}$ are first analysed in the simple case where the quality norms are - ex ante - known with certainty. In this instance the subjective beliefs are as follows:

$$
f\left(q_{1}, q_{2} ; Q_{c}\right)=\quad \begin{aligned}
& 1 \text { if and only if } \theta . q_{1}+q_{2} \geq Q_{c} \\
& 0 \text { if and only if } \theta . q_{1}+q_{2}<Q_{c},
\end{aligned}
$$

where $\theta$ is the importance weight attached by the courts to internal auditing as compared to external auditing in obtaining an overall quality level of financial statements; and

$$
g\left(q ; q_{2}\right)=\quad \begin{aligned}
& 1 \text { if and only if } q \geq q_{2} \\
& 0 \text { if and only if } q<q_{2}
\end{aligned}
$$

In the remainder of this chapter, $g$ will be used instead of $g\left(q ; q_{2}\right)$, and $f$ instead of $f\left(q_{1}\right.$, $\left.\left.q_{2} ; Q_{c}\right)\right]$

\subsection{The external auditor's problem under certainty}

As described earlier, the directors will first analyse the auditor's reaction function, $q^{*}\left(q_{1}, q_{2}\right)$, and assess $g\left(q ; q_{2}\right)$, in order to complete their optimisation problem. Given a pair $\left(q_{1}, q_{2}\right)$, the directors calculate the level $q^{*}$ of external audit quality which minimises expression (5.2). Since the objective function is discontinuous at $q_{2}$, the problem can written as: 
Min

$$
C(q)+L .\left[s_{2}+s_{I} \cdot f\right] \quad \text { if } q<q_{2}
$$

q $\quad C(q) \quad$ if $q \geq q_{2}$

Graph 5.1 illustrates the analysis. The auditor will certainly not choose to produce $q>$ $q_{2}$, because then $C(q)>C\left(q_{2}\right)$ holds, as $d C / d q>0$ by assumption. This would only imply a higher cost. The auditor will also not choose $q<q_{2}$, because he would then be held liable and bear direct audit costs plus losses (that is, $C(q)+L .\left[s_{2}+s_{1} \cdot f\right]$ ). If for all $q<q_{2}$, it holds that $C(q)+L \cdot\left[s_{2}+s_{1} \cdot f\right]>C\left(q_{2}\right)$, The auditor will choose $q_{2}$. This however implies the assumption ${ }^{73}$ that expected losses are large enough, that is: L. [s 2 $\left.+s_{1} \cdot f\right]>C\left(q_{2}\right)-C(q)$. The conclusion is that $q^{*}$ coincides with $q_{2}$ and that $\mathrm{g}=1$. External auditors will not provide liability insurance.

${ }^{73}$ In chapter 6 the case will be considered where losses are not large enough. 
Graph 5.1: Auditor compliance when the due care level is certain

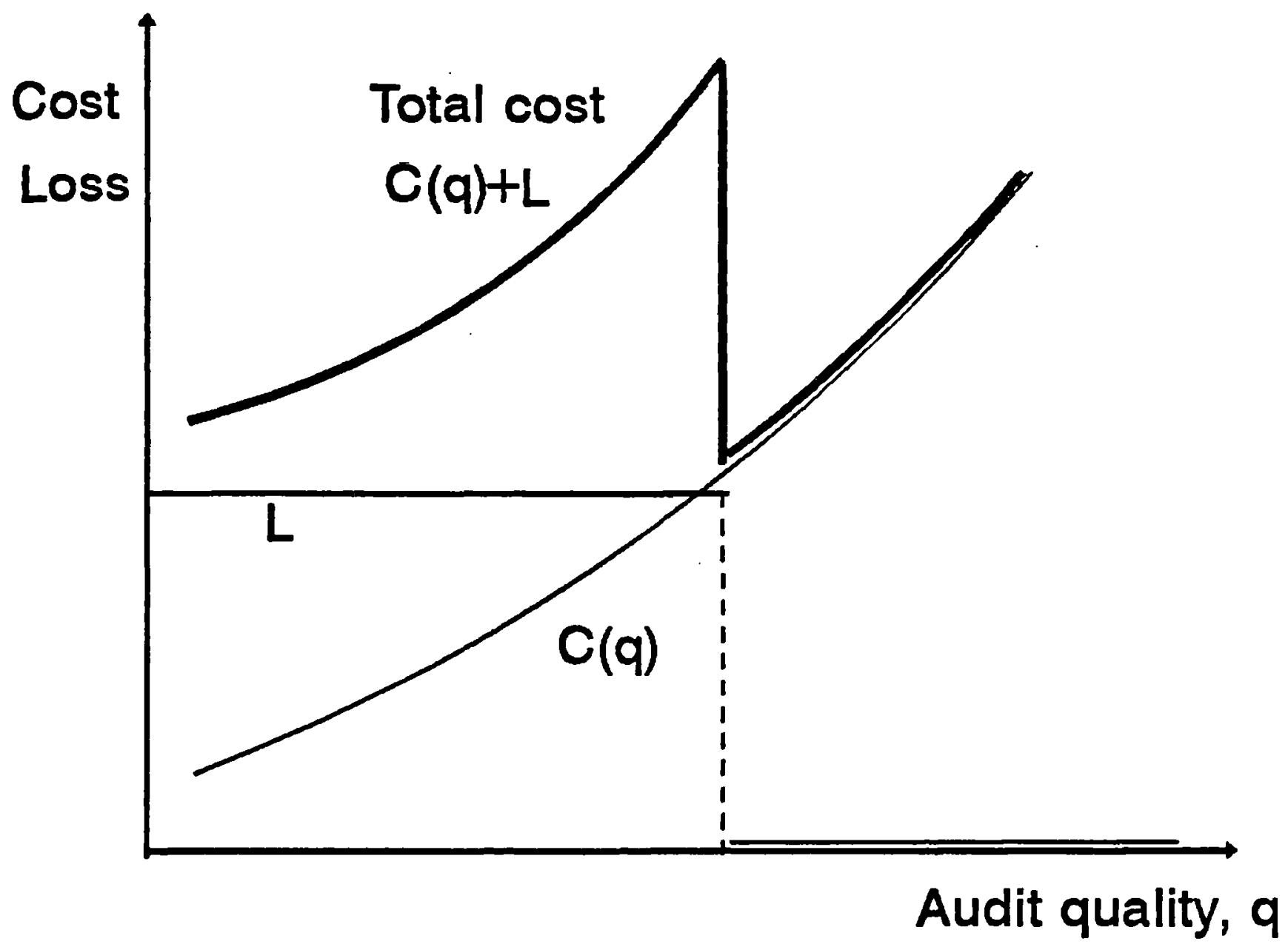




\subsection{The directors' problem under certainty}

Once the external auditor's reaction function is known, the directors optimise their own objective function, which now reduces to

$$
C_{1}\left(q_{1}\right)+C_{2}\left(q_{2}\right)+L \cdot\left[1-f\left(q_{1}, q_{2} ; Q_{c}\right)\right]
$$

since the auditors will always comply with the legally required level $q_{2}$ and $g=I$. In analogy to the auditor's optimisation problem, the director's objective can written as:

$$
C_{1}\left(q_{1}\right)+C_{2}\left(q_{2}\right)+L \quad \text { if } \theta q_{1}+q_{2}<Q_{c}
$$

Min

$q_{1}, q_{2}$

$$
C_{1}\left(q_{1}\right)+C_{2}\left(q_{2}\right) \quad \text { if } \theta q_{1}+q_{2} \geq Q_{c}
$$

The conclusion is similar to the auditor's case. Demanding $\left(q_{1}, q_{2}\right)$, such that $\theta q_{1}+q_{2}>$ $Q_{c}$, only results in higher direct costs. Demanding $\left(q_{1}, q_{2}\right)$, such that $\theta q_{1}+q_{2}<Q_{c}$, implies that directors become liable. The directors will choose $\left(q_{1}{ }^{*}, q_{2}{ }^{*}\right)$ such that $Q^{*}=$ $\theta q_{1}{ }^{*}+q_{2}{ }^{*}$ equals $\mathrm{Q}_{\mathrm{c}}$ (Note that this implies the assumption that losses are large enough).

As the directors always comply with the norm, $f=1$ holds. As a result the constraint $f\left(q_{1}, q_{2} ; \mathrm{Q}_{\mathrm{c}}\right)=1$ or $\theta . q_{1}+q_{2}=Q_{c}$ can be imposed on the director's optimisation problem. The solution $\left(q_{1}^{*}, q_{2}^{*}\right)$ satifies the following first order condition

$$
M C_{1} / M C_{2}=\theta
$$

expressing that the ratio of marginal costs equals the weight $\theta$. The more weight given by the courts to internal control in meeting the quality norm, $Q_{c}$, (that is, the larger $\theta$ ), 
the larger $q_{1}{ }^{*}$ will be at the expense of external audit demand, $q_{2}{ }^{*}$, and vice versa. Note that corner solutions may occur. For example, in the case of linear cost functions $C_{i}\left(q_{i}\right)$ $=c_{i} \cdot q_{i}$, it follows that $c_{1} / c_{2}>\theta$ implies $\left(q_{1}{ }^{*}, q_{2}{ }^{*}\right)=(0, Q)$ and that $c_{1} / c_{2}<\theta$ implies $\left(q_{1}^{*}, q_{2}^{*}\right)=(Q / \theta, 0)$.

To conclude, if the quality norms are known with certainty, both the directors and external auditor will comply with the norms. The choice of the level of external audit demand will be dependent on marginal cost considerations and on the relative importance, as attached by the courts, of internal control compared to external audit in achieving an overall quality level.

The following propositions summarise the results:

\section{Proposition 5.1.}

When the levels of due care applying to external auditors and directors are known with certainty, the external auditor is believed to produce exactly the external audit quality level demanded, and directors will demand a level of overall financial statement quality equal to the due care level.

\section{Proposition 5.2.}

When the levels of due care applying to external auditors and directors are known with certainty, there is no liability insurance demand for external audit quality.

Since the provision of inaccurate accounts with an unqualified audit report attached to it might be seen as a jointly causing damage to third parties, the results could be generalised to a more generic setting of accidents or torts where there are multiple injurers whose liability is subject to a certain negligence standard. It is worthwile to compare the above propositions which are derived in a leader-follower framework with 
the conclusions in Shavell (1987) where no such setting was used. Shavell discusses two different possible cases of compliance with negligence standards when there are multiple injurers, i.e. the case where it is assumed that the injurers act independently and where each injurer's expected portion of damage payments equals 1 ; and the second case where the injurers act in concert so as to minimize their joint expenses. Shavell proves that in both cases all injurers will take due care. This result is here confirmed in a leader-follower framework.

\subsection{The impact of a statutory audit requirement on overall financial statement quality when quality norms are certain}

The statutory audit requirement is a form of ex ante regulation that monitors external audit demand. It is a public policy instrument to control for damage to financial statement users (see also chapter 4 , section 4). However, what is important to users is the produced level of overall financial statement quality, rather than the level that is demanded. The produced level of overall financial statement quality without a statutory audit requirement, denoted here by $\mathrm{Q}_{\mathrm{p}}{ }^{*}$, is the level of produced internal audit quality74 times its relative importance weight, plus the produced level of external audit quality. Thus:

$$
Q_{p}^{*}=\theta \cdot q_{1}^{*}+q^{*}
$$

Equation (5.5) needs some further explanation. It is assumed here that the overall financial statement quality that is produced is linearly additive in $q_{1}$ and $\mathrm{q}^{*}$. This assumption is an oversimplification of reality. The nature of the relationship between

\footnotetext{
74 Note that it is assumed that the the produced level of internal audit quality is assumed to be equal to the demanded level of internal audit quality. See section 2.1 .
} 
$\mathrm{Q}^{*}, q_{1}$ and $q^{*}$ is unknown and open to empirical investigation. Clearly, the level of external audit quality produced, $q^{*}$, is a function of the level of internal audit quality that has been produced in a firm, and the level of overall financial statement quality that is demanded, $\mathrm{Q}^{*}$, or:

$$
\mathrm{q}^{*}=\mathrm{f}\left(\mathrm{Q}^{*}, q_{1}^{*}\right)
$$

This is the case, because it is the external auditor's task to express an opinion on the accounts after they have been subject to internal controls. In equation (5.5) the coefficient $\theta$ can be interpreted as an adjustment index, to indicate that internal and external audit quality are not merely additive, but that additional overall financial statement quality is obtained (to the quality already obtained from internal auditing alone) from external auditing.

It is assumed that the external auditor's production behaviour is as conjectured by the directors. Since $\mathrm{q}_{2}{ }^{*}$ is known after the directors' demand decision has been taken, it follows that $q^{*}=q_{2}{ }^{*}$. This implies that $Q_{p}{ }^{*}=Q_{c}$ when the quality norms are known with certainty. In this situation liability regulation alone will guarantee overall financial statement quality and no statutory external audit requirements need to be imposed.

In case directors are subject to a statutory (external) audit requirement, denoted here as $\mathrm{q}_{\mathrm{r}}$, the constraint $\mathrm{q}_{\mathrm{r}} \geq \mathrm{q}_{2}$ is imposed on the directors' optimisation problem. This would only result in a higher level of external audit demand if $\mathrm{q}_{\mathrm{r}}>\mathrm{q}_{2}{ }^{*}$, that is when the requirement is strictly larger than what would be demanded if there were no such requirement. However, the increase in external audit demand would be at the expense of the level internal audit demand. There will be no impact on the overall level of demanded financial statement quality, if $\mathrm{q}_{\mathrm{r}} \leq \mathrm{Q}_{\mathrm{c}}$. The latter condition implies that the minimum level of demanded external audit quality that is imposed on directors by 
statute (namely $\mathrm{q}_{\mathrm{r}}$ ) is not larger than the legally required level of overall level of financial statement quality (that is, the 'due care' level). Since this is a realistic assumption to make, the conclusion is that statutory audit requirements would have no effect on the overall level of financial statement quality demanded and produced, when the quality norms are certain. The only result of imposing a statutory audit requirement would be an increase in the overall cost in achieving a produced level of overall financial statement quality, if $\mathrm{q}_{\mathrm{r}}>\mathrm{q}_{2}{ }^{*}$. Relatively cheaper internal audit is (partially) replaced by relatively more expensive external audit. Note that if $\mathrm{q}_{\mathrm{r}}<\mathrm{q}_{2}{ }^{*}$, the statutory audit requirement would have no impact at all on the directors ' decision, which would still be $\left(q_{1}{ }^{*}, q_{2}{ }^{*}\right)$, and would do no harm.

\section{Proposition 5.3.}

In case of certainty about due care levels applying to directors and external auditors, statutory external audit requirements should not be imposed, since they would have no effect on the overall financial statement quality produced and could be cost increasing.

\section{Compliance when the quality norms $Q_{\underline{c}}$ and $\mathrm{q}_{2}$ are uncertain}

In this section the quality norms applying to directors and external auditors are both uncertain. In particular, it is assumed that the directors believe that the minimum norm is a random variable drawn from a bounded set, denoted by $\left[Q_{c}-\varepsilon, Q_{c}+\varepsilon\right]$, with uniform ${ }^{75}$ probability. The subjective belief function $f$ is therefore given by:

\footnotetext{
${ }^{75}$ For characteristics of uniform distributions see, for example, Spanos (1986).
} 


$$
f\left(q_{1}, q_{2} ; Q_{c}\right)=\quad \begin{aligned}
& 1 \text { if and only if } \theta . q_{1}+q_{2} \geq Q_{c}+\varepsilon \\
& 0 \text { if and only if } \theta . q^{I}+q_{2} \leq Q_{c}-\varepsilon, \\
& \left(\theta . q_{1}+q_{2}-Q_{c}+\varepsilon\right) / 2 \varepsilon \text { otherwise }
\end{aligned}
$$

This specification of $f$ implies that the directors are only uncertain about their liability for choices of $\left(q_{1}, q_{2}\right)$ which yield an overall quality level, $\theta . q_{1}+q_{2}$, that is strictly larger than $Q_{c}-\varepsilon$ but strictly smaller than $Q_{c}+\varepsilon$. If very large quality levels are produced, i.e larger than $Q_{c}+\varepsilon$, the directors know with certainty that they won't be held liable; analogously if very small quality levels are produced, i.e. smaller than $Q_{c}-\varepsilon$, the directors are certain that they will be held liable.

The uncertainty for the auditor is modelled analogously. The subjective belief function $g$ is given by:

$$
g\left(q ; q_{2}\right)=\quad \begin{aligned}
& 1 \text { if and only if } q \geq q_{2}+\delta \\
& 0 \text { if and only if } q \leq q_{2}-\delta \\
& \left(q-q_{2}+\delta\right) / 2 \delta \text { otherwise }
\end{aligned}
$$

Given the quality $q_{2}$ demanded by the directors, the external auditor believes that the court's interpretation of $q_{2}$ is drawn from the bounded set $\left[q_{2}-\delta, q_{2}+\delta\right]$. Again, external auditors are assumed to be uncertain about their liability only when the external audit quality they produce, $\mathrm{q}$, is strictly larger than $q_{2}-\delta$ but strictly smaller than $q_{2}+\delta$. For external audit quality levels with a value outside this interval, the directors are certain about the court's view.

From the assumptions above and the analysis of the certainty case in section 3 , it follows that it does not pay for directors and external auditors to provide quality levels 
that are strictly larger than $Q_{c}+\varepsilon$ and $q_{2}+\delta$, since they are certain not to be held liable and would only incur larger costs. Hence, the constraints $\theta . q_{1}+q_{2} \leq Q_{c}+\varepsilon$ and $q \leq q_{2}+\delta$ can be imposed on their respective optimisation problems. To simplify calculations quadratic cost functions are assumed, i.e. $C_{i}\left(q_{i}\right)=\left(c_{i} \cdot q_{i}{ }^{2}\right) / 4$ and $C(q)=$ $\left(c . q^{2}\right) / 4$. Furthermore, changes in $L$ and $s_{i}$ caused by changes in $q, q_{1}$, and $q_{2}$ are ignored; i.e. in the neighbourhood of the equilibrium the quantities $L$ and $s_{i}$ are assumed to be stable.

\subsection{The auditor's reaction function under uncertainty}

The directors first conjecture ${ }^{76}$ what the auditor's quality decision, $\mathrm{q}^{*}$, would be for alternative levels of demanded internal and external audit quality. The auditor's reaction function 77 is given by

$$
q^{*}=q^{*}\left(q_{1}, q_{2}\right)=\min \left\{q_{2}+\delta, q_{*}=1 / c \delta . L .\left[s_{2}+s_{1} \cdot f\right]\right\}
$$

Note that $q_{*}$ (subscript) represents the optimum if there were no constraint. In this subsection the following questions will be addressed. First, what is the impact of uncertainty about the external audit quality norm on external audit quality production behaviour and on compliance with that quality norm. Second, do auditors faced with

\footnotetext{
$77 \mathrm{q}^{*}$ is the solution to the following optimisation problem:

$$
\underset{q}{\operatorname{Min}} c . q^{2} / 4+L .(1-g) .\left(s_{2}+s_{1} . f\right)
$$$$
\text { s.t.: } \quad q \leq q_{2}+\delta
$$

${ }^{76}$ Although the external audit quality production decision is considered here from the anticipative perspective of the directors, section 4.1 could stand on its own. For a detailed analysis of the impact of auditor liability and uncertainty about the negligence standard on external audit quality, see chapter 6 . 
uncertain quality standards satisfy the quality needs of their clients. And, third, how does a change in the level of demanded internal and external audit quality affect the auditor's reaction when quality norms are uncertain. To deal with these questions the auditor's quality decision, $\mathrm{q}^{*}$, is looked at as a function of uncertainty, $\delta$., hereby ignoring the effect of the other parameters.

\subsubsection{Impact of uncertainty, $\delta$, on external audit quality quality production}

Graph 5.2 illustrates the auditor's reaction function $q^{*}$ as a function of $\delta$. The smaller the uncertainty about the court's quality standard, that is the smaller $\delta$ is, the larger $q_{*}$ is and the smaller $q_{2}+\delta$. For sufficiently small values of $\delta$, i.e for $\delta$ smaller than a critical value $\delta_{u}, q_{*}$ is larger than $q_{2}+\delta$, and $q_{2}+\delta$ will be chosen. This coincides with the situation where the external auditor respects the court's norm with certainty. However, if uncertainty about the court's quality standard is large enough and $\delta$ is strictly larger than $\delta_{u}, q_{*}$ is smaller than $q_{2}+\delta$. The auditor will then produce $q_{*}$, and he may no longer respect the court's norm. This may even result in an optimum $q^{*}$ which is strictly smaller than $q_{2}-\delta$, but only if $\delta$ is strictly larger than a second critical value denoted by, $\delta_{l}$. In the latter case, the auditor's optimal choice is one where it pays not to comply with the court's norm and to be held liable with certainty.

Graph 5.2 illustrates that uncertainty has the effect of increasing the level of quality produced, but only up to a certain level of uncertainty, $\delta_{\mathrm{u}}$. Beyond that level, uncertainty has a negative effect on production of quality.

The auditor, thus, will only accept a gamble on liability if uncertainty about the quality norm takes a value within the interval $] \delta_{u}, \delta_{l}\left[\right.$. The critical value $\delta_{u}$ from where the auditor starts producing $q_{*}$ instead of $q_{2}+\delta$, that is where it becomes likely that the 
auditor will no longer comply with the court's quality standard and accepts a gamble, has the following functional form:

$$
\delta_{u}=1 / 2 \cdot\left[-q_{2}+\left(q_{2}^{2}+4 L / c \cdot\left(s_{2}+s_{1} \cdot f\right)\right)^{1 / 2}\right]
$$

The critical value $\delta_{l}$ from where the auditor starts producing $q_{2}-\delta$ and from beyond where he is certainly not complying with the court's quality standard, has the following functional form ${ }^{78}$ :

$$
\delta_{l}=1 / 2 \cdot\left[q_{2}-\left(q_{2}^{2}-4 L / c \cdot\left(s_{2}+s_{1} \cdot f\right)\right)^{1 / 2}\right]
$$

\footnotetext{
${ }^{78}$ Note that $\delta_{l}$ is only defined if $q_{2}^{2}>4 L / c .\left(s_{2}+s_{1}, f\right)$.
} 
Graph 5.2: The auditor's reaction function when the due care level is uncertain, and the corresponding optima for the directors.

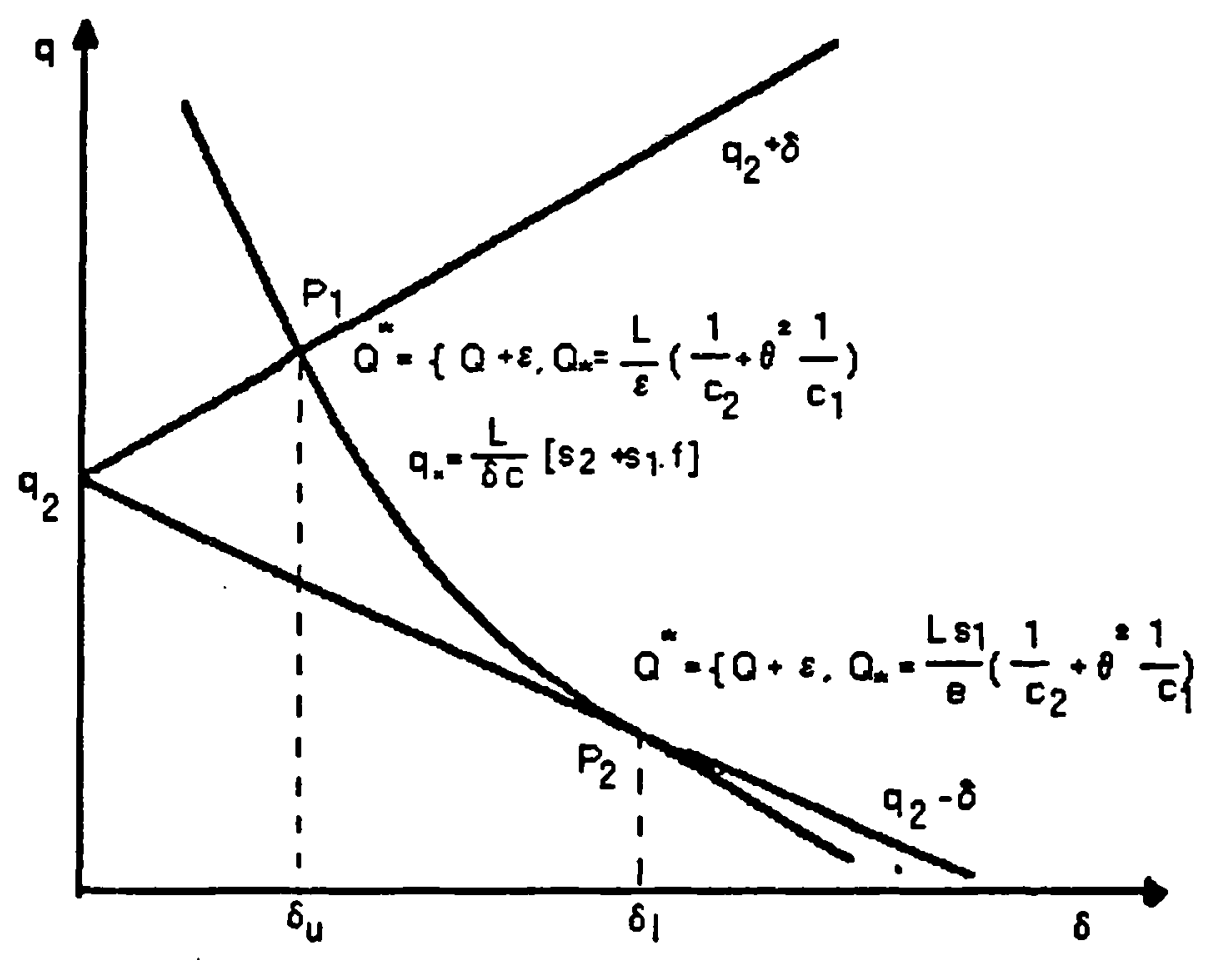


Graph 5.2 also illustrates that for small (respectively large) enough values of $\delta$, the auditor will produce a higher (respectively lower) quality level than the one that is demanded, that is $q_{2}$. A critical value $\delta_{e}$ can be defined at which the auditor produces exactly what is demanded 79 :

$$
\delta_{e}=1 / c q_{2} \cdot L \cdot\left[s_{2}+s_{1} \cdot f\right]
$$

Table 5.2 summarises the the auditor's reaction, $q^{*}$, for alternative levels of uncertainty, $\delta$. The corresponding conclusions are summarised in the following propositions:

\section{Proposition 5.4.}

Given that the external auditor is (believed by the directors to be) uncertain about the legally required quality norm as specified by the subjective belief function $g, a$ sufficiently small uncertainty (i.e. $\delta \leq \delta_{u}$ ) will result in overprotection and compliance with the norm, whereas a sufficiently large uncertainty (i.e. $\delta \geq \delta_{l}$ ) will result in underprotection and non-compliance with the norm.

\section{Proposition 5.5.}

Given that the external auditor is (believed by the directors to be) uncertain about the legally required quality norm as specified by the subjective belief function $g$, the external auditor will (be believed to) produce a higher (lower) quality level than what is demanded when uncertainty is small, i.e. $\delta<\delta_{e}$ (large, i.e. $\delta>\delta_{e}$ ).

Proposition 5.5 is in line with the results obtained by Kolstadt et al. (1990), who analyse the generic case of compliance with uncertain legal standards of precaution when there is one single injurer, but where the subjective beliefs about liability are assumed to be normally distributed. In section 4.2 the analysis is expanded in a leaderfollower framework for the case of 2 injurers.

\footnotetext{
${ }^{79}$ Note that a second feasible solution is : $\delta_{\mathrm{e}}=0$. In the certainty case, the auditor also exactly produces what is demanded.
} 
Table 5.2: Overview of the auditor's reaction function for different $\delta$ values

\begin{tabular}{|c|c|c|}
\hline Uncertainty, $\delta$ & Auditor's reaction & Compliance \\
\hline$\delta \leq \delta_{u}$ & $q_{2}+\delta$ & Yes \\
\hline$\delta_{u}<\delta \leq \delta_{l}$ & $\begin{array}{l}q_{*}=1 / c \delta . L .\left[s_{2}+s_{\jmath} \cdot f\right] \\
\text { and: } q_{2}-\delta<q_{*} \leq q_{2}+\delta\end{array}$ & Not guaranteed \\
\hline$\delta_{u}<\delta \leq \delta_{e}$ & $q_{*}>q_{2}$ & $\begin{array}{l}\text { Auditor produces more } \\
\text { than what is demanded }\end{array}$ \\
\hline$\delta=\delta_{e}$ & $q_{*}=q_{2}$ & $\begin{array}{l}\text { Auditor produces exactly } \\
\text { what is demanded }\end{array}$ \\
\hline$\delta_{e}<\delta \leq \delta_{l}$ & $q_{*}<q_{2}$ & $\begin{array}{l}\text { Auditor produces less } \\
\text { than what is demanded }\end{array}$ \\
\hline$\delta>\delta_{l}$ & $\begin{array}{l}q * \\
\text { and: } \mathrm{q}_{*}<\mathrm{q}_{2}-\delta\end{array}$ & No \\
\hline
\end{tabular}




\subsubsection{The impact of internal and external audit demand levels on the auditor's} decision

The effect of changes in $q_{1}$ and respectively $q_{2}$ on the critical values $\delta_{u}$ and $\delta_{l}$ can now be examined ${ }^{80}$. An increase in the level of internal audit quality demanded by directors, $\mathrm{q}_{1}$, induces an increase in both the critical values $\delta_{\mathrm{u}}$ and $\delta_{1}$. This can be explained as follows. An increase in the level of demanded internal audit quality increases the probability that the directors will comply with the legal norm applying to them, that is $f$, and hence increases the chance that the auditor will end up being the sole party being held responsible if he produces a quality level below the court's norm. The auditor's expected damage payments increase, and as a result $\mathrm{q}_{*}$ increases. The impact on the critical values $\delta_{u}$ and $\delta_{l}$ is graphically illustrated in graph 5.3, panel A. The q* curve, as depicted in graph 2 has now shifted to the right. The result is that the auditor will produce $q_{2}+\delta$ much longer, which is the case where he is certainly not liable, and $\delta_{\mathrm{u}}$ increases. It will also take longer before non-compliance, or producing an audit quality level that is smaller than $q_{2}-\delta$, will be an optimal solution, i.e. $\delta_{1}$ increases. Note that the critical values $\delta_{u}$ and $\delta_{l}$ are largest when $f=1$.

The effect of a change in $q_{2}$ on the critical values $\delta_{u}$ and $\delta_{1}$ is not straightforward (note that the signs of the relevant partial derivates in footnote 80 is indeterminate). An

\footnotetext{
${ }^{80}$ This is done by investigating the signs of the following partial derivatives, given that $f\left(q_{1}, q_{2} ; Q_{c}\right)=$ $\left(\theta . q_{1}+q_{2}-Q_{c}+\varepsilon\right) / 2 \varepsilon$ :$$
\partial \mathrm{d}_{\mathrm{u}} / \partial \mathrm{q}_{1}=\left[\mathrm{q}_{2}^{2}+4 \mathrm{~L} / \mathrm{c} \cdot\left(\mathrm{s}_{2}+\mathrm{s}_{1} \cdot \mathrm{f}\right)\right]^{-1 / 2} \cdot\left(\mathrm{L} \cdot \mathrm{s}_{1} \cdot \mathrm{q}\right) / 2 c \mathcal{E}>0
$$$$
\partial \mathrm{d}_{\mathrm{u}} / \partial \mathrm{q}_{2}=-1 / 2+1 / 2 \cdot\left[\mathrm{q}_{2}^{2}+4 \mathrm{~L} / \mathrm{c} \cdot\left(\mathrm{s}_{2}+\mathrm{s}_{1} \cdot \mathrm{f}\right)\right]^{-1 / 2} \cdot\left[\mathrm{q}_{2}+\mathrm{L} \cdot \mathrm{s}_{1} / \mathrm{c} \cdot \varepsilon\right]
$$$$
\partial \mathrm{d}_{1} / \partial \mathrm{q}_{1}=\left[\mathrm{q}_{2}^{2}-4 \mathrm{~L} / \mathrm{c} \cdot\left(\mathrm{s}_{2}+\mathrm{s}_{1} \cdot \mathrm{f}\right)\right]^{-1 / 2} \cdot\left(\mathrm{L} \cdot \mathrm{s}_{1} \cdot \mathrm{q}\right) / 2 \mathrm{c} \varepsilon>0
$$$$
\partial \mathrm{d}_{1} / \partial \mathrm{q}_{2}=1 / 2-1 / 2 \cdot\left[\mathrm{q}_{2}^{2}-4 \mathrm{~L} / \mathrm{c} \cdot\left(\mathrm{s}_{2}+\mathrm{s}_{1} \cdot \mathrm{f}\right)\right]^{-1 / 2} \cdot\left[\mathrm{q}_{2}-\mathrm{L} \cdot \mathrm{s}_{1} / \mathrm{c} . \varepsilon\right]
$$ 
increase in the level of external audit quality demanded $q_{2}$ also has the effect of increasing $f$ and thereby the chance that the auditor will end up being the sole party held responsible if he produces a quality level below the court's norm. The auditor's expected liability payments increase, and so does $\mathrm{q}_{*}$. In panel B of graph 5.3 it can be seen that the $\mathrm{q}_{*}$ curve has shifted to the right. However, the quality production levels at which the auditor would always comply, i.e. $q_{2}+\delta$, and will never comply, i.e. $q_{2}-\delta$, also increase. The $q_{2}+\delta$ line shifts to the left and the $q_{2}-\delta$ line shifts to the right. The ultimate effect on $\delta_{u}$ depends upon the value of $\varepsilon{ }^{81}$. For small enough (respectively large) values of $\varepsilon$, both $\delta_{\mathrm{u}}$ and $\delta_{1}$ are positively (respectively negatively) related with $\mathrm{q}_{2}$. Thus, if the uncertainty of the directors is sufficiently small, the increase in the external auditor's expected damage payments will be large enough to offset the increase in $q_{2}+\delta$ (resp. $q_{2}-\delta$ ), and $\delta_{u}$ (respectively $\delta_{1}$ ) will increase. On the other hand, if the uncertainty of the directors is sufficiently large, the external auditor's expected damage payments will not increase enough to offset the increase in $q_{2}+\delta$ (respectively $q_{2}-\delta$ ), and $\delta_{u}$ (respectively. $\delta_{1}$ ) will decrease.

In case $\mathrm{q}_{1}$ and $\mathrm{q}_{2}$ are simultaneously changed, holding $f$ fixed, an increase in $\mathrm{q}_{2}$ will decrease both $\delta_{\mathrm{u}}$ and $\delta_{1}$. As $f$ doesn't change, the $\mathrm{q}_{*}$ curve doesn't shift, but the $\mathrm{q}_{2}+\delta$ line moves to the left and the $q_{2}-\delta$ line moves to the right. In result, $\delta_{u}$ and $\delta_{1}$ become smaller.This is shown in panel $C$ of graph 5.3.

\footnotetext{
${ }^{81}$ And, of course on the value of the other parameters $s_{1}, L$ and $c$. Since the focus of this paper is on uncertainty, the impact of $\varepsilon$ is investigated here.
} 


\section{Graph 5.3}

Panel A: Effect of an increase in internal audit quality demand on the critical $\delta$ values

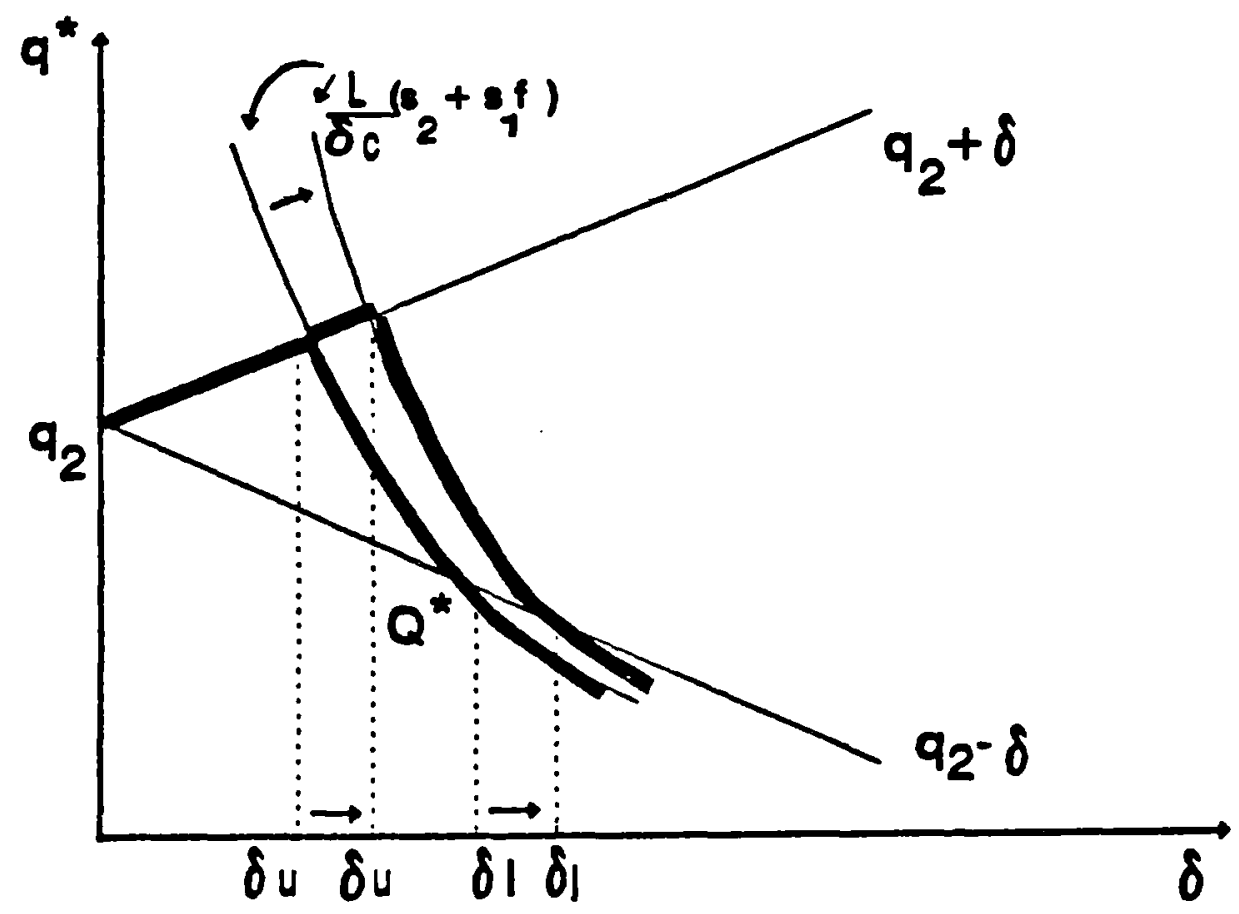

Panel B: Effect of an increase in external audit quality demand on the critical $\delta$ values

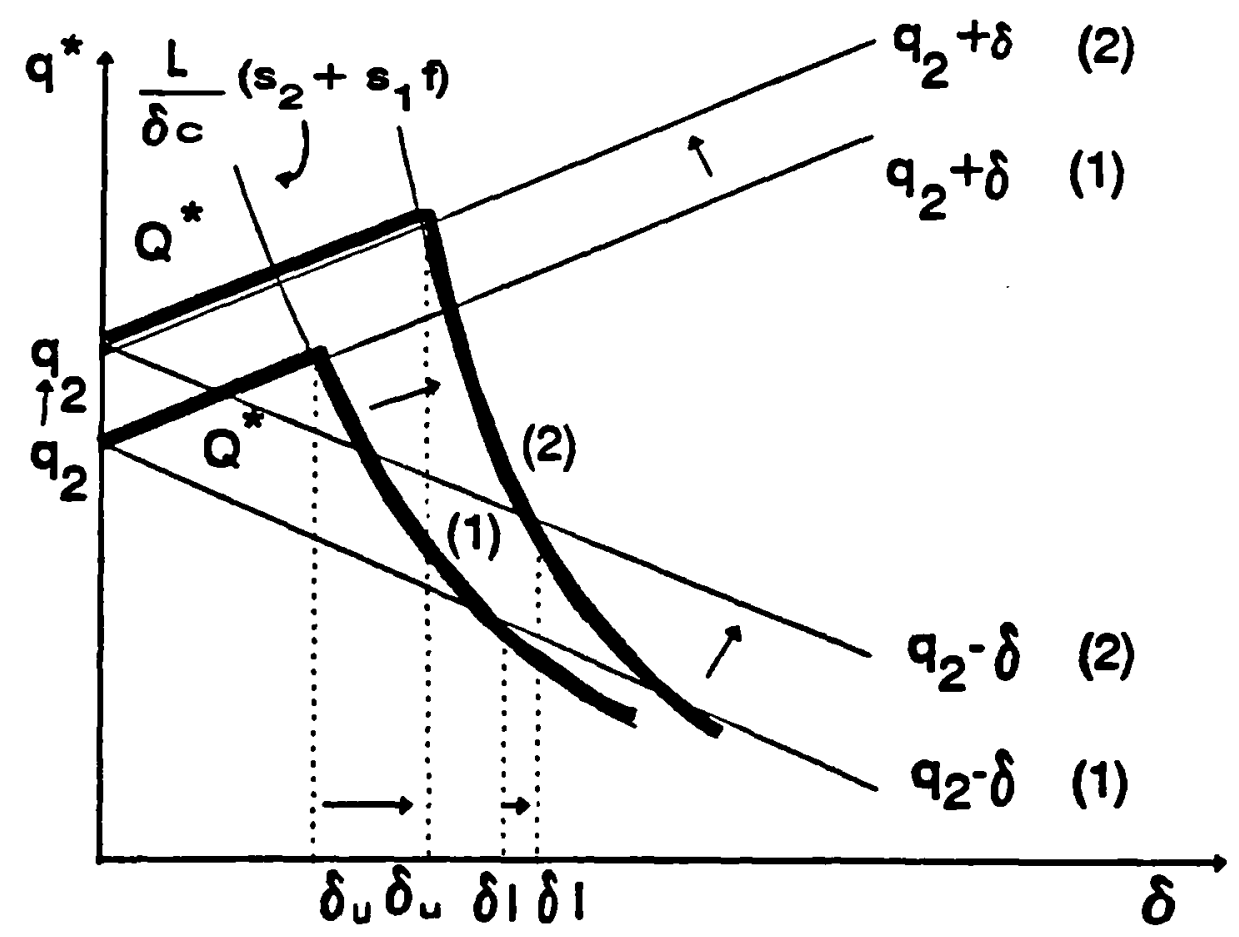




\section{Graph 5.3}

Panel C: Effect of an increase in external audit quality demand on the critical $\delta$ values, when $f$ remains constant

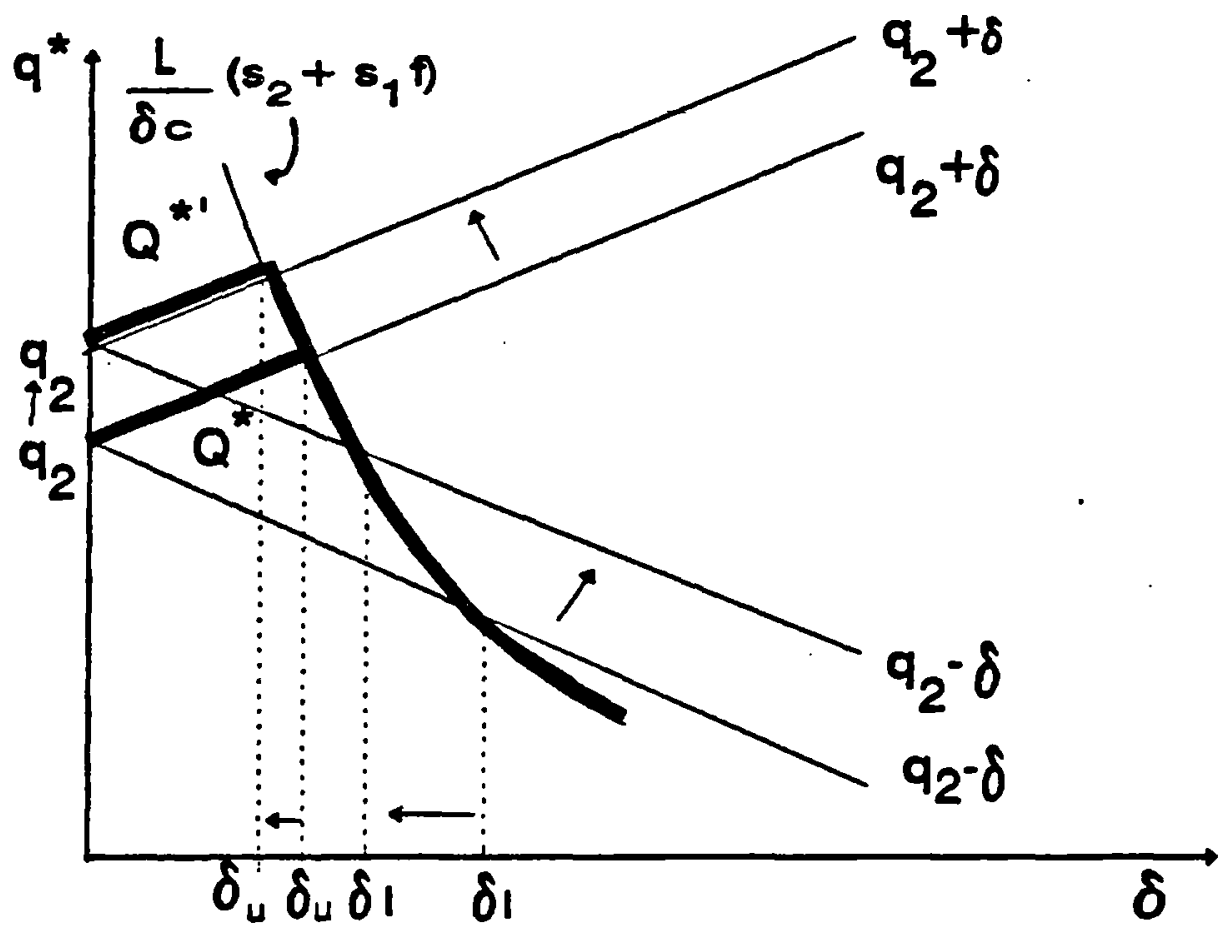




\subsection{The directors' demand decision under uncertainty}

\subsubsection{The impact of auditor compliance on the directors' decision}

The directors' optimum is now analysed. Three different situations exist. First, the situation where the external auditor's reaction function is assessed to be $q^{*}\left(q_{1}, q_{2}\right)=q_{2}$ $+\delta$; this occurs when uncertainty about the external audit quality norm is very small, and the auditor's subjective belief function, $g$, takes the value 1 . Second, the situation where $\mathrm{q}^{*}\left(\mathrm{q}_{1}, \mathrm{q}_{2}\right)=\mathrm{q}_{*}$ and $\mathrm{q}_{*} \leq \mathrm{q}_{2}-\delta$; this occurs when uncertainty about the external audit quality norm is very large, and the auditor's subjective belief function, $\mathrm{g}$, takes the value 0 . Third, the case where $q^{*}\left(q_{1}, q_{2}\right)=q_{*}$ and $q^{*} \geq q_{2}-\delta$; in this case the auditor's subjective belief function, $\mathrm{g}$, takes a value between 0 and 1 .

In the first case where the auditor produces $\mathrm{q}_{2}+\delta$ and $g=1$, that is when $\mathrm{q}^{*}$ is at point $P_{1}$ in graph 5.2, the optimal level of overall quality demanded ${ }^{82}$ by the directors, defined as $\mathrm{Q}_{1}{ }^{*}$, is equal to:

$$
\mathrm{Q}_{1}{ }^{*}=\theta \cdot \mathrm{q}^{*}{ }_{1}+\mathrm{q}^{*}{ }_{2}=\min \left\{\mathrm{Q}_{\mathrm{c}}+\varepsilon, \mathrm{Q}^{*}, 1=\mathrm{L} / \varepsilon \cdot\left(\mathrm{c}_{2}{ }^{-1}+\theta^{2} \cdot \mathrm{c}_{1}{ }^{-1}\right)\right\}
$$

Note that $Q_{*, 1}$ respresents the optimum if there were no constraint. In the second case, when the auditor produces $\mathrm{q}^{*}\left(\mathrm{q}_{1}, \mathrm{q}_{2}\right) \leq \mathrm{q}_{2}-\delta$ and $g=0$, that is when $\mathrm{q}^{*}$ is at point $\mathrm{P}_{2}$ in graph 5.2 , the optimal level of overall quality demanded ${ }^{83}$ by the directors, defined as $\mathrm{Q}_{1}{ }^{*}$, is given by:

82 This is the solution to the following optimisation problem:

$$
\begin{array}{ll}
\operatorname{Min} & c_{1} \cdot q_{1}{ }^{2} \cdot / 4+c_{2} \cdot q_{2}{ }^{2} \cdot / 4+L .(1-f) \\
q_{1}, q_{2} & \text { s.t. } \quad \theta . q_{1}+q_{2} \leq Q_{c}+\varepsilon
\end{array}
$$

${ }^{83}$ This is the solution to the following optimisation problem: 


$$
\mathrm{Q}_{2}{ }^{*}=\theta \cdot \mathrm{q}^{*}{ }_{1}+\mathrm{q}^{*}{ }_{2}=\min \left\{\mathrm{Q}_{\mathrm{c}}+\varepsilon, \mathrm{Q}^{*}, 2=\mathrm{L} \cdot \mathrm{s}_{1} / \varepsilon \cdot\left(\mathrm{c}_{2}{ }^{-1}+\theta^{2} \cdot \mathrm{c}_{1}{ }^{-1}\right)\right\}
$$

Note that $\mathrm{Q}_{*, 2}$ is smaller than $\mathrm{Q}_{*, 1}$.

When $0<\mathrm{g}<1$ holds, the optimisation problem occurs in its most complex form, as $\mathrm{g}$ is then a function of $\left(q_{1}, q_{2}\right)$. Appendix II gives the solution to the optimisation problem in case of quadratic cost functions as specified before. Its voluminous format allows for little straightforward conclusion. However, by treating the optimal $\mathrm{g}^{*}\left(\mathrm{q}_{1}{ }^{*}, \mathrm{q}_{2}{ }^{*}\right)$ as known (that is the value that $g$ would take given the directors optimal choice $\left(q_{1}{ }^{*}, q_{2}{ }^{*}\right)$ ), the solution can be expressed as follows:

$$
\mathrm{Q}_{3}^{*}=\min \left\{\mathrm{Q}_{\mathrm{c}}+\varepsilon, \mathrm{Q}^{*}, 3=(\mathrm{L} / \varepsilon) \cdot\left(\mathrm{s}_{1}+\mathrm{s}_{2} \cdot \mathrm{g}^{*}\right) \cdot\left(\mathrm{c}_{2}{ }^{-1}+\theta^{2} \mathrm{c}_{1}{ }^{-1}\right)\right\}
$$

Since $0<\mathrm{g}^{*}<1$ holds, the following holds as well:

$$
\mathrm{Q}_{*, 2}<\mathrm{Q}_{*, 3}<\mathrm{Q} * 1
$$

\subsubsection{The effect of uncertainty, $\varepsilon$, on the directors' decision for alternative} levels of auditor compliance (g)

In analogy with the the analysis in 4.1 , three types of critical values for $\varepsilon$ can be defined for the directors' uncertainty: denoted by $\varepsilon_{\mathrm{u}}, \varepsilon_{\mathrm{l}}$, and $\varepsilon_{\mathrm{e}}$. The critical value $\varepsilon_{\mathrm{u}}$ is defined as the level of uncertainty at which $Q^{*}=Q_{c}+\varepsilon=Q_{*}$ holds. If $\varepsilon \leq \varepsilon_{u}$, the directors will

$$
\begin{array}{ll}
\operatorname{Min}_{1}, q_{2} & c_{1} \cdot q_{1}^{2} \cdot / 4+c_{2} \cdot q_{2}^{2} \cdot / 4+L \cdot s_{1} \cdot(1-f) \\
& \text { s.t. } \quad \theta . q_{1}+q_{2} \leq Q_{c}+\varepsilon
\end{array}
$$


decide to demand quality levels that always comply with the court's norm, and will never be held liable. The critical value $\varepsilon_{1}$ is defined as the level of uncertainty at which $\mathrm{Q}^{*}=\mathrm{Q}_{\mathrm{c}}-\varepsilon=\mathrm{Q}_{*}$ holds. If $\varepsilon \geq \varepsilon_{1}$, the directors will decide to demand quality levels that will certainly not comply with the court's norm. The critical value $\varepsilon_{\mathrm{e}}$ is defined as the level of uncertainty at which $Q^{*}=E\left[Q_{c}\right]=Q_{c}$ holds. Each type of critical value will take different values depending on the auditor's reaction function $\mathrm{q}^{*}$, and hence depending on $\mathrm{g}^{*}$. 
Table 5.3: Critical values on $\varepsilon$

\begin{tabular}{lll}
\hline $\begin{array}{l}\text { Critical } \\
\varepsilon \text { value }\end{array}$ & Formula & $\begin{array}{l}\text { corresponding } \\
\text { value for } \mathrm{g}\end{array}$ \\
\hline$\varepsilon_{\mathrm{u}, 1}=$ & $1 / 2 \cdot\left[-\mathrm{Q}_{\mathrm{c}}+\left(\mathrm{Q}_{\mathrm{c}}{ }^{2}+4 \mathrm{~L} \cdot\left(\mathrm{c}_{2}{ }^{-1}+\theta^{2} \cdot \mathrm{c}_{1}{ }^{-1}\right)\right)^{1 / 2}\right]$ & $\mathrm{g}=1$ \\
$\varepsilon_{\mathrm{u}, 2}=$ & $1 / 2 \cdot\left[-\mathrm{Q}_{\mathrm{c}}+\left(\mathrm{Q}_{\mathrm{c}}{ }^{2}+4 \mathrm{~L} \cdot \mathrm{s}_{1}\left(\mathrm{c}_{2}{ }^{-1}+\theta^{2} \cdot \mathrm{c}_{1}{ }^{-1}\right)\right)^{1 / 2}\right]$ & $\mathrm{g}=0$ \\
$\varepsilon_{\mathrm{u}, 3}=$ & $1 / 2 \cdot\left[-\mathrm{Q}_{\mathrm{c}}+\left(\mathrm{Q}_{\mathrm{c}}{ }^{2}+4 \mathrm{~L} \cdot\left(\mathrm{s}_{1}+\mathrm{s}_{2} \cdot \mathrm{g}^{*}\right)\left(\mathrm{c}_{2}{ }^{-1}+\theta^{2} \cdot \mathrm{c}_{1}{ }^{-1}\right)\right)^{1 / 2}\right]$ & $0<\mathrm{g}<1$ \\
$\varepsilon_{l, 1}=$ & $1 / 2 \cdot\left[\mathrm{Q}_{\mathrm{c}}-\left(\mathrm{Q}_{\mathrm{c}}{ }^{2}-4 \mathrm{~L} \cdot\left(\mathrm{c}_{2}{ }^{-1}+\theta^{2} \cdot \mathrm{c}_{1}{ }^{-1}\right)\right)^{1 / 2}\right]$ & $\mathrm{g}=1$ \\
$\varepsilon_{l, 2}=$ & $1 / 2 \cdot\left[\mathrm{Q}_{\mathrm{c}}-\left(\mathrm{Q}_{\mathrm{c}}{ }^{2}-4 \mathrm{~L} \cdot \mathrm{s}_{1}\left(\mathrm{c}_{2}{ }^{-1}+\theta^{2} \cdot \mathrm{c}_{1}{ }^{-1}\right)\right)^{1 / 2}\right]$ & $\mathrm{g}=0$ \\
$\varepsilon_{l, 3}=$ & $1 / 2 \cdot\left[\mathrm{Q}_{\mathrm{c}}-\left(\mathrm{Q}_{\mathrm{c}}{ }^{2}-4 \mathrm{~L} \cdot\left(\mathrm{s}_{1}+\mathrm{s}_{2} \cdot \mathrm{g}^{*}\right) \cdot\left(\mathrm{c}_{2}{ }^{-1}+\theta^{2} \cdot \mathrm{c}_{1}{ }^{-1}\right)\right)^{1 / 2}\right]$ & $0<\mathrm{g}<1$ \\
$\varepsilon_{\mathrm{e}, 1}=$ & $\left(\mathrm{L} / \mathrm{Q}_{\mathrm{c}}\right) \cdot\left(\mathrm{c}_{2}{ }^{-1}+\theta^{2} \cdot \mathrm{c}_{1}{ }^{-1}\right)$ & $\mathrm{g}=1$ \\
$\varepsilon_{\mathrm{e}, 2}=$ & $\left(\mathrm{L} \cdot \mathrm{s}_{1} / \mathrm{Q}_{c}\right) \cdot\left(\mathrm{c}_{2}{ }^{-1}+\theta^{2} \cdot \mathrm{c}_{1}{ }^{-1}\right)$ & $\mathrm{g}=0$ \\
$\varepsilon_{\mathrm{e}, 3}=$ & $\left(\mathrm{L} / \mathrm{Q}_{c}\right) \cdot\left(\mathrm{s}_{1}+\mathrm{s}_{2} \cdot \mathrm{g}^{*}\right) \cdot\left(\mathrm{c}_{2}{ }^{-1}+\theta^{2} \cdot \mathrm{c}_{1}{ }^{-1}\right)$ & $0<\mathrm{g}<1$
\end{tabular}

Note: Subscript 1 represents the critical values when $\mathrm{g}^{*}=1$, subscript 2 represents the critical values when $\mathrm{g}^{*}=0$, and subscript 3 represents the critical values when $0<\mathrm{g}^{*}<1$.

Table 5.3 gives an overview of the critical values on $\varepsilon$ for alternative levels of $\mathrm{g}^{*}$. Table 5.4 gives a summary overview of the directors' decision on $Q^{*}, q^{*}{ }_{1}$ and $q^{*}{ }_{2}$ for alternative combinations of levels of $\varepsilon$ and $\delta$. 
From table 5.3 it is a trivial observation that:

$$
\begin{aligned}
& \varepsilon_{\mathrm{u}, 1}>\varepsilon_{\mathrm{u}, 3}>\varepsilon_{\mathrm{u}, 1}, \\
& \text { and } \\
& \varepsilon_{l, 1}>\varepsilon_{l, 3}>\varepsilon_{l, 1} .
\end{aligned}
$$




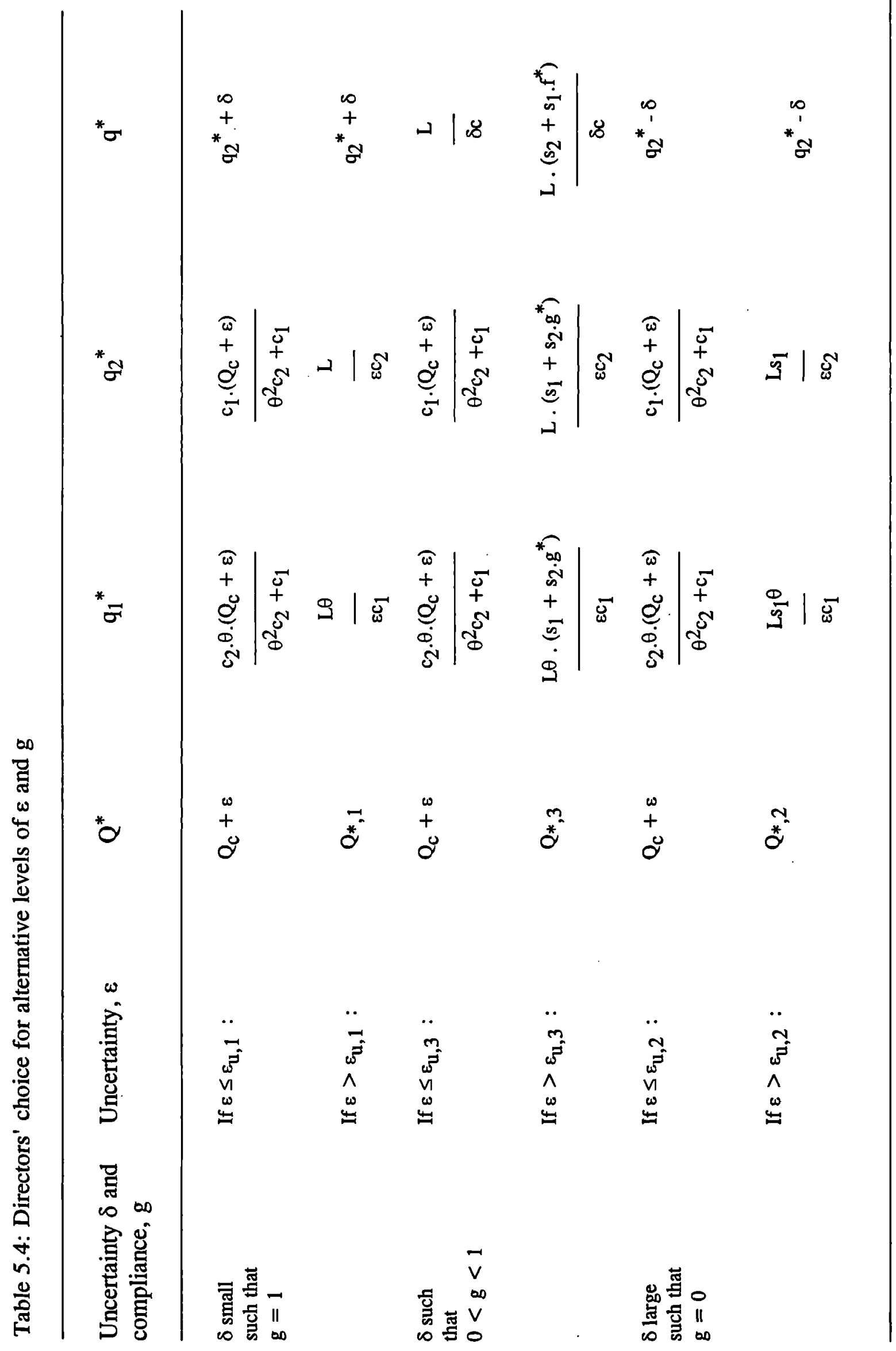


Graph 5.4 illustrates how the directors' choice, $Q^{*}$, as a function of $\varepsilon$ for the two extreme cases, namely when uncertainty for auditors is very small (such that $g=1$ ) and very large (such that $\mathrm{g}=0$ ). Recall that when $\mathrm{g}=0$ holds, the auditors are perceived to act as insurers, since the will always be held liable. Graph 5.4 also shows how the critical values, $\varepsilon_{\mathrm{u}}$ and $\varepsilon_{l}$ change in the two extreme cases.

For a given level of uncertainty about the directors due care level, $\varepsilon$, directors will never demand more $Q^{*}$ when uncertainty about the auditors due care level, $\delta$, is very large (such that $g=0$ ) than when $\delta$ is very small (such that $g=1$ ). If the uncertainty about the directors' due care level, $\varepsilon$, is very small, namely if $\varepsilon \leq \varepsilon_{\mathbf{u}, 2}$, the uncertainty about the auditor's due care level does not affect the directors' decision. In graph 5.4 the $\mathrm{Q}^{*}{ }_{1}$ and $\mathrm{Q}_{2}^{*}$ lines coincide. Directors will always overprotect and demand $\mathrm{Q}_{\mathrm{c}}+\varepsilon$. However, if $\varepsilon$ $>\varepsilon_{\mathbf{u}, 2}$, uncertainty about the auditors' due care level does affect the directors' decision. When $\delta$ is very small such that $g=1$, the directors will still demand $Q_{c}+\varepsilon$, if $\varepsilon \leq \varepsilon_{\mathrm{u}, 1}$. For any $\varepsilon>\varepsilon_{\mathrm{u}, 1}$ directors will demand $\mathrm{Q}_{*, 1}$. Both $\mathrm{Q}_{\mathrm{c}}+\varepsilon$ and $\mathrm{Q}_{*, 1}$ are larger than $\mathrm{Q}_{*, 2}$. The latter represents the level of overall quality demanded when $\delta$ is very large such that $\mathrm{g}=0$. In conclusion, for any $\varepsilon>\varepsilon_{\mathrm{u}, 2}$ it holds that $\mathrm{Q}^{*}{ }_{2}<\mathrm{Q}^{*}{ }_{1}$. In graph 5.4 the $\mathrm{Q}^{*}{ }_{1}$ and $\mathrm{Q}_{2}^{*}$ lines start to be different values of $\varepsilon$ beyond $\varepsilon_{\mathrm{u}, 2}$.

Note that not only $\mathrm{Q}^{*}{ }_{2}<\mathrm{Q}^{*}$. holds when $\varepsilon>\varepsilon_{\mathrm{u}, 2}$. The chosen levels of both internal and external audit quality demand will be larger when uncertainty about the external audit quality norm is very small (and $g=1$ ) than when the latter uncertainty is very large (and $\mathrm{g}=0$ ). This can be concluded from table 5.4 .

When the the auditor's uncertainty, $\delta$, is such that $0<\mathrm{g}^{*}<1$ holds, the $\mathrm{Q}_{*, 3}$ curve will be located somewhere in between the $Q^{*}, 2$ curve and the $Q^{*}, 1$ curve in graph 5.4 . The exact shape and location will depend on the size of the optimal $\mathrm{g}^{*}$. If $\varepsilon>\varepsilon_{\mathrm{u}, 3}$, the directors' choice will be smaller than when $g=1$, but larger than when $g=0$. 
Graph 5.4: The directors' choice, $Q^{*}$, as a function of $\varepsilon$ and $\mathrm{g}$

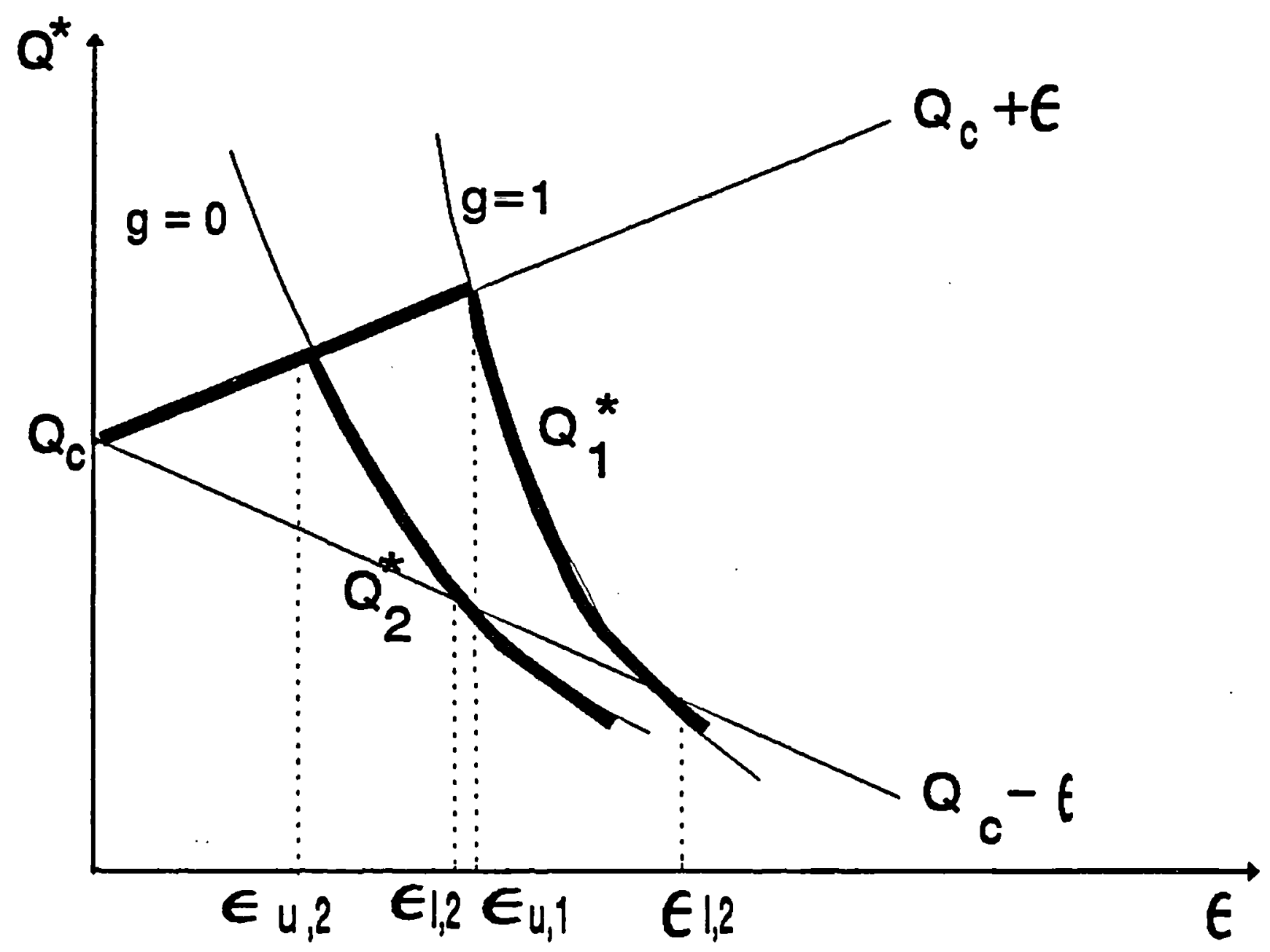




\section{Proposition 5.6}

When the uncertainty about the due care level applying to the directors is sufficiently small $^{84}$, uncertainty about the external audit quality standard does not affect the directors' quality decision, and directors will choose a level of overall financial statement quality demand such that they comply with certainty with the due care level.

Note that, when proposition 5.6 is applicable to a legal environment, liability insurance grounds for external audit demand are irrelevant.

\section{Proposition 5.7}

If uncertainty about the directors' due care level is sufficiently large ${ }^{85}$, and if uncertainty about auditor's due care level is so large that they are perceived to be liability insurers ${ }^{86}$, directors will demand less overall financial statement quality and external audit quality than when external auditors are not perceived as liability insurers.

The intuition behind proposition 5.7 is as follows. When auditors provide complete insurance, the directors' expected damage payments decrease, and the marginal benefit from demanding external audit services is lower at all feasible levels of demand. A lower level of demand is the result.

\section{Statutory audit requirements and uncertainty about liability}

This section examines whether statutory audit requirements should be imposed when the quality norms applying to directors and external auditors are uncertain. Since it is the produced level of overall financial statement quality that matters to users, rather

\footnotetext{
${ }^{84}$ By this it is meant that $\varepsilon \leq \varepsilon_{\mathrm{u}, 2}$.

${ }^{85}$ By this it is meant that $\varepsilon>\varepsilon_{\mathrm{u}, 2}$.

${ }^{86}$ By this it is meant that $\delta$ is such that $g=0$. If $g=0$, external auditors are believed to be always held liable. Therefore they can be seen as insurers.
} 
than the level demanded, the effect of imposing $\mathrm{q}_{\mathrm{r}}$ on demand and production of external audit quality needs to be analysed. It is assumed (as in the certainty case in subsection 3.3) that the external auditor's production behaviour is as conjectured by the directors. Since $\mathrm{q}_{2}{ }^{*}$ is known after the demand decision, $\mathrm{q}^{*}$ is easily derived from the reaction function. Three questions are relevant in this context. First, what are the conditions for statutory audit requirements to be effective in increasing the produced level of overall financial statement quality. Second, in which situations is an increase in produced overall financial statement quality needed? And, third, are statutory audit requirements effective when needed? The first question is addressed in subsection 5.1. The second and third question in subsection 5.2.

\subsection{The effectiveness of statutory audit requirements}

In general, three conditions apply for statutory audit requirements to have an increasing effect on the level of overall financial statement quality produced. These are:

$$
\begin{aligned}
& \mathrm{q}_{\mathrm{r}}>\mathrm{q}_{2}{ }^{*} \\
& \mathrm{q}^{\prime}>\mathrm{q}^{*} \\
& \mathrm{Q}_{\mathrm{p}}{ }^{\prime}>\mathrm{Q}_{\mathrm{p}}{ }^{*}
\end{aligned}
$$

Where:

$\mathrm{q}_{\mathrm{r}}=$ the level of external audit quality implied by statutory audit requirement; $\mathrm{q}_{2}{ }^{*}=$ the level of external audit quality in the absence of a statutory audit requirement; or when the requirement is set below this level;

$q^{\prime}=$ the level of external audit quality produced by the external auditor when there are statutory audit requirements;

$\mathrm{q}^{*}=$ the level of external audit quality produced by the external auditor when there are no statutory audit requirements; 
$\mathrm{Q}_{\mathrm{p}}{ }^{\prime}=$ the level of overall financial statement quality produced when there are statutory audit requirements;

$\mathrm{Q}_{\mathrm{p}}{ }^{*}=$ the level of overall financial statement quality produced when there are no statutory audit requirements.

In the remainder of this analysis it is assumed that condition (5.15) is fulfilled. If (5.15) is not fulfilled, there would be no effect on external audit demand, and conditions (5.16) and (5.17) would also not be fulfilled. Condition (5.16) is now examined. From the analysis in section 4.1 it follows that the produced level of external audit quality without statutory audit requirement is:

$$
q^{*}=\min \left(q_{2}{ }^{*}+\delta, q_{*}=1 / c \delta \cdot L \cdot\left[s_{2}+s_{1} \cdot f^{*}\right]\right\}
$$

Where $\mathrm{f}^{*}$ is the probability that directors comply given their decision on $\mathrm{q}_{1}{ }^{*}$ and $\mathrm{q}_{2}{ }^{*}$. The produced level of external audit quality with statutory audit requirement is:

$$
q^{\prime}=\min \left\{q_{r}+\delta, q^{\prime}=1 / c \delta \cdot L \cdot\left[s_{2}+s_{1} \cdot f^{\prime}\right]\right\}
$$

The effect of the statutory audit requirement on the produced level of external audit quality depends on the level of $\mathrm{q}_{\mathrm{r}}$ and $f^{\prime}$. Two different situations are identified: First, the case where staturory audit requirements are set at a level below the level of overall financial statement quality which would be demanded if there were no requirement.Second, the case where staturory audit requirements are set at a level above the level of overall financial statement quality which would be demanded if there were no requirement. In the first case, that if $\mathbf{q}_{2}{ }^{*}<\mathbf{q}_{\mathbf{r}}<\mathbf{Q}^{*}$, it follows that $\mathrm{f}^{\prime}=\mathrm{f}^{*}$. This is so because the level of overall financial statement quality demanded does not change when statutory audit requirements are introduced; the increase in external audit demand is at the expense of internal audit demand which decreases. Graph 5.5 illustrates the effect of $\mathrm{q}_{\mathrm{r}}$ on $\mathrm{q}^{\prime}$ in this situation. Here, external audit quality production only increases when 
uncertainty about the external audit quality norm is sufficiently small, that is if without such a requirement $\delta<\delta_{\mathrm{u}}$ held. In the second case, that is if $\mathbf{q}_{\mathbf{r}}>\mathbf{Q}^{*}$, it follows that $\mathrm{f}^{\prime}>$ $f^{*}$. Graph 5.6 illustrates the effect of $q_{r}$ on $q^{\prime}$ in this situation. Here, the statutory audit requirement will always have the effect of an increased level of produced external audit quality. 
Graph 5.5: The auditor's reaction to increased demand from imposing a statutory audit requirement, where $q_{2}^{*}<g_{r}<Q^{*}$, and hence $f^{\prime}=f^{*}$.

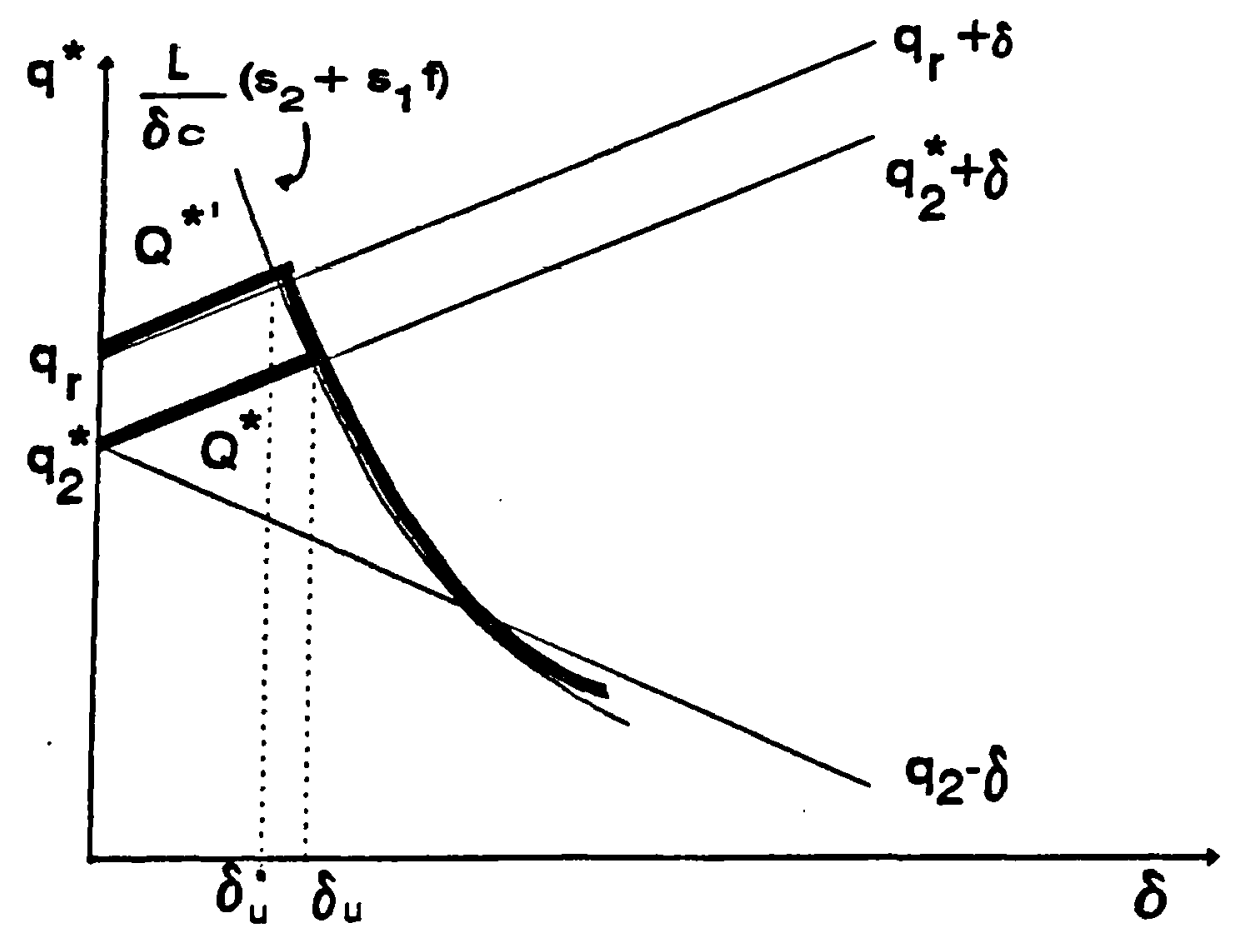

Graph 5.6: The auditor's reaction to increased demand from imposing a statutory audit requirement, where $q_{r}>Q^{*}$, and hence $f^{\prime}>f^{*}$ :

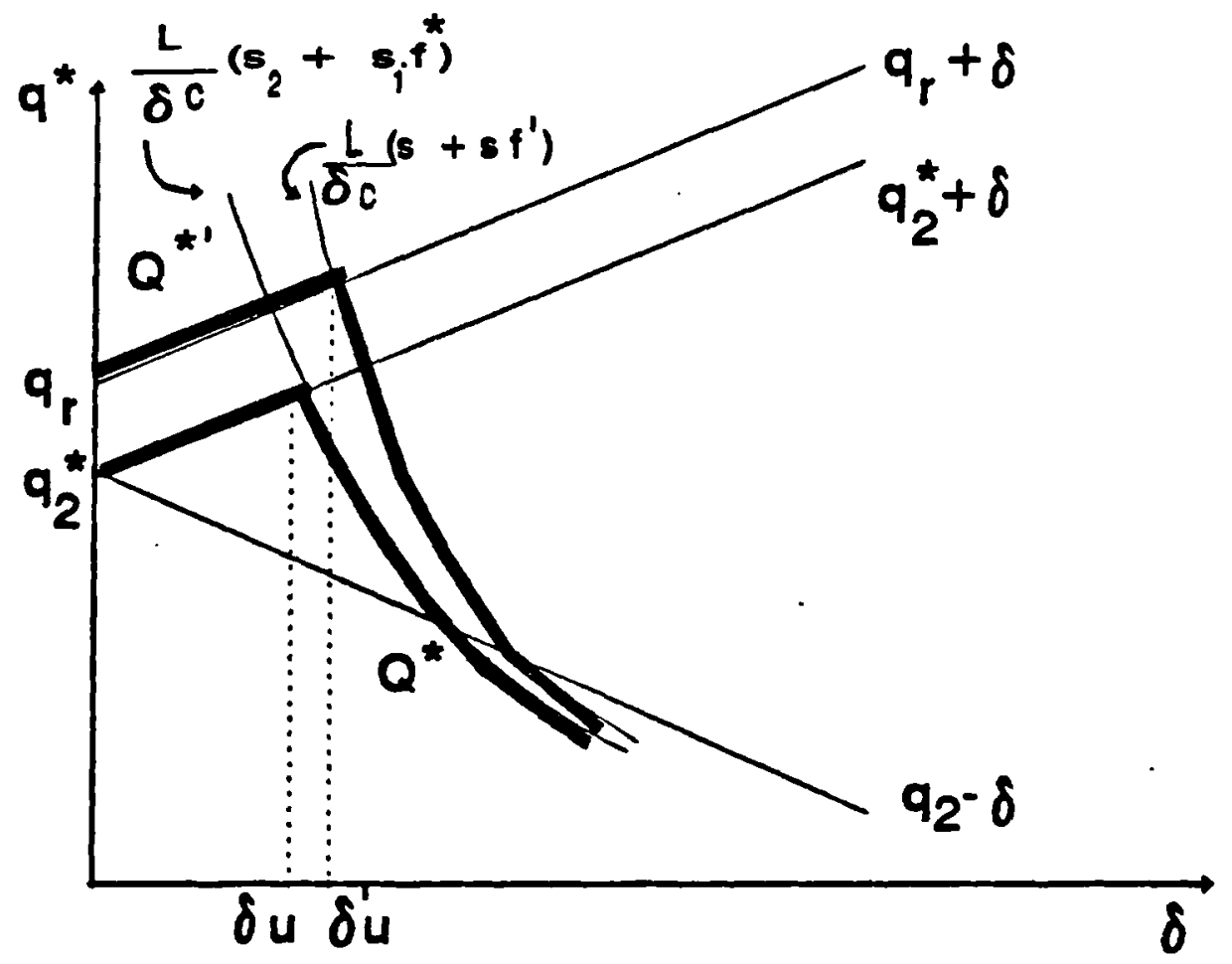


Condition (5.17) states that the produced level of overall financial statement quality with a statutory audit requirement must be larger than without. An increased level of external audit quality production (condition 5.16) is not a sufficient condition for increased production of overall financial statement quality. The reason is that the level of produced internal audit quality may decrease when a staturory audit requirement is imposed. Let the level of overall financial statement quality produced with a statutory audit requirement, denoted by $\mathrm{Q}_{\mathrm{p}}{ }^{\prime}$, be defined as:

$$
\mathrm{Q}_{\mathrm{p}}{ }^{\prime}=\theta \cdot \mathrm{q}^{\prime}+\mathrm{q}^{\prime}
$$

where $q_{1}$ is defined as the level of internal audit quality produced when there is a statutory audit requirement. By replacing $Q_{p}{ }^{*}$ and $Q_{p}{ }^{\prime}$ by the RHS of equations (5.5) and resp. (5.20), and rearranging the terms, condition (5.17) can be expressed as:

$$
q^{\prime}-q^{*}>\theta \cdot q_{1}^{*}-\theta \cdot q_{1}^{\prime}
$$

\subsubsection{Analysis when $f^{*}=f^{\prime}$}

If $\mathbf{q}_{2}{ }^{*}<\mathbf{q}_{\mathbf{r}}<\mathrm{Q}^{*}$, and hence $\mathrm{f}^{\prime}=\mathrm{f}^{*}$ holds, the increase in external audit demand is at the expense of internal audit demand, which decreases. The term at the RHS of condition (5.21) is thus strictly positive. Consequently, the term on the LHS of (5.21) also needs to be strictly positive (and larger). From graph 5.5 it is obvious that $\mathrm{q}^{\prime}=\mathrm{q}^{*}$ holds if $\delta \geq$ $\delta_{\mathrm{u}}$ holds. When uncertainty about the external auditor's due care level is such that external auditor compliance before the imposition of a statutory audit requirement, $\mathrm{g}$, is strictly smaller than 1, the LHS in condition (5.21) is zero, and thus smaller than the RHS. Condition (5.17) is not fulfilled. The statutory audit requirement has the effect of decreasing the level overall financial statement quality produced. If $\delta \leq \delta_{u}$, and auditor 
compliance before the statutory audit requirement was equal to 1 , two situations can occur, namely 1) $\mathbf{q}^{\prime}=\mathbf{q}_{\mathbf{r}}+\delta$, if $\delta \leq \delta_{u}^{\prime}$, and 2) $\mathbf{q}^{\prime}<\mathbf{q}_{\mathbf{r}}+\delta$ if $\delta_{u}^{\prime}<\delta<\delta_{\mathrm{u}}$. Note that $\delta_{u}^{\prime}$ is the critical value for $\delta$ at which $\mathrm{q}_{*}^{\prime}=\mathbf{q}_{\mathrm{r}}+\delta$, when there is a statutory audit requirement. From graph 5.5 it is clear that $\delta_{u}^{\prime}<\delta_{u}$ holds. In the first case, when $q^{\prime}=q_{r}$ $+\delta$ holds, the LHS of condition (5.21) becomes:

$$
q^{\prime}-q^{*}=q_{r}+\delta-\left(q_{2}^{*}+\delta\right)=q_{r}-q_{2}^{*}
$$

As $f$ remains constant, it holds that demand of overall financial statement quality remains the same with or without a statutory audit requirement (that is, $Q^{* \prime}=Q^{*}$ ), and hence:

$$
\mathrm{Q}^{*}=\theta \cdot \mathrm{q}_{1}{ }^{\prime}+\mathrm{q}_{\mathrm{r}}
$$

Or:

$$
\theta \cdot \mathrm{q}_{1}{ }^{\prime}=\mathrm{Q}^{*}-\mathrm{q}_{\mathrm{r}}
$$

By putting the RHS of (5.22) in condition (5.21), and rearranging the terms, this condition becomes:

$$
\mathrm{Q}^{*}>\theta \cdot \mathrm{q}_{1}^{*}+\mathrm{q}_{2}^{*}
$$

It is clear that this can never be fulfilled, as $Q^{*} \equiv \theta \cdot q_{1}{ }^{*}+q_{2}{ }^{*}$. The conclusion is that in this case the produced level of overall financial statement quality stays the same. The imposition of a staturory audit requirement has no impact. 
In the second case, when $\mathbf{q}^{\prime}<\mathbf{q}_{\mathbf{r}}+\delta$ holds, because $\delta$ is such that $\delta_{u}^{\prime}<\delta<\delta_{\mathrm{u}}$ holds, it is trivial that the produced level of overall financial statement quality with statutory audit requirement will be smaller than without.

The overall conclusion is that a statutory audit requirement will never increase the level of overall financial statement quality produced, when set below the level of overall financial statement quality that directors would demand without such a requirement. There will be no impact on the overall level of financial statement quality produced, when the level of uncertainty about the external auditors due care level, $\delta$, is smaller than $\delta_{\mathrm{u}^{\prime}}^{\prime}$. However, if $\delta$ is larger than $\delta_{\mathrm{u}^{\prime}}^{\prime}$, the effect of a statutory audit requirement is to decrease the overall level of financial statement quality produced.

\section{Proposition 5.8}

When there is uncertainty about the due care levels applying to directors and external auditors, statutory audit requirements should not be imposed, if they only have an effect on external audit demand, but have no effect on the level of overall financial statement quality demanded.

\subsubsection{Analysis when $f^{*}>f^{\prime}$}

If $\mathbf{q}_{\mathbf{r}}>\mathbf{Q}^{*}$, and hence $\mathrm{f}^{\prime}>\mathrm{f}^{*}$, it follows that the level of overall financial statement quality demanded with a statutory audit requirement, denoted by $Q^{*}$, will be exactly $q_{r}$ and $\mathrm{q}_{1}{ }^{\prime}$ will be equal to zero. Only external audit quality will be demanded. In this case the condition in (5.21) becomes:

$$
q^{\prime}-q^{*}>\theta \cdot q_{1}^{*}
$$


From graph 5.6 it is clear that the LHS of (5.23) is always positive, since q' will always be strictly larger than $\mathrm{q}^{*}$. Four situations are possible here. This is due to the fact that $\delta_{\mathrm{u}}^{\prime}$ can be either larger or smaller than $\delta_{\mathrm{u}}$. (see also section 4.1.2), depending on the other parameters. These situations are given in table 5.5, together with the corresponding situation specific conditions ${ }^{87}$

${ }^{87}$ These situation specific conditions are derived by putting the corresponding values for $q^{\prime}$ and $q^{*}$ in condition (5.23). 
Table 5.5: Conditions for increased overall level of financial statement quality produced, when $\mathbf{q}_{\mathbf{r}}>\mathbf{Q}^{*}$, and hence $\mathrm{f}^{\prime}>\mathrm{f}^{*}$.

$\begin{array}{lll}\text { External audit quality } & \begin{array}{l}\text { External audit quality } \\ \text { production after }\end{array} & \text { Condition for } Q_{n}{ }^{\prime}>Q_{n}{ }^{*} \\ \text { statutory requirement } & \text { statutory requirement } & \end{array}$
A) $\quad q^{\prime}=q_{r}+\delta$
$q^{*}=q_{2}^{*}+\delta$
$\theta \cdot q_{1}^{*}<q_{r}-q_{2}^{*}$, or
$\mathrm{Q}^{*}<\mathrm{q}_{\mathrm{r}}$
B) $\quad q^{\prime}=L / \delta c \cdot\left(s_{2}+s_{1} \cdot f^{\prime}\right) \quad q^{*}=q_{2}^{*}+\delta$
$\theta \cdot \mathrm{q}_{1}^{*}<\mathrm{q}^{\prime}-\mathrm{q}_{2}^{*}-\delta$, or
$Q^{*}<q^{\prime}-\delta$
C) $\quad q^{\prime}=q_{r}+\delta$
$q^{*}=L / \delta c \cdot\left(s_{2}+s_{1} \cdot f^{*}\right)$
$\theta \cdot \mathrm{q}_{1}^{*}<\mathrm{q}_{\mathrm{r}}+\delta-\mathrm{q}^{*}$
D) $\quad q^{\prime}=L / \delta c \cdot\left(s_{2}+s_{1} \cdot f^{\prime}\right)$
$q^{*}=L / \delta c \cdot\left(s_{2}+s_{1} \cdot f^{*}\right)$
$\theta . q_{1}^{*}<\mathrm{L} . \mathrm{s}_{1} / \delta \mathrm{c} .\left(\mathrm{f}^{\prime}-\mathrm{f}^{*}\right)$

Situation A occurs when uncertainty about the external audit quality standard is relatively small, and $\delta<\delta_{\mathrm{u}}$ as well as $\delta<\delta_{\mathrm{u}}^{\prime}$ holds. Condition (5.23) is here always fulfilled (by assumption). The overall financial statement quality produced will be larger with statutory requirement than without. Statutory audit requirements are effective here. Situation B occurs when $\delta<\delta_{\mathrm{u}}$ but $\delta>\delta_{\mathrm{u}}^{\prime}$ holds. Here, condition (5.23) can be fulfilled when the demanded level of overall financial statement quality before statutory audit requirements was very low. Situation $C$ occurs when $\delta>\delta_{u}$ but $\delta<\delta_{u}^{\prime}$. Finally, situation D occurs when $\delta>\delta_{\mathrm{u}}$ and $\delta>\delta_{\mathrm{u}}^{\prime}$. Here, the larger the difference is between $f^{\prime}$ and $f^{*}$, the more likely that condition (5.23) will be fulfilled. This is the case when the demanded level of overall financial statement quality without statutory audit requirement was relatively small compared to the level imposed by the requirement.

The overall conclusion is that a statutory audit requirement may increase the level of overall financial statement quality produced, when this requirement is set above the 
The overall conclusion is that a statutory audit requirement may increase the level of overall financial statement quality produced, when this requirement is set above the level of overall financial statement quality that directors would demand without such a requirement. This is always the case when the uncertainty about the external auditor's due care level is very small (and $\delta<\delta_{\mathrm{u}}$ as well as $\delta<\delta_{\mathrm{u}}^{\prime}$ ). In all other situations, the gain from a higher level of external audit quality production must be larger than the level of internal audit quality that would have been produced without a statutory audit requirement, times the relative importance weigth of internal audit quality in achieving overall financial statement quality, or $\theta$.

\section{Proposition 5.9}

When there is uncertainty about the due care levels applying to directors and external auditors, statutory audit requirements always have a positive effect on the level of overall financial statement quality that is produced when set at a high enough level 88 and when uncertainty about the external auditor's due care level is sufficiently small ${ }^{89}$.

An implication of proposition 5.9 is that the effectiveness of statutory audit requirements is only guaranteed in environments where there is no liability insurance rationale for external audit demand.

\subsection{Need and effectiveness of statutory audit requirements}

Table 5.6 provides an overview of the level of produced overall financial statement quality $\left(\mathrm{Q}_{\mathrm{p}}{ }^{*}\right)$ for alternative levels of overall quality demanded $\left(\mathrm{Q}^{*}\right)$ and external audit

\footnotetext{
${ }^{88}$ By this it is meant at a level above the level of overall financial statement quality that directors would demand without such a requirement, or $\mathrm{q}_{\mathrm{r}}>\mathrm{Q}^{*}$

${ }^{89} \mathrm{By}$ this it is meant that $\delta<\delta_{\mathrm{u}}$ as well as $\delta<\delta_{\mathrm{u}}^{\prime}$ hold.
} 
quality produced $\left(\mathrm{q}^{*}\right)$ in the absence of statutory audit requirements (or when $\mathrm{q}_{\mathrm{r}}$ is set below $\mathrm{q}_{2}{ }^{*}$ ). Recall from equation (5.5) that $\mathrm{Q}_{\mathrm{p}}{ }^{*}=\theta \cdot \mathrm{q}_{1}{ }^{*}+\mathrm{q}^{*}$. From table 5.6 it is clear that the produced level of overall financial statement quality is at least $Q_{c}$ when: $q^{*} \geq q_{2}$ and $\mathrm{Q}^{*} \geq \mathrm{Q}_{\mathrm{c}}$. This implies that statutory audit requirements are redundant when $\varepsilon \leq \varepsilon_{\mathrm{e}}$ and the corresponding $\delta \leq \delta_{\mathrm{e}}$. An increase in produced overall financial statement quality is needed in situations 1,2 and 4 in table 5.6. In situations 3 and 7 the produced overall financial statement quality can be either larger or smaller than $Q_{c}$. An increase is only needed when it is smaller. 
Table 5.6: The need for statutory audit requirements

$$
\mathrm{Q}^{*}<\mathrm{Q}_{\mathrm{c}} \quad \mathrm{Q}^{*}=\mathrm{Q}_{\mathrm{c}} \quad \mathrm{Q}^{*}>\mathrm{Q}_{\mathrm{c}}
$$
$\mathrm{q}^{*}<\mathrm{q}_{2}$
(1) $\mathrm{Q}_{\mathrm{n}}{ }^{*}<\mathrm{Q}_{\mathrm{c}}$
(2) $Q_{n}^{*}<Q_{c}$
(3) $\mathrm{Q}_{\mathrm{n}}{ }^{*}<\mathrm{Q}_{\mathrm{c}}$
$\mathrm{Q}_{\mathrm{n}}{ }^{*}=\mathrm{Q}_{\mathrm{c}}$
$\mathrm{Q}_{\mathrm{n}}{ }^{*}>\mathrm{Q}_{\mathrm{c}}$
$\mathrm{q}^{*}=\mathrm{q}_{2}$
(4) $\mathrm{Q}_{\mathrm{n}}{ }^{*}<\mathrm{Q}_{\mathrm{c}}$
(5) $\mathrm{Q}_{\mathrm{n}}{ }^{*}=\mathrm{Q}_{\mathrm{c}}$
(6) $\mathrm{Q}_{\mathrm{n}}{ }^{*}>\mathrm{Q}_{\mathrm{c}}$
$\mathrm{q}^{*}>\mathrm{q}_{2}$
(7) $\mathrm{Q}_{\mathrm{n}}{ }^{*}<\mathrm{Q}_{\mathrm{c}}$
$\mathrm{Q}_{\mathrm{n}}{ }^{*}=\mathrm{Q}_{\mathrm{c}}$
$\mathrm{Q}_{\mathrm{n}}{ }^{*}>\mathrm{Q}_{\mathrm{c}}$
(8) $\mathrm{Q}_{\mathrm{n}}{ }^{*}>\mathrm{Q}_{\mathrm{c}}$
(9) $\mathrm{Q}_{n}{ }^{*}>\mathrm{Q}_{\mathrm{c}}$

Note: recall from section 3.3 that $\mathrm{Q}_{\mathrm{p}}{ }^{*}$ is the level of overall financial statement quality produced in the absence of statutory audit requirements, or when the requirement is set such that it is lower than $\mathrm{q}_{2}{ }^{*}$.

When situations 2 or 3 in table 5.6 hold, statutory audit requirements would however not improve the overall financial statement quality produced. The reason is that in those cases $f^{\prime}$ will be equal to $f^{*}$. This follows from the assumption that the level of quality implied by a statutory audit requirement is not larger than the legally required level of overall financial statement quality imposed on directors, or: $Q_{c} \geq q_{r}$ (see also subsection 3.3).In situation 2 of table $5.6, Q^{*}=Q_{c}$ and in situation $3, Q^{*}>Q_{c}$. The result is that in both situations $\mathrm{q}_{\mathrm{r}}$ cannot be larger than $\mathrm{Q}^{*}$. From proposition 5.8 in subsection 5.1 it follows that no statutory audit requirements should be imposed in situations 2 and 3 . The low quality production behaviour by the external auditors $\left(\mathrm{q}^{*}<\mathrm{q}_{2}\right)$ cannot be cured by imposing a statutory audit requirement. Note that situations 2 and 3 occur when $\varepsilon \leq$ 
$\varepsilon_{\mathrm{e}}$. A general conclusion is that when $\varepsilon \leq \varepsilon_{\mathrm{e}}$ holds, staturory audit requirements are either redundant (see previous paragraph) or not effective (and may even be harmful, see subsection 5.1). Only in situations 1,4 and 7 as listed in table 5.6, that is when $\varepsilon>$ $\varepsilon_{\mathrm{e}}$, statutory audit requirements may be effective, since $f$ can be increased. However, $\mathrm{Q}_{\mathrm{p}}{ }^{\prime}$ will only be strictly larger than $\mathrm{Q}_{\mathrm{p}}{ }^{*}$ when condition (5.23) is fulfilled. When $\delta$, or the uncertainty about the external auditor's due care level is relatively small, in the sense that proposition 5.9 is applicable, there will be a certain improvement. This might be the case for situation 7 in table 5.6.

\section{Conclusions}

This chapter has focused on two major issues: 1) the joint effect of director and auditor liability on demand for overall financial statement quality, and 2) the impact of a statutory external audit requirement on demand and production of overall financial statement quality. The major results from the analysis are summarised in this section. When the due care levels applying to directors and external auditors are known with certainty, both auditors and directors will comply with them. In this situation no liability insurance can be obtained from external auditors. Further, statutory audit requirements are redundant, and should not be imposed since they would either have no effect or would work cost increasing.

Uncertainty about the respective due care levels of directors and external auditors changes both parties' behaviour. At large enough levels of uncertainty about the external auditor's due care level, auditor compliance is no longer guaranteed. In such situations external auditors (are perceived to) provide (at least some) liability insurance to directors. The external auditor (is believed to) provides complete liability insurance when uncertainty about his due care level is so large that he will produce external audit 
quality levels which certainly not comply with the due care level. If in such a situation the directors would only acquire external audit services, and no internal audit services, they would never be held liable in a litigation case.

Demand for overall financial statement quality changes when the respective due care levels are uncertain. When uncertainty about the directors' due care level is very small, the liability insurance arguments for external audit demand are irrelevant. Directors will always demand more than what is required such that they comply with certainty. For larger levels of uncertainty about the directors' due care level, external auditor liability becomes relevant for the demand decision. The analysis has shown that in this situation a lower level of external audit quality will be demanded when external auditors provide complete liability insurance, than when they provide no liability insurance at all. When external audit quality production is low, cost minimising directors need to demand less.

When the due care levels are uncertain, statutory audit requirements which would have no effect on the level of overall financial statement quality demanded, and only on the level of external audit demanded, should no be imposed. They would either have no effect or would even decrease the level of overall financial statement quality produced. This is the case when uncertainty about the directors' due care level is not too large, such that more financial statement quality is demanded than the expected due care level. In situations where the level of overall financial statement quality produced is low due to low quality producing behaviour from the part of the external auditor, statutory audit requirement do not make sense.

Statutory audit requirements can only have a positive effect on overall quality produced when uncertainty about the directors' due care level is large enough, in the sense that they would demand less financial statement quality than the expected due care level. In this situation, a guaranteed improvement in overall quality produced exists when the 
external auditor does not provide liability insurance and always complies with the due care level. However, statutory audit requirements may also improve overall quality produced when the external auditor provides (partial) liability insurance, as long as the increase in produced external audit quality is not offset by the decrease in produced internal audit quality. 


\section{Chapter 6:}

\section{Auditor liability, professional audit standards and}

\section{audit quality production}

\section{Introduction}

Prior economic models of audit production have ignored the legal environment in which the auditor operates. In this chapter the auditor's quality production behaviour is analysed from a micro-economic perspective, taking the legal environment in which the auditor operates into account. The major objectives are to examine the effect on audit quality production of 1) the level of the legal standard of care, 2) uncertainty about the legal standard of care; 3 ) professional audit quality standards (or ex ante standards); and 4) restrictions on auditor liability. For a number of alternative regulatory scenarios, conclusions are drawn regarding the private audit quality production choice for an individual audit engagement.

The structure of this chapter is as follows. In section 2, the major assumptions underlying the analysis are given. In section 3 the auditor's production behaviour for an individual audit engagement is analysed when legal standards of care are certain. In section 4 , audit quality production is investigated when there is uncertainty over the finding of negligence. The impact of complementary regulatory policies on audit quality production under uncertainty is examined in the subsequent two sections. In section 5 it is examined how the results change when an ex ante audit quality standard is introduced. The focus in section 6 is on the effect of policies which restrict auditor liability, both when there is an ex ante quality standard and when there is no such standard specified, or when it is set at a very low level. Conclusions are summarised in section 7 . 


\section{The auditor's decision environment: assumptions and definitions}

\subsection{Assumptions}

Throughout this chapter it is hypothesised that the auditor is liable for losses to third party users of audited financial statements, that this liability is subject to a standard of negligence, and that the auditor controls this legal exposure by managing the audit quality he produces. Since the expected monetary consequences (damage payments) of litigation are different across the engagements an auditor accepts, liability is presumed to be managed per individual engagement, and the optimal audit quality level produced may differ across engagements within the same audit firm and across audit firms ${ }^{90}$. The notion of 'audit quality' can be seen as related to the levels of assurance that the financial statements are free of errors. This implies that in selecting the audit quality level to produce, the auditor makes a decision as to the level of audit risk he is willing to accept for a particular engagement, since 'levels of assurance' can be seen as the complement of audit risk ${ }^{91}$. The auditor's decision is modelled such that audit quality and hence audit risk are the output rather than the input in the auditor's production decision problem. The model developed in this chapter is related to the 'audit modelling

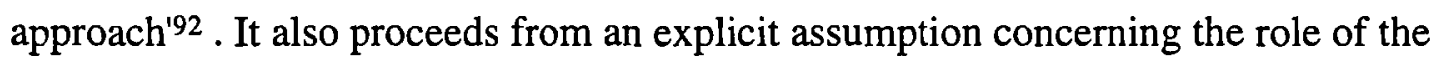
auditor in society, which is to optimise rather than to minimise financial statement error for all engagements in a society ${ }^{93}$. The auditor's production choice problem is recast in terms of the optimisation of an auditor objective function which is based on maximisation of subjective expected utility. The model is different from other models

\footnotetext{
90 This differs from approaches that model the auditor's production function such that a constant target audit quality level for all engagements has to be achieved within an audit firm (See, O'Keefe et al. (1992)).

${ }^{91}$ Levels of assurance $=1$ - audit risk.

92 See also chapter 2 for the characteristics of this approach, as defined by Cushing \& Loebbecke (1983).

93 The social efficiency of liability regulation, given that the auditor responds to the legal parameter as modelled in this chapter, is the focus of chapter 7.
} 
belonging to this category as it incorporates a legal parameter. The focus is on the impact of this legal parameter; the various stages of the audit process are not considered.

The focus in this chapter is on auditor liability towards third party users of financial statements, such as (potential) shareholders, creditors, etc.... Although the auditor and the audited firm are jointly liable for defects in financial statements to third party financial statement users in the US and the UK (see chapter 4 for a discussion of auditor liability rules), the auditor and the audited firm's management (the auditee) are assumed here to make their decisions independent from each other. The auditor therefore presumes that there will be no apportionment of damage payments with the audited firm's management should the auditor be held liable by the courts ${ }^{94}$.

It is assumed that the auditor wants to maximise the expected profit of an individual audit engagement and that he is risk neutral. The auditor therefore has to choose the level of audit quality that maximises his profit on the engagement. It is assumed that the audit fee is exogenous to the auditor's decision problem. This would is the case in price competitive audit markets ${ }^{95}$. The auditor's profit is maximised when the total expected cost of delivering the audit service is minimised. The total expected cost of an audit engagement is defined as the sum of two components: the direct audit cost and a risk premium. Both the direct audit cost and the risk premium are functions of the level of audit quality that will be produced: the direct cost is increasing as quality increases whereas the risk premium decreases as audit quality increases. The direct audit cost is the cost of producing the audit report and includes all costs the auditor incurs from the planning stage of the audit through the final write up of the audit report. The risk

\footnotetext{
94 In the context of the analysis in chapter 5 , it is thus assumed that the auditee's liability is zero, or that $f$ $=1$ holds. This is the case when uncertainty about the directors standard of care is fairly certain.

95 Evidence of price competition has been discussed in chapter 3. Price competition in audit markets implies that unit price equals marginal total cost (direct cost + risk premium).
} 
premium equals the expected damage payments to third party users of audited financial statements should the auditor be held liable afterwards. The risk premium is further defined as the product of the size of the damage payments and the probability that the auditor will be held liable by the courts and will have to pay for damage. Hence the auditor's objective function for an individual audit engagement is:

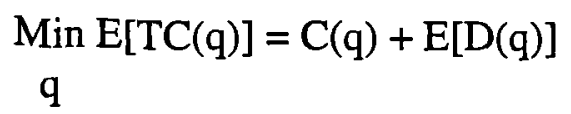

Where:

$\mathrm{q} \quad=$ level of audit quality variable

$\mathrm{E}[\mathrm{TC}(\mathrm{q})]=$ total expected cost of an individual audit engagement

$\mathrm{C}(\mathrm{q}) \quad=$ direct audit cost function;

for example: $C(q)=\left(c q^{2}\right) / 4$, where $c$ is a cost parameter.

$\mathrm{D}(\mathrm{q}) \quad=$ size of damage payments function ${ }^{96}$ (auditor losses);

for example: $\mathrm{D}(\mathrm{q})=\mathrm{d} / \mathrm{q}$, where $d$ is a damage parameter

$\mathrm{N}(\mathrm{q}) \quad=$ probability that the auditor will be held liable

$\mathrm{E}[\mathrm{D}(\mathrm{q})]=$ risk premium

$=D(q) \cdot N(q)$

It is further assumed that $\mathrm{C}(\mathrm{q})$ and $\mathrm{D}(\mathrm{q})$ are convex in $\mathrm{q}$, in particular $\mathrm{C}(\mathrm{q})>0, \mathrm{dC} / \mathrm{dq}>$ 0 and $\mathrm{d}^{2} \mathrm{C} / \mathrm{dq}^{2}>0$; and $\mathrm{D}(\mathrm{q})>0, \mathrm{dD} / \mathrm{dq}<0$, and $\mathrm{d}^{2} \mathrm{D} / \mathrm{dq}^{2}>0$ is assumed to hold. To illustrate or elaborate some of the findings in this chapter, $C(q)$ and $D(q)$ will, by example, be specified as indicated above. Note that the parameters $c$ and $d$ are engagement specific. The shape of $\mathrm{N}(\mathrm{q})$ will be discussed later.

\footnotetext{
${ }^{96}$ Note that the size of damage payments depends, amongst other things, on the presence of liability restrictions (see also section 6).
} 
Given that the auditor's liability is subject to a negligence standard set by the courts, $N(q)$ can be interpreted as a test of negligence. This test involves the comparison of the level of audit quality produced by the auditor, q, with a legal standard of audit quality. If the produced level of audit quality is strictly below the legal standard, the court will decide that the auditor is liable to pay for damage. Let $\mathrm{q}_{\mathrm{c}}$ be the legally required level of audit quality, the auditor's liability subject to the test of negligence by the courts can then be expressed as:

$$
N(q)=\operatorname{Prob}\left(q<q_{c}\right)
$$

Note that the private objective function in expression (6.1) implies that the auditor will not go bankrupt and will be able to fully pay for damage. Since most audit firms are partnerships with partners being jointly and severally liable, this assumption is realistic.

\subsection{Business Risk and auditor reputation}

In the previous subsection $\mathrm{D}(\mathrm{q})$ has been defined as the size of the damage payment function, and $E[D(q)]$ as the risk premium or the related expected losses accruing to the auditor. $E[D(q)]$ could however be interpreted in a broader sense, and be seen as the auditor's business risk (see also chapter 2) with respect to a particular audit engagement. Business risk is a monetary concept and refers to the many potential adverse consequences to the audit firm arising from any litigation or criticism concerning the auditor's work or the client's audited financial statements (see, for example, Brumfield, Elliott and Jacobson (1983)). The focus of this and the subsequent chapter is on auditor losses because of damage payments from litigation, which forms a paramount element of the auditor's business risk. Sanctions imposed by public or private regulatory bodies and impaired professional reputation which can occur as a result of adverse publicity are however also important elements of the auditor's 
business risk. $E[D(q)]$ could therefore be seen as the present value of all losses accruing to the auditor from a particular engagement, hence including, amongst other things, reputational effects. $E[D(q)]$, therefore, is not only engagement specific (as stated in subsection 2.1) but also audit firm specific, since different audit firms may have different reputations. As a result the reputational effects may differ across audit firms (or types of audit firms) as some audit firms may have more at stake than others.

In the literature a variety of studies has investigated the issue of differing reputations amongst auditors. In a review study, Moizer (1993) concludes that auditor reputation has been addressed from a large number of angles; the overall conclusion is that Big Eight firms are clearly seen to be differentiated from non-Big Eight firms in the majority of studies. Supporting evidence of product differentiation and differing reputation is found in: 1) studies on audit changes, suggesting that changes from non-Big Eight to Big Eight firms are viewed more favourable by the stock market than any other type of change; 2) studies on the underpricing of initial public offerings (IPO's), which have found that there is an auditor variable, but without an agreement as to which firms should be included in the higher reputation group ; 3 ) studies of audit fees (see also chapter 3 and appendix I), which report a Big Eight effect on audit fees (i.e. premium pricing by Big Eight firms) supportive of the product differentiation hypothesis. However, other types of studies report less supportive evidence. Little hard evidence was presented by a number of studies investigating whether adverse information has an effect on the audit firm's reputation. Further, studies relating the name of the audit firm to the quality of the financial statements audited found little correlation; no subset of CPA firms have systematically lower accounting quality clients than other subsets.

In terms of the model presented in this chapter, auditor losses, $D(q)$, for a given level of audit quality, q, can be seen to be larger for high reputation firms (Big-Eight) than 
for low reputation firms (non-Big Eight). The result is that, ceteris paribus, the optimal level of audit quality produced, $\mathrm{q}^{*}$, will be larger for high reputation firms.

\section{Audit quality production when legal standards of care are certain}

When the auditor knows the legally required audit quality standard, $q_{c}$, with certainty at the time that he makes the audit quality decision, the negligence test in equation (6.2) can be expressed as:

$$
\begin{aligned}
N(q) & =1 \text { iff } q<q_{c} \\
& =0 \text { otherwise }
\end{aligned}
$$

The auditor's optimisation problem then becomes:

$$
\underset{q}{\operatorname{Min}} E[T C(q)]=C(q)+D(q) \cdot N(q)
$$

or,

$\operatorname{Min} \mathrm{E}[\mathrm{TC}(\mathrm{q})]=$ $\mathrm{q}$

$$
C(q)+D(q) \quad \text { if } q<q_{c}
$$

$\mathrm{C}(\mathrm{q}) \quad$ if $\mathrm{q} \geq \mathrm{q}_{\mathrm{c}}$

Graph 6.1 illustrates the auditor's decision problem for alternative values of $\mathrm{q}_{\mathrm{c}}$. The heavy kinked line represents the total costs an auditor will eventually bear. In the event of litigation, auditors who undercomplied with the legal standard of audit quality, $\mathrm{q}_{\mathrm{c}}$, will be held liable with certainty and will have to bear the total cost, which is the sum of audit costs and losses to third parties. Those who satisfy the legal requirement will 
not be held liable at all, even if losses occur to third parties, and will only incur the direct audit cost.

It is a trivial observation that the auditor will never choose to produce more than what is legally required, since this would only increase the auditor's direct cost, as $d C / d q>0$. The question remains whether the auditor will choose to produce less than what is legally required, and will choose to bear the total cost, $\mathrm{C}(\mathrm{q})+\mathrm{D}(\mathrm{q})$, instead of $\mathrm{C}\left(\mathrm{q}_{\mathrm{c}}\right)$. This is only the case if:

$$
\left.\underset{\mathrm{q}<\mathrm{q}_{\mathrm{c}}}{\operatorname{Min}} \mathrm{C}(\mathrm{q})+\mathrm{D}(\mathrm{q})\right]<\mathrm{C}\left(\mathrm{q}_{\mathrm{c}}\right)
$$

holds to be true.

Define $q_{m}{ }^{a 9}{ }^{97}$ :

$$
\mathrm{q}_{\mathrm{m}}=\operatorname{Arg} \underset{\mathrm{q}}{\operatorname{Min}} \mathrm{C}(\mathrm{q})+\mathrm{D}(\mathrm{q})
$$

From the convexity of $C(q)+D(q)$, the value $q_{m}$ is uniquely defined. In addition, if $q_{c} \leq$ $\mathrm{q}_{\mathrm{m}}$, then $\mathrm{q}<\mathrm{q}_{\mathrm{c}}$ implies $\mathrm{C}(\mathrm{q})+\mathrm{D}(\mathrm{q})>\mathrm{C}\left(\mathrm{q}_{\mathrm{c}}\right)$. In result the auditor's decision will be to produce $q_{c}$. Panels A and B of graph 6.1 illustrate this situation. If $q_{c}>q_{m}$, the auditor will produce $q_{c}$ only if $q_{c}$ is smaller than a critical value, denoted as $q_{c, u}$. This is shown in panel $C$ of graph 6.1. The critical value, $q_{c, u}$, is the value for $q_{c}$ which satisfies the following condition:

$$
C\left(q_{m}\right)+D\left(q_{m}\right)=C\left(q_{c}\right)
$$

\footnotetext{
${ }^{97} q_{m}$ would be the auditor's choice if there were strict liability.
} 
However, if $\mathrm{q}_{\mathrm{c}}>\mathrm{q}_{\mathrm{c}, \mathrm{u}}$, the auditor will choose to produce less than what is legally required, and will produce exactly $\mathrm{q}_{\mathrm{m}}$. Not complying with the legal standard of care is then a cheaper option. This situation is illustrated in Panel E of graph 6.1. If $q_{c}=q_{c, u}$, as is shown in panel $D$ of graph 6.1, the auditor is indifferent as to producing $q_{c}$ or $q_{m}$. 
Graph 6.1: Audit quality production for alternative levels of $q_{c}$ when legal standards of care are certain

Panel A: when $q_{c}<q_{m}$

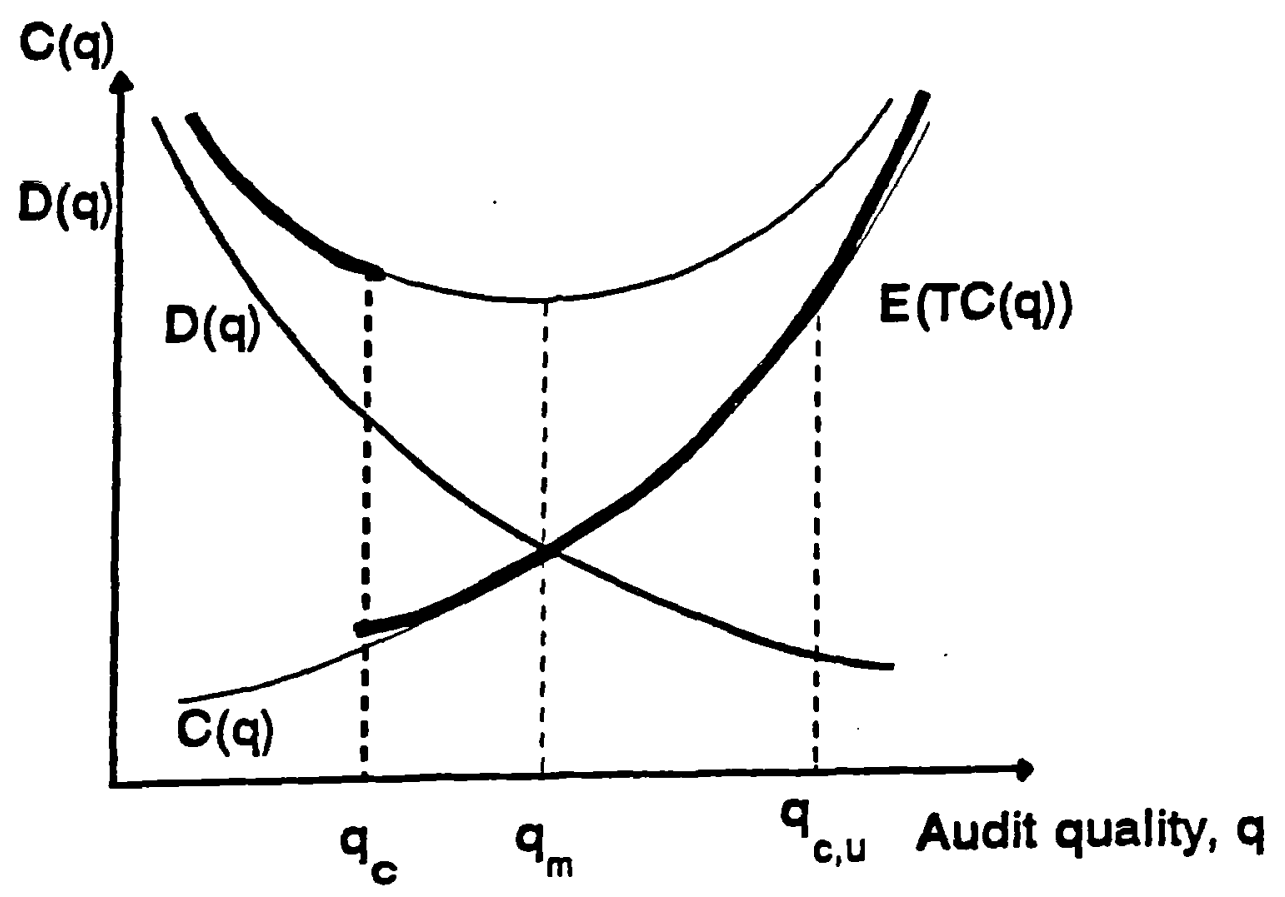

Panel B: when $q_{c}=q_{m}$

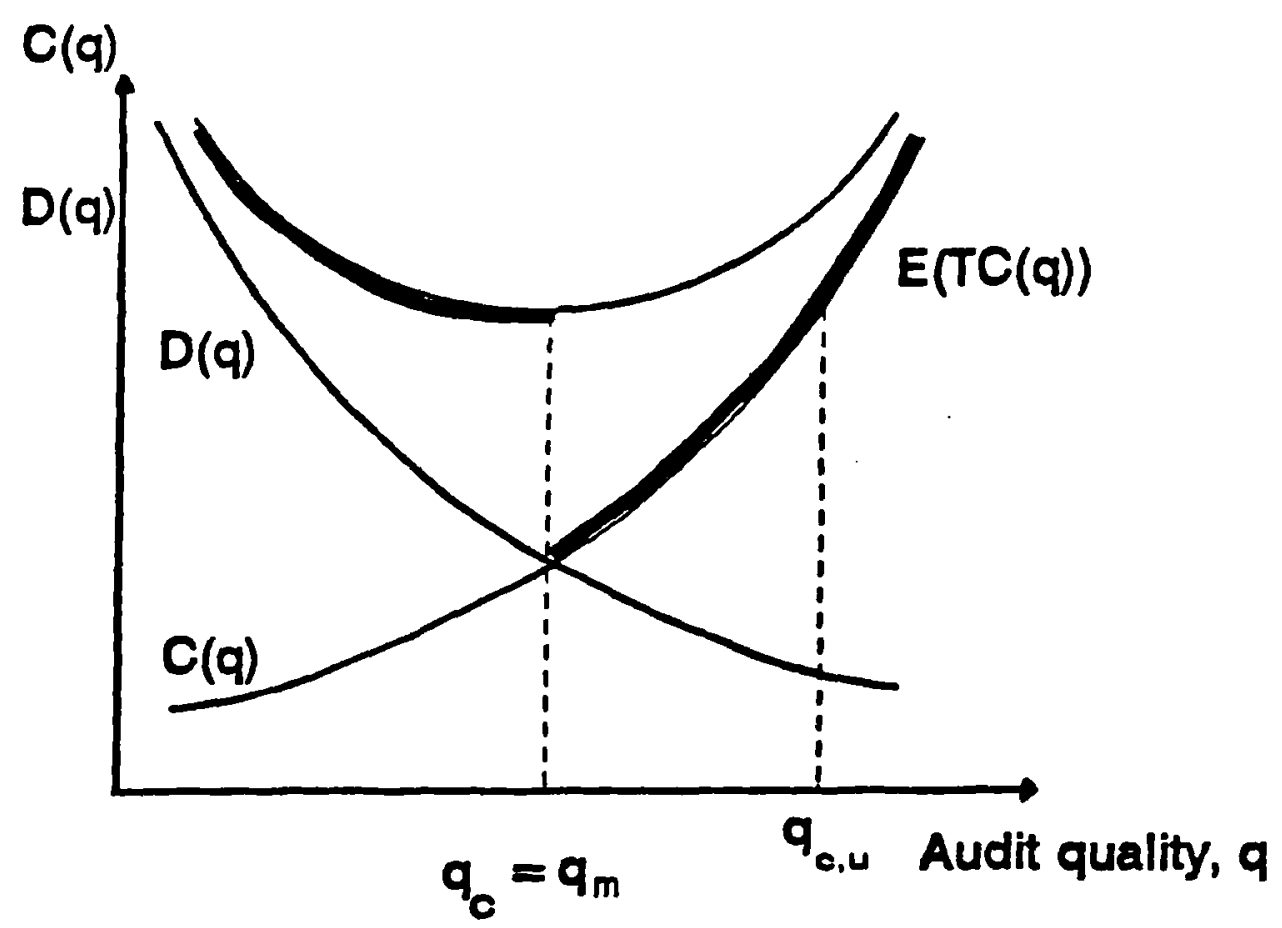


Panel C: when $\mathbf{q}_{\mathrm{m}}<\mathbf{q}_{\mathrm{c}}<\mathbf{q}_{\mathrm{c}, \mathrm{u}}$

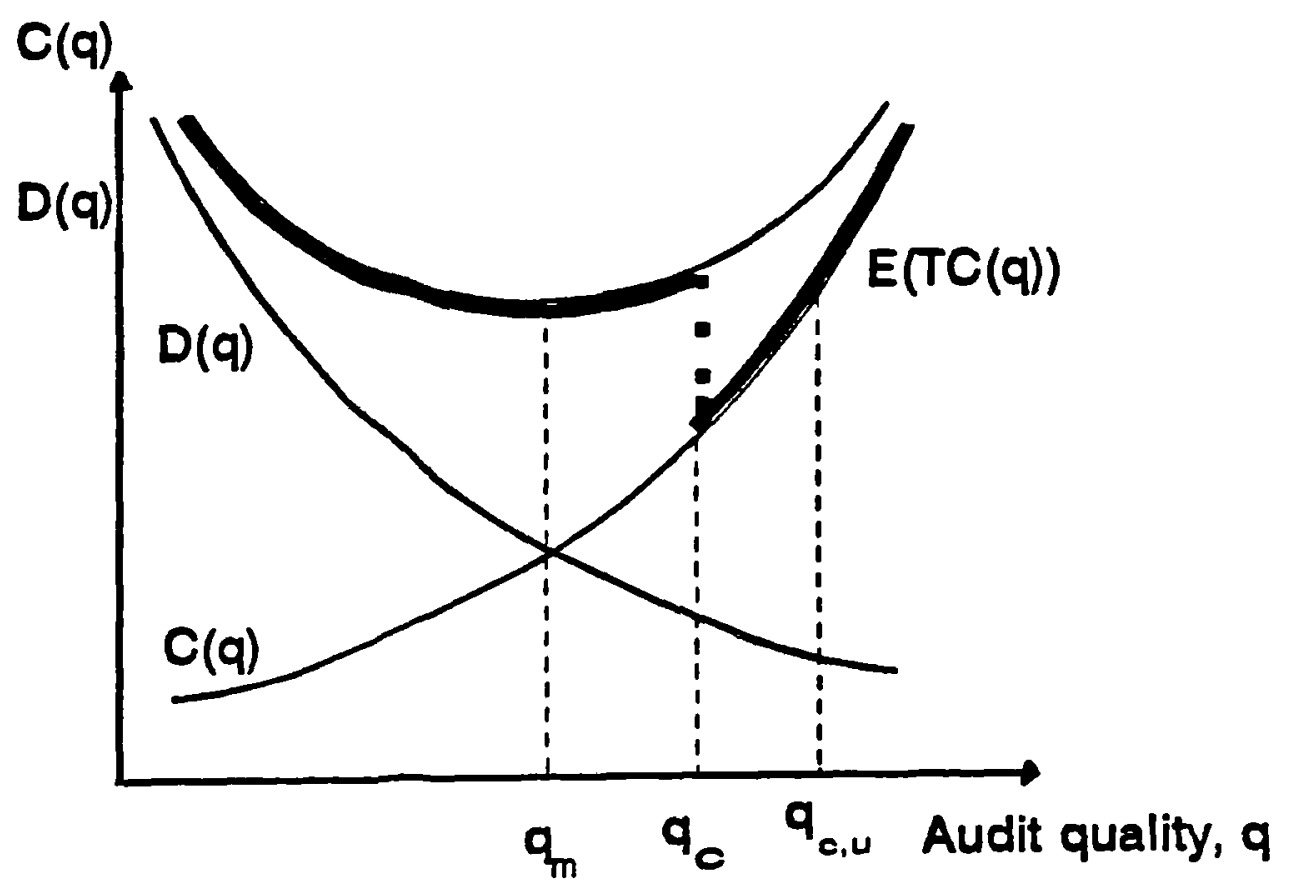

Panel D: when $q_{c}=q_{c, u}$

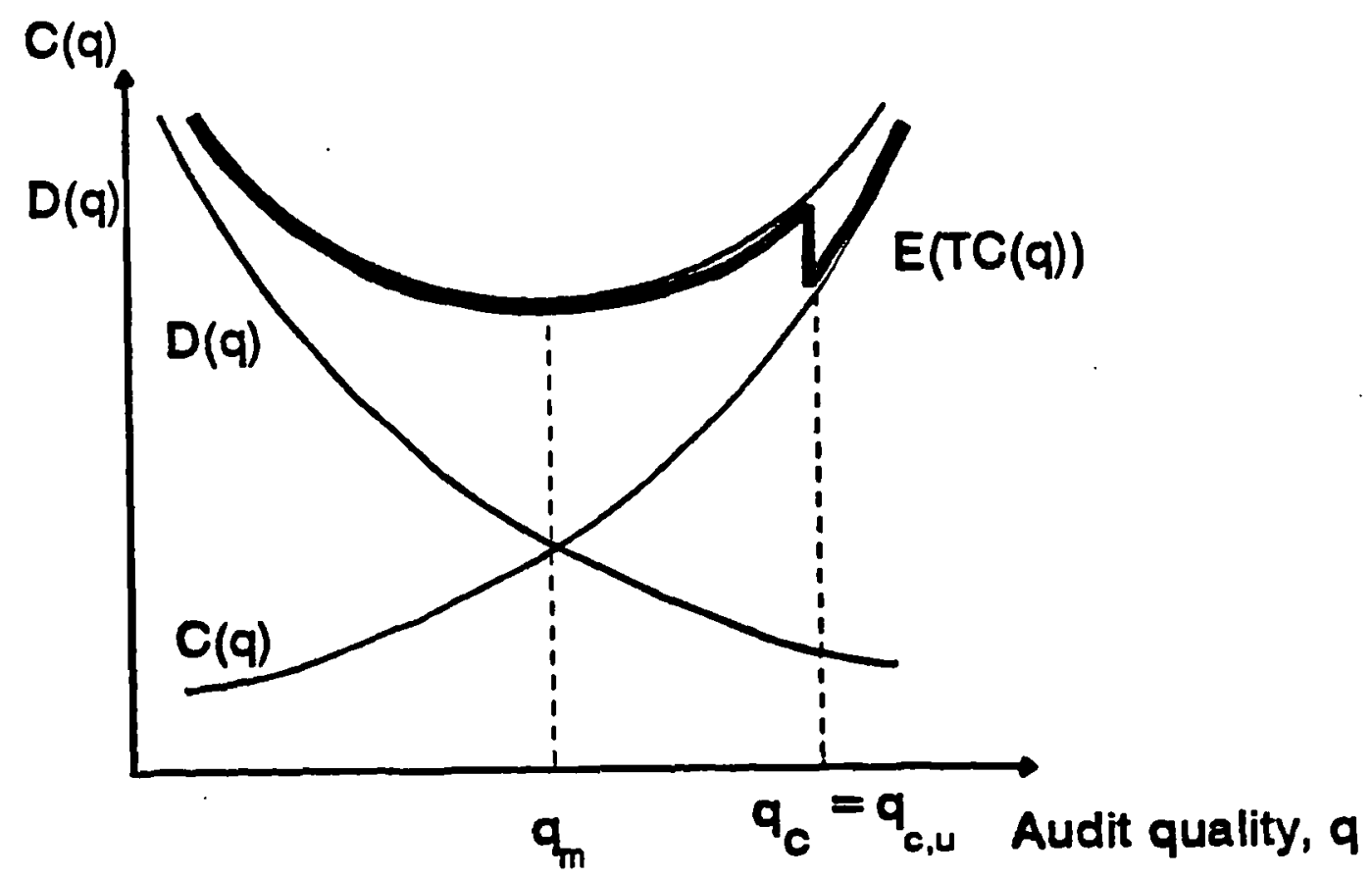


Panel E: when $q_{c}>q_{c, u}$

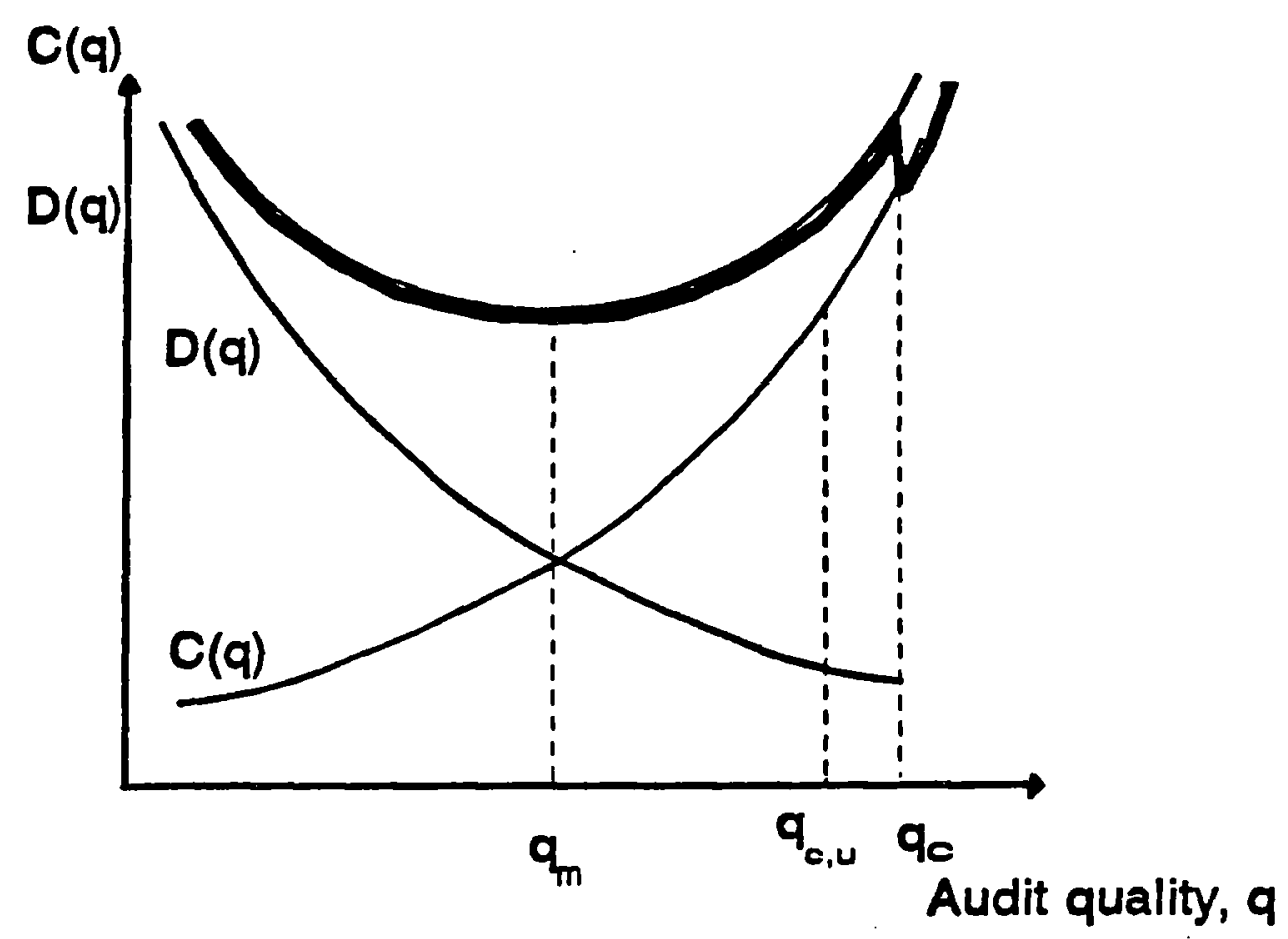


In the illustration, where $C(\mathrm{q})=c \mathrm{q}^{2} / 4$, and $\mathrm{D}(\mathrm{q})=d / \mathrm{q}$, then $\mathrm{q}_{\mathrm{m}}$ and $\mathrm{q}_{\mathrm{c}, \mathrm{u}}$ are defined by:

$$
\begin{aligned}
& \mathrm{q}_{\mathrm{m}}=[2 d / c]^{1 / 3} \\
& \mathrm{q}_{\mathrm{c}, \mathrm{u}}=3^{1 / 2} \cdot[2 d / c]^{1 / 3} .
\end{aligned}
$$

It is trivial that the larger (smaller) the ratio is of the client specific parameters $d / c$ (that is, the ratio of the cost parameter to the damage parameter), the larger (smaller) the values of $q_{m}$ and $q_{c, u}$ will be. This is however an important result, since liability is restricted to classes of claimants in both the US and the UK. Restriction will have the effect that for a particular client situation, the value of the damage parameter will be smaller when there is restriction compared to the situation where there is no restriction. This implies that the critical value, $q_{c, u}$, will be smaller with restriction than without restriction, and hence the range of $q_{c}$ values for which the auditor will produce what is legally required will be smaller than without restriction.

From the analysis in this section, the following propositions can be formulated. Note that these hold both when there and is no restriction of liability.

\section{Proposition 6.1}

An auditor will never produce more than what is legally required, if legal standards of care are known with certainty.

\section{Proposition 6.2}

An auditor will exactly produce what is legally required, if legal standards of audit care are known with certainty and set at a level that is not too high ${ }^{98}$.

${ }^{98}$ By this it is meant that $q_{c}$ must be smaller than $q_{c}, u$. 


\section{Proposition 6.3}

An auditor will produce less than what is legally required, and hence takes the role of an insurer for third party losses, if legal standards of care are known with certainty and set at a level that is significantly high ${ }^{99}$.

\section{Audit quality production when there is uncertainty over the finding of neqligence}

A more reasonable assumption is that the auditor is - ex ante - not certain about the finding of negligence ${ }^{100}$. The auditor's uncertainty over the finding of negligence can have several reasons: a) uncertainty about the court's assessment of the auditor's level of care; b) inability of the auditor to completely control the level of care he produces; and c) uncertainty about the legal standard of care. Since the court has to interpret the level of care exercised by the auditor, the court's assessment of auditor care may differ from the level of care actually produced by the auditor. Hence, when executing the negligence test, the court will compare its assessment of auditor care, which is defined as $q$ plus some random error, denoted by $\delta$, instead of $q$, with the legal standard of care, $\mathrm{q}_{\mathrm{c}}$. On the other hand, the auditor may be unable to control completely the level of care he produces. In result, the auditor knows that if he chooses an audit quality level q, the actual level of care might be $q$ plus some random error, $\delta$. If the court observes the true level of care, it will compare $\mathrm{q}_{\mathrm{c}}$ to $\mathrm{q}+\delta$. Finally, the legal standard of care itself may be ex ante uncertain to the auditor, as it depends upon jurisdiction and legal precedents. The auditor clearly has some expectation of what constitutes due auditor care, but a certain ex ante definition is not generally available. The auditor is thus not certain how the courts will interprete due audit care in a particular audit case. Although professional

\footnotetext{
99 By this it is meant that $\mathrm{q}_{\mathrm{c}}$ must be larger than $\mathrm{q}_{\mathrm{c}, \mathrm{u}}$

100 See, for example, Shavell (1987), Kolstadt et al (1990), and Cooter \& Ulen (1993), who also discuss in general - reasons for uncertainty about the finding of negligence.
} 
audit standards are a guideline for the auditor to execute the audit job, these standards tend to be general in nature. Furthermore, legal evidence ${ }^{101}$ exists of cases where the courts' interpretation of due care reached beyond the level of care implied by professional audit standards. The auditor's expectation of the legal standard of care is $\mathrm{q}_{\mathrm{c}}$, but the auditor knows that the ex post value of the legal standard of care may be $\mathrm{q}_{\mathrm{c}}$ plus some random component, $\delta$. In this case, the auditor's ex ante perception of the negligence test is that the level of care, $q$, that he chooses will be compared with $q_{c}+\delta$, instead of $\mathrm{q}_{\mathrm{c}}$. In the discussion below, uncertainty over the finding of negligence is discussed as if it originates from uncertainty about $q_{c}$. The results hold as well if uncertainty stems from the other two sources discussed.

\subsection{The auditor's decision problem when legal standards are uncertain}

The legally required level of audit care in the following discussion is, as indicated above, defined as, $\mathrm{q}_{\mathrm{c}}$, plus a random variable, $\delta$, about which the auditor has some subjective beliefs. The random variable has a subjective probability distribution $f(\delta)$, with a mean of zero, and a standard deviation $\sigma$. The random variable is realised when the court delivers a judgement, a realisation that the auditor conjectures when executing the audit. The auditor's subjective probability distribution around the legal standard is thus defined as $f(\delta)$. The auditor's expectation about the legal standard of care is unbiased and equal to $q_{c}$, i.e. $E\left[q_{c}+\delta\right]=q_{c}$, but the auditor faces some probability that he will have to pay for damage to third parties if his actual level of audit care is above $\mathrm{q}_{\mathrm{c}}$. Similarly, he only faces some probability that he might be found liable if he took care below the expected legally required level, $\mathrm{q}_{\mathrm{c}}$.

The negligence test in (6.2) can now be expressed as:

101 See also chapter 4 , section 4.2 .2 , for a discussion about uncertainty about the finding of negligence. 


$$
\begin{aligned}
N(q) & =1 \text { if } q<q_{c}+\delta \\
& =0 \text { otherwise }
\end{aligned}
$$

The probability of being liable at a choice of quality $q$, or $N(q)$, is here defined as $R(q)$, and is:

$$
R(q)=\operatorname{prob}\left(q<q_{c}+\delta\right)=\int_{q}^{+\infty} f
$$

Graph 6.2 illustrates the auditor's subjective probability of being found liable, given a level of $q$ he chooses. $R(q)$ corresponds with the shaded area in graph 6.2. The auditor's expected private cost function in equation (6.2) now becomes:

$$
E[T C(q)]=C(q)+D(q) \cdot R(q)
$$

There is no longer a step discontinuity in the total cost curve at $q_{c}$, because the step function $N(q)$ in equation (6.2) is replaced by the cumulative density function $R(q)$. The total cost curve now presents the auditor with a gamble:

$$
\begin{aligned}
\mathrm{TC}(\mathrm{q})= & \mathrm{C}(\mathrm{q}) \text { with probability }(1-\mathrm{R}(\mathrm{q})) \\
& \mathrm{OR} \\
& \mathrm{C}(\mathrm{q})+\mathrm{D}(\mathrm{q}) \text { with probability } \mathrm{R}(\mathrm{q}),
\end{aligned}
$$

whose expected value is given by equation (6.10). Consider the situation in which the auditor is risk neutral to the size a gamble being presented, as might be the case under audit independence rules which preclude the auditor from being overexposed to any one particular client as a source of fees. 
To analyse the impact of uncertainty on the auditor's choice, a slightly stronger assumption needs to be introduced. It was already assumed that $C(q)$ and $D(q)$ are convex functions. A further assumption is that $D(q) \cdot R(q)$ is also convex and downward sloping over the relevant region, such that $E[T C(q)]$ is strictly convex and has a unique minimum. Denoting $\mathrm{q}^{*}$ as the auditor's level of quality which minimises equation (6.10), the first order condition for minimisation is:

$$
C^{\prime}\left(q^{*}\right)+R\left(q^{*}\right) \cdot D^{\prime}\left(q^{*}\right)-f\left(q^{*}\right) \cdot D\left(q^{*}\right)=0
$$

This gives the marginal conditions at the unique minimum as:

$$
C^{\prime}\left(q^{*}\right)=-R\left(q^{*}\right) \cdot D^{\prime}\left(q^{*}\right)+f\left(q^{*}\right) \cdot D\left(q^{*}\right)
$$

The interpretation of this condition requires the auditor to equate the marginal cost of providing the $\mathrm{q}^{*}$ th unit of quality to the sum of two terms arising from the negligence rule. The first term is the marginal reduction in damages times the probability of being held liable if the level of audit quality is $\mathrm{q}^{*}$. This is the "injury effect" and represents the savings to the auditor from the application of greater precaution in reducing expected damages. The second term is the "liability effect", and is the product of the expected damages at $\mathrm{q}^{*}$ and the marginal reduction in the probability of being liable. The liability effect thus represents the benefit that the auditor derives from a greater level of precaution in reducing the probability of being found liable. 
Graph 6.2: The probability of being found liable for a given quality level, $q$

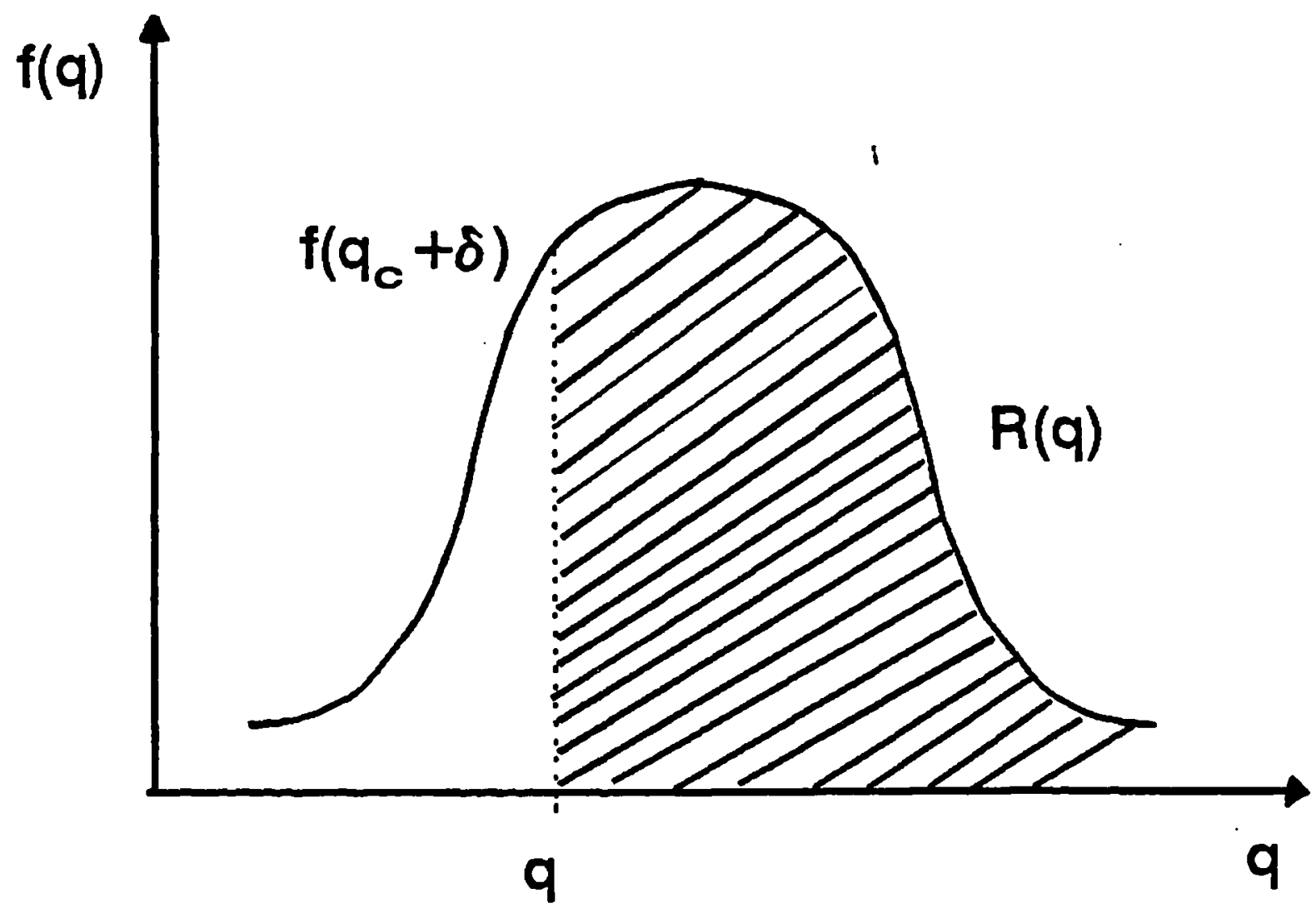




\subsection{General impact of uncertainty on audit quality production}

Let $\sigma=\sigma_{\mathrm{c}}$ be the parameter, here treated as a constant, that describes the auditor's perception of vagueness about the court's standard for a particular audit engagement. Given that the auditor's expectations are unbiased so that $\mathrm{E}\left(\mathrm{q}_{\mathrm{c}}+\delta\right)=\mathrm{q}_{\mathrm{c}}$, one cannot generally predict the impact of $\sigma$ on the choice of audit quality, without a restriction on the nature of the auditor's subjective belief function. To illustrate this statement, suppose that there are three auditors indexed by $i=1,2,3$, who agree on the direct cost function, $C(q)$, and the damage function, $D(q)$, of a client situation, but who disagree in their subjective beliefs about the due standard of care, using probability functions $f_{i}(q)$ and $R_{i}(q)$. Each auditor's choice of the optimal quality based on $f_{j}(q)$ is denoted as $q_{i}$. Let the first auditor's choice of the optimal level of audit quality based on $f_{1}(q)$ take the value $q_{1}=q_{c}$. Then it is possible for the second auditor that $f_{2}\left(q_{c}\right)=f_{1}\left(q_{c}\right)$, but $R_{2}\left(q_{c}\right)<$ $\mathrm{R}_{1}\left(\mathrm{q}_{\mathrm{c}}\right)$. The probability functions have the same value at $\mathrm{q}_{\mathrm{c}}=\mathrm{q}_{1}$, but a different cumulant value at the optimal point for auditor 1 when integrated. It follows that the value at the RHS of equation (6.12) will decrease, causing the second auditor to choose a level of audit quality, $q_{2}$, smaller than $q_{1}=q_{c}$. A similar argument for the third auditor, where $f_{3}\left(q_{c}\right)=f_{1}\left(q_{c}\right)$, but $R_{3}\left(q_{c}\right)>R_{1}\left(q_{c}\right)$, leads to the third auditor choosing a level of audit quality, $q_{3}$, above $q_{1}=q_{c}$. Where in the case of certain legal standards of care all three auditors would have produced the same level of audit quality, i.e. $q_{c}$, they each will produce a different level of audit quality for the same engagement even though the degree of uncertainty, $\sigma$, is the same for each auditor. The audit quality decision depends thus crucially on beliefs about the standard of care required, which need to be specified to draw further conclusions about auditor behaviour under uncertainty. However, it can already be stated that propositions 1,2, and 3 are no longer valid in a legal environment characterised by a legal standard of care that is uncertain. 


\subsection{Impact of uncertainty on audit quality production when beliefs are normally distributed}

In order to make more powerful statements about how uncertainty affects audit quality, we need to specify the nature of the auditor's subjective belief function. It is assumed that $f(\delta)$ is normally distributed about zero. It can now be shown in which direction uncertainty affects the level of care the auditor will take. In particular, the question that is addressed in this context is at which critical level of $\sigma$, denoted by $\sigma_{\mathrm{e}}$, the auditor's decision, $\mathrm{q}^{*}$, coincides with the expectation of the court's standard of care, $\mathrm{q}_{\mathrm{c}}$ (that is the auditor's choice if legal standards were certain), and for which values of $\sigma$ the auditor's decision will be smaller or larger than $\mathrm{q}_{\mathrm{c}}$.

It follows from equation (6.11) that the auditor will produce:

$$
\begin{array}{lll}
q^{*}>q_{c} & \text { iff } & C^{\prime}\left(q_{c}\right)+D^{\prime}\left(q_{c}\right) \cdot R\left(q_{c}\right)-f\left(q_{c}\right) \cdot D\left(q_{c}\right)<0 \\
q^{*}=q_{c} & \text { iff } & C^{\prime}\left(q_{c}\right)+D^{\prime}\left(q_{c}\right) \cdot R\left(q_{c}\right)-f\left(q_{c}\right) \cdot D\left(q_{c}\right)=0 \\
q^{*}<q_{c} & \text { iff } & C^{\prime}\left(q_{c}\right)+D^{\prime}\left(q_{c}\right) \cdot R\left(q_{c}\right)-f\left(q_{c}\right) \cdot D\left(q_{c}\right)>0
\end{array}
$$

Since $R\left(q_{c}\right)=0.5$, irrespective of the value of $\sigma$, it will be the third term in condition (6.13), i.e. $f\left(q_{c}\right) \cdot D\left(q_{c}\right)$ or the "liability effect", that determines whether the auditor will produce more or less than $\mathrm{q}_{\mathrm{c}}$. Given that $\mathrm{f}\left(\mathrm{q}_{\mathrm{c}}+\delta\right)$ is normally distributed about $\mathrm{q}_{\mathrm{c}}$, and hence $f\left(q_{c}\right)=\sigma^{-1} \cdot(2 \pi)^{-0.5}$, the following holds:

$$
\begin{aligned}
& \text { If } \mathrm{q}^{*}>\mathrm{q}_{\mathrm{c}}, \quad \text { then: } \mathrm{C}^{\prime}\left(\mathrm{q}_{\mathrm{c}}\right)+0.5 \mathrm{D}^{\prime}\left(\mathrm{q}_{\mathrm{c}}\right)<\sigma^{-1} \cdot(2 \pi)^{-0.5} \cdot \mathrm{D}\left(\mathrm{q}_{\mathrm{c}}\right) \\
& \text { If } \mathrm{q}^{*}=\mathrm{q}_{\mathrm{c}}, \quad \text { then: } \mathrm{C}^{\prime}\left(\mathrm{q}_{\mathrm{c}}\right)+0.5 \mathrm{D}^{\prime}\left(\mathrm{q}_{\mathrm{c}}\right)=\sigma^{-1} \cdot(2 \pi)^{-0.5} \cdot \mathrm{D}\left(\mathrm{q}_{\mathrm{c}}\right) \\
& \text { If } \mathrm{q}^{*}<\mathrm{q}_{\mathrm{c}}, \quad \text { then: } \mathrm{C}^{\prime}\left(\mathrm{q}_{\mathrm{c}}\right)+0.5 \mathrm{D}^{\prime}\left(\mathrm{q}_{\mathrm{c}}\right)>\sigma^{-1} \cdot(2 \pi)^{-0.5} \cdot \mathrm{D}\left(\mathrm{q}_{\mathrm{c}}\right)
\end{aligned}
$$


Note that two situations can occur here: (a) $C^{\prime}\left(q_{c}\right)+0.5 D^{\prime}\left(q_{c}\right) \leq 0$; and

(b) $C^{\prime}\left(q_{c}\right)+0.5 D^{\prime}\left(q_{c}\right)>0$. In the first case, the conditions in (6.14b) and (6.14c) cannot be fulfilled as $\sigma$ is strictly positive. In such a situation, the auditor will always produce more than what is legally required, irrespective of the size $\sigma$ takes. This is due to a very strong "injury effect", such that the "liability effect" does not influence the auditor's decision. Indeed, note that if $C^{\prime}\left(q_{c}\right)+0.5 D^{\prime}\left(q_{c}\right) \leq 0$ holds, the slope of the damage payments curve at $\mathrm{q}_{\mathrm{c}}$, must be at least twice as steep as the slope of the direct audit cost curve at $\mathrm{q}_{\mathrm{c}}$. Given that both curves are convex, and should a value of $\mathrm{q}$ be defined where this might hold, this situation can only occur if $\mathrm{q}_{c}$ is set at level that is significantly small enough. A 'significantly small enough' value of $\mathrm{q}_{\mathrm{c}}$ in this context is defined by the critical value $q_{c, l}$ (where subscript $l$ stands for lower bound), which is the value of $\mathrm{q}_{\mathrm{c}}$ for which the following holds:

$$
\mathrm{C}^{\prime}\left(\mathrm{q}_{\mathrm{c}}\right)+0.5 \mathrm{D}^{\prime}\left(\mathrm{q}_{\mathrm{c}}\right)=0
$$

The more realistic case, is the situation where $C^{\prime}\left(q_{c}\right)+0.5 D^{\prime}\left(q_{c}\right)>0$ is true, and where overcompliance or undercompliance depends on the magnitude of the liability effect at $\mathrm{q}_{\mathrm{c}}$, and hence on the value that $\sigma$ takes. Graph 6.3 illustrates that the shape of the $E[D(q)]$ curve determines the auditor's choice, and also shows how the shape of this curve is changed as $\sigma$, and thus also $R(q)$ and $f(q)$ change. Three feasible situations are illustrated: 1) production that is larger than $q_{c}, 2$ ) production that is exactly $q_{c}$, and 3 ) production that is smaller than $\mathrm{q}_{\mathrm{c}}$. 
Graph 6.3: Audit quality production for alternative levels of uncertainty, when $C^{\prime}\left(q_{\underline{c}}\right)+0.5 D^{\prime}\left(q_{c}\right)>0$
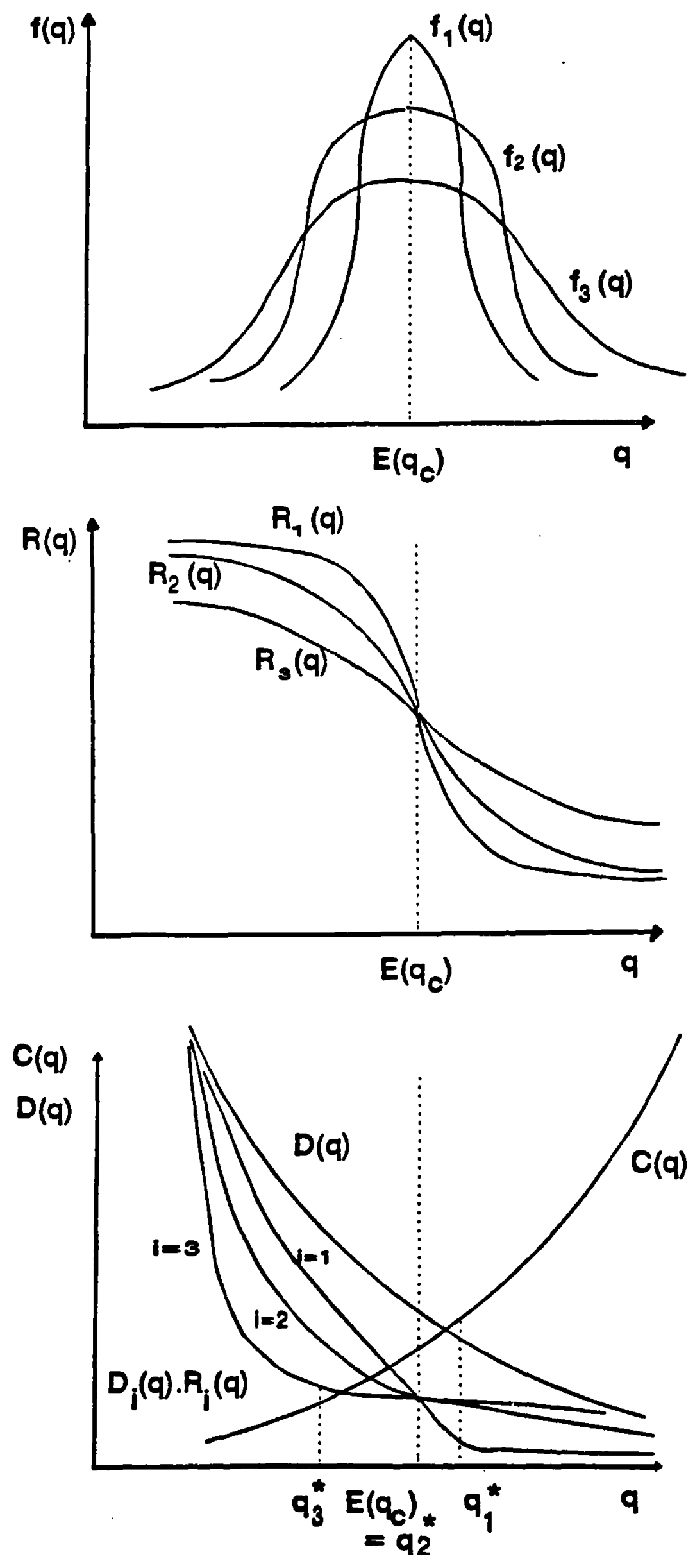
Note that $C(q)$ and $D(q)$ are identical in all situations, but the auditor's subjective beliefs, denoted by $f_{i}$, where $i=\{1,2,3\}$, differ. In particular, $f_{1}$ is less dispersed than $f_{2}$, as $\sigma_{1}<\sigma_{2}$; and $f_{2}$ is less dispersed than $f_{3}$, as $\sigma_{2}<\sigma_{3}$. Note that $f_{2}$ is defined so that $\sigma_{2}=\sigma_{\mathrm{e}}$. From graph 6.3 it is clear that :

$$
\begin{aligned}
& \text { if } q^{*}<q_{c}: R_{1}>R_{2}>R_{3} \text {, hence } R_{1}(q) \cdot D(q)>R_{2}(q) \cdot D(q)>R_{3}(q) \cdot D(q) \\
& \text { if } q^{*}=q_{c}: R_{1}=F_{2}=F_{3} \text {, hence } R_{1}(q) \cdot D(q)=R_{2}(q) \cdot D(q)=R_{3}(q) \cdot D(q) \\
& \text { if } q^{*}>q_{c}: R_{1}<R_{2}<R_{3} \text {, hence } R_{1}(q) \cdot D(q)<R_{2}(q) \cdot D(q)<R_{3}(q) \cdot D(q)
\end{aligned}
$$

The general conclusion is that the smaller (larger) the uncertainty or variance in the auditor's beliefs, the more (less) that is gained from expanding $\mathrm{q}$ beyond $\mathrm{q}_{\mathrm{c}}$. Since the injury effect at $\mathrm{q}_{c}$ is the same for each belief function, the smaller (larger) the variance the larger (smaller) the liability effect will be beyond $\mathrm{q}_{\mathrm{c}}$ (that is, the larger the marginal reduction in the probability of being found liable at levels of $q>q_{c}$ ). From condition (6.13b), it follows that the critical $\sigma$-value, denoted as $\sigma_{\mathrm{e}}$, at which the auditor will exactly produce $\mathrm{q}_{\mathrm{c}}$, or the level of audit quality that would have been produced in the certainty case, is given by:

$$
\sigma_{e}=\frac{D\left(q_{c}\right)}{(2 \pi)^{0.5} \cdot\left[C^{\prime}\left(q_{c}\right)+0.5 D^{\prime}\left(q_{c}\right)\right]} \text {, }
$$

and that the conditions for over and underproduction are :

$$
\begin{array}{ll}
\mathrm{q}^{*}>\mathrm{q}_{\mathrm{c}} & \text { iff } \sigma<\sigma_{\mathrm{e}} \\
\mathrm{q}^{*}<\mathrm{q}_{\mathrm{c}} & \text { iff } \sigma>\sigma_{\mathrm{e}}
\end{array}
$$

The size of $\sigma_{e}$ depends upon: 1) the level at which the courts set $q_{c} ; 2$ ) the slope of the direct cost function, $C(q)$, and 3 ) the slope of the damage function, $D(q)$. The smaller $q_{c}$ 
is set by the courts, the larger $\sigma_{e}$ will be. Indeed, the smaller $q_{c}$, the smaller the denominator in (6.17) and the larger the numerator in (6.17). The flatter the direct cost function, $C(q)$, is the smaller $C^{\prime}\left(q_{c}\right)$ will be, and hence the larger $\sigma_{e}$ will be. Finally, the steeper the damage function, $D(q)$, the smaller $D^{\prime}\left(q_{c}\right)$ will be (note that $D^{\prime}(q)<0$ ), and the larger $\sigma_{\mathrm{e}}$ will be.

In the illustration where $\mathrm{C}(\mathrm{q})=c \mathrm{q}^{2} / 4$, and $\mathrm{D}(\mathrm{q})=d / \mathrm{q}$. The auditor will produce more than would have been produced in the certainty case, due to a strong injury effect, if:

$$
\mathrm{q}_{\mathrm{c}} \leq[d / c]^{1 / 3}
$$

This will be the case when a relatively steep loss function is combined with a relatively flat direct cost function. In case $\mathrm{q}_{c}>[d / c]^{1 / 3}$ holds, the critical value $\sigma_{\mathrm{e}}$ is defined as:

$$
\sigma_{\mathrm{e}}=\frac{2 d \cdot \mathrm{q}_{\mathrm{c}}}{(2 \pi)^{1 / 2}\left(c \mathrm{q}_{\mathrm{c}}{ }^{3}-d\right)}
$$

Note also that the following holds:

$\frac{\partial \sigma_{\mathrm{e}}}{\partial \mathrm{q}_{\mathrm{c}}}<0, \quad \frac{\partial \sigma_{\mathrm{e}}}{\partial \mathrm{d}}>0, \quad \frac{\partial \sigma_{\mathrm{e}}}{\partial \mathrm{c}}<0$




\subsection{Audit quality production: certainty versus uncertainty about the finding of negligence}

In table 6.1 the major conclusions from the analysis in this section are compared to the results in the certainty case. Clearly, for an individual audit engagement, audit quality production is affected both by a) the degree of uncertainty about the court's standard of care, and b) the size of the court's standard of care ( or the expectation of the size of the court's standard of care in case of uncertainty). Note that in case of uncertainty and when $\mathrm{q}_{\mathrm{c}}$ is set at a very high level, undercompliance becomes the more likely scenario for auditor behaviour, since $\sigma_{\mathrm{e}}$ decreases as $\mathrm{q}_{\mathrm{c}}$ becomes larger. Note also that since

$$
\lim _{\mathrm{q}_{\mathrm{c}} \rightarrow+\infty} \sigma_{\mathrm{e}}=0
$$

the auditor's decision under uncertainty will not differ much from his decision if legal standards were certain, when those standards are set at an extremely high level (i.e. far beyond $\mathrm{q}_{\mathrm{c}, \mathrm{u}}$ ).

The following propositions are derived from the analysis. Note that in all propositions uncertainty needs to be understood as if the auditor's beliefs are unbiased w.r.t. $q_{c}$, and normally distributed about $q_{c}$, and the degree of uncertainty is given by $\sigma$. The results, however, hold for any unbiased symmetrical belief function ${ }^{102}$. The reason is that $R\left(q_{c}\right)$ is then always equal to 0.5 , irrespective of the variance of such distributions.

102 As long as $D(q) \cdot R(q)$ is convex. 


\section{Proposition 6.4}

If the legal standard of care is set at a level that is significantly low ${ }^{103}$, uncertainty about the legal standard of care increases audit quality production above the level that would have been produced if the legal standard were certain.

\section{Proposition 6.5}

If the legal standard of care is set at a level that is significantly low ${ }^{104}$, but also not too large ${ }^{105}$, uncertainty about the legal standard of care can increase (or decrease) audit quality production above (or below) the level that would have been produced if the legal standard were certain, if uncertainty is sufficiently small (large) $)^{106}$.

103 By this it is meant that $C^{\prime}\left(q_{c}\right)+0.5 D^{\prime}\left(q_{c}\right)<$ or $=0$ holds.

104 By this it is meant that $C^{\prime}\left(q_{c}\right)+0.5 D^{\prime}\left(q_{c}\right)<$ or $=0$ holds.

105 By this it is meant that $q_{c}<q_{c, u}$ holds.

106 Small uncertainty is defined as $\sigma<\sigma_{e}$; large uncertainty by $\sigma>\sigma_{e}$ 
Table 6.1: Certainty versus uncertainty about legal standards : comparison of auditor compliance for alternative sizes of $\mathrm{q}_{\mathrm{c}}$

Size of the (expected) $\quad$ Production decision $\left(\mathrm{q}^{*}\right): \quad$ Production decision $\left(\mathrm{q}^{*}\right)$ :

legal standard of care, $\quad$ Certainty about $\mathrm{q}_{\mathrm{c}} \quad$ Uncertainty about $\mathrm{q}_{\mathrm{c}}$,

$\mathrm{q}_{\mathrm{c}}$

where $\mathrm{E}\left(\mathrm{q}_{\mathrm{c}}+\delta\right)=\mathrm{q}_{\mathrm{c}}$

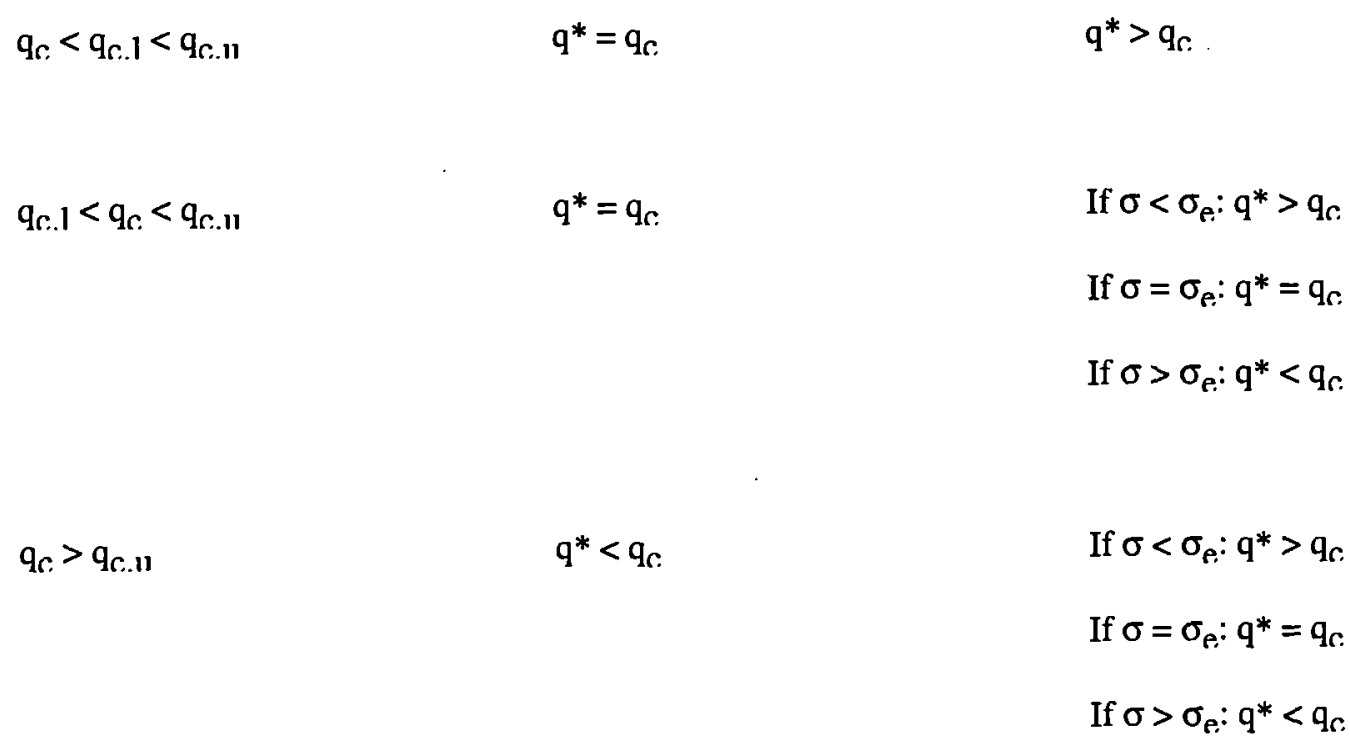

Where:

$q_{c, l}$ is the value for $\mathrm{q}_{\mathrm{c}}$ for which $\mathrm{C}^{\prime}\left(\mathrm{q}_{\mathrm{c}}\right)+0.5 \mathrm{D}^{\prime}\left(\mathrm{q}_{\mathrm{c}}\right)=0$.

$q_{c, u}$ is the value for $\mathrm{q}_{c}$ for which $\mathrm{C}\left(\mathrm{q}_{\mathrm{m}}\right)+\mathrm{D}\left(\mathrm{q}_{\mathrm{m}}\right)=\mathrm{C}\left(\mathrm{q}_{\mathrm{c}}\right)$; where $\mathrm{q}_{\mathrm{m}}=\operatorname{Arg} \underset{\mathrm{q}}{\min } \quad \mathrm{C}(\mathrm{q})+\mathrm{D}(\mathrm{q})$. 


\section{The impact of an ex ante quality standard on audit quality production}

In this section the impact of the imposition of an ex ante audit quality standard is analysed. This can be interpreted as if more prescriptive, and hence less general professional audit standards would be issued, such that an ex ante certain lower bound on due audit quality is defined. An example of an ex ante audit quality standard would be a standard that prescribes the audit industry conduct all audit engagements such that achieved audit risk per engagement is not larger than a certain percentage. The auditor's decision problem for an individual engagement is restated, taking this change in the regulatory environment into account.

The analogy that is developed in this section is that more prescriptive professional audit standards ${ }^{107}$ operate in the same role that ex ante safety standards serve in the control of hazards. Safety standards typically specify a minimum acceptable level of precaution. The situation that is analysed is where there is no uncertainty with regard to the ex ante standard, denoted by $\mathrm{q}_{s}$, which is known by the auditor, the regulator and the courts. The manner in which the effect on audit behaviour is modelled is through changing beliefs about the legal standard. The project of developing audit standards may have a political agenda in influencing the court's view about the appropriate legal standard. Certainly the auditor believes that the ex post legal standard of precaution cannot be less than $\mathrm{q}_{\mathrm{s}}$, and hence that $\mathrm{q}_{\mathrm{c}}+\delta$ is larger than $\mathrm{q}_{\mathrm{s}}$. The auditor may, however, perceive that the legal standard of care, $q_{c}+\delta$, exceeds $q_{s}$. This appears to be a reasonable approximation to the prevailing relationship between audit standards and the courts.

107 Recall that in the case of liability regulation by uncertain legal standards of care, it was assumed that professional audit standards were so general that they do not provide guidance to the auditor's subjective beliefs of about the legal standard of care. 
The manner in which ex ante audit standards change beliefs is fundamental to analysing their behavioural impact. Note that the remaining results depend on how ex ante audit standards are considered to affect beliefs about legal standards. The analysis follows Kolstadt, Ulen and Johnson (1990) and makes the Bayesian assumption that the auditor's probability distribution on $\mathrm{q}_{\mathrm{c}}$ is truncated at $\mathrm{q}_{\mathrm{c}}$, by assumption that there is zero probability that the ex post legal standard, $\mathrm{q}_{\mathrm{c}}+\delta$, is below $\mathrm{q}_{\mathrm{s}}$. The probability mass below $\mathrm{q}_{\mathrm{s}}$ is now distributed above $\mathrm{q}_{\mathrm{s}}$. The conditional probability that the auditor will pay damages if his choice of audit quality is q will be given by:

$$
S(q)=R(q) / R\left(q_{s}\right)
$$

The expected total costs for an individual audit engagement in equation (6.10) now becomes:

$$
E[T C(q)]=C(q)+S(q) \cdot D(q)
$$

The first order condition for optimality becomes:

$$
R\left(q_{s}\right) \cdot C^{\prime}\left(q^{*}\right)=-R\left(q^{*}\right) \cdot D^{\prime}\left(q^{*}\right)+f\left(q^{*}\right) \cdot D\left(q^{*}\right)
$$

Comparison of equation (6.21) with equation (6.11) reveals that the effect of an ex ante standard is captured by the term $\mathrm{R}\left(\mathrm{q}_{\mathrm{s}}\right)$ on the LHS of equation (6.21). This is the probability that prior to the imposition of the ex ante audit quality standard the auditor believed that the legal standard of care was above qs. Since $R\left(q_{s}\right)$ is bounded to the range $[0,1]$, the effect of multiplying $C^{\prime}\left(q^{*}\right)$ by $R\left(q_{s}\right)$ is either to leave it unchanged, if $\mathrm{q}_{\mathrm{s}}$ is set at the left of the auditor's belief function, or to reduce it. Graph 6.4 illustrates the two situations. Reducing the effect of the marginal direct cost, increases the optimal level of produced audit quality, since the RHS of equation (6.21) is decreasing in q. It 
follows for all values of $\mathrm{q}_{s}$, that $\mathrm{dq}^{*} / \mathrm{dq}_{s} \geq 0$, and that an ex ante audit quality standard never reduces the level of audit quality produced.

\section{Proposition 6.6}

When the auditor is uncertain about the legal standard of care, the imposition of an ex ante audit quality standard never reduces the level of audit quality produced for an individual audit engagement. 
Graph 6.4: Ex ante quality standards: effective versus non-effective standards

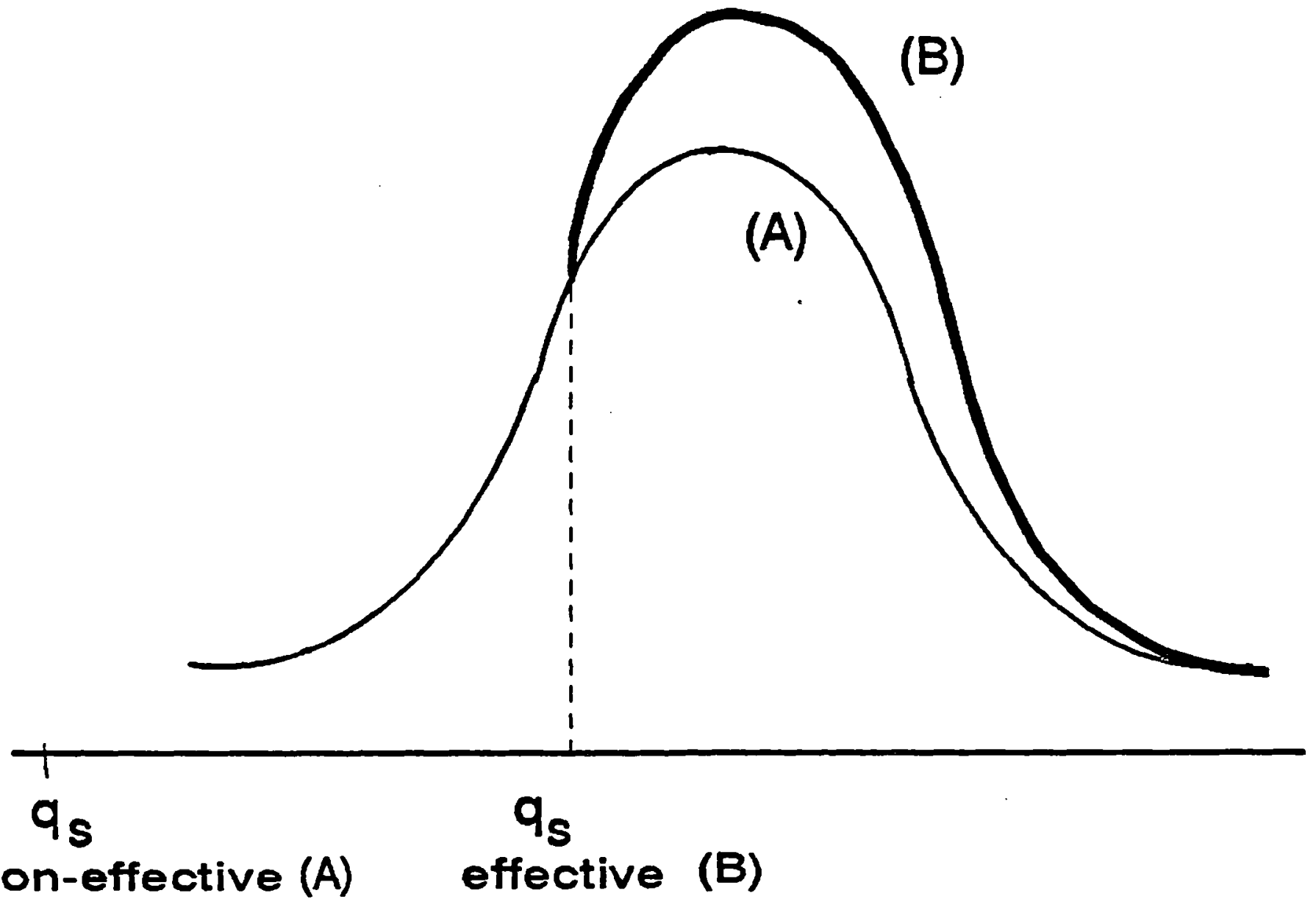




\section{The impact of liability restriction on audit quality production}

In the previous sections, $D(q)$ was treated as given and the effect of liability restrictions was ignored. Several forms of liability restriction exist (see chapter 4 ). The focus is here on restriction of liability to classes of claimants. Let $L(q)$ be the expected losses to all users of the financial statements of an audited firm. Without restrictions, $D(q)=L(q)$ would hold. With restriction, however, $\mathrm{D}(\mathrm{q})<\mathrm{L}(\mathrm{q})$.

Let:

$$
D(q)=\alpha \cdot L(q) \quad \text { where } 0<\alpha \leq 1
$$

be a more detailed formulation of the expected damage payments, where $\alpha$ is a restriction parameter. Without restriction, $\alpha$ takes the value 1 . In case of restriction to classes of claimants, $\alpha$ represents the ratio of losses to classes of claimants to losses of all users.

The auditor's decision problem under uncertainty and without en ex ante quality standard, can now be rewritten as:

$$
\operatorname{Min} E(T C(q)]=C(q)+\alpha \cdot L(q) \cdot R(q)
$$

q

The marginal condition for optimality becomes:

$$
C^{\prime}\left(q^{*}\right)=\alpha \cdot\left[-R\left(q^{*}\right) \cdot L^{\prime}\left(q^{*}\right)+f\left(q^{*}\right) \cdot L\left(q^{*}\right)\right]
$$

The effect of restriction is captured by the parameter $\alpha$ on the RHS of equation (6.24). Since $0<\alpha<1$ holds with restriction, the effect of multiplying both the liability and 
injury effect by $\alpha$, is to reduce it. Reducing the marginal benefit of audit quality, reduces the optimal level of produced audit quality, since the LHS in equation (6.24) is increasing in $\mathrm{q}$.

\section{Proposition 6.7}

Liability restriction to classes of claimants never increases the level of audit quality produced for an individual engagement if auditors are uncertain about the legal standard of care.

Combining the results of section 5 with the results in this section, leads to the conclusion that liability restrictions and the imposition of an ex ante quality standard creates opposite incentives for the auditor. The courts, however have always restricted the auditors liability to classes of claimants. However, the definition of classes of claimants has become broader over the years, until the judgement in Caparo Industries vs Dickman (1990), where audit liability was restricted only to directors and shareholders as a body. Thus, the auditor's liability has become more restricted, after Caparo. From proposition 6.7 it also follows that a policy that expands the classes of claimants to include a broader category of users, and thus where the parameter $\alpha$ becomes larger, has a positive effect on audit quality production. A similar incentive can be created by broadening classes of claimants as by imposing an ex ante audit quality standard, and both policies can be seen as substitutes.

However, narrowing the classes of claimants and/or introducing proportionate liability, combined with a profession that sets more prescriptive audit standards may result no effect on the level of audit quality produced. 


\section{Conclusion}

The objective of this chapter was to analyse the regulatory impact on the quality of audit work. In this context, a model of audit production behaviour for an individual audit engagement was proposed, assuming that auditor liability is regulated through ex post legal standards of care. A major insight from the analysis is that certainty about the legal standard of care can guarantee auditor compliance with the legal standard of care, whereas vagueness about the legal standard of care may result in larger or smaller audit quality production as compared to the certainty case. The audit quality decision crucially depends on the degree of uncertainty or vagueness about the legal standard of care. The conclusion is that in legal environments that are characterised by a severe vagueness about the legal standard of care, less audit quality will be produced than in legal environments where legal standards of care are reasonably clear (or where there is small uncertainty). The quality of audit work thus depends upon consistency of judicial reasoning.

When legal standards of care are uncertain, a policy option available to regulators to increase audit quality production, is the imposition of a general ex ante audit quality standard. More prescriptive professional audit standards can thus improve the quality produced by the audit industry. However, from the analysis it is also clear that a weak ex ante quality standard may have no impact at all. Unlike the imposition of an ex ante quality standard, restriction of liability to classes of claimants has a negative impact on audit quality production, if the classes of claimants defined by the courts constitute a smaller category than the users of audited financial statements that suffer losses. The opposite is also true, that is by expanding the classes of claimants, audit quality production can be enhanced. This implies that the broader definition of classes of claimants by the courts over the years (until Caparo), may have resulted in an improvement of the quality produced by the audit industry. 
The ambition of this chapter has been to reveal purely analytical properties of the technology of regulation. The static trade-offs between alternative regulatory scenarios have been analysed from the perspective of an individual audit engagement for which these are exogenous parameters. For regulators and legislators seeking to influence audit behaviour, the nature of these trade-offs and the dynamics of their joint interactions needs to be appreciated. The economic analysis applied itself is a technology of simplification, powerful in revealing structure, but subversive in privileging certain assumptions and conjectures, neglecting others. The major assumptions that are employed - risk neutrality, ex ante certain standards, treating quality and negligence as having a single component, a Bayesian revision of beliefs, the view of the court uninfluenced by professional standards other than a lower bound, unlimited liability with no bankruptcy, are all refinements whose relaxation would be needed for a complete analysis. 


\title{
Chapter 7
}

\section{Auditor liability, professional audit standards and}

\author{
social efficiency
}

\section{Introduction}

In the previous chapter, audit quality production has been analysed, given the legal environment in which the auditor operates. The auditor is however only concerned with social welfare to the extent that it is reflected in the law. In this chapter the results of chapter 6 are elaborated. It is investigated whether and when the auditor's privately optimal quality choice is also socially efficient. Definitions and notations are as in chapter 6 . Where necessary for the analysis, some additional notation will be added. The objective is thus to examine which regulatory scenarios create socially efficient audit quality production, both for an individual audit engagement and for all engagements in a legal environment. The results are summarised in a set of colloraries drawn from the propositions in chapter 6 . The chapter is structured as follows. Socially efficient audit quality production for an individual engagement is defined in section 2 . Social efficiency of auditor liability by certain negligence standards is analysed in section 3, both when there is and is no restriction of liability to classes of claimants. Section 4 reports on the conditions for social efficiency when legal standards of care are uncertain and there is no restriction of liability. This is first done for an individual audit engagement and then for all engagements in a legal environment. The impact of the imposition of an ex ante quality standard on social efficiency of audit quality production is examined in section 5. The focus of section 6 is social efficiency in a legal environment characterised by restriction of liability. The major conclusions of the chapter are summarised in section 7 . 


\section{Socially efficient audit production}

Losses to financial statement users due to resource allocation decisions based on defects in those statements which the auditor did not detect or report are here treated as negative externalities. Assuming zero transaction costs, the total social cost of an individual audit engagement is the sum of the cost of producing an audit report and the losses suffered by financial statement users. Both components of social cost are functions of the quality the auditor produces. The social objective of auditor regulation is to minimise the total social cost of an audit engagement, or:

$$
\underset{q}{\operatorname{Min} S C(q)}=C(q)+L(q)
$$

Where:

$$
\begin{array}{ll}
\mathrm{q} & =\text { level of audit quality variable } \\
\mathrm{SC}(\mathrm{q}) & =\text { total social cost of an individual audit engagement } \\
\mathrm{C}(\mathrm{q}) & =\text { direct audit cost; } \\
& \text { for example: } \mathrm{C}(\mathrm{q})=\mathrm{c} \cdot \mathrm{q}^{2} / 4 \text {, where } \mathrm{c} \text { is a cost parameter. } \\
\mathrm{L}(\mathrm{q}) \quad & =\text { negative externalities or losses suffered by third parties; } \\
& \text { for example: } \mathrm{L}(\mathrm{q})=\lambda \mathrm{q}, \text { where } \lambda \text { is the loss parameter. }
\end{array}
$$

It is assumed that the social cost function is strictly convex in $\mathrm{q}$, since $\mathrm{C}(\mathrm{q})>0, \mathrm{dC} / \mathrm{dq}$ $>0$ and $\mathrm{d}^{2} \mathrm{C} / \mathrm{dq}^{2}>0$; and $\mathrm{L}(\mathrm{q})>0, \mathrm{dL} / \mathrm{dq}<0$, and $\mathrm{d}^{2} \mathrm{~L} / \mathrm{dq}^{2}>0$ is assumed to hold. Consequently a unique socially optimal level of audit quality, $q^{* *}$, is defined by the first order condition:

$$
C^{\prime}\left(q^{* *}\right)=-L^{\prime}\left(q^{* *}\right)
$$


Note that the costs of regulation are not included in the objective function in (7.1). The reason is that (7.1) describes an individual audit engagement. The fraction of total regulatory costs accruing to one engagement is difficult to estimate. Since regulatory costs are not a function of quality, $\mathrm{q}$, omission of such costs does not affect the analysis. A social cost function for all engagements in a legal environment would, however, require the inclusion of a regulatory cost, but would only affect the analysis to the extent that such costs are a function of a target level of audit quality that is imposed.

In graph 7.1 the socially optimal level of audit quality for an individual audit engagement is graphically exhibited. Since $C(q)$ and $L(q)$ are engagement specific, the value $q^{* *}$ depends on the form $C(q)$ and $L(q)$ take. For a specific illustration, to make this abstract and stylised discussion more concrete, let us assume that $\mathrm{C}(\mathrm{q})=\mathrm{cq}^{2} / 4$, and $L(q)=\lambda / q$. Using (7.2) the socially efficient level of quality:

$$
q^{* *}=[2 \lambda / c]^{1 / 3}
$$

The larger the ratio of the client specific parameters $\lambda_{\mathrm{c}}$ is, the larger the socially optimal level of audit quality will be for an individual audit engagement. Regulation that drives the auditor's private audit quality decision in the direction of the social optimum can improve social welfare in a Pareto sense. For regulation to be socially efficient, it should be such that for all engagements in a legal environment the engagement specific socially optimal level of audit quality be produced. 
Graph 7.1: The socially efficient level of audit quality production

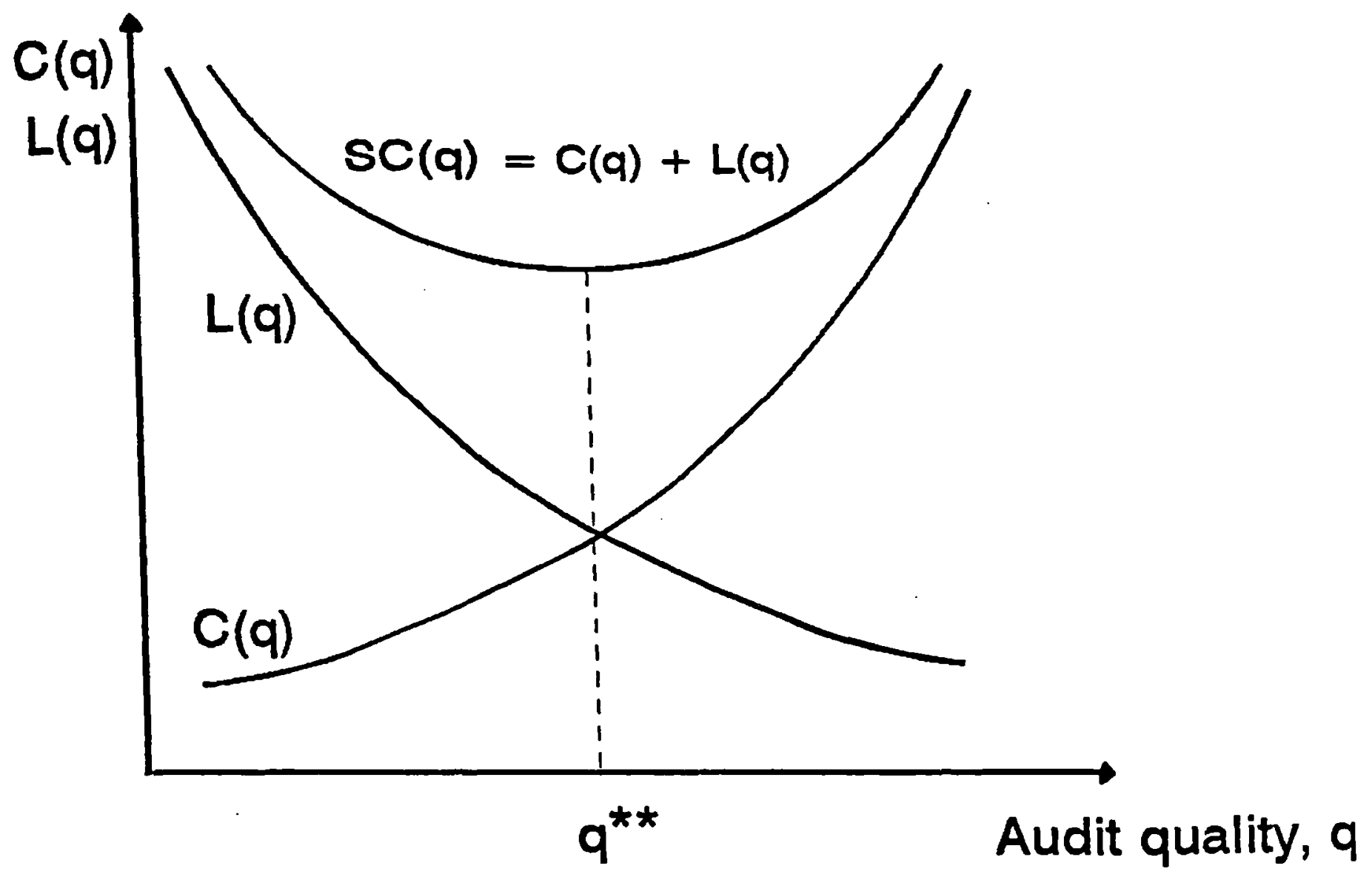




\section{Social efficiency of neqligence standards}

In this section it is analysed whether auditor regulation by way of certain ex post audit quality standards is efficient and serves the public interest. In section 3.1 it is assumed that $\mathrm{D}(\mathrm{q})=\mathrm{L}(\mathrm{q})$ holds, that is the damage payment function of the auditor (as defined in chapter 6) is equal to the negative externality function of the users. This coincides with environments where there is: 1) no statutory capping of liability allowed; and 2) no restriction as to classes of claimants, or where classes of claimants coincide with the users of audited financial statements that suffer losses. In section 3.2 it is then investigated how the conclusions about social efficiency of certain negligence standards change when there is restriction of liability to classes of claimants, and the claimants are a smaller category than the users of audited financial statements. In this situation $\mathrm{D}(\mathrm{q})<\mathrm{L}(\mathrm{q})$ holds, for all values of $\mathrm{q}$. 


\subsection{Efficiency of certain legal standards of care when there is no restriction}

When legal standards of care are known with certainty, the choice of $q_{c}$ by the courts is paramount for the auditor to produce a socially optimal level of audit quality. For alternative values of $q_{c}$, the auditor's private audit quality decision is compared with the socially optimal level of audit quality production. The distribution of the total social cost among auditor and third parties is also considered.

Given that $D(q)=L(q), q_{m}=q^{* *}$ holds ${ }^{108}$. Since $q_{c, u}>q_{m}, q_{c, u}>q^{* *}$ is also true. We can deduce in the illustration $\left(C(q)=c q^{2} / 4 \text { and } D(q)=L(q)=\lambda / q\right)^{109}$, that $q_{c, u}$ is defined by:

$$
\mathrm{q}_{\mathrm{c}, \mathrm{u}}=3^{1 / 2} \cdot[2 \lambda / \mathrm{c}]^{1 / 3}
$$

which is clearly strictly larger than $\mathrm{q}^{* *}=[2 \lambda / \mathrm{c}]^{1 / 3}$. It is trivial that the larger the ratio $\lambda / \mathrm{c}$ is, that is the larger the ratio of the loss parameter to the cost parameter, the larger the critical value $\mathrm{q}_{\mathrm{c}, \mathrm{u}}$ will be. Note that since $\lambda$ and $\mathrm{c}$ are engagement specific, $\mathrm{q}_{\mathrm{c}, \mathrm{u}}$ also is.

Two corollaries about the social efficiency of audit production can be drawn from propositions 6.2 and 6.3 (see previous chapter). Recall that these corollaries only hold if the auditor's liability is not restricted.

\footnotetext{
${ }^{108} \mathrm{q}_{\mathrm{m}}$ is defined as in section 3 of chapter 6 , that is:$$
\mathrm{q}_{\mathrm{m}}=\operatorname{Arg} \quad \min \mathrm{C}(\mathrm{q})+\mathrm{D}(\mathrm{q})
$$$$
\mathbf{q}
$$

$\mathrm{q}_{\mathrm{c}, \mathrm{u}}$ is defined as in section 3 of chapter 6 , as the value for $\mathrm{q}_{\mathrm{c}}$ that fulfills the following condition: $C\left(q_{c}\right)=C\left(q_{m}\right)+D\left(q_{m}\right)$

${ }^{109}$ Note that $d=\alpha . \lambda$. When there is bo restriction, $\alpha=1$ and hence $d=\lambda$.
} 


\section{Corollary 7.1}

An auditor will produce the socially optimal level of quality for an individual audit engagement, if the legal standard of care is known with certainty and set at the socially optimal level, or, at a level that is significantly high110.

\section{Corollary 7.2}

For an auditor to produce the socially optimal level of quality and to act as an insurer of losses suffered by users, the legal standard of care needs to be known with certainty and set at a sufficiently large level ${ }^{111}$.

Two remarks are in place. First, it is trivial that if the courts would maintain one constant level of quality as being the uniform legal standard across all audit cases, liability regulation would not be socially efficient, since the social optimum for an engagement is dependent on the cost and loss parameters which may differ across audit cases. Second, the situation where the auditor takes the role of an insurer provides the same result as a regime of strict liability.Under a regime of strict liability, the auditor's objective function would coincide with the social objective function, and hence total social costs would always be minimised, since the auditor would choose to produce $\mathrm{q}^{* *}$

Table 7.1 summarises the auditor's decision for different values of $\mathrm{q}_{\mathrm{c}}$, the distribution of costs and losses among the auditor and the users, and evaluates social efficiency. Graph 7.2 illustrates the social cost and its distribution among the auditor and the users as a function of the level of $\mathrm{q}_{\mathrm{c}}$ the courts set.

110 By this it is meant that $q_{c}>q_{c, u}$ holds. $111 \mathrm{By}$ this it is meant that $q_{c}>q_{c, u}$ holds. 


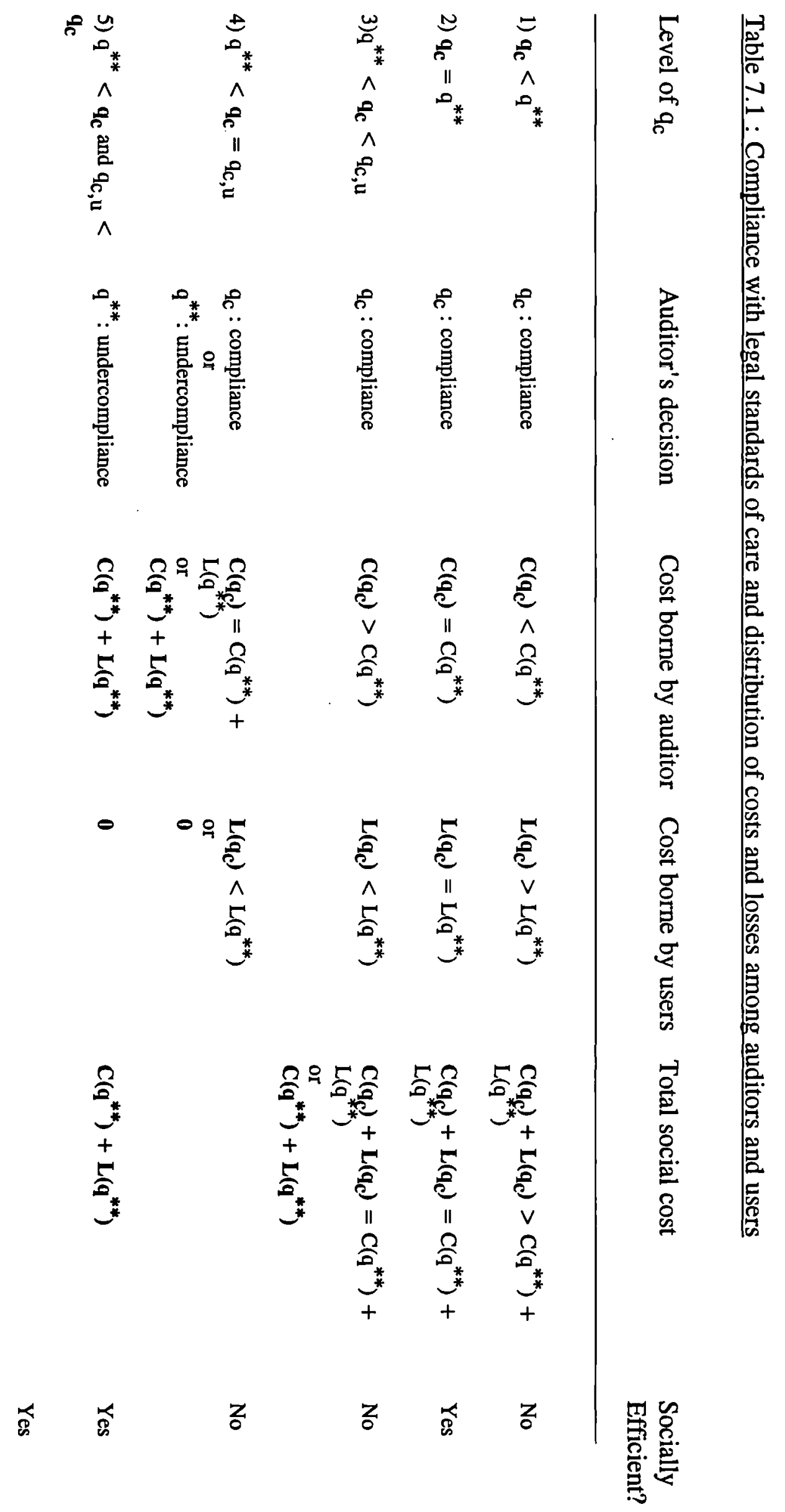


Graph 7.2: Social cost as a function of $q_{\underline{c}}$ when $q_{c}$ is certain

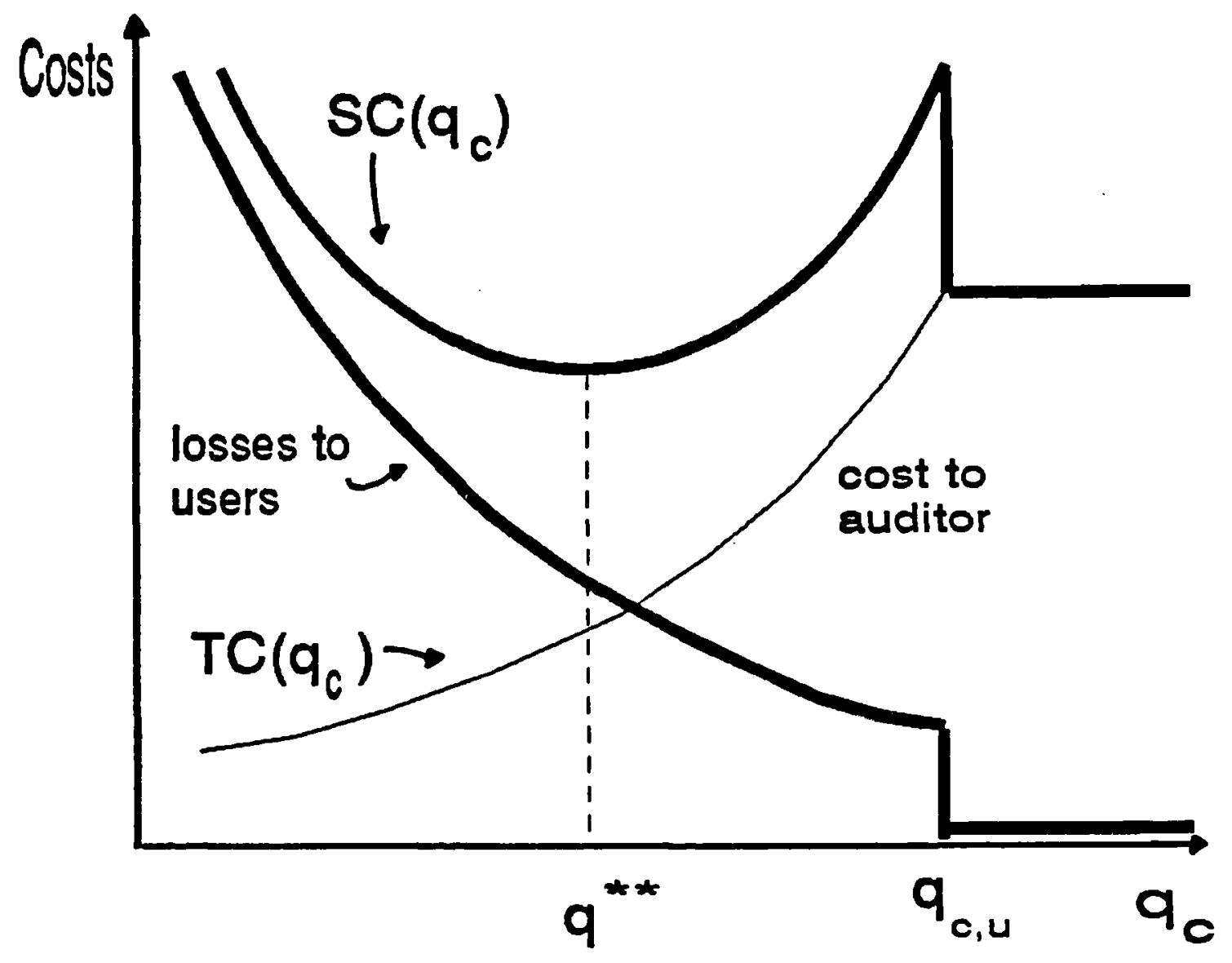




\subsection{Efficiency of certain legal standards of care when there is restriction of liability}

In this section it is assumed that $\mathrm{D}(\mathrm{q})<\mathrm{L}(\mathrm{q})$, for all values of $\mathrm{q}$. For an individual audit engagement, the size of the damage payments with restriction is modelled as in chapter 6:

$$
D(q)=\alpha . L(q), \quad \text { where } 0<\alpha<1
$$

Since $D(q)$ differs from $L(q)$, the conditions for social efficiency change. Propositions 6.1 and 6.2 (previous chapter) are general statements of auditor behaviour when there is certainty about the legal standard of care, and do not depend on the size of damage payments. Therefore, they still hold when $\mathrm{D}(\mathrm{q})<\mathrm{L}(\mathrm{q})$, and thus the auditor will comply with the certain legal standard of care ${ }^{112}, \mathrm{q}_{\mathrm{c}}$, as long as it is set below a critical value, $\mathrm{q}_{\mathrm{c}, \mathrm{u}}$. As to efficiency under restriction, corollary 7.1 does no longer hold when there is a restriction on damage payments. Corollary 7.1 stated that efficiency can be obtained when the legal standard of care, $\mathrm{q}_{\mathrm{c}}$, is set at the socially optimal level of care, $\mathrm{q}^{* *}$, or when it is set above the critical value, $q_{c, u}$.

If the legal standard of care is set at the socially optimal level, i. e. $q_{c}=q^{* *}$, inefficiency may result from the introduction of a liability restriction. The reason is that restriction has the effect of reducing the values of both $\mathrm{q}_{\mathrm{m}}$ and $\mathrm{q}_{\mathrm{c}, \mathrm{u}}$. Reduction of the size of the damage payments in the objective function of the auditor has the effect of reducing the marginal benefit (i.e. marginal damage payments) at $q^{* *}$. It is clear that $q_{m}$ is no longer equal to $\mathrm{q}^{* *}$, but is smaller than $\mathrm{q}^{* *}$. Also, it is no longer guaranteed that

112 Recall that the legal standard of care was treated as a variable in the analysis preceeding propositions 1 and 2. 
$\mathrm{q}_{\mathrm{c}, \mathrm{u}}$ will be larger than $\mathrm{q}^{* *}$, and it depends on the size the parameter $\alpha$ takes whether this is the case. A critical value for $\alpha$, defined as $\alpha_{l}$, can be defined at which $\mathrm{q}_{\mathrm{c}, \mathrm{u}}=\mathrm{q}^{* *}$ holds ${ }^{113}$, and hence at which the auditor is indifferent as to produce $\mathrm{q}^{* *}$ or $\mathrm{q}_{\mathrm{m}}$.

$$
\alpha_{l}=\frac{C\left(\mathrm{q}^{* *}\right)-\mathrm{C}\left(\mathrm{q}_{\mathrm{m}}\right)}{\mathrm{L}\left(\mathrm{q}_{\mathrm{m}}\right)}
$$

Given that $\mathrm{q}_{\mathrm{c}}=\mathrm{q}^{* *}$, efficiency can thus only be obtained when $\alpha$ is strictly larger than $\alpha_{l}$, such that $\mathrm{q}_{\mathrm{c}, \mathrm{u}}>\mathrm{q}^{* *}$. If $\alpha$ is strictly smaller than $\alpha_{l}$, then $\mathrm{q}_{\mathrm{c}, \mathrm{u}}<\mathrm{q}^{* *}$, and the auditor will produce $\mathrm{q}_{\mathrm{m}}$ which is smaller than $\mathrm{q}^{* *}$. Thus if restriction on liability is very pronounced, the auditor will produce less quality than what is socially optimal. Graph 7.3 illustrates the case where $\alpha=\alpha_{l}$.

If the legal standard of care is set above the critical value, i. e. $q_{c}>q_{c, u}$, or the second case where - without restriction - the auditor would produce $\mathrm{q}^{* *}$, with restriction the auditor will produce $\mathrm{q}_{\mathrm{m}}$, and $\mathrm{q}_{\mathrm{m}}$ is always smaller than $\mathrm{q}^{* *}$, since $\alpha<1$. The result is that with restriction, not only corollary 7.1 , but also corollary 7.2 is no longer valid. In conclusion, with restriction on liability the only case where certain legal standards of care will be efficient, is where the legal standard of care is set at the social optimum, and where restriction is targeted at a level above $\alpha_{l}$. In all other cases, the auditor will produce less than $\mathrm{q}^{* *}$ and act as an insurer.

${ }^{113}$ Recall that $q_{c, u}$ is defined by: $C\left(q_{c}\right)=C\left(q_{m}\right)+D\left(q_{m}\right)$. Since $q_{c}=q^{* *}$, and $D\left(q_{m}\right)=\alpha L\left(q_{m}\right)$, the critical $\alpha_{l}$ value is found by rearranging the terms. 


\section{Corollary 7.3}

If auditor liability is restricted to classes of claimants and the legal standard of care is known with certainty, the auditor will only produce a socially optimal level of care if the courts set the legal standard of care at the social optimum, and if restriction is not too severe ${ }^{114}$.

In the illustration, where $\mathrm{C}(\mathrm{q})=\mathrm{cq} \mathrm{q}^{2} / 4$, and introducing restriction in the damage function, such that $D(q)=d / q=\alpha . \lambda / q, q_{m}$ and $q_{c, u}$ can be deduced and are given by:

$$
\begin{aligned}
& \mathrm{q}_{\mathrm{m}}=\alpha^{1 / 3} \cdot[2 . \lambda / \mathrm{c}]^{1 / 3} \quad<\mathrm{q}^{* *} \\
& \mathrm{q}_{\mathrm{c}, \mathrm{u}}=(3)^{1 / 2} \cdot[2 \cdot \alpha \cdot \lambda / \mathrm{c}]^{1 / 3}
\end{aligned}
$$

114 By this it is meant that $\alpha>\alpha_{l}$.needs to hold. 
Graph 7.3: Restriction on liability and social efficiency: illustration of the auditor's decision when $\alpha=\alpha_{l}$

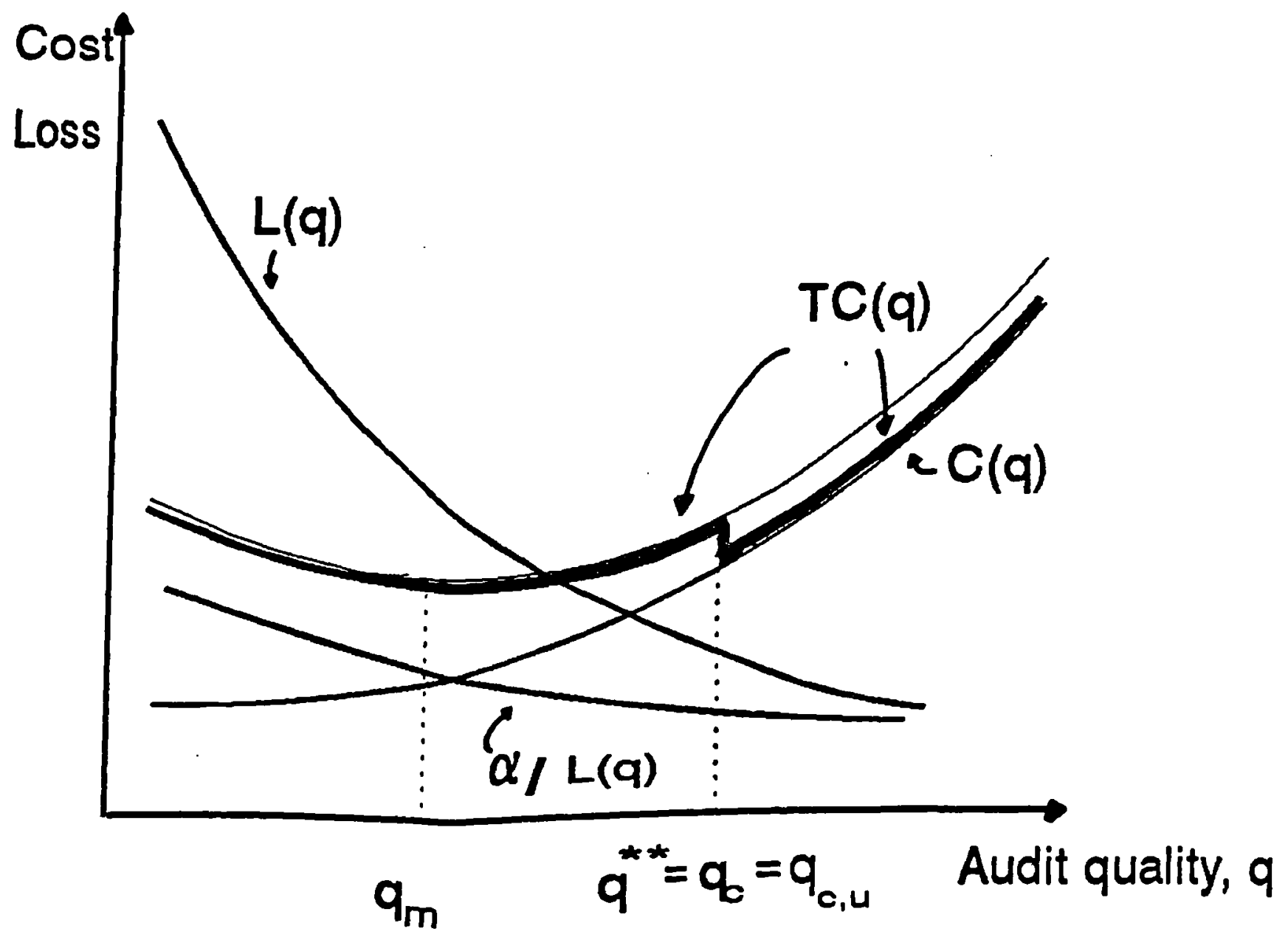


$\mathrm{q}_{\mathrm{m}}$ and $\mathrm{q}_{\mathrm{c}, \mathrm{u}}$ only differ by a constant (3)1/2.

The critical value for $\alpha$, i.e. $\alpha_{l}$, at which $\mathrm{q}^{* *}=q_{\mathrm{c}, \mathrm{u}}$ is given by:

$$
\alpha_{l}=\frac{1}{3 .(3)^{1 / 2}} \quad=19 \%
$$

An interesting result is that the size of $a_{l}$ does not depend on the parameters of a client situation. Therefore, for restriction to be generally efficient, the parameter $\alpha\left(=\alpha_{l}\right)$ will have to be the same for all engagements in a legal environment, whereas the legal standard of care needs to be engagement specific and set at the socially optimal level of care for the situation. This implies that the ratio of 'losses to claimants' to 'losses to all users of audited financial statements' needs to be constant over all engagements within a jurisdiction. Since the composition of user categories may differ across engagements, it is likely that the parameter $\alpha$ resulting from jurisdiction that restricts liability to classes of claimants is engagement specific. As a result, for some situations $\alpha$ may be smaller and for others larger than $\alpha_{l}$. As a result, restriction of liability to classes of claimants may result in overall inefficiency, although the legal standard of care is certain.

If, however, restriction is such that the parameter $\alpha$ is constant for all engagements in a legal environment, the following corollaries hold:

\section{Corollary 7.4}

In jurisdictions where certain negligence standards which are set at $q^{* *}$ for each engagement, are combined with a severe restriction on the size of the damage payments, in the sense that the parameter $\alpha<\alpha_{l}$, a socially optimal level of audit care will never be produced. 


\section{Corollary 7.5}

Jurisdictions that combine a severe restriction on auditor liability, i.e. $\alpha<\alpha_{b}$, with setting the certain legal standard of care at the engagement specific social optimum, provide a protected category of users with insurance.

\section{Corollary 7.6}

Jurisdictions that combine a severe restriction on auditor liability, i.e. $\alpha<\alpha_{l}$, with setting the certain legal standard of care at the social optimum, and hence provide a protected category of users with insurance are not socially efficient.

Note that when there were restriction of liability, a regime of strict liability would never be socially efficient.

\subsection{Conclusion}

In this section it has been shown that liability regulation by certain legal standards of care and where there is no restriction of liability to classes of claimants is socially efficient in two cases: 1 ) if the courts consistently set the legal standard of care at the engagement specific socially optimal level of care for all engagements in a legal environment; This would be the case when the courts compare losses to users to direct audit cost, and derive an efficient quality standard therefrom. 2) if the courts set the legal standard of care consistently and sufficiently above the engagement specific socially optimal level of care for all engagements in a legal environment. In the second case, the audit profession acts as an insurer of financial statement risk. When there is restriction of liability to classes of claimants, social efficiency can no longer be achieved by policies that turn auditors into insurers. The only way to achieve overall social efficiency is to consistently set the legal standard of care at the engagement specific social optimum and to watch that restriction is not too severe. 


\section{Social efficiency of uncertain legal standards of care when there is no restriction}

The social efficiency of vague legal standards is here examined, assuming 115 that the auditor's expectation of the legal standard is the socially optimal level of care, $\mathrm{q}^{* *}$, and thus $\mathrm{E}\left(\mathrm{q}_{\mathrm{c}}+\delta\right)=\mathrm{q}^{* *}$. Unlike the certainty case, where efficiency of audit production for a particular audit engagement was examined for alternative values of $q_{c}, q_{c}$ is assumed to be constant. Note however, that for alternative audit engagements $q^{* *}$ will take a different value, since $\mathrm{C}(\mathrm{q})$ and $\mathrm{L}(\mathrm{q})$ are engagement specific (i.e. the parameters $\lambda$ and $c$ are engagement specific). Efficiency is first examined for an individual audit engagement in section 4.1. Efficiency of vague legal standards in general, that is, for all engagements in a legal environment is discussed in section 4.2. In this section it is assumed that $\mathrm{D}(\mathrm{q})=\mathrm{L}(\mathrm{q})$.

\subsection{Efficiency of negligence standards for an individual audit engagement}

Given that $E\left(q_{c}+\delta\right)=q_{c}=q^{* *}$, and $f(q) \sim N\left(q ; q^{* *}, \sigma\right)$, the following holds:

$$
C^{\prime}\left(q_{c}\right)+0.5 L^{\prime}\left(q_{c}\right)>0
$$

and proposition 6.4 is not applicable. Since $\mathrm{q}^{* *}<\mathrm{q}_{\mathrm{c}, \mathrm{u}}$ always holds, the conditions in proposition 6.5 are fulfilled. If $\sigma=\sigma_{e}$, the auditor will produce $q^{* *}$. Corollary 7.7 can now be formulated:

115 This assumption is maintained throughout the remainder of this chapter. 


\section{Corollary 7.7}

An auditor will produce more (less) than the socially optimal level of quality for an individual audit engagement, if he is uncertain about the legal standard of care and if uncertainty is sufficiently small (large).116

In the illustration, where $C(q)=c q^{2} / 4$, and $D(q)=d / q=\lambda / q$, and hence $q_{c}=q^{* *}=$ $(2 \lambda / c)^{1 / 3}$, the critical value $\sigma_{\mathrm{e}}$ takes the following value ${ }^{117}$ :

$$
\sigma_{\mathrm{e}}=\frac{2}{(2 \pi)^{1 / 2}} \cdot \mathrm{q}^{* *}
$$

The steeper the social loss function and the flatter the direct cost function, the larger $\mathrm{q}^{* *}$ will be and the larger $\sigma_{\mathrm{e}}$ will be.

It is important that the courts are aware that, even if jurisdiction leads to auditors expecting the legal standard of care to be the social optimum, the auditor's behaviour may deviate from what is socially optimal. This is clearly different from the results in the certainty case, where a socially optimal level of audit quality will always be produced when the legal standard is set at the social optimum. As compliance with the social optimum depends upon the subjective beliefs of the auditor, and in particular on the auditor's perception of $\sigma$, it cannot be generally concluded whether different auditors will or will not produce a socially optimal level of audit quality, even if they agree on the parameters of a particular client situation. If their beliefs are

116 small uncertainty is defined as $\sigma<\sigma_{\mathrm{e}}$. Large uncertainty is defined as $\sigma>\sigma_{\mathrm{e}}$.

117 Recall from chapter 6 that se is defined as:

$$
\sigma_{e}=\frac{D\left(q_{c}\right)}{(2 \pi) 0.5\left[C^{\prime}\left(q_{c}\right)+0.5 D^{\prime}\left(q_{c}\right)\right]}
$$


heterogeneous, that is, they disagree on the value of $\sigma$, they will produce a different level of audit quality for the same client situation.

\subsection{Efficiency of negligence standards in a particular jurisdiction}

In this section the overall efficiency of uncertain legal standards across audit engagements in a legal environment is examined. It follows from corollary 7.7 that if the auditors' beliefs are heterogeneous, in the sense that $\sigma$ differs for the same type of engagement, social efficiency cannot be established for one type of audit engagement, and hence certainly not for all engagements in a legal environment. Overall social efficiency can also not be achieved when all auditors agree on $\sigma$ as being the uncertainty that characterises a legal environment. In this case $\sigma$ is the same for all engagements, but the engagement specific expectation of the legal standard of care may differ, since it is, by assumption, equal to the engagement specific social optimum. Since $\sigma_{\mathrm{e}}$ is engagement specific, some client situations $\sigma_{\mathrm{e}}=\sigma$ will hold, but for other client situations $\sigma_{\mathrm{e}}<\sigma$ will hold, and for still some other client situations $\sigma_{\mathrm{e}}>\sigma$ will hold. The reason is that the direct cost and loss parameters of alternative audit engagements merely differ.

It may, however, be unreasonable to assume that the uncertainty that characterises a legal environment is constant over all audit engagements. The value that $\sigma$ takes may rather be proportional to the auditor's expectation of court's standard of care, i.e. qc $=$ $q^{* *}$. Let the audit engagements in a legal environment be indexed by $i$. Hence, $\sigma_{i}$

indicates the uncertainty about the legal standard of care, where $\mathrm{q}_{\mathrm{i}}{ }^{* *}$ is the expectation about the legal standard of care for an engagement. The critical value, $\sigma_{e, i}$, indicates the level of uncertainty at which the auditor would produce $q_{i}^{* *}$, for engagement $i$. In the subsequent analysis it is assumed that the uncertainty about the legal standard of 
care for alternative audit engagements that results from jurisdiction in a legal environment is such that:

$$
\frac{\sigma_{\mathrm{i}}}{\mathrm{q}_{\mathrm{i}}^{* *}}=\mathrm{b}
$$

where b is constant for all audit engagements and characterises the "relative" uncertainty resulting from jurisdiction in a legal environment. Since auditor behaviour is here examined across client situations, the parameters of a client situation need to be specified in order to draw conclusions about the efficiency of a legal environment characterised by a constant " $b$ ". As before it is assumed that $C_{i}(q)=c_{i} q^{2 / 4}$, and that $\mathrm{D}_{\mathrm{i}}(\mathrm{q})=\mathrm{d}_{\mathrm{i}} / \mathrm{q}=\mathrm{L}_{\mathrm{i}}(\mathrm{q})=\lambda_{\mathrm{i}} / \mathrm{q}$. It follows from equations (7.5) and (7.6) that:

$$
\frac{\sigma_{e, i}}{\sigma_{i}}=\frac{2}{\text { b. }(2 \pi)^{1 / 2}}
$$

In such a legal environment, auditors will produce a socially optimal level of audit quality for all audit engagements, $i$, if $\sigma_{e, i}$ equals $\sigma_{i}$, and the LHS of equation (7.7) is equal to one. This situation can be achieved if $b$ equals a critical value, $b_{e}$, which is defined as:

$$
b_{e}=\frac{2^{1 / 2}}{\pi^{1 / 2}}
$$

From this, it can be concluded that for all audit engagements, i, in a particular legal environment: 


$$
\begin{aligned}
& \mathrm{q}_{\mathrm{i}}^{*}>\mathrm{q}^{* *} \text { iff } \mathrm{b}<\mathrm{b}_{\mathrm{e}} \\
& \mathrm{q}_{\mathrm{i}}^{*}<\mathrm{q}_{\mathrm{i}}^{* *} \text { iff }: \quad \mathrm{b}>\mathrm{b}_{\mathrm{e}}
\end{aligned}
$$

Given the assumptions in this section, liability regulation by uncertain negligence standards may result in audit quality levels that are generally too high or too low. In such legal environments complementary regulatory policies that drive $b_{e}$ closer to $b$ may be welfare improving.

\section{Corollary 7.8}

If a legal environment is characterised by a constant "relative" uncertainty about the legal standard of care for all engagements in that environment, the audit profession will systematically produce more (less) audit quality than what is socially optimal, if the "relative" uncertainty about the legal standard of care is sufficiently small (large) $)^{118}$.

\subsection{Conclusion}

If legal standards of care are ex ante uncertain to the auditor, liability regulation by negligence standards no longer guarantees socially efficient audit quality production, even though the expectation of the legal standard of care is the socially optimal level. The auditor may thus produce more or less than what is socially optimal for a client situation. Since uncertainty about the legal standard of care follows from jurisdiction in a legal environment, it is reasonable to assume that the engagement specific uncertainty,

\footnotetext{
118 By a small "relative" uncertainty it is meant that $b<b_{e}$; by a large "relative" uncertainty it is meant that $b>b_{e}$.
} 
in terms of standard deviation, is a constant fraction of the auditor's expection of the legal standard of care. If this is the case, it has been shown, that liability regulation through negligence standards that are uncertain may lead to either systematical overproduction of quality or systematical underproduction of quality by the entire audit profession. Given that this may occur, it is analysed in the subsequent 2 sections whether complementary regulatory policies can establish overall efficiency in a legal environment with uncertain negligence standards.

\section{Social efficiency of the imposition of an ex ante quality standard when} negligence standards are uncertain and where there is no restriction of liability

\subsection{Social efficiency for an individual audit engagement}

It follows from proposition 6.6 that an ex ante audit quality standard cannot improve efficieny in situations where the prior beliefs of the auditor were such that he would have produced an audit quality level equal to, or larger than the socially optimal level. If the auditor would have produced less than what is socially optimal because $\sigma>\sigma_{\mathrm{e}}$ holds, it follows from equation (6.21) in chapter 6 that an efficient ex ante quality standard for an individual engagement needs to be such that:

$$
\mathrm{R}\left(\mathrm{q}_{\mathrm{s}}\right) \cdot \mathrm{C}^{\prime}\left(\mathrm{q}^{* *}\right)=-0.5 \mathrm{D}^{\prime}\left(\mathrm{q}^{* *}\right)+\sigma^{-1}(2 \pi)^{-1 / 2} \cdot \mathrm{D}\left(\mathrm{q}^{* *}\right),
$$

assuming, as before, that the auditor's prior expectation of the legal standard of care is the level of audit quality that is socially optimal for the engagement. Also: 


$$
\begin{aligned}
& \text { If } \mathrm{R}\left(\mathrm{q}_{\mathrm{s}}\right) \cdot \mathrm{C}^{\prime}\left(\mathrm{q}^{* *}\right)<-0.5 \mathrm{D}^{\prime}\left(\mathrm{q}^{* *}\right)+\sigma^{-1}(2 \pi)^{-1 / 2} \cdot \mathrm{D}\left(\mathrm{q}^{* *}\right) \text {, then : } \mathrm{q}^{*}>\mathrm{q}^{* *} \\
& \text { If } \mathrm{R}\left(\mathrm{q}_{\mathrm{s}}\right) \cdot \mathrm{C}^{\prime}\left(\mathrm{q}^{* *}\right)>-0.5 \mathrm{D}^{\prime}\left(\mathrm{q}^{* *}\right)+\sigma^{-1}(2 \pi)^{-1 / 2} \cdot \mathrm{D}\left(\mathrm{q}^{* *}\right) \text {, then }: \mathrm{q}^{*}<\mathrm{q}^{* *}
\end{aligned}
$$

In the illustration, where $C(q)=c q^{2} / 4$ and $D(q)=d / q=\lambda / q$, and where $q^{* *}=(2 \lambda / c)^{1 / 3}$, efficiency will prevail only if:

$$
R\left(q_{s}\right)=0.5+q^{* *} \cdot \sigma^{-1}(2 \pi)^{-1 / 2}
$$

Note that if the ex ante quality standard is set above the socially optimal level of quality $\left(\mathrm{q}_{\mathrm{s}}>\mathrm{q}^{* *}\right), \mathrm{R}\left(\mathrm{q}_{\mathrm{s}}\right)$ takes a value smaller than 0.5 , and the LHS in (7.9) is always strictly smaller than the RHS in (7.9). The condition in (7.9) cannot be fulfilled. The implication is that the auditor will produce a quality level that is larger than the social optimum.

\section{Corollary 7.9}

If the legal standard of care is uncertain, the imposition of an ex ante quality standard can never lead to socially efficient quality production for an individual engagement if the ex ante quality standard is larger than the engagement specific socially optimal level of quality.

\subsection{Efficiency of a general ex ante standard in a particular legal environment}

A self-regulatory audit profession does not prescribe alternative audit quality standards for alternative client situations. The imposition of an ex ante quality standard therefore implies that qs will be the same for all audit engagements in a legal environment. The question that urges is whether an overall ex ante quality standard can improve social efficiency in the stylised legal environment characterised by a constant "relative" 
uncertainty, b (as introduced in section 4.2), and where there is systematical underproduction of quality because $b>b_{e}$. Recall that in such an environment uncertainty, in terms of $\sigma$, is a constant fraction of the client specific socially optimal level of quality, $q_{i}{ }^{*}$, across all engagements, $i$. Let $R_{i}\left(q_{s}\right)$ be the prior probability that the auditor would be held liable if he produced an audit quality level qs for an audit engagement, i. From equation (7.6) it follows that $\mathrm{q}_{\mathrm{i}}^{* *} \cdot \sigma_{\mathrm{i}}^{-1}=\mathrm{b}^{-1}$. Equation (7.9) can now be rewritten as:

$$
R_{i}\left(q_{s}\right)=b^{-1} \cdot(2 \pi)^{-1 / 2}+0.5
$$

Overall efficiency can only be achieved if the condition in equation (7.10) holds for all audit engagements. Given that $\mathrm{q}_{s}$ is the same for all client situations, this is not possible as $\mathrm{R}_{\mathrm{i}}\left(\mathrm{q}_{\mathrm{s}}\right)$ will take a different value for alternative client situations. The larger $\mathrm{q}_{\mathrm{i}}{ }^{* *}$, and hence the larger $\sigma_{\mathrm{i}}$, the larger $\mathrm{R}_{\mathrm{i}}\left(\mathrm{q}_{\mathrm{s}}\right)$ will be, and the more likely that the auditor will still produce an audit quality level below the social optimum, $\mathrm{q}_{i}{ }^{* *}$, albeit larger than before the imposition of the ex ante standard. The smaller $\mathrm{q}_{\mathrm{i}}{ }^{* *}$, and hence the smaller $\sigma_{i}$, the smaller $R_{i}\left(q_{s}\right)$ will be, and the more likely that the auditor will start to produce an audit quality level above the social optimum, $q_{i}^{* *}$. Note that the results are conform with corollary 7.9 , since the smaller $\mathrm{q}_{i}{ }^{* *}$ is, the more likely that the general ex ante standard, qs, will be larger than $\mathrm{q}^{* *}$.

\section{Corollary 7.10}

In a legal environment that is characterised by constant "relative" uncertainty about the legal standard of care for all engagements in that environment, and where the audit profession systematically produces less audit quality than is socially optimal, overall social efficiency cannot be achieved by imposing an overall ex ante quality standard. 
An example illustrating the conclusions is given in table 7.2. Three audit engagements with different direct cost and loss parameters are considered. For all three engagements the auditor produces - without a complementary policy - less audit quality than the engagement specific social optimum, since $\sigma_{\mathrm{i}}>\sigma_{\mathrm{e}, \mathrm{i}}$. The impact of an overall ex ante standard, $\mathrm{q}_{\mathrm{s}}=1.57$, has the effect that for engagement 3 , the auditor still undercomplies. The overall ex ante quality standard is too small for this situation, since socially efficient audit quality production requires the ex ante audit quality standard to be 1.97 . For engagement 2 , the auditor will exactly produce what is socially optimal. For engagement 1 , the auditor would even produces more than what is socially optimal. Here, the general ex ante standard, $\mathrm{q}_{\mathrm{s}}=1.57$, is too large for this engagement, since the ex ante standard that would induce the auditor to produce exactly what is socially optimal needs to be equal to 1.18 . 
Table 7.2: Example of the introduction of an ex ante quality standard in a stylised legal environment, with $b=2 / 3$ and a constant $q_{s}=1.57$

\begin{tabular}{|c|c|c|c|}
\hline & ENGAGEMENT 1 & ENGAGEMENT 2 & ENGAGEMENT 3 \\
\hline $\mathrm{c}_{\mathrm{i}}$ & 2 & 2 & 6 \\
\hline$\lambda_{i}$ & 27 & 64 & 375 \\
\hline $\mathrm{q}_{\mathrm{i}}^{* *}$ & 3 & 4 & 5 \\
\hline$\sigma_{i}$ & 2.0 & 2.67 & 3.33 \\
\hline$\sigma_{e . i}$ & 1.69 & 2.26 & 2.82 \\
\hline $\mathrm{R}_{\mathrm{i}}\left(\mathrm{q}_{\mathrm{s}}\right)$ & 0.761 & 0.818 & 0.849 \\
\hline $\mathrm{q}_{\mathrm{s} . \mathrm{i}}$ & 1.18 & 1.57 & 1.97 \\
\hline
\end{tabular}

\subsection{Conclusion}

From the analysis in this section, a number of conclusions can be drawn. First, since an overall ex ante standard of audit quality can never reduce audit quality production, the imposition of an ex ante quality standard will thus increase the audit quality produced by the audit industry. However, if the regulators aims for social efficiency, an ex ante audit quality standard should not be used if the profession systematically produces more quality than what is socially optimal. Second, an ex ante quality standard that is so weak that it does not change beliefs about the legal standard of care, has no impact on audit quality production and thus can do no harm. A politically weak self regulatory body, relying on the power of consensus to set audit standards would write such standards. 
However, a politically strong self regulating industry might also choose to develop such standards inorder to pre-empt effective regulation. Third, the combination of an uncertain negligence standard with a very strong ex ante quality standard, that is an ex ante standard that is stronger than the socially efficient level of audit quality, cannot create socially efficient quality production. Fourth, and most important for public policy, the imposition of an overall ex ante audit quality standard, that is constant for all audit situations, cannot create overall social efficiency. Overall efficiency can only be established by an ex ante audit quality standard, if it were tailor made to the audit situation. Since such a standard would require the intervention of an "arbiter", the ex ante standard would become the same as a certain legal standard. This conclusion corroborates the earlier finding that certain legal standards of care can create overall social efficiency.

\section{Uncertain negligence standards and restriction of liability to classes of claimants}

Auditor liability in the UK and the US is restricted to classes of claimants. In this section it is analysed what the effect of such a restriction is on social efficiency, when the classes of claimants defined by jurisdiction constitute a smaller category than the users of audited financial statements that suffer losses. In such a situation, the auditor's private damage payment function will differ from the social loss function. As before it is assumed that for an individual engagement:

$$
D(q)=\alpha . L(q), \quad \text { where } 0<\alpha \leq 1
$$

Thus, for an individual audit engagement, it is assumed that restriction has the effect of decreasing the expected damage payments by a factor $\alpha$. 


\subsection{Social efficiency for an individual audit engagement}

It follows from proposition 6.7 that restriction cannot improve efficiency in situations where the beliefs of the auditor are such that he would have produced an audit quality level equal to or below the socially optimal level without restriction. The introduction of restriction has the effect of decreasing the critical value for $\sigma$ at which the auditor exactly produces the socially optimal level of audit quality. Let, as before, $\sigma_{\mathrm{e}}$ be the critical value for $\sigma$ at which $\mathrm{q}^{*}=\mathrm{q}^{* *}$ holds without restriction, and let $\sigma_{\mathrm{r}}$ be the critical value for $\sigma$ at which $\mathrm{q}^{*}=\mathrm{q}^{* *}$ holds with restriction. Hence, without restriction, the marginal condition for social optimality is:

$$
\mathrm{C}^{\prime}\left(\mathrm{q}^{* *}\right)=-0.5 \mathrm{~L}^{\prime}\left(\mathrm{q}^{* *}\right)+\sigma_{\mathrm{e}}^{-1} \cdot(2 \pi)^{-0.5} \cdot \mathrm{L}\left(\mathrm{q}^{* *}\right)
$$

and with restriction:

$$
C^{\prime}\left(q^{* *}\right)=-0.5 \alpha \cdot L^{\prime}\left(q^{* *}\right)+\sigma_{r}^{-1} \cdot(2 \pi)^{-0.5} \cdot \alpha \cdot L\left(q^{* *}\right)
$$

From equating the RHS in (7.11) and (7.12) and rearranging the terms, it follows that:

$$
\frac{(1-\alpha) \cdot L^{\prime}\left(q^{* *}\right)}{2}=\left(\sigma_{\mathrm{e}}^{-1}-\alpha \cdot \sigma_{\mathrm{r}}^{-1}\right) \cdot(2 \pi)^{-0.5} \cdot \mathrm{L}\left(\mathrm{q}^{* *}\right)
$$

The LHS of (7.13) is negative, and therefore $\sigma_{\mathrm{e}}^{-1}-\alpha . \sigma_{\mathrm{r}}{ }^{-1}<0$ must also be true. Since $\alpha$ takes a value between 0 and 1 , the following holds: 


$$
\frac{\sigma_{\mathrm{e}}}{\sigma_{\mathrm{r}}}<1
$$

The conclusion is that if $\sigma_{\mathrm{e}} \leq \sigma$ holds, $\sigma_{\mathrm{r}}<\sigma$ will also hold, and restriction can never be welfare improving. However, if $\sigma_{\mathrm{e}}>\sigma$ holds, $\sigma_{\mathrm{r}}=\sigma$ can be obtained and efficiency can be established by restriction. It depends however on the value that the parameter $\alpha$ takes whether this will eventually be the case.

Assuming that $C(q)=c q^{2} / 4$, and that $D(q)=\alpha . \lambda / q, \sigma_{r}$ is defined by the following function of $\alpha$ :

$$
\sigma_{\mathrm{r}}=\frac{\alpha}{2-\alpha} \cdot \sigma_{\mathrm{e}}=\frac{2 . \alpha \cdot(2 \pi)^{-0.5} \cdot \mathrm{q}^{* *}}{2-\alpha}
$$

Efficiency is obtained when $\sigma_{\mathrm{r}}=\sigma$, or where $\alpha$ takes the critical value, defined as $\alpha_{\mathrm{e}}$ :

$$
\alpha_{e}=\frac{2 . \sigma_{r}}{\sigma_{e}+\sigma_{r}}
$$

If restriction is such that $\alpha<\alpha_{\mathrm{e}}$, the auditor will produce less than the socially optimal level of audit quality. If $\alpha>\alpha_{\mathrm{e}}$, the auditor will still produce more than the socially optimal level, albeit less than without restriction.

\section{Corollary 7.11}

Restriction on liability is welfare improving for an individual audit engagement, if without restriction an auditor produced more than the socially optimal level of audit quality, and if restriction is such that $\alpha \geq \alpha_{e}$. If restriction is such that $\alpha=\alpha_{e}$, audit quality production is socially efficient. 


\subsection{Efficiency of restriction of liability in a particular legal environment}

The question addressed in this section is whether liability restriction can generally improve social efficiency over all engagements in a stylised legal environment that is characterised by a constant " $b$ " (as introduced in section 4.2), and where there is systematical overproduction of quality as compared to what would be socially optimal because "relative" uncertainty is too small (i.e. $b<b_{e}$ ). It is shown that overall social efficiency can only be obtained if restriction is such that the parameter a is constant for all engagements, $i$, in that legal environment.

From equations (7.14) and (7.6) it can be derived that for any engagement, i:

$$
\begin{aligned}
\frac{\sigma_{r, i}}{\sigma_{i}} & =\frac{2 . \alpha \cdot(2 \pi)^{-0.5}}{(2-\alpha)} \cdot \frac{q^{* *}}{\sigma_{i}} \\
& =\frac{2 . \alpha \cdot(2 \pi)^{-0.5}}{(2-\alpha) \cdot b}
\end{aligned}
$$

Social efficiency is obtained if $\sigma_{\mathrm{r}, \mathrm{i}}=\sigma_{\mathrm{i}}$, for all engagements, and the RHS of equation (7.16) equals one. Since $b$ is constant across all engagements in the environment, overall social efficiency can only be obtained when the parameter $\alpha$ is also a constant over all engagements, and if:

$$
\alpha_{e, i}=\frac{2 . b}{b+2 .(2 \pi)^{-0.5}}=\alpha_{e}
$$


for all engagements. An example illustrating the above findings is given in table 7.3. As in table 7.2, three audit engagements are considered with different direct cost and loss parameters. These parameters are as in table 7.2 , but the legal environment is relatively less uncertain, and thus $\mathrm{b}$ is smaller. For all three engagements the auditor produces systematically more than the engagement specific social optimum, since $\sigma_{\mathrm{i}}<\sigma_{\mathrm{e}, \mathrm{i}}$. From the data in table 7.3 it is clear that if restriction is such that $\alpha_{i}=0.77$ for all engagements, overall efficiency can be achieved. Overall social efficiency can thus not be established if the parameter $\alpha_{i}$ differs across engagements. If, for example $\alpha_{1}=0.66$, the auditor will produce less than what is socially optimal for engagement 1 ; whereas he will produce more for engagment 3 if $\alpha_{3}=0.90$. 
Table 7.3: example of restriction of liability in a stylised legal environment, with $b=$ 0.5

\begin{tabular}{|c|c|c|c|}
\hline & ENGAGEMENT 1 & ENGAGEMENT 2 & ENGAGEMENT 3 \\
\hline$c_{i}$ & 2 & 2 & 6 \\
\hline$\lambda_{\mathrm{i}}$ & 27 & 64 & 375 \\
\hline $\mathrm{q}^{* *}$ & 3 & 4 & 5 \\
\hline$\sigma_{i}$ & 1.5 & 2.0 & 2.5 \\
\hline$\sigma_{\mathrm{e} . \mathrm{i}}$ & 2.394 & 3.192 & 3.989 \\
\hline Values of $\alpha_{i}$ & $\sigma_{\mathrm{r} .1}$ & $\sigma_{\mathrm{r} .2}$ & $\sigma_{\mathrm{r} .3}$ \\
\hline 0.60 & 1.026 & 1.368 & 1.710 \\
\hline $0.77\left(=\alpha_{e . i}\right)$ & 1.5 & 2.0 & 2.5 \\
\hline 0.90 & 1.602 & 2.611 & 3.264 \\
\hline
\end{tabular}




\subsection{Uncertain legal standards of care, restriction and an ex ante quality standard}

From the analysis in this and the previous chapter it follows that restriction of liability and the imposition of an ex ante quality standard create opposite incentives for the auditor. Therefore, for an individual audit engagement, social welfare can only be improved if:

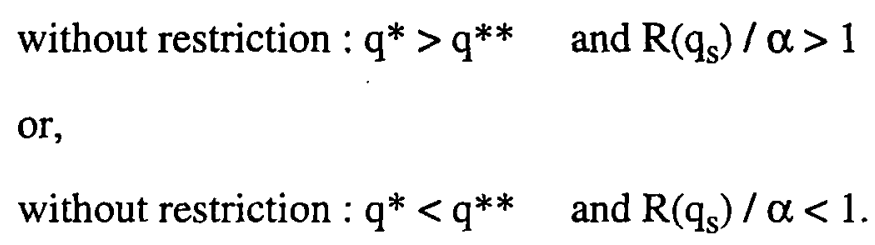

This implies that if there is overproduction of quality, as compared to what is socially optimal, without complementary policies, a weak ex ante standard combined with strong restriction on liability is welfare improving. In such a case the combination of a strong ex ante standard and little restriction on liability drives the auditor's decision further away from the social optimum. The latter combination is however welfare improving if there is underproduction without complementary policies. In case of underproduction, a weak ex ante standard combined with a strong restriction on liability is bad.

Note that social optimality is only achieved at one particular value of the ratio $\mathrm{R}\left(\mathrm{q}_{\mathrm{s}}\right) / \alpha$. Given that $C(q)=c . q^{2} / 4$ and $D(q)=\alpha . \lambda / q$, the condition for socially efficient audit quality production is:

$$
\underline{\mathrm{R}\left(\mathrm{q}_{\mathrm{s}}\right)}-0.5=\mathrm{q}^{* *} \cdot \sigma^{-1}(2 \pi)^{-1 / 2}
$$

$\alpha$ 
Note that if $\mathrm{R}\left(\mathrm{q}_{\mathrm{s}}\right) / \alpha<0.5$, or alternatively if $\mathrm{R}\left(\mathrm{q}_{\mathrm{s}}\right)<0.5 \alpha$, social efficiency can never be achieved. Thus, if the effect of an ex ante quality standard is too pronounced such that $R\left(q_{s}\right)$ becomes very small, and the effect of restriction is very small such that $\alpha$ takes a large value (close to 1 , i.e. at least twice as large as $\mathrm{R}\left(\mathrm{q}_{\mathrm{s}}\right)$ ), socially efficient audit quality production is impossible. The auditor will then always produce more than what is socially optimal.

Efficiency for all engagements in a legal environment that is characterised by a constant relativel uncertainty, $b$, cannot be established when an ex ante quality standard and restriction on liability are jointly used. The reason is - as pointed in section 5.2 - that an overall constant ex ante quality standard can never lead to overall social optimality.

\subsection{Conclusion}

Public policymakers that consider to restrict the auditor's liability should be aware of the welfare implications of such a rule, and should carefully examine its effect.

Restriction can never be welfare improving if vagueness about the legal standard of care is so large that without restriction the auditor underproduces quality $\left(\mathrm{q}^{*}<\mathrm{q}^{* *}\right)$. Overall social optimality for all engagements in a legal environment is only possible when restriction has the same linear effect on the engagement specific damage function for all engagements in the legal environment. The joint use of restriction and a constant ex ante audit quality standard can never be overall efficient. 


\section{Summary and conclusions}

The objective of the chapter was to investigate whether and when audit liability regulation by way of legal standards of care serves the public interest. An important insight is that liability regulation is socially inefficient if the legal standard of audit quality is the same for all engagements in a legal environment. When legal standards of care are clear (that is, known with certainty) and set at the engagement specific socially optimal level of audit care for all engagements in a legal environment, audit quality production will be overall efficient. Overall social efficiency can also be obtained if a clear legal standard is consistently set at a level that is substantially above the socially optimal level of care for all engagements in a legal environment. In this case the socially efficient policy would turn the audit industry into the guarantor of truth and fairness of the audited financial statements.

Social efficiency is no longer guaranteed when there exists uncertainty about the legal standard of care, even when the auditor's expectation of the legal standard is the socially optimal level of care. When the legal standard is very vague such that the auditor will produce a level of audit quality below the social optimum, the imposition of an ex ante quality standard may drive quality production in the direction of the social optimum. However, since the ex ante quality standard implied by more prescriptive professional audit standards would be the same for all engagements in a legal environment, overall efficiency cannot be achieved by a combination of legal standards of care and an ex ante quality standard. When the legal standard of care is reasonably clear, that is not very uncertain, such that the auditor produces more quality than what is socially optimal, an ex ante standard can never improve efficiency. In such a situation, restriction of liability to classes of claimants may be a welfare improving policy for a single audit engagement. Overall efficiency can however only be achieved when restriction has the same linear effect on the expected damage payments for all 
engagements in a legal environment, and when it is targeted at a certain level. This may be an unreasonable assumption, since the types of users may differ across engagements.

The general conclusion is that if there exists uncertainty about legal standards of care, social efficiency can be generally established if jurisdiction itself becomes consistent, such that certainty about the legal standard of care prevails. In this case, the question whether complementary policies can enhance efficiency becomes irrelevant. Changing jurisdiction and legal precedents is however a slow process. Reality is that liability regulation by way of a negligence standard has always been complemented with a judiciary that has restricted the auditor's liability to classes of claimants, both in the US and the UK. From the analysis in this chapter it follows indeed that a judiciary that is relatively consistent in its verdicts, such that uncertainty about the legal standard of care is reasonably small and the audit industry would produce more quality than what is socially efficient, would act in such a way. For a judiciary that is $100 \%$ consistent in its verdicts (where certainty prevails) liability restriction is of no use. It is not necessarily bad, as long as restriction is not too severe. The question, however, remains why it is necessary to complement negligence standards with more prescriptive professional audit standards, since restriction and an ex ante standard create opposite incentives for the auditor. Of course, weak professional audit standards would do no harm in such a context. However, from the analysis it follows that the recent debate in the UK to make professional audit standards more prescriptive seems - from a social welfare maximising point of view - inapproppriate. 


\section{Chapter 8}

\section{Conclusions}

\section{Auditing as a professional, economic and regulated activity:}

\section{conclusions from the literature review}

The objective of the first part of this thesis was to provide a literature review covering three related aspects of auditing: 1) auditing as a professional / risky activity; 2) auditing as an economic activity; and 3) auditing as a regulated activity. From review of the literature along these three dimensions, the following can be concluded:

1) Prior research on audit production modelling is mainly of a normative nature. Normative models of the audit production process can be classified into two categories:

a) audit risk models, which focus on achieving a target level of audit risk, hereby ignoring economic considerations; and b) decision theory models, which take a wider set of parameters into account, including economic. Prior decision theory models, although they explicitly included expected losses into total audit cost, have ignored the process by which these losses eventuate. This means that they have ignored the regulatory and liability framework in which the auditor operates.

2) Very few positive models of audit production emerged. To the author's knowledge, no audit production model is published which includes a legal parameter.

3) Audit production has rather been the subject of empirical work. Audit pricing studies shed some light on what is priced in the audit market, and thus on the product attributes of the audit service. However, since proxies for audit effort were included in most studies, little conclusion can be drawn about audit production per se. A worthwile topic for future empirical research in this area would be to investigate the determinants of audit effort (audit time). 
4) Several demand hypotheses for auditing have been put forward. The insurance hypothesis of audit demand is one of them. It has gained more attention over the last years, due to the litigation wave in auditing. However, to the author's knowledge, no formal economic analysis has been performed on the liability insurance rationale for audit demand.

5) A micro-economic model of audit demand has been suggested by Simunic (1980). Interesting is that loss sharing between auditees and auditors is assumed, based on their joint liability for losses to users resulting from defective audited financial statements. Auditors and auditees are however assumed to co-operate. An analysis of demand on liability insurance grounds, howeve, requires a non-cooperative setting.

6) From the review of the audit pricing studies in chapter 3, it can be concluded that audit markets are fairly price competitive, and that internal and external auditing can be considered - at least to some extent - as substitutes. These are assumptions underlying the analyses of chapters 5 and 6.

7) A review of the rich literature discussing economic arguments for and against 'accounting' regulation has revealed that little attention has been directed towards the question of how audit demand and production are optimally governed.

8) The author suggests that applied welfare economics and externality theory offers a viable framework for analysing economic impacts of audit regulations and liability. The rationale is that the production of audited financial statements can be seen as an externality generating activity. Directors and external auditors can be considered as jointly responsible for losses (or negative externalities) to financial statement users from defects in those statements.

9) From the economic literature on optimal policy choice it can be concluded that two alternative policy types exist for controlling externalities: ex ante regulation and ex post liability. In chapter 4 , policy instruments of either type that affect audit demand and production were identified and discussed. On the audit demand side, statutory audit requirements can be seen as an ex ante policy to control hazardous behaviour of 
directors, and liability provisions applying to directors as an ex post policy. On the production side, professional audit standards were identified as an ex ante policy to monitor externality generating behaviour of auditors and liability provisions applying to auditors as an ex post policy.

Given the above conclusions, two major research questions were addressed in part II of this thesis. First, how does liability and regulation affect audit demand. In particular, a) how does joint liability of directors and external auditors for losses to users from defective audited statements affect demand for external audit services; and b) are statutory audit requirements an effective policy instrument in monitoring the level of quality of financial statements provided to users. Second, how does auditor liability and professional audit standards affect the production of audit services. In particular: a) how do liability rules, professional audit standards and liability restriction affect the quality of the external audit service; and $b$ ) is the joint use of auditor liability and professional audit standards to monitor the auditor's production behaviour socially efficient. From the economic analysis a number of propositions and corollaries were drawn. An overview of these is provided in appendix III.

\section{Audit demand, liability and statutory audit requirements: major conclusions from the analysis in chapter 5}

The economic model proposed in chapter 5 was constructed in such a way that directors anticipate the external auditors' liability insurance behaviour before deciding on the levels of internal and external quality to demand. This allows for an analysis of the impact of liability insurance arguments on the level of external audit quality demanded. The following conclusions may be of relevance to public policy makers: 
1) Consistency in judicial reasoning should be promoted. Certainty about the due care levels applying to directors and auditors would lead to compliance by each party. The level of financial statement quality provided to users would then be equal to what is required. In this situation no liability insurance is obtained from external auditors. Statutory audit requirements should not be imposed, since they would either have no effect or would work cost increasing.

2) In the more realistic case where due care levels are not ex ante certain, the levels of uncertainty of each party's due care level are an important determinant for their resp. behaviour.

a) It is the level of uncertainty about the external auditor's due care level that determines whether liability insurance demand is possible or not. External auditors will be considered as liability insurers when there is large uncertainty about their due care level; in this situation they undercomply. On the other hand, when the auditors' due care level is fairly certain they will overprotect and always comply. In the latter case auditors provide no liability insurance at all.

b) Liability insurance arguments are irrelevant to the directors' demand decision when their due care level is fairly certain. When uncertainty about the directors' due care level is large enough, the auditors' behaviour does have an impact on the directors' decision. The result is interesting: when external auditors provide complete liability insurance, not more but less external audit quality is demanded. There is less demand for auditors that are perceived to provide a low quality audit.

3) The results of the analysis were not very much in favour of imposing statutory audit requirements when the resp. due care levels are uncertain. To be effective when needed, that is to increase the level of financial statement quality provided to users when below standard, statutory audit requirements must be set large enough. However in some situations they would have to be set larger than the expected legal standard of overall 
financial statement quality, to be effective. This is unrealistic, since it would imply that regulators set an external audit demand standard above the courts' standard for overall financial statement quality. The conclusion is that statutory audit requirements can only have a positive effect on overall quality produced in environments where uncertainty about the directors' due care level is large enough, in the sense that they would demand less financial statement quality than the expected due care level. However, a guaranteed improvement in financial statement quality provided to users only occurs when external auditors do not provide liability insurance, that is when they are fairly certain about their due care level.

4) If the legal environment in which external auditors and directors operate would be characterised by relatively small uncertainty about the directors' due care level, and relatively larger uncertainty about the external auditors' due care level, the following holds: a) there would be no insurance demand for external audit quality; b) directors would always comply; c) auditors are the only possible party to be held liable; auditor liability depends on the exact level of uncertainty; d) the level of financial statement quality provided to users might be larger or smaller than the standard, depending on the auditors behaviour (and hence his uncertainty); e) when the level of financial statement quality provided to users is below the standard, statutory audit requirements will be of no use, since they will be ineffective.

Note that this scenario may apply to the UK, where the courts seem to be reluctant to make the duties of the directors too rigorous (see chapter 4 , section 4.1 , for a discussion), and where uncertainty about the directors' duties can be assumed to be relatively small. 


\section{Audit quality production, liability and requlation: major conclusions from the analysis in chapters 6 and 7}

If auditors behave in a rational economic way, the audit production process can be seen as a process of risk management. The cost minimising level of risk corresponds with an optimal level of audit quality produced, which is specific for a particular client situation. Risk is not minimised, but total cost is. Conclusions about the impact of liability and professional audit standards on the auditor's behaviour (chapter 6) can be summarised as follows:

1) The audit quality decision crucially depends on the degree of uncertainty or vagueness about the legal standard of care. In legal environments that are characterised by a severe vagueness about the legal standard of care, less audit quality will be produced than in legal environments where legal standards of care are reasonably clear (or where there is small uncertainty). The quality of audit work thus depends upon consistency of judicial reasoning.

2) More prescriptive professional audit standards can improve the quality produced by the audit industry. However, a weak ex ante quality standard may have no impact at all. 3) Restriction of liability to classes of claimants has a negative impact on audit quality production. By expanding the classes of claimants, audit quality production can be enhanced.

From the analysis in chapter 7, a number of policy guidelines can be derived, which might be of use to regulators and courts who are interested in setting socially efficient policies:

1) Liability cannot be socially efficient if the legal standard of care is the same for all engagements in a legal environment. Judgement is needed for individual cases, comparing social costs and losses. 
2) Social efficiency can be achieved if legal standards of care are certain and set at the engagement specific socially efficient level.

3) An alternative way to achieve social efficiency when legal standards are certain is to set the legal standard at an extremely high level. This, however, would turn the audit profession into insurers of third party losses.

4) More prescriptive professional audit standards should not be imposed when uncertainty about the due care level is small. This would only increase total social cost. 5) One ex ante quality standard for all, that is one level of audit quality for all client situations can never be socially efficient. It may however be welfare improving if uncertainty about the due care level is large.

6) Liability restriction can be useful in attaining social efficiency when there is overproduction of audit quality, due to small uncertainty about the due care level and/or very prescriptive professional standards.

7) the joint use of liability restriction and more prescriptive professional standards creates opposite effects, and may have little impact on total social social cost, and hence on social welfare.

The general conclusion is that consistency in judicial reasoning should be promoted. Certainty about the due care level guarantees social efficiency, when the due care level is set at the socially optimal level. This is however conditional on the rate of liability restriction. When restriction is very pronounced, social efficiency cannot be obtained, even when the due care level is known with certainty. Furthermore, auditors would act as insurers for third party losses in such a situation. However, only a protected category of users would be provided with insurance. 


\section{Limitations of the thesis and directions for future research}

The major contribution of the thesis is the theoretical micro-economic analysis of the impacts of audit regulation and auditor liability on audit demand and production. The economic analysis applied is itself a technology of simplification, powerful in revealing structure, but subversive in privileging certain assumptions and conjectures, neglecting others. The major assumptions that are employed have been listed in section 5 of chapter 1, which discusses the limitations of the thesis. Relaxation of these assumptions is needed for a more complete analysis and is a major suggestion for future research in this area. One of the major assumptions which drives the results of the analysis, is that auditors are risk-neutral in making their decisions, and hence base these on expected values for damage payments. A rationale for this assumption are the rules of independence, which preclude the auditor from being overexposed to any particular client as a source of fees (i.e. the auditor is risk neutral to the size of a gamble presented). A suggestion for future research is to analyse the situation of risk-averse auditor behaviour.

The analysis did not explicitly model the role of insurance companies in the auditor's audit quality decision. As the analysis focuses on individual audit engagements, the impact of audit quality produced on insurance premia paid by auditors to their insurers is hard to grasp. A more complete analysis would allow for insurance cost.

The model, however, provides a solution to the level of the 'expected damage payment' (also called 'risk premium' in chapter 6 ) charged by the auditor to the client. Given that there is price competition in audit markets, the audit fee charged to a client equals the marginal total cost, which is equal to a direct cost component plus a risk premium. A suggestion for future empirical research is to investigate the size of insurance premia paid by an audit firm (to their insurers), and to relate the findings back to the results 
about 'risk premia charged to clients' from the model proposed in chapter 6 . This model predicts that relatively small insurance premia are paid on high quality audits and relatively large insurance premia are paid on low quality audits. High quality audits occur when the optimal level of audit quality is large, for example due to a relatively steep expected damage payment function as compared to the direct audit cost function. A low quality audit is done when the optimal level of audit quality is small, for example due to a relatively steep direct audit cost function as compared to the expected damage payment function. Since direct cost functions can be expected to be steepest for engagements where internal control systems are poor, relatively large insurance premia can be expected for low internal control clients, and vice versa. This hypothesis is testable, and an interesting empirical question for future research in the field.

A final suggestion for future empirical research related to the thesis, is to use the theoretical analyses in chapters 6 and 7 to investigate the social efficiency of audit regulation and auditor liability in several countries (for example, the US, the UK and Australia), and/or to explain legal and regulatory changes in several countries from a social welfare perspective. This first necessitates an investigation into the legal and regulatory situation in each country under investigation, and then a comparison of the situation between countries. The following questions are relevant in this context: 1) Are professional audit standards prescriptive, and are they set at a high or low level? 2) Is there a movement towards more prescriptive professional audit standards? 3) Is there consistency in judicial reasoning in lawsuits against audit firms. This will shed some light on the degree of uncertainty about the negligence standard which applies to auditors. 4) Is there restriction of auditor liability, or do there exist suggestions in this direction? Given the assessment of the above questions, and the conclusions from the model in chapter 7 (see also section 3 above), conclusions can then be drawn whether audit regulation and auditor liability are indeed complementary policies in the pursuance of social efficiency in the countries under investigation, or whether lobbies to restrict 
auditor liability and/or to tighten professional audit standards are leading to a status quo situation, or even a decrease in social welfare. Differences between countries in the legal and regulatory framework and changes therein could also be explained. 


\section{Bibliography}

Akerlof, G. A., "The Market for 'Lemons': Quality Uncertainty and the Market Mechanism", Quarterly Journal of Economics, Vol. 84, August 1970, pp. 488-500.

Alderman, C. W. and R. H. Tabor, "The Case for Risk-driven Audits", Journal of Accountancy, March 1989, pp. 55-61.

Aldersley, S. J.,"Discussion of Achieved Audit Risk and the Audit Outcome Space", Auditing: A Journal of Practice and Theory, Vol. 8, Supplement 1989, pp. 85-97.

American Institute of Certified Public Accountants, Statement on Auditing Standards No. $I$ - "Codification of Auditing Standards and Procedures", AICPA 1973.

American Institute of Certified Public Accountants, Statement on Auditing Standards No. 39 - "Audit Sampling", AICPA 1981.

American Institute of Certified Public Accountants, Statement on Auditing Standards No. 47 - "Audit Risk and Materiality in Conducting an Audit", AICPA 1983.

Anderson, R. J., "The Interrelationship of Compliance and Substantive Verification in Auditing", In: B.E. Cushing and J. L. Krogstadt (eds.), Frontiers of Auditing Research, University of Texas at Austin, 1977.

Antle, R., "Auditor Independence", Journal of Accounting Research, Spring 1984, pp. $1-20$.

Antle, R., "Discussion of Error Rates, Detection Rates, and Payoff Functions in Auditing", Auditing: A Journal of Practice and Theory, Vol. 8, Supplement 1989, pp. 64-66.

Antle, R., "The Auditor as an Economic Agent", Journal of Accounting Research, Vol. 20, No. 2 Part II, Autumn 1982, pp. 503-27.

Arens, A. A. and J. K. Loebbecke, Auditing: An Integrated Approach, Prentice Hall, Englewood Cliffs, N.J., Third Edition, 1984.

Arrow, K. J., Social choice and Individual Values, Cowles Foundation Monograph, New York: John Wiley, 1963.

Ashton, A. H., "The Descriptive Validity of Normative Decision Theory in Auditing Contexts", Journal of Accounting Research, Vol. 20, No. 2 Part I, Autumn 1982, pp. $415-28$. 
Ashton, R. H., Human Information Processing in Accounting, Studies in Accounting Research No. 17, American Accounting Association, Sarasota, 1982.

Baiman, S., Evans J. H. and J. Noel, "Optimal Contracts with a Utility-Maximizing Auditor", ournal of Accounting Research, Vol. 25, No. 2, Autumn 1987, pp. 217-44.

Ball, R., "The Firm as a Specialist Contracting Intermediary: Application to Accounting and Auditing", Working Paper, University of Rochester, April 1989.

Bar-Yosef, S. and J. Livnat, "Auditor Selection: An Incentive-Signalling Approach", Accounting and Business Research, Autumn 1984, pp. 301-309.

Barzel, Y., "Some Fallacies in the Interpretation of Information Costs", Journal of Law and Economics, Vol. 20, October 1977, pp. 291-307.

Baumol, W. J. and W. E. Oates, "The Use of Standards and Prices of Protection of the Environment", Swedish Journal of Economics, Vol. 73, March 1971, pp. 42-54.

Beaver, W. H., "What Should BE FASB's Objectives", Journal of Accountancy, August 1973, pp. 49-57.

Beaver, W.H., and J. S. Demski, "The Nature of Financial Accounting Objectives: A Summary and Synthesis", Studies on Financial Accounting Objectives: Supplement to Vol. 12 of the Journal of Accounting Research, 1974, pp. 170-187.

Beaver, W. H., "The implications of Security Price Research for Disclosure Policy and the Analyst Community", in: A.R. Abdel-Khalik and T. F. Keller (eds.): Financial Information Requirements for Security Analysis, 1976, pp. 65-81.

Beaver, W. H., "The Nature of Mandated Disclosure", Source: Report of the Advisory Committee on Corporate Disclosure to the SEC (1977); Reprinted in: Economics of Corporation Law and Securities Regulation, R.A. Posner \& K.E. Scott (eds), Boston: Little Brown and Company, 1980, pp. 317-331.

Benston, G. J., "The Value of the SEC's Accounting Disclosure Requirements", Accounting Review, Vol. 44, July 1969, pp. 515-532.(a)

Benston, G. J., "The Effectiveness and Effects of the SEC's Accounting Disclosure Requirements", in Henry G. Manne (ed.), Economic Policy and the Regulation of Corporate Securities, pp. 23-79, Washington D. C.: American Enterprise Institute, 1969.(b)

Benston, G. J., "Required Disclosure and the Stock Market: An Evaluation of the Securities Exchange Act of 1934", Amercian Economic Review, Vol. 63, March 1973, pp. 132-55.

Benston, G. J., Corporate Financial Disclosure in the UK and the USA, Farnborough, Hants: Saxon House, 1976. 
Black's Law Dictionary, West Publishing Co., St Paul, Minn., 1990.

Boockholdt, J. L. and D.R. Finley, "A Minimum-Cost Audit Sampling Methodology under Conditions of Predetermined Beta Risk", Decision Sciences, October 1980, pp. 702-713.

Brecht, H. D., "Auditor's Duty of Care to Third Parties: A Comment on Judicial Reasoning Underlying US Cases", Accounting and Business Research, Vol. 19, No. 74, Spring 1989, pp. 175-178

Bromwich, M., The Economics of Accounting Standards Setting, Englewood Cliffs, London: Prentice Hall International (UK).

Brumfield, C. A., R. K. Elliott and P. D. Jacobson, "Business Risk and the Audit Process", Journal of Accountancy, April 1983, pp. 60-68.

Buijinck, W. and S. Maijoor, "Entry, exit, and Market Share Mobility in an Audit Market: Evidence from the Netherlands", Working Paper, University of Limburg at Maastricht (theNetherlands), 1993.

Burton, J. C., "Forecasts: A Changing View from the Securities and Exchange Commission", in P. Prakash and A. Rappaport, eds., Public Reporting of Corporate Financial Forecasts, pp. 81-91, New york: Commerce Clearing House, 1974.

Byington, J. R., and S. G. Sutton, "The Self-Regulating Profession: An Analysis of the Political Monopoly Tendencies of the Audit Profession", Critical Perspectives on Accounting, Vol. 2, 1991, pp. 315-30.

Calfee, J. E., and R. Craswell, "Some Effects of Uncertainty on Compliance With Legal Standards", Virginia Law Review, Vol. 70, 1984, pp. 965-1003.

Canadian Institute of Chartered Accountants, Extent of Audit Testing: A Research Study, CICA 1980.

Carlton, and J. Perloff, Modern Industrial Organization, Glenview: Scott, Foreman / Little Brown, 1990.

Carmichael, D. R., "Behavioral Hypotheses of Internal Control", The Accounting Review, Vol. IIV, No. 2, April 1970, pp. 235-245.

Chan, P., Ezzamel, M. and D. Gwilliam, "Determinants of Audit Fees for Quoted UK Companies", Working Paper, 1991.

Chow, C. W., "The Demand for External Auditing: Size, Debt and Ownership Influences", The Accounting Review, Vol. LVII, No. 2, April 1982, pp. 272-91. 
Chua, S., "The Auditors' Liability in Negligence in Respect of the Audit Report", Professional Negligence, Vol. 9, No. 3, 1993, pp. 106-117.

Coase, R. H., "The nature of the Firm", Economica, New Series 4, November 1937, pp. 386-405.

Committee on Basic Auditing Concepts, A Statement of Basic Auditing Concepts, Sarasota, Florida: Amercian accounting Association, 1973.

Cooper, D. J., and M. J. Sherer, "The Value of Corporate Accounting Reports: Arguments for a Political Economy of Accounting", Accounting, Organizations and Society, Vol. 9, No. 4, 1984, pp. 207-32.

Cooper, K. and G. D. Keim, "The Economic Rationale for the Nature and Extent of Corporate Financial Disclosure Regulation: A critical Assessment", Journal of Accounting and Public Policy, Vol. 2, Fall 1983, pp. 189-205.

Cooter, R. D., "Economic Theories of Legal Liability", Journal of Economic Perspectives, Vol. 5, No. 3, summer 1991, pp. 11-30.

Cooter, R., and T. S. Ulen, Law and Economics, Glenview, IL: Scott, Foresman \& Co., 1993.

Craswell, R. and J. E. Calfee, "Deterrence and Uncertain Legal Standards", Journal of Law, Economics and Organization, Vol. 2, 1986, pp. 279-303.

Cushing, B. E. and J. K. Loebbecke, "Analytical Approaches to Audit Risk: A Survey and Analysis", Auditing: A Journal of Practice and Theory, Vol. 2, No. 1, Fall 1982, pp. 23-41.

Cushing, B. E., Searfoss, D. G. and H. Rendall, "Materiality Allocation in Audit Planning: A Feasibility Study", Journal of Accounting Research, Vol. 17, Supplement 1979, pp. 172-216.

Daniel, S. J., "Some Empirical Evidence about the Assessment of Audit Risk in Practice", Auditing: A Journal of Practice and Theory, Vol. 7, No. 2, Spring 1988, pp. 174-181.

Danos, P. and J. W. Eichenseher, "Long-term Trends Toward Seller Concentration in the U.S. Audit Market", The Accounting Review, Vol. 61, No. 4, 1986, pp. 633-650.

Datar, S. Feltham, G. and J. Hughes, "The Role of Audits and Audit Quality in Valuing New Issues", Journal of Accounting and Economics, March 1991, pp. 3-49.

Datar, S., "The Effects of Auditor reputation in Moral Hazard and Adverse Selection Settings", Ph.D. Dissertation, Stanford University, 1985. 
Davies, J. J., "Accountants' Third Party Liability: A History of Applied Sociological Jurisprudence", Abacus, December 1979, pp. 93-112.

DeAngelo, L. E., "Auditor Independence, 'Low Balling', and Disclosure Regulation", Journal of Accounting and Economics, Vol. 3, 1981, pp. 113-127.(a)

DeAngelo, L. E., "Auditor Size and Audit Quality", Journal of Accounting and Economics, Vol. 3, 1981, pp. 189-199.(b)

Demsetz, H., "Information and Efficiency: Another Viewpoint", Journal of law and Economics, Vol. 12, April 1969, pp. 1-22.

Demski, J. S. and R. J. Swieringa, "A Cooperative Formulation of the Audit Choice Problem", The Accounting Review, July 1974, pp. 506-513.

Dopuch, N. and D. Simunic, "The Nature of Competition in the Accounting Profession: A Descriptive and Normative View", In: J. Buckly, J. Weston (eds.), Regulation and the Accounting Profession, Belmont: Lifetime Learning, 1980, pp. 77-94.

Downs, A., "An Economic Theory of Political Action in a Democracy", Journal of Political Economy, 1957, pp. 135-150.(a)

Downs, A., An Economic Theory of Democracy, New York: Harper \& Row, 1957.(b)

Dresher, M. and S. Moglewer, "Statistical Acceptance Sampling in a Competitive Environment", Operations Research, May-June 1980, pp. 503-511.

Easterbrook, F. H., and D.R. Fischel, "Mandatory Disclosure and the Protection of Investors", Virginia Law Review, Vol. 70, 1984, pp. 669-715.

Eichenseher, J. W. and P. Danos, "The Analysis of Industry-specific Auditor Concentration: Towards an Explanatory Model", The Accounting Review, Vol. 56, 1981, pp. 479-492.

Elliott, R. K. and J. R. Rogers, "Relating Statistical Sampling to Audit Objectives", Journal of Accountancy, July 1972, pp. 46-55.

Elliott, R. K., "Unique Audit Methods: Peat Marwick International", Auditing: A Journal of Practice and Theory, Vol. 2, No. 2, Spring 1983, pp. 1-12.

Ettredge, M. and R. Greenberg, "Determinants of Fee Cuttings on Initial Audit Engagements", Journal of Accounting Research, Vol. 28, No. 1, Spring 1990, pp. 198210.

Ezzamel, M., Gwilliam, D., and K. Holland, "On the Relationship Between the Pricing of Audit and Non-Audit Services: Some Empirical Evidence From Publicly Quoted UK Companies", Working Paper, 1994. 
Fama, E. F., and A. B. Laffer, "Information and Capital Markets", Journal of Business, Vol. 44, July 1971, pp. 289-298.

Fama, E. F., Foundations of Finance: Portfolio Decisions and Security Prices, New York, 1976.

Fearnley, S. and M. Page, "Audit Regulation in the UK: Lemons, Cadillacs and Free Riders", Working paper, September 1993.

Felix, W. L. and R. A. Grimlund, "A Sampling Model for Audit Tests of Composite Accounts", Journal of Accounting Research, Vol. 13, No. 1, Spring 1977, pp; 23-41.

Fellingham, J. C. and D. P. Newman, "Strategic Considerations in Auditing", The Accounting Review, Vol. LX, No. 4, October 1985, pp. 634-50.

Finley, D. R. and J. L. Boockholdt, "A Continuous Constrained Optimization Model for Audit Sampling", Auditing: A journal of Practice and Theory, Vol. 6, No. 2, Spring 1987, pp. 22-39.

Finley, D. R., "Normal Form Decision Theory Development for the Audit Sampling Model", Auditing: A Journal of Practice and Theory, Vol. 3, No. 1, Fall 1983, pp. 104115.

Firth, M., "An Analysis of Audit Fees and Their Determinants in New Zealand, Auditing: A Journal of Practice and Theory, Vol. 4, No. 2, Spring 1985, pp. 23-37.

Fogarty, T. J., Heian, J. B. and D. L. Knutson, "The Rationality of Doing "Nothing": Auditors' Responses to Legal Liability in an Institutionalized Environment", Critical Perspectives on Accounting, Vol. 2, 1991, pp. 201-26.

Foster, G., "Externalities and Financial Reporting", Journal of Finance, Vol. 35, May 1980, pp. 521-533.

Francis, J. R. and D. J. Stokes, "Audit Prices, Product Differentiation, and Scale Economies: Further Evidence from the Australian Market", Journal of Accounting Research, Vol. 24, No. 2, Autumn 1986, pp. 383-93.

Francis, J. R. and D. T. Simon, "A Test of Audit Pricing in the Small Client Segment of the U.S. Audit Market", The Accounting Review, Vol. LXII, No. 1, January 1987, pp. 145-57.

Francis, J. R., "The Effect of Audit Firm Size on Audit Prices, A Study of the Australian Market", Journal of Accounting and Economics, Vol. 6, 1984, pp. 133-51.

Gaa, J. C., "The Expectations Game: Regulation of Auditors by Government and the Profession", Critical Perspectives on Accounting, Vol. 2, 1991, pp. 83-107. 
Gist, W. E., "Explaining Variability in external Audit Fees", Accounting and Business Research, Vol. 23, No. 89, 1992, pp. 79-84.

Godsell, D., Auditors' Legal Duties and Liabilities in Australia, Melbourne, Longman Professional Publishing, 1993.

Gonedes, N. J., and N. Dopuch, "Capital Market Equilibrium, Information Production and Selecting Accounting Techniques: Theoretical Framework and Review of Empirical Work", In: Studies on Financial Accounting Objectives, Supplement to Journal of Accounting Research, Vol. 12, 1974, pp. 48-130.

Gonedes, N. J., Dopuch, N. and S. H. Penman, "Disclosure Rules, InformationProduction, and Capital Market Equilibrium: The Case of Forecast Disclosure Rules", Journal of Accounting Research, Vol 14, Spring 1976, pp. 89-137.

Gonedes, N. J., "Corporate Signalling, External Accounting, and Capital Market Equilibrium: Evidence on Dividends, Income and Extraordinary Items", Journal of Accounting Research, Vol. 16, Spring 1978, pp. 26-79.

Gough, B., Whithe R., and I. Brindle (eds.), News Release: Reforms of Auditors' Liability, London, February 1994.

Grobstein, M. and P. W. Craig, "A Risk Analysis Approach to Auditing", Auditing: A Journal of Practice and Theory, Vol. 3, No. 2, Spring 1984, pp. 1-16.

Gwilliam, D., A Survey of Auditing Research, Prentice Hall International in association with The Institute of Chartered Accountants in England and Wales, 1987.(a)

Gwilliam, D., "The Auditor, Third Parties and Contributory Negligence", Accounting and Business Research, Vol. 18, No. 69, Winter 1987, pp. 25-35.(b)

Gwilliam, D., "Apportionment in Actions Against Auditors", Abacus, Vol. 24, No. 1, 1988, pp. 37-54.(a)

Gwilliam, D., "The Court's Power of Discretionary Relief in Actions Against Auditors", Accounting and Business Research, Vol. 19, No. 73, Winter 1988, pp. 43-46.(b)

Gwilliam, D. "Auditors' Duty of Care: UK Developments", European Accounting, 1991, pp. 6-8.

Gwilliam, D., "Auditors' Liability: the public policy arguments", Professional Negligence, Vol. 8, No. 4, 1992 pp. 147-151.

Gwilliam, D., "Contributory Negligence and the Auditor: Recent Developments in the Law and their Public Policy Implications", Working paper, University of Aberystwyth, February 1994,14 p. 
Haddock, D. D., and J. R. Macey, "Regulation on Demand: A Private Interest Model with an Application to Insider Trading Regulation", Journal of Law and Economics, Vol. 30, October 1987, pp. 311-352.

Haskins, M. E. and D. D. Williams, "The Association Between Client Factors and Audit Fees: a Comparison by Country and by Firm", Accounting and Business Research, Vol. 18 , No. 70 , pp. 183-90.

Heimann, S. R. and G. R. Chesley, "Audit Sample Sizes for Aggregated Statement Accounts", Journal of Accounting Research, Vol. 13, No. 2, Autumn 1977, pp. 193206.

Hirschleifer, J., "The Private and Social Value of Information and the Reward to Inventive Activity", Amercian Economic Review, Vol. 61, September 1971, pp. 561-74.

Holstrum, G. L. and J. L. Kirtland, "Audit Risk Model: A Framework for Current Practice and Future Research", Symposium on Auditing research $V$, University of Illinois at Urbana-Champaign, 1982, pp. 267-310.

Horwitz, B. and R. Kolodny, "Financial Reporting Rules and Corporate Decisions: A study of Public Policy", In: Contempory Studies in Economic and Financial Analysis, Vol. 36, Greenwich, Conn: JAI Press, 1982.

Jiambalvo, J. and W. Waller, "Decomposition of Audit Risk", Auditing: A Journal of Practice and Theory, Vol. 3, No. 2, Spring 1984, pp. 80-88.

Just, R. E., Hueth, D. L., and A. Schmitz, Applied Welfare Economics and Public Policy, Englewood Cliffs, NJ: Prentice Hall, 1982.

Kaplan, S. E. and R. G. Ruland, "Positive Theory, Rationality and Accounting Regulation", Critical Perspectives on Accounting, Vol. 2, 1991, pp. 316-374.

Kinney, W. R. Jr., "A Decision-Theory Approach to Audit Sampling", Journal of Accounting Research, Vol. 13, spring 1975, pp. 117-132.(a)

Kinney, W. R. Jr., "Decision-Theory Aspects of Internal Control System Design / Compliance and Substantive Tests ", Journal of Accounting Research, Vol. 13, supplement 1975, pp. 14-29.(b)

Kinney, W. R. Jr., "A Note on Compounding Probabilities in Auditing", Auditing: A Journal of Practice and Theory, Vol. 2, No. 2, Spring 1983, pp. 13-22.

Kinney, W. R. Jr., "Achieved Audit Risk and the Audit Outcome Space", Auditing: A Journal of Practice and Theory, Vol. 8, Supplement 1989, pp. 67-84.

Kinney, W. R. Jr. and C. S. Warren, "The Decision-Theory Approach to Audit Sampling: An Extension and Application to Receivables Confirmation", Journal of Accounting Research, Vol. 17, spring 1979, pp. 275-285. 
Kissinger, J. N., "Audit Timing Decisions: A Normative Model, A Practical Heuristic, and Some Empirical Evidence", Auditing: A Journal of Practice and Theory, Vol. 3, No. 1, Fall 1983, pp. 42-54.

Kolstadt, C. D., Ulen, T. S., and G. V. Johnson, "Ex Post Liability for Harm vs. Ex Ante Safety Regulation: Substitutes or Complements?", American Economic Review, Vol. 80, No. 4, September 1990, pp. 888-901.

Largay, J. A. III and J. W. Paul, "Comment: Market Efficiency and the Legal Liability of auditors, Accounting Review, October 1983, pp. 820-832.

Lauwers, L. and M. Willekens, "Five Hundred Years of Bookkeeping: A Portrait of Luca Pacioli", Tijdschrift voor Economie en Management, November 1994, pp. 289304.

Leftwich, R., "Market Failure Fallacies and Accounting Information", Journal of Accounting and Economics, Vol. 2, December 1980, pp. 193-211.

Leslie, D. A., "An Analysis of the Audit framework Focusing on Inherent Risk and the Role of Statistical Sampling in Compliance Testing", Auditing Symposium VII (Touche Ross), University of Kansas, pp. 89-125.

Lindahl, F. W., "Accounting Standards and Olson's Theory of Collective Action", Journal of Accounting and Public Policy, Vol. 6, Spring 1987, pp. 59-72.

Low, L., Tan, P. H. and H. Koh, "The Determination of Audit Fees: An Analysis in the Singapore Context", Journal of Business Finance and Accounting, 1990, pp. 285-95.

Magee, R. P., "A Discussion of Auditor's Loss Functions Implicit in ConsumptionInvestment Models", Journal of Accounting Research, Vol. 13, Supplement 1975, pp. 121-23.

Magee, R. P. and M.-C. Tseng, "Audit Pricing and Independence", The Accounting Review, Vol. 65, No. 2, April 1990, pp. 315-336.

Maijoor, S. J., The Economics of Accounting Regulation. Effects of Dutch Accounting Regulation for Public Accountants and Firms, Maastricht, Datawyse, 1991.

Melumad, N. D. and L. Thoman, "On Auditors and the Courts in an Adverse Selection Setting", Journal of Accounting Research, Vol. 28, No. 1, Spring 1990, pp. 77-120.

Menzefricke, U., "On Sampling Plan Selection With Dollar-Unit Sampling", Journal of Accounting Research, Vol. 21, 1983, pp. 96-105.

Merino, B. D., and M. D. Neimark, "Disclosure Regulation and Public Policy: A Sociohistorical Reappraisal", Journal of Accounting and Public Policy, Vol. 1, Fall 1982, pp. 35-57. 
Minow, N. N., "Accountants' Liability and the Litigation Explosion", Journal of Accountancy, September 1984, pp. 70-86.

Moizer, P. "Review of the Literature of Audit Quality and Auditor Reputation,", Working Paper, University of Leeds, September 1993.

Moizer, P. and S. Turley, "Changes in the UK Market for Audit Services", Journal of Business Finance and Accounting, Vol. 16, 1989, pp. 41-53.

Nagarajan, N., "Auditor Contracts and Regulatory Standards: An Approach to Investigating the Effectiveness of Legal Liability in Regulating Auditor Performance", $\mathrm{Ph}$.D. Dissertation, Northwestern University, 1988.

Neu, D., "Trust, Impression Management and the Public Accounting Profession", Critical Perspectives on Accounting, Vol. 2, 1991, pp. 295-313.

Newman, P. and J. Noel, "Error Rates, Detection Rates, and Payoff Functions in Auditing", Auditing: A Journal of Practice and Theory, Vol. 8, Supplement 1989, pp. 50-63.

$\mathrm{Ng}, \mathrm{D}$. S., "An Information Economics Analysis of Financial Reporting and External Auditing", The Accounting Review, Vol. LIII, October 1978, pp. 910-920.

Niskanen, W. A., Bureaucracy and Representative Government, Chicago: AldineAtherton, 1971.

O'Keefe, T. B. , Dimunic, D. A. and M. T. Stein, "The Production of Audit Services: Evidence from a Major Public Accounting Firm", Working Paper, University of British Columbia, September 1992.

Ogus, A. I., Regulation. Legal Form and Economic Theory, Oxford, Clarendon Press, 1994.

Palmrose, Z.-V., "Audit Fees and Auditor Size: Further Evidence", Journal of Accounting Research, Vol. 24, No. 1, Spring 1986, pp. 97-110.

Palmrose, Z.-V., "The Effect of Nonaudit Services on the Pricing of Audit Services: Further Evidence", Journal of Accounting Research, Vol. 24, No. 2, Autumn 1986, pp. 405-11.(a)

Palmrose, Z.-V., "Litigation and Independent Auditors: The Role of Business Failures and Management Fraud", Auditing: A Journal of Practice and Theory, Vol. 6, No. 2, Spring 1987, pp. 90-103.

Palmrose, Z.-V., "An Analysis of Auditor Litigation and Audit Service Quality", The Accounting Review, January 1988, pp. 55-73.(a) 
Palmrose, Z.-V., "The relation of Audit Contract type to audit Fees and Hours", The Accounting Review, Vol. 66, No. 3, July 1989, pp. 488-499.

Palmrose, Z.-V., "Trials of Legal Disputes Involving Independent Auditors: some Empirical evidence", Journal of Accounting Research, Vol. 29 Supplement 1991, pp. 149-185.

Patterson, E .R., "Strategic Sample Size Choice in Auditing", Journal of Accounting Research, Vol. 31, No. 2, Autumn 1993, pp. 272-293.

Peltzman, S., "Towards a More General Theory of Regulation", Journal of Law and Economics, August 1976, pp. 211-240.

Pong, C. K .M and G. Whittington, "The Determinants of Audit Fees: Some Empirical Models", Working Paper, University of Cambridge, 1993.

Posner, R. A., Economic Analysis of Law, Boston, Mass.: Little, Brown, 1986.

Rankine, G. and W. L. Felix, "The Relationship Between Audit Fees and Competition", Working Paper, Rice University, October 1993.

Roberts, D. M., Statistical Auditing, American Institute of Certified Public Accountants, $1978,274 \mathrm{pp}$.

Rose-Ackerman, S., "Effluent Charges: A Critique", Canadian Journal of Economics, Vol. 6, 1973, pp. 521-528.

Ross, S. A., "The Economics of Information and The Disclosure Regulation Debate", In: Issues in Financial Regulation, F. Edwards (Eds), NY: McGraw Hill, 1979, pp. 177-202.

Schultz, J. J. Jr., and K. Pany, "The Independent Auditor's Civil Liability - An Overview", Accounting Review, April 1980, pp. 319-326.

Scott, W. R., "A Bayesian Approach to Asset Valuation and Audit Size", Journal of Accounting Research, Vol. 11, Autumn 1973, pp. 304-330.

Scott, W. R., "Auditor's Loss Functions Implicit in Consumption-Investment Models", Journal of Accounting Research, Vol. 13, Supplement 1975, pp. 98-117.

Sennetti, J. T., "Toward a More Consistent Model for Audit Risk", A Journal of Practice and Theory, Vol. 9, No. 2, Spring 1990, pp. 103-112.

Shavell, S., "A Model of the Optimal Use of Liability and Safety Regulation", Rand Journal of Economics, Vol. 15, Summer 1984, pp. 271-280.(b)

Shavell, S., "Liability for Harm Versus Regulation of Safety", Journal of Legal Studies, Vol. 13, June1984, pp. 357-374.(a) 
Shavell, S., Economic Analysis of Accident Law, Cambridge, MA: Harvard University Press, 1987.

Shibano, T., "Assessing Audit Risk from Errors and Irregularities", Journal of Accounting Research, Vol. 28, Supplement 1990, pp. 110-40.

Simon, D. T., "The Audit Services Market: Additional Empirical Evidence", A Journal of Practice and Theory, Vol. 5, No. 1, Fall 1985, pp. 71-78.

Simon, D. T. and J. R. Francis, "The Effects of Auditor Change on Audit Fees: Tests of Price Cutting and Price Recovery", The Accounting Review, Vol. LXIII, No. 2, April 1988, pp. 255-69.

Simunic., D. A., "The Pricing of Audit Services: Theory and Evidence", Journal of Accounting Research, Vol. 18, No. 1, Spring 1980, pp. 161-90.

Simunic, D. A., "Auditing, Consulting, and Auditor Independence", Journal of Accounting Research, Vol. 22, No. 2, Autumn 1984, pp. 679-702.

Solomans, D., "The Politicization of Accounting', Journal of Accountancy, Nov. 1978, pp. 65-72.

Spanos, A., Statitistical Foundations of Econometric Modelling, Cambridge University Press, 1986.

Spence, M. "Job Market Signalling", Quarterly Journal of Economics, Vol. 87, August, 1973, pp. 355-374.

St. Pierre, K. and J. A. Anderson, "An Analysis of the Factors Associated with Lawsuits Against Public Accountants", The Accounting Review, Vol. LIX, No. 2, April 1984, pp. 242-63.

Steele, A., "Another Look at the Levels of Assurance Issue in Auditing", Accounting and Business Research, Spring 1984, pp. 147-156.

Steele, A., Audit Risk and Audit Evidence: Bayesian Approach to Statistical Auditing, ACCA, 1992, 200 pp.

Stice, J. D., "Using Financial and Market Information to Identify Pre-Engagement Factors Associated with Lawsuits Against Auditors", Accounting Review, Vol. 66, No. 3, July 1991, pp. 516-533.

Stigler, G., "The Theory of Economic Regulation", Bell Journal of Economics, Spring 1971, pp. 3-21.

Stiglitz, J. E., "Incentives, risk and Information: Notes Towards a Theory of Hierarchy", Bell Journal of Economics, Vol. 6, Autumn 1975, pp. 552-579. 
Strawser, J. R., "Human Information Processing and the Consistency of Audit Risk Judgments", Accounting and Business Research, Vol. 21, No. 18, Winter 1990, pp. 6775.

Strawser, J. R., "Examination of the Effect of Risk Model Components on Perceived Audit Risk", Auditing: A Journal of Practice and Theory, Vol. 10, No. 1, Spring 1991, pp. 126-135.

Stringer, K. W., "A Statistical Technique for Analytical Review", Studies on statistical Methodology in Auditing, Supplement to the Journal of Accounting Research, 1975, pp. 1-9.

Strong, N., and M. Walkner, Information and Capital Markets, Oxford: Basil Blackwell, 1987.

Sutton, S. G., "Toward an Understanding of the Factors Affecting the Quality of the Audit Process", Decision Sciences, Vol. 24, No. 1, Jan/Feb 1993, pp. 88-105.

Sutton, T.G., "Lobbying of Accounting Standard-Setting Bodies in the UK and the USA: A Downsian Analysis", Accounting, Organizations and Society, Vol. 9, No. 1, 1984, pp. 81-95.

Taylor, M. E. and R. L. Baker, "An Analysis of the External Audit Fee", Accounting and Business Research, Winter 1981, pp. 55-60.

Taylor, R. G., "Discussion of Decision-Theory Aspects of Internal Control System Design / Compliance and Substantive Tests ", Journal of Accounting Research, Vol. 13, supplement 1975, pp. 35-37.

Teitlebaum, A. D. and C. F. Robinson, "The Real Risks in Audit Sampling", Studies on Statistical Methodology in Auditing, Supplement to the Journal of Accounting Research, 1975, pp. 70-97.

Tinker, A., "Theories of the State and the State of Accounting: Economic Reductionism and Political Voluntarism in Accounting Regulation Theory", Journal of Accounting and Public Policy, Vol. 3, Spring 1984, pp. 55-74.

Titman, S. and B. Trueman, "Information Quality and the valuation of New Issues", Journal of Accounting and Economics, June 1986, pp. 159-172.

Tollison, R. D., "Rent Seeking: A Survey", Kyklos, Vol. 35, No. 4, pp. 575-602.

Tomczyk, S. and W. J. Read, "Direct Measurement of Supplier Concentration in the MArket for Audit Services", Auditing: A Journal of Practice and Theory, Vol. 9, No.1, 1989, pp. 98-106. 
Turpen, R. A., "Differential Pricing on Auditors' Initial Engagements: Further Evidence", Auditing: A Journal of Practice and Theory, Vol. 9, No. 2, pp. 60-76.

Ulen ,T. S., "Cognitive Imperfections and the Efficiency of Legal Rules", Working paper, University of Illinois at Urbana-Champaign, 1993, 44p.

Varian, H. R., Microeconomic analysis, Norton, 1984.

Wallace, W. A., The Economic Role of the Audit in Free and Regulated Markets, New york: Touche Ross, 1980.

Wallace, W. A., "Internal Auditors Can cut Outside CPA Costs", Harvard Business Review, March-April 1984, pp. 16 and 20.

Waller, W. S., "Auditors' Assessments of Inherent and Control Risk in Field Setting", The Accounting Review, Vol. 68, No. 4, October 1993, pp. 783-803.

Warren, C. S., "Audit Risk", Journal of Accountancy, August 1979, pp. 66-74.

Watts, J. S., "Discussion of Assessing Audit Risk from Errors and Irregularities", Journal of Accounting Research, Vol. 28, Supplement 1990, pp. 141-47.

Watts, R., and J. Zimmerman, "Towards a Positive Theory of the Determination of Accounting Standards, Accounting Review, Vol. 53, January 1978, pp. 112-134.

Watts, R., and J. Zimmerman, "THe Demand for and Supply of Accounting Theories: The Market for Excuses", Accounting Review, Vol. 54, April 1979, pp. 273-305.

Watts, R. L. and J. L. Zimmerman, Positive Accounting Theory, Englewood Cliffs, NJ: Prentice Hall, 1986.

Weitzman, M. L., "Prices versus Quantities", Review of Economic Studies, October 1974, Vol. 41, pp. 477-491.

Wiesen, J., The Securities Acts and Independent Auditors: What Did Congress Intend, Research Study No. 2, Commission on Auditors' responsibilities. New York: American Institute of Certified Public Accountants, 1978

Wittman, D., "Prior Regulation Versus Ex Post Liability: The Choice Between Input and Output Monitoring, Journal of Legal Studies, Vol. 6, January 1977, pp. 193-211.

Yoon, S. S., "The Auditor's Off Equilibrium Behavior", Auditing: A Journal of Practice and Theory, Vol. 10, Supplement 1990, pp.

Zeff, S. A. and R. L. Fossum, "An Analysis of Large Audit Clients", The Accounting Review, Vol. 42, 1967, pp. 298-320. 
Zind, R. G. and D. Zéghal, "Some Characteristics of the Canadian Audit Industry", Contemporary Accounting Research, Vol. 6, 1989, pp. 26-47. 


\section{Appendices}


Appendix I (to chapter 3)

Review of empirical audit fee research 

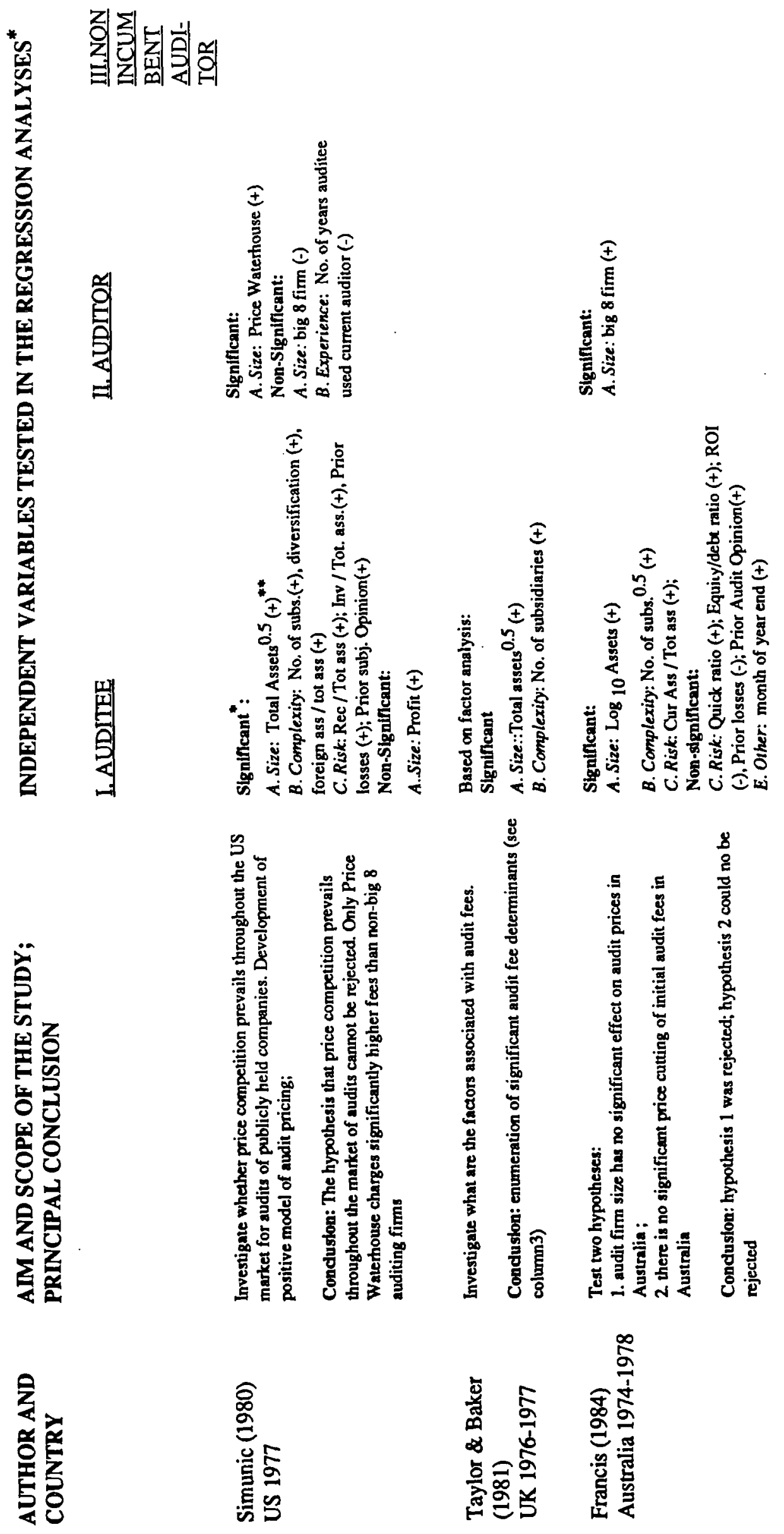

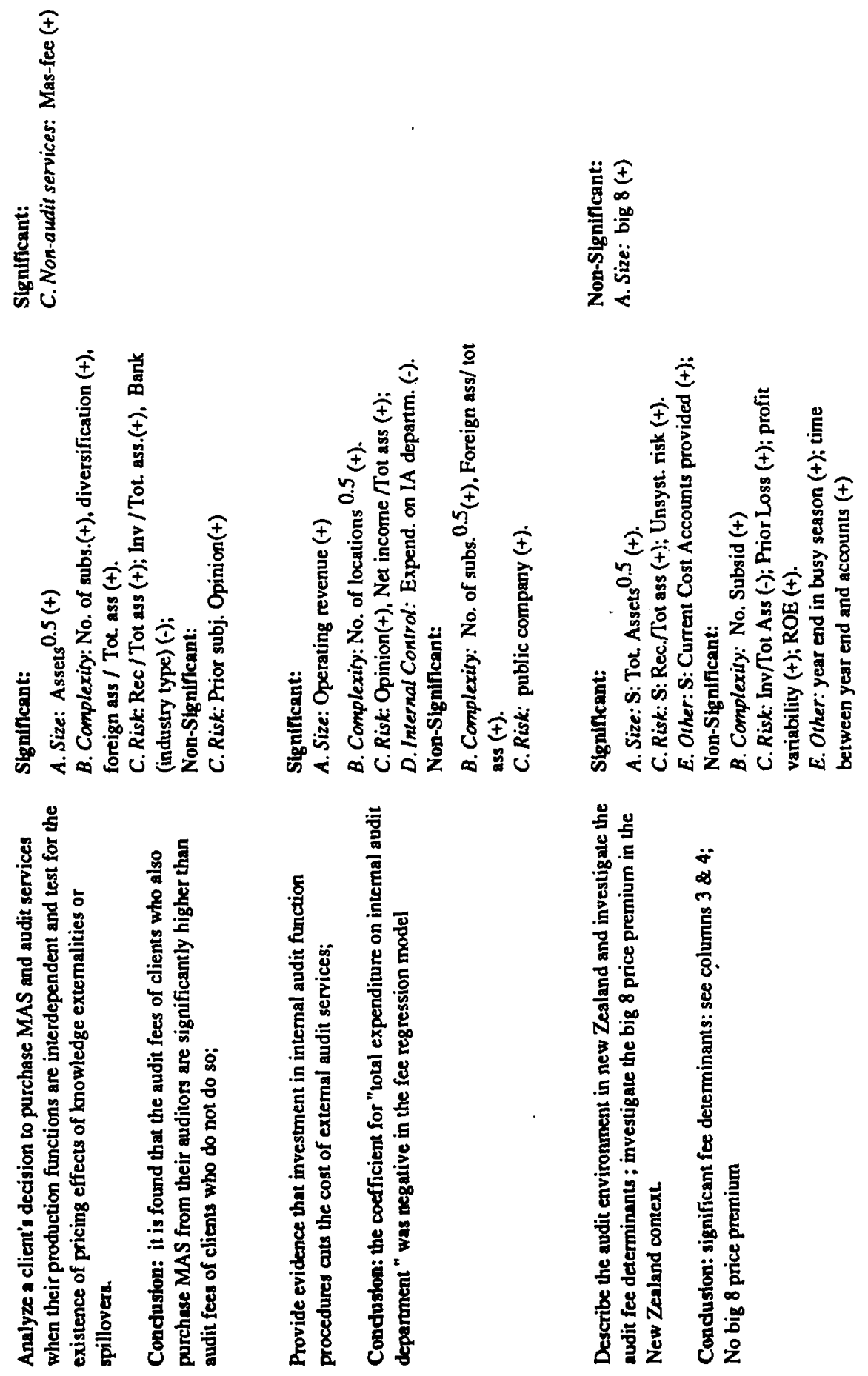

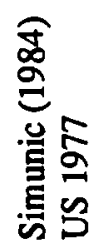
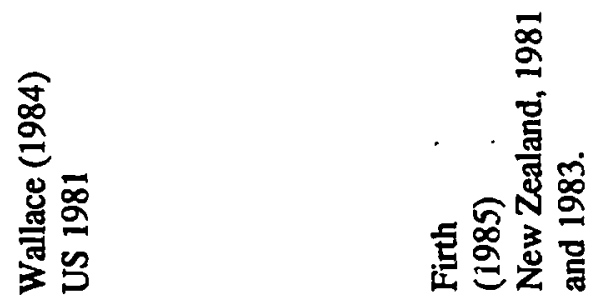

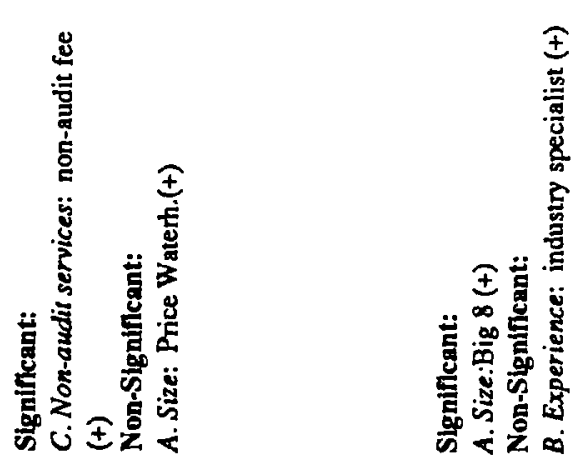

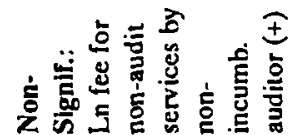
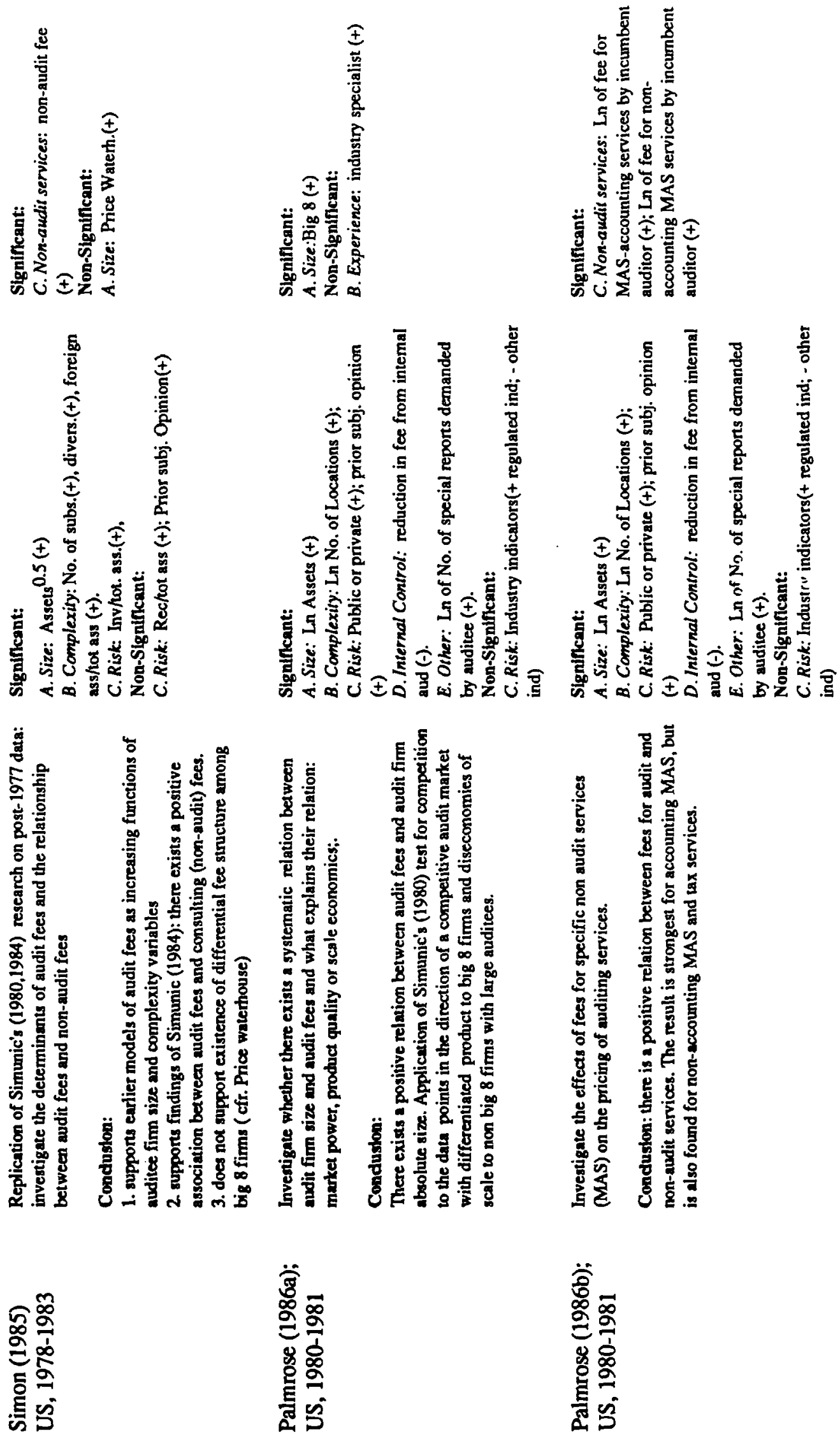

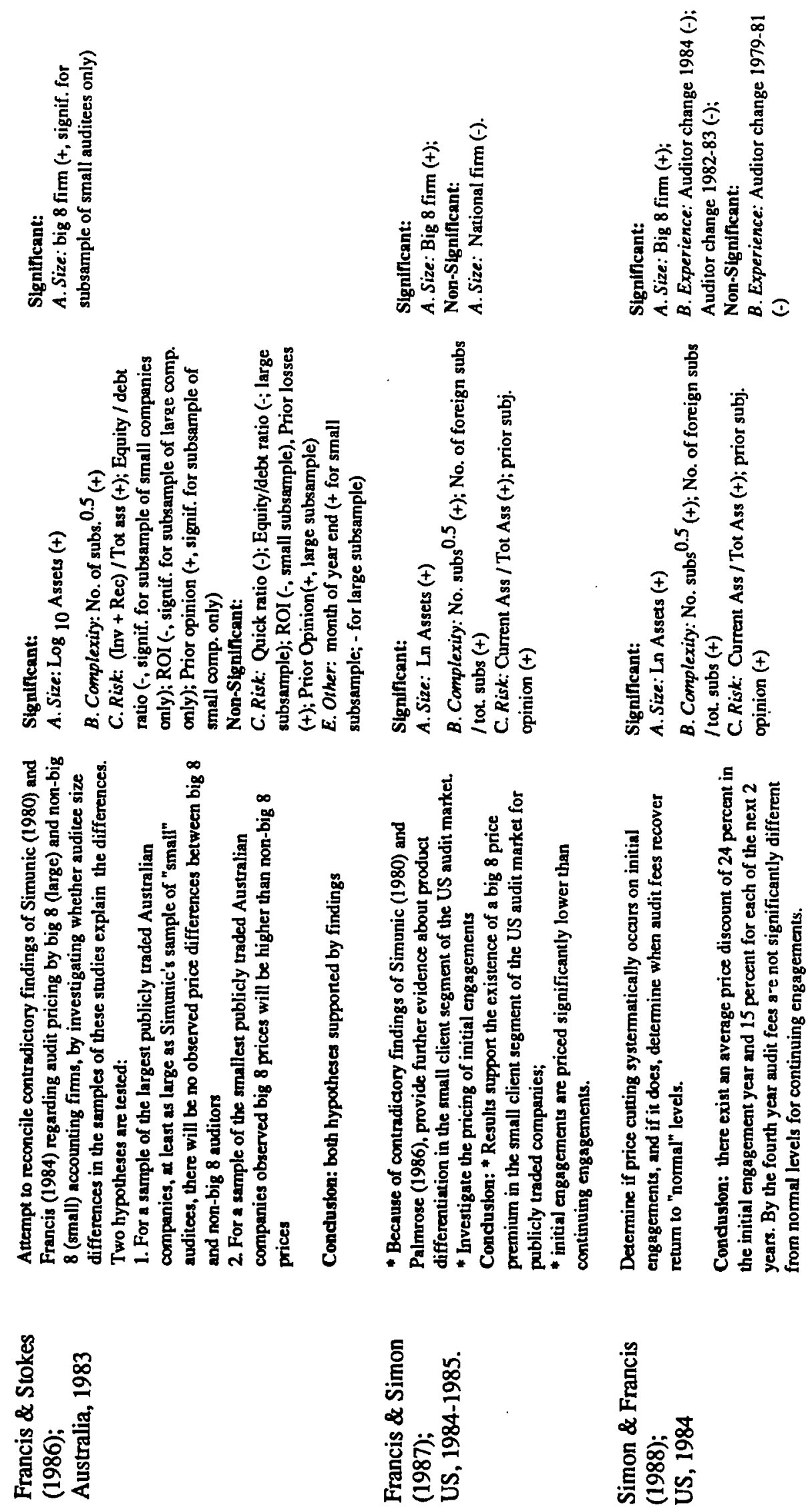


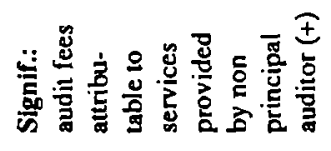
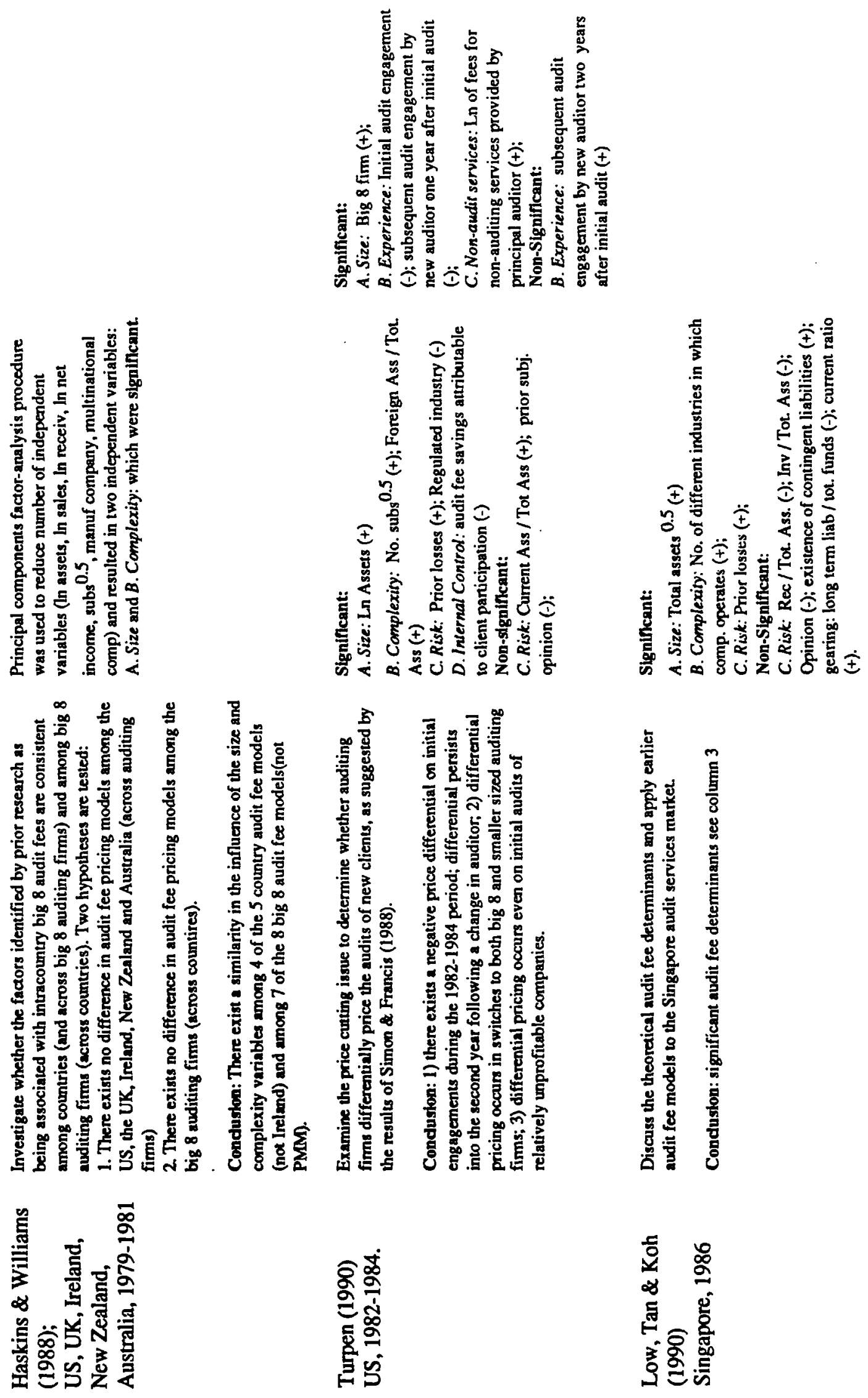

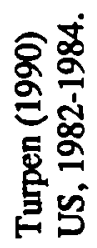

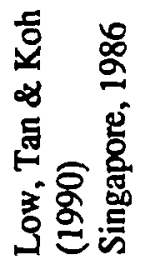



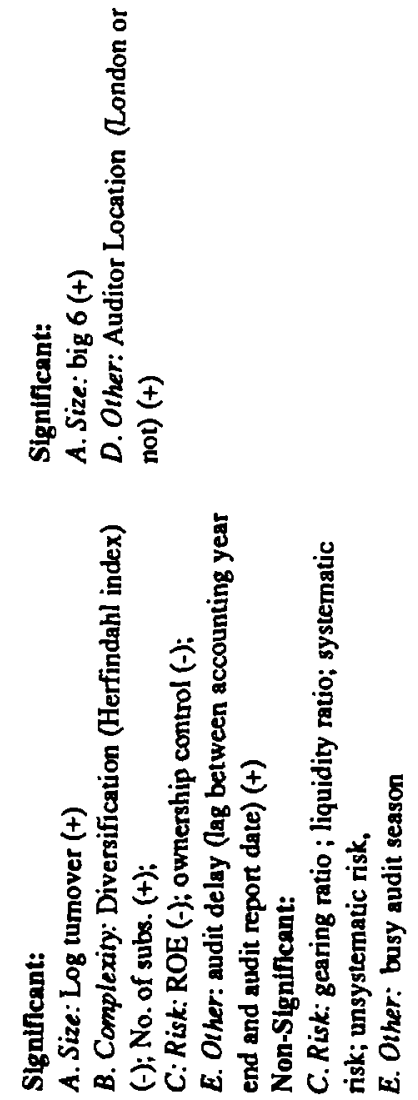

.
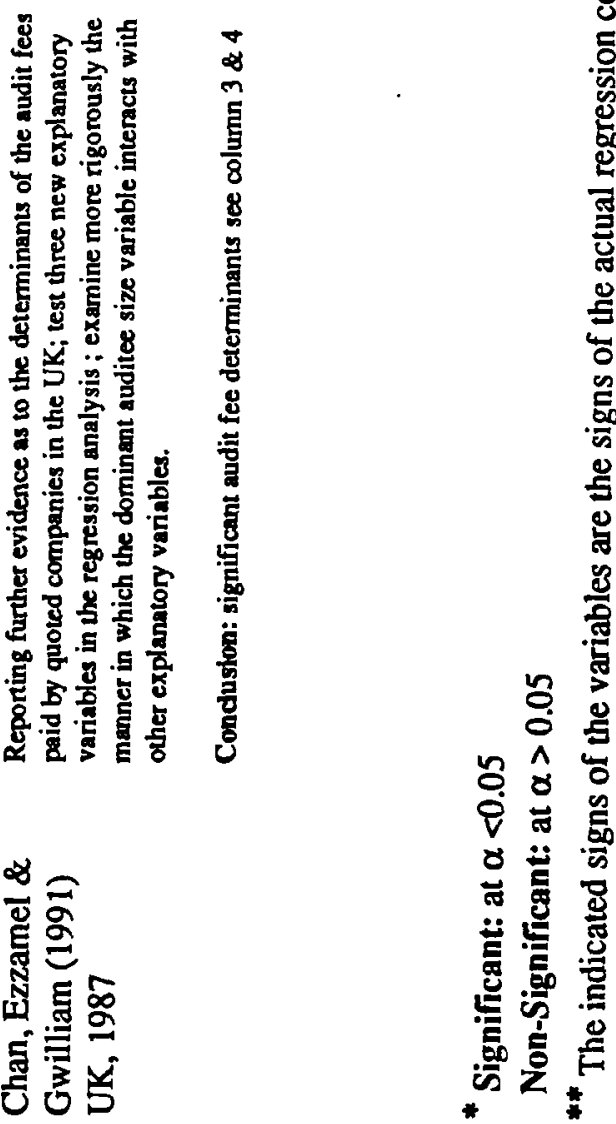


\section{Appendix II (to chapter 5)}

\section{The directors' problem when $0<\mathrm{g}<1$}

When $0<\mathrm{g}<1$ holds, the optimisation problem occurs in its most complex form, as $\mathrm{g}$ is then a function of $\left(q_{1}, q_{2}\right)$ :

$$
\begin{aligned}
g=g\left(q_{1}, q_{2}\right) & =\frac{q^{*}\left(q_{1}, q_{2}\right)-q_{2}+\delta}{2 \delta} \\
& =\frac{(L / \delta c) \cdot\left[s_{2}+s_{1} \cdot\left(\left(\theta q_{1}+q_{2}-Q_{c}-\varepsilon\right) / 2 \varepsilon-q_{2}+\delta\right)\right]}{2 \delta}
\end{aligned}
$$

The optimisation problem is given by:

$$
\begin{aligned}
& \operatorname{Min} C_{1}\left(q_{1}\right)+C_{2}\left(q_{2}\right)+L \cdot\left[1-f\left(q_{1}, q_{2} ; Q_{d}\right)\right] \cdot\left[s_{1}+s_{2} \cdot g\left(q_{1}, q_{2}\right)\right] \\
& \mathrm{q}_{1}, \mathrm{q}_{2} \\
& \text { subject to: } \quad \begin{array}{l}
\theta \mathrm{q}_{1}+\mathrm{q}_{2} \leq \mathrm{Q}_{\mathrm{c}}+\varepsilon \\
\quad 0 \leq \mathrm{g} \leq 1
\end{array}
\end{aligned}
$$

Given the constraint (A5.1), the solution to the problem can be defined as:

$$
\mathrm{Q}_{3}{ }^{*}=\min \left\{\mathrm{Q}_{\mathrm{c}}+\varepsilon, \mathrm{Q}^{*}, 3\right\}
$$

where $Q_{*, 3}$ is the solution if the constraint (A5.1) were not imposed. If $\mathrm{Q}_{3}{ }^{*}=\mathrm{Q}_{\mathrm{c}}+\varepsilon, f$ will take the value 1 . And, then:

$$
\begin{array}{ll}
\mathrm{q}_{1}^{*}= & \theta c_{2} \cdot\left(\mathrm{Q}_{\mathrm{c}}+\varepsilon\right) /\left(\theta^{2} \mathrm{c}_{2}+\mathrm{c}_{1}\right) \\
\mathrm{q}_{2}{ }^{*}= & \mathrm{c}_{1} \cdot\left(\mathrm{Q}_{\mathrm{c}}+\varepsilon\right) /\left(\theta^{2} \mathrm{c}_{2}+\mathrm{c}_{1}\right)
\end{array}
$$


Let $\left(q_{1, n}{ }^{*}, q_{2, n}{ }^{*}\right)$ be the minimum if the constraint in (A5.1) were not imposed. From the first order conditions 119 for a minimum it follows that:

$$
\begin{aligned}
& C_{1}\left(q_{1, n}{ }^{*}\right)=L \theta \cdot\left(s_{1}+s_{2} \cdot g\right) /(2 \varepsilon)-(1-f) \cdot\left(L^{2} \theta s_{1} s_{2}\right) /\left(4 \varepsilon \delta^{2} c\right) \\
& C_{2}{ }^{\prime}\left(q_{2, n}{ }^{*}\right)=L \cdot\left(s_{1}+s_{2} \cdot g\right) /(2 \varepsilon)-\left[L s_{2} \cdot(1-f) /(2 \delta)\right] \cdot\left[L s_{1} /(2 \varepsilon \delta c)-1\right]
\end{aligned}
$$

The following effects can be identified from demanding more internal and external audit quality. By demanding more internal audit, $\mathrm{q}_{1}$, the probability of directors complying with the overall quality norm increases. This effect is called the internal audit effect, and is given by the first term on the RHS of equation (A5.3). More internal audit demand decreases expected damage payments. However, an increased demand of internal audit quality also increases the probability that external auditors comply with the external audit quality norm. This is due to a second effect, called the reaction effect to internal audit demand. It is given by the second term on the RHS of equation (A5.3). From its negative sign it is clear it works opposite to the internal audit effect. Note that the first order condition can only be fulfilled if the internal audit effect is larger than the reaction effect. In the subsequent analysis it is assumed that this is the case. Internal audit will be demanded up to the level where marginal cost equals the net effect on marginal damage payments.

The effects from demanding more external audit quality are as follows. The first term in equaltion (A5.4) represents the external audit effect. By demanding more external audit, $q_{2}$, the probability of directors complying with the overall quality norm increases, and expected damage payments decrease. There is also a reaction effect to external audit demand, given by

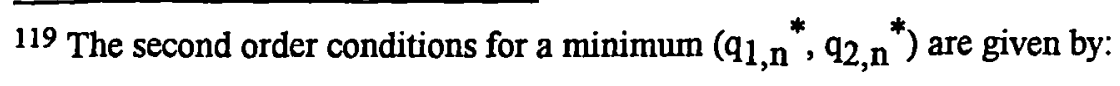

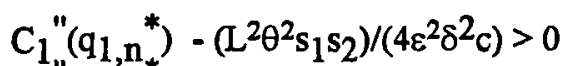

$\mathrm{C}_{2}{ }^{\prime \prime}\left(\mathrm{q}_{2, \mathrm{n}}{ }^{*}\right)-\left[\mathrm{Ls}_{2} /(2 \varepsilon \delta)\right] \cdot\left[\mathrm{Ls}_{1} /(2 \varepsilon \delta \mathrm{c})-1\right]>0$

It depends on the parameters whether this is the case. In the subsequent analysis it is assumed that the second order conditions for a minimum are fulfilled. 
the second term in equation (A5.4). It indicates the effect on the probability that the external auditor complies with the external audit quality norm. Its sign can be positive or negative, depending on the product of the uncertainties. If $\mathrm{Ls}_{1} /(2 \varepsilon \delta \mathrm{c})<1$, the second term in (A5.4) is positive. The larger $(\varepsilon . \delta)$, or the product of the uncertainties about the directors' and external auditors' respective quality norms, the more likely that is will be the case. Also, the more likely that both effects (external audit effect and reaction effect) work in the same direction. If both effects work in the same direction, the first order condition in (A5.4) is always fulfilled. In the other case, if $\mathrm{Ls}_{1} /(2 \varepsilon \delta \mathrm{c})>1$, the first order condition can only be fulfilled if the external audit effect is larger than the reaction effect. In the subsequent analysis it is assumed that the RHS in equation (A5.4) is positive. External audit quality will be demanded up to the level where marginal cost equals the joint effect on marginal damage payments.

The solution for $\left(\mathrm{q}_{1, \mathrm{n}^{*}}, \mathrm{q}_{2, \mathrm{n}^{*}}\right)$ are given below. From its voluminous format little straightforward conclusion can be drawn. 

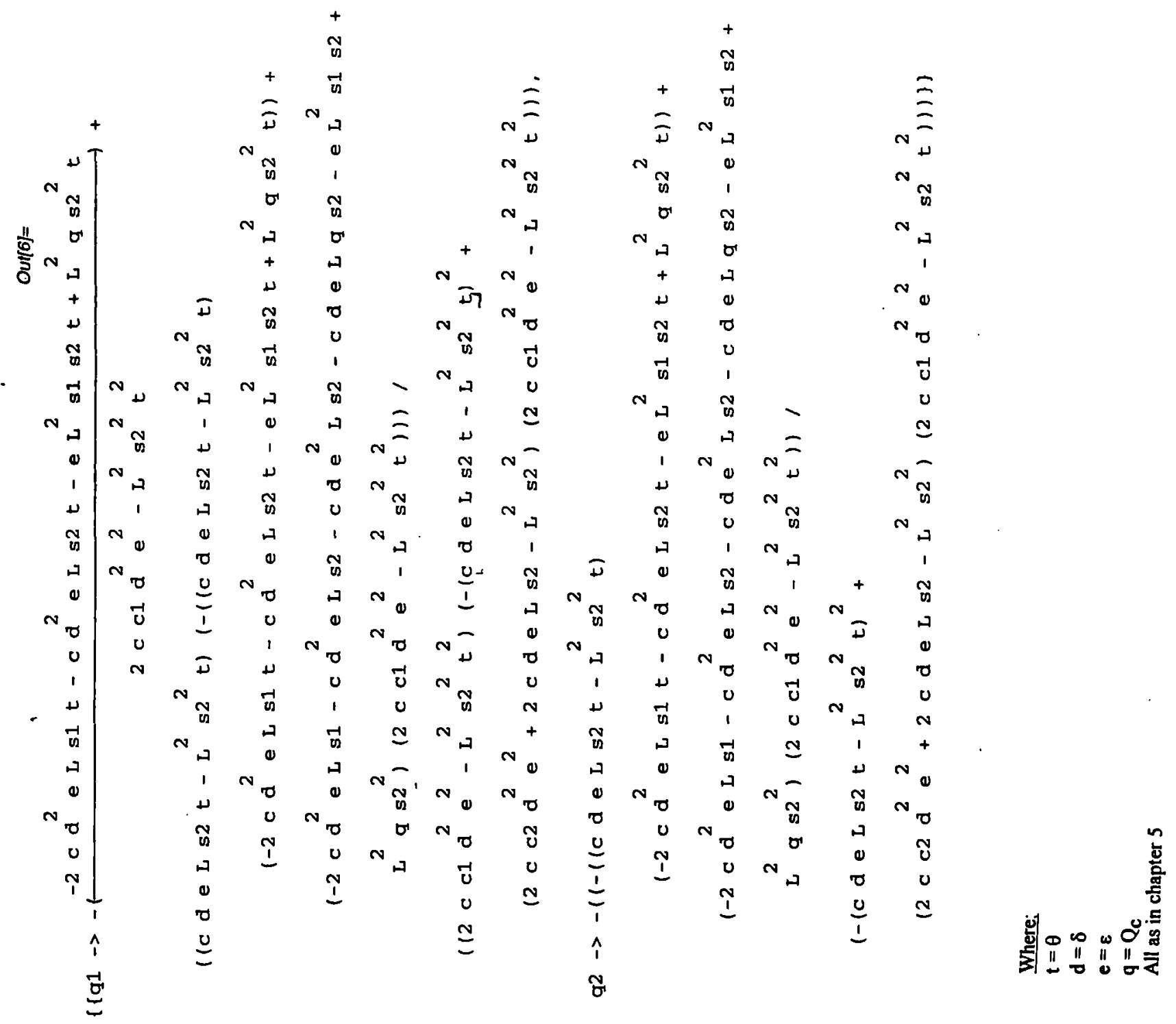


\section{Appendix III (to chapters 5, 6 and 7) \\ Overview of propositions and corollaries}

\section{Chapter 5}

\section{Proposition 5.1.}

When the levels of due care applying to external auditors and directors are known with certainty, the external auditor is believed to produce exactly the external audit quality level demanded, and directors will demand a level of overall financial statement quality equal to the due care level.

\section{Proposition 5.2.}

When the levels of due care applying to external auditors and directors are known with certainty, there is no liability insurance demand for external audit quality.

\section{Proposition 5.3.}

In case of certainty about due care levels applying to directors and external auditors, statutory external audit requirements should not be imposed since they would have no effect on the overall financial statement quality produced and could be cost increasing.

\section{Proposition 5.4.}

Given that the external auditor is (believed by the directors to be) uncertain about the legally required quality norm as specified by the subjective belief function $g$, a sufficiently small uncertainty (i.e. $\delta \leq \delta_{\psi}$ ) will result in overprotection and compliance with the norm, whereas a sufficiently large uncertainty (i.e. $\delta \geq \delta_{l}$ ) will result in underprotection and noncompliance with the norm.

\section{Proposition 5.5.}

Given that the external auditor is (believed by the directors to be) uncertain about the legally required quality norm as specified by the subjective belief function $\mathrm{g}$, the external auditor will (be believed to) produce a higher (lower) quality level than what is demanded when uncertainty is small, i.e. $\delta<\delta_{e}$ (large, i.e. $\delta>\delta_{e}$ ). 


\section{Proposition 5.6}

When the uncertainty about the due care level applying to the directors is sufficiently small", uncertainty about the external audit quality standard does not affect the directors' quality decision, and directors will choose a level of overall financial statement quality demand such that they comply with certainty with the due care level.

\section{Proposition 5.7}

If uncertainty about the directors' due care level is sufficiently large ${ }^{2}$, and if uncertainty about auditor's due care level is so large that they are perceived to be liability insurers ${ }^{3}$, directors will demand less overall financial statement quality and external audit quality than when external auditors are not perceived as liability insurers.

\section{Proposition 5.8}

When there is uncertainty about the due care levels applying to directors and external auditors, statutory audit requirements should not be imposed if they only have an effect on external audit demand, but have no effect the level of overall financial statement quality demanded.

\section{Proposition 5.9}

When there is uncertainty about the due care levels applying to directors and external auditors, statutory audit requirements always have a positive effect on the level of overall financial statement quality that is produced when set at a high enough level ${ }^{4}$ and when uncertainty about the external auditor's due care level is sufficiently smalls.

\footnotetext{
${ }^{1}$ By this it is meant that $\varepsilon \leq \varepsilon_{\mathrm{u}, 2}$.

2 By this it is meant that $\varepsilon>\varepsilon_{u, 2}$.

${ }^{3}$ By this it is meant that $\delta$ is such that $g=0$. If $g=0$, external auditors are believed to be always held liable. Therefore they can be seen as insurers.

${ }^{4} \mathrm{By}$ this it is meant at a level above the level of overall financial statement quality that directors would demand without such a requirement, or $q_{r}>Q^{*}$

${ }^{5}$ By this it is meant that $\delta<\delta_{u}$ as well as $\delta<\delta_{u}^{\prime}$, hold.
} 


\section{Chapter 6}

\section{Proposition 6.1}

An auditor will never produce more than what is legally required, if legal standards of care are known with certainty.

\section{Proposition 6.2}

An auditor will exactly produce what is legally required, if legal standards of audit care are known with certainty and set at a level that is not too high ${ }^{6}$.

\section{Proposition 6.3}

An auditor will produce less than what is legally required, and hence takes the role of an insurer for third party losses, if legal standards of care are known with certainty and set at a level that is significantly high?

\section{Proposition 6.4}

If the legal standard of care is set at a level that is significantly low, uncertainty about the legal standard of care increases audit quality production above the level that would have been produced if the legal standard were certain.

\section{Proposition 6.5}

If the legal standard of care is set at a level that is significantly low', but also not too large ${ }^{10}$, uncertainty about the legal standard of care can increase (or decrease) audit quality production above (or below) the level that would have been produced if the legal standard were certain, if uncertainty is sufficiently small (large)"1.

\section{Proposition 6.6}

When the auditor is uncertain about the legal standard of care, the imposition of an ex ante audit quality standard never reduces the level of audit quality produced for an individual audit engagement.

\section{Proposition 6.7}

Liability restriction to classes of claimants never increases the level of audit quality produced for an individual engagement if auditors are uncertain about the legal standard of care.

\footnotetext{
${ }^{6}$ By this it is meant that $q_{c}$ must be smaller than $q_{c, u}$.

${ }^{7}$ By this it is meant that $q_{C}$ must be larger than $q_{C, u}$

${ }^{8}$ By this it is meant that $C^{\prime}\left(q_{C}\right)+0.5 D^{\prime}\left(q_{C}\right)<$ or $=0$ holds.

${ }^{9}$ By this it is meant that $C^{\prime}\left(q_{C}\right)+0.5 D^{\prime}\left(q_{C}\right)<$ or $=0$ holds.

${ }^{10}$ By this it is meant that $\mathrm{q}_{\mathrm{C}}<\mathrm{q}_{\mathrm{c}, \mathrm{u}}$ holds.

11 Small uncertainty is defined as $\sigma<\sigma_{e}$; large uncertainty by $\sigma>\sigma_{e}$
} 


\section{Chapter 7}

\section{Corollary 7.1}

An auditor will produce the socially optimal level of quality for an individual audit engagement, if the legal standard of care is known with certainty and set at the socially optimal level, or at a level that is significantly high'2.

\section{Corollary 7.2}

For an auditor to produce the socially optimal level of quality and to act as an insurer of losses suffered by users, the legal standard of care needs to be known with certainty and set at a sufficiently large level ${ }^{13}$.

\section{Corollary 7.3}

If auditor liability is restricted to classes of claimants and the legal standard of care is known with certainty, the auditor will only produce a socially optimal level of care if the courts set the legal standard of care at the social optimum, and if restriction is not too severe ${ }^{14}$.

\section{Corollary 7.4}

In jurisdictions where certain negligence standards which are set at $q^{* *}$ for each engagement, are combined with a severe restriction on the size of the damage payments, in the sense that the parameter $\alpha<\alpha_{l}$, a socially optimal level of audit care will never be produced.

\section{Corollary 7.5}

Jurisdictions that combine a severe restriction on auditor liability, i.e. $\alpha<\alpha_{l}$, with setting the certain legal standard of care at the engagement specific social optimum, provide a protected category of users with insurance.

\section{Corollary 7.6}

Jurisdictions that combine a severe restriction on auditor liability, i.e. $\alpha<\alpha_{l}$, with setting the certain legal standard of care at the social optimum, and hence provide a protected category of users with insurance are not socially efficient.

\section{Corollary 7.7}

An auditor will produce more (less) than the socially optimal level of quality for an individual audit engagement, if he is uncertain about the legal standard of care and if uncertainty is sufficiently small (large).15

\footnotetext{
12 By this it is meant that $q_{c}>q_{c, u}$ holds.

13 By this it is meant that $q_{c}>q_{c, u}$ holds.

14 By this it is meant that $\alpha>\alpha_{l}$. needs to hold.

15 small uncertainty is defined as $\sigma<\sigma_{e}$. Large uncertainty is defined as $\sigma>\sigma_{e}$.
} 


\section{Corollary 7.8}

If a legal environment is characterised by a constant "relative" uncertainty about the legal standard of care for all engagements in that environment, the audit profession will systematically produce more (less) audit quality than what is socially optimal, if the "relative" uncertainty about the legal standard of care is sufficiently small (large)"6.

\section{Corollary 7.9}

If the legal standard of care is uncertain, the imposition of an ex ante quality standard can never lead to socially efficient quality production for an individual engagement if the ex ante quality standard is larger than the engagement specific socially optimal level of quality.

\section{Corollary 7.10}

In a legal environment that is characterised by constant "relative" uncertainty about the legal standard of care for all engagements in that environment, and where the audit profession systematically produces less audit quality than is socially optimal, overall social efficiency cannot be achieved by imposing an overall ex ante quality standard.

\section{Corollary 7.11}

Restriction on liability is welfare improving for an individual audit engagement, if without restriction an auditor produced more than the socially optimal level of audit quality, and if restriction is such that $\alpha \geq \alpha_{e}$. If restriction is such that $\alpha=\alpha_{e}$, audit quality production is socially efficient.

\footnotetext{
${ }^{16}$ By a small "relative" uncertainty it is meant that $b<b_{e}$; by a large "relative" uncertainty it is meant that $b>$
} $\mathrm{b}_{\mathrm{e}}$. 